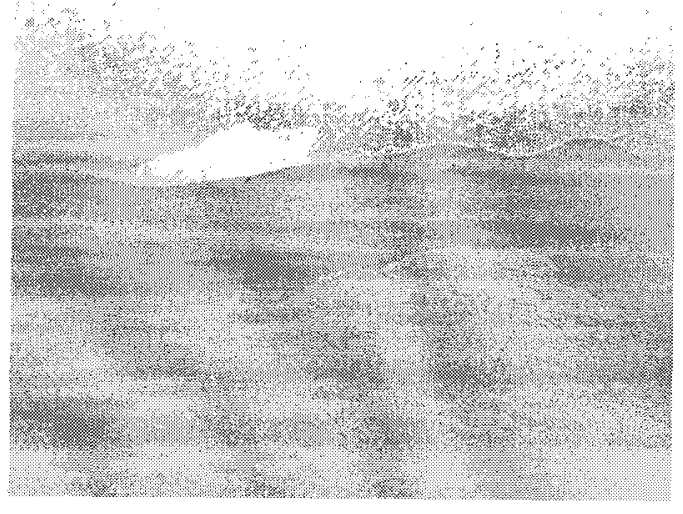

$$
\text { DOE }|E R| 6228 q-1
$$

FINAL REPORT

FLORIDA INTERNATIONAL UNIVERSITY

\title{
CURRENT AND FUTURE CARBON BUDGETS OF TROPICAL RAIN FOREST: A CROSS SCALE ANALYSIS
}

A CONTRIBUTION TO THE OFFICE OF SCIENCE TECO RESEARCH PROGRAM

\section{Submitted by}

Steven F. Oberbauer, Deborah A. Clark, David B. Clark, and Edzo Veldkamp

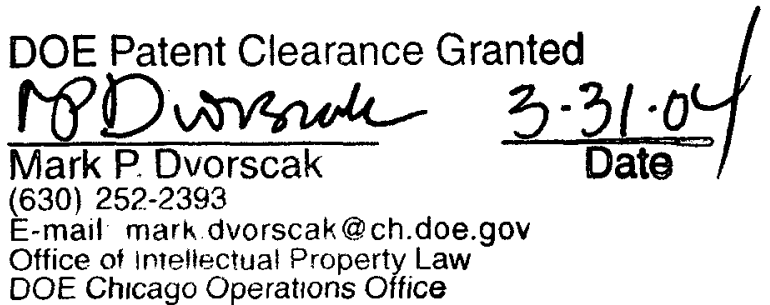

FLORIDA INTERNATIONAL UNIVERSITY, MIAMI, FLORIDA

UNIVERSITY OF MISSOURI ST.-LOUIS, ST. LOUIS, MISSOURI

UNIVERSITY OF GÖTTINGEN, GÖTTINGEN, GERMANY 


\section{DISCLAIMER}

This report was prepared as an account of work sponsored by an agency of the United States Government. Neither the United States Government nor any agency thereof, nor any of their employees, makes any warranty, express or implied, or assumes any legal liability or responsibility for the accuracy, completeness, or usefulness of any information, apparatus, product, or process disclosed, or represents that its use would not infringe privately owned rights. Reference herein to any specific commercial product, process, or service by trade name, trademark, manufacturer, or otherwise does not necessarily constitute or imply its endorsement, recommendation, or favoring by the United States Government or any agency thereof. The views and opinions of authors expressed herein do not necessarily state or reflect those of the United States Government or any agency thereof. 


\section{DISCLAIMER}

Portions of this document may be illegible in electronic image products. Images are produced from the best available original document. 


\section{SUMMARY}

\section{Activites}

The goal of this project was to make a first assessment of the major carbon stocks and fluxes and their climatic determinants in a lowland neotropical rain forest, the La Selva Biological Station, Costa Rica. Our research design was based on the concurrent use of several of the best available approaches, so that data could be cross-validated. A major focus of our effort was to combine tower-based eddy covariance studies of whole-forest carbon exchange, with parallel independent measurements of key components of the forest carbon budget. After a siting study based on La Selva's GIS coverages for topography and soil, analysis of local wind data, and a site visit by the Ameriflux coordinator, we installed a $42 \mathrm{~m}$ tall walk-up tower in the old-growth forest and instrumented it for eddy covariance studies of $\mathrm{CO}_{2}$, energy and water with concurrent meteorological monitoring. A buried mains power cable was routed through the forest to the tower. The eddy flux tower and a profile system operated from February 1998 to February 2001. To obtain field data that could be scaled up to the landscape level, we monitored carbon stocks, NPP components, and soil respiration in a series of replicated plots stratified across the major environmental gradients of the forest. A second major focus of this project was on the stocks and dynamics of carbon in the soil. We used isotope studies and intensive monitoring to investigate SOC stocks and the climatic variation of soil respiration down the soil profile, in a set of six $4 \mathrm{~m}$ deep soil shafts stratified across the landscape. We measured short term tree growth, climate responses of sap flow, and phenology in a suite of ten canopy trees to develop individual models of tree growth to daytime weather variables. For the ground-based measurements of carbon stocks, above- and belowground production, and soil respiration, we installed 180.5 ha plots to provide 6 samples of forest that were unbiased in terms of forest structure, in each of the three major edaphic conditions of this landscape (inceptisol terraces, flat terrain on ultisols, and steep slopes on ultisols. These plots provided a set of replicated unbiased samples of forest structure and biomass across the La Selva landscape. Within each plot all trees and lianas $>10 \mathrm{~cm}$ diameter were identified and mapped, and replicated soil samples (stratified by depth to $1 \mathrm{~m}$ ) were taken for analyses of cations, Fe, Al, P, N, total carbon, and $\mathrm{pH}$. Standing stocks of coarse woody debris (CWD; all pieces $>30 \mathrm{~cm}$ dia.; subsamples of those $10-<30 \mathrm{~cm}$ dia.) were mapped, measured, and subsampled for specific density in all plots in late 1997-early 1998. A preliminary inventory was made of coarse roots by depth, in both the ultisols and the inceptisols, by sieving all roots $>2 \mathrm{~mm}$ in diameter out of soil at successive depths in $0.8 \times 0.8 \times 3.0 \mathrm{~m}$ monoliths ( 3 in each soil type). Methods appropriate to the conditions of tropical rain forest were worked out for sampling fine litterfall and fine roots. Because of the potential for within-year changes in the depth distribution of fine roots, these were sampled with cores that integrated from the ground surface to $50 \mathrm{~cm}$ depth. Since September 1997, on-going measurements in all plots include: aboveground biomass increment (annual re-measurement of all trees $>10 \mathrm{~cm}$ diameter); fine litterfall (biweekly); fine woody litterfall ( $1-<10 \mathrm{~cm}$ diameter; monthly); standing stocks of live and dead fine roots ( $<2 \mathrm{~mm}$ and $2-<5 \mathrm{~mm}$ diameter; approximately bimonthly); and annual input of CWD. Twice annually (wet season and dry season), hemispherical canopy photographs were taken at the same set of 6 randomly chosen grid points in each plot for an estimation of percent canopy coverage and leaf area index. In 3 ultisol plots and 3 inceptisol plots, $4 \mathrm{~m}$ deep shafts were installed for studies of below ground carbon stocks and dynamics. The shafts were instrumented to measure $\mathrm{CO}_{2}$ profiles, and soil moisture and temperature by depth. Two of the six shafts were equipped with a data logger for automated readings of soil moisture and temperature. Soil samples were taken by depth for bulk density, soil organic carbon (SOC), and for ${ }^{13} \mathrm{C}$ and ${ }^{14} \mathrm{C}$ isotope studies. Soil respiration was measured biweekly by depth down the shafts 
and on the surface using chambers in the adjacent plots. To develop species-level climatic response functions, $20-50 \mathrm{~cm}$ diameter trees from each of ten canopy species, including the La Selva dominant, were assessed monthly for stem diameter, growth (band dendrometers) and phenology. At this size range these ten species span a broad range of growth capacities, from very fast- to very slow-growing. We had 10-11 individuals in each of the ten species. The data were analyzed for monthly growth increments in relation to temporal variation in climatic factors. Sap flow combined with leaf-carbon isotope ratios was used to estimate carbon gain on individual tree level. Meteorological factors were monitored from two above-canopy towers in the old-growth forest, at the eddy flux tower and a second, $30 \mathrm{~m}$ climb-up tower ca. $1.5 \mathrm{~km}$ away, and soil moisture and temperature are monitored at old-growth sites on each of the two principal soil types.

\section{Major findings}

- large interannual variation in the NEE estimated from eddy covariance studies during 19982001 , with estimated net $C$ uptake much less in the record-hot $1997 / 8$ Niño year than in the subsequent, cooler years

- large interannual variation in the above ground primary production during the years 19982002 , with estimated production much less $(40 \%)$ in the record-hot $1997 / 8$ Niño year than in the subsequent, cooler years

- exceptionally high tree mortality in the $97 / 98$ Niño compared to rates in the following years

- substantial interannual variation in fine root stocks and in estimated total belowground C allocation

- edaphic variation in the large SOC stocks (200-400 Mg C/ha to $4 \mathrm{~m}$ depth)

- important flows of DOC to deeper soil layers

- very large quantities of carbon stored in course woody debris

- strong temporal variation of nutrients in leaf litterfall through the Niño and Niña years in $1997-2000$

- strong decreases in fine root biomass and in soil respiration with increasing fertility (P and $\mathrm{K}$, $0-1 \mathrm{~m}$ depth)

- strikingly similar climate responses in sap flow among ten important canopy tree species

- no indication of soil moisture limitation of sap flow and strong effects of liana cover on sap flow of canopy trees

- relatively small or no effects of seasonality on tree growth in most of the 10 focal study species

- relatively small explanatory power of sap flow to models of individual tree growth suggesting that photosynthesis is not a major determinant of short-term tree growth

- detectable variation in leaf area index seasonally and interannually, with high importance of canopy dynamics for variation in leaf area coverage. 
Table of Contents

I. SUMMARY

II. INTRODUCTION

II.1. Participants

II.2. Partner Organizations

II.3. Additional Collaborations

II.4. Publications-Journal

II.5. Publications-Chapters, theses

II.6. Presentations

II.7. Report Overview

III STUDY SITE

14

IV ECOSYSTEM CARBON, WATER, AND ENERGY FLUXES

16

IV.1. $\mathrm{CO}_{2}$ fluxes

IV.2. Canopy Throughfall

IV.3. Water and Energy Fluxes

IV.4. Aerosol Carbon fluxes

V. WHOLE TREE RESPONSES TO CLIMATE VARIATION

$\begin{array}{ll}\text { V.1. Sap flow response } & 94\end{array}$

V.2. Stem growth and seasonality

$\begin{array}{lr}\text { VI.1. Course Woody Debris Stocks and Fluxes } & 147\end{array}$

VI.2. Biomass production

VII.1. Soil Carbon Stocks

VII.2. Soil $\mathrm{CO}_{2}$ Fluxes

VII.3. Dissolved Organic Carbon Fluxes 


\section{INTRODUCTION}

Tropical forests are major drivers in the global carbon cycle. They are estimated to account for $32 \%$ (Field et al. 1998) to 43\% (Melillo et al. 1993) of potential terrestrial net primary production (NPP) and contain a large fraction of the terrestrial above and belowground carbon. Despite their importance, the carbon balance of tropical forests is poorly understood. The goal of this project was to make the first multi-year assessment of major carbon stocks and fluxes and their climatic determinants for a tropical rain forest. Because of the continuing methods challenges for investigating forest carbon budgets (Goulden et al. 1996a; Lavigne et al. 1997, our research design was based on the multi-pronged approaches to enable cross validation of data. The central focus of our project was to combine tower-based eddy covariance studies of whole-forest carbon exchange with biometric measurements of key components of the forest carbon stocks and flow measured independently.

Project data collection commenced in June 1996 with installation of the canopy tower at La Selva and initiation of canopy-level climate measurements. The initial biometric assessment of tree growth took place in fall 1997. Canopy level flux measurement started in February 1998, the dry season of the 1997-1998 mega ENSO. The project was originally funded for 3 years, and one more year of additional funding was obtained that kept the tower fluxes going. No cost extensions continued canopy level meteorology and soil respiration studies to September of 2002.

\section{Original Project Objectives}

- Direct estimation of forest-level (canopy) carbon flux through eddy covariance studies carried out under varied climatic conditions through three years. Cross-scale interpretation of the La Selva fluxes will be enabled by parallel replicated field studies of NPP.

- Determination of whole-tree response functions to climatic variation, for the major functional types of tropical rain forest (TRF) canopy trees. We will use short-term $(1-2 d)$ studies with dendrometers and sap flow measurement under diverse climatic/soil moisture conditions to develop response functions for contrasting tree functional group). We will use these functions to link between tree-level productivity and climate.

- Assessment of net primary productivity and its spatio-temporal variation. Based on plots replicated across La Selva's edaphic gradients, these studies will also enable assessment of the degree of within-landscape variation of carbon dynamics due to the high internal variability now known to characterize tropical rain forest. We predict that major components of NPP vary substantially across the soil and topographic gradients within the La Selva old-growth (e.g., greater belowground allocation in the ultisols than in the inceptisols).

- Assessment of above- and below-ground carbon pools and dynamics. In parallel with our above-ground, fine root, and eddy covariance studies, we will assess soil organic carbon dynamics to a depth of $4 \mathrm{~m}$.

- Development and validation of process models of TRF productivity. Model development will be iteratively based on studies at complementary scales. A simple physiological model of wholeforest carbon exchange will be developed from the eddy covariance studies. Parallel modeling will be based on the field studies: 1) tree-level climatic response functions, initially derived from short-term controlled observations, will be calibrated against longer-term (mo-yr) tree growth/climate data.

The following report is broken down into sections corresponding to the specific objectives. Because of the power of the replicated plot design and the location of the flux tower, we recruited 
a number of collaborations that levered the power of this project toward meeting specific project objectives. Those contributions are included within the appropriate sections.

\section{II.1. Participants}

Co-Principal Investigator(s): Deborah A Clark; David B Clark (University of Missouri-St. Louis), Edzo Veldkamp (University of Göttingen)

Graduate student(s): Henry W. Loescher (University of Florida), Joseph O'Brien (Florida International University), Kevin R. Whelan (Florida International University), Luitgard

Schwendenmann (University of Göttingen)

Undergraduate student(s): Laura Abreu, Nadine Chipon, Carol Morris, Greg Robbins, Cara Jensen.

Technician, programmer(s): Tania Brenes; Leonel Campos; Mauricio Cascante, William

Miranda, Danilo Villegas, Marcela Fernandez

Post-doc(s): Jens Makensen

\section{II.2. Partner Organizations}

Organization for Tropical Studies provided facilities in the form of field station operation. They also provided administrative support for payment of Costa Rican technicians and for interactions with the U.S. embassy.

University of Missouri-Saint Louis: provided administration of the co-principal investigators salaries and benefits.

Andrew $W$ Mellon Foundation supported the Co-Investigators, Deborah and David Clark to do supportive research at La Selva including bringing in potential collaborators. The Mellon foundation project has supported some areas where we had insufficient funds to carry out the work.

University of Göttingen: Prof. Edzo Veldkamp of the University ofGottingen carried out the nutrient analyses as well as being an active participant in all aspects of the project. He had a $\$ 60,000$ Germany funded project that was fully complementary with our work.

Lawrence Livermore Laboratory: We had an agreement with LLL to have 14-C measurements done on the accelerated mass spectrometer

University of California at Irvine. Personnel at Irvine facilitated analysis of our 14-C. measurements.

\section{II.3. Additional Collaborations}

Our team actively recruited collaborators to fill in unmeasured aspects of the forest carbon budget. Collaborators to date have included: P.M. Crill (U. New Hampshire), continuous soil respiration monitoring with automated chambers, with co-PI's M. Ryan (Rocky Mtn.

Experimental Station) and M. Goulden (U. California-Irvine) funded for tree respiration studies; J. Bentz and S. Loyalka (U. Missouri-Columbia), C inputs as airborne particulates; A. Guenther (NCAR), preliminary isoprene measurements; Deborah Lawrence (University of Virginia) leaf 
litter biochemistry, J. Powers (Duke U.), leaf litter nutrient content and decomposition; D. Genereux (Florida International U.), forest hydrologic budget; R. Dubayah and S. Prince (U. Maryland), R. Knox (NASA), and J. Weishampel (U. Central Florida) - remote sensing of forest biomass and topography; J. Whitbeck (Tulane U.), the fine root component of NPP; S. Brown (Winrock Int.) and O. Krankina (Oregon State U.) carbon fluxes from CWD; Ed Rastetter (MBL) - modeling of forest ecosystem processes; Catherine Lovelock (Smithsonian)- below ground productivity; Nora Bynum (OTS) flowering phenology and productivity.

\section{II.4. Publications-Journal}

Clark, D.A., "Are tropical forests an important carbon sink?: reanalysis of the long-term plot data.", Ecological Applications, vol. 12, (2002), p. 3.

Clark, D.A., in press "Sources or sinks?: the responses of tropical forests to current and future climate and atmospheric composition.", Philosophical Transactions of the Royal Society of London, Series B., vol. , (), p. .

Clark, D.A., S. Brown, D. Kicklighter, J. Chambers, J. Ni, E. Holland, "NPP in tropical forests: an evaluation and synthesis of the existing field data.", Ecological Applications, vol. 11, (2001), p. 371

Clark, D.A., S. Brown, D. Kicklighter, J. Chambers, J.R. Thomlinson, and Jian Ni., "Measuring net primary production in forests: concepts and field methods.", Ecological Applications, vol. 11, (2001), p. 356.

Clark, D.A., S. C. Piper, C. D. Keeling, and D. B. Clark, "Tropical rain forest tree growth and atmospheric carbon dynamics linked to interannual temperature variation during 1984-2000", Proceedings of the National Academy of Science, vol. 100, (2003), p. 5852.

Clark, D.B, J.M. Read, M. Clark, A. Murillo Cruz, M. Fallas Dotti \& D.A. Clark., in press. "Application of 1-m and 4-m resolution satellite data to studies of tree demography, stand structure and land use classification in tropical rain forest landscapes.", Ecological Applications., vol. ,

Clark, D.B. and D.A. Clark., "Landscape-scale variation in forest structure and biomass in a tropical rain forest", Forest Ecology and Management, vol. 137, (2000), p. 185.

Clark, D.B., D.A. Clark, S. Brown, S.F. Oberbauer, and E.Veldkamp, "Stocks and flows of coarse woody debris across a tropical rain forest nutrient and topography gradient", Forest Ecology and Management, vol. 164, (2002), p. 237.

Davidson, E.A., K. Savage, P. Bolstad, D.A. Clark, P.S. Curtis, D.S. Ellsworth, P.J. Hanson, B.E. Law, Y. Luo, K.S. Pregitzer, J.C. Randolph, and D.Zak, "Belowground carbon allocation in forests estimated from litterfall and IRGA-based soil respiration measurements.", Agricultural and Forest Meteorology, vol. 113, (2002), p. 39. 
Drake, J.B., R. Dubayah, R. Knox, D. B. Clark, and J. B. Blair, "Sensitivity of large-footprint lidar to canopy structure and biomass in a neotropical rainforest. Remote Sensing of Environment :-392.", Remote Sensing of Environment, vol. 81, (2002), p. 378

Drake, J.B., R.G. Knox, R.O. Dubayah, D.B. Clark, and R. Condit, "Above-ground biomass estimation in closed-canopy Neotropical forests using lidar remote sensing: factors affecting the generality of relationships.", Global Ecology and Biogeography, vol. 12, (2003), p. 147.

Drake, J.B., R.O. Dubayah, D.B. Clark, R.G. Knox, J.B. Blair, M.A. Hofton, R.L. Chazdon, J.F. Weishampel, and S.D. Prince, "Estimation of tropical forest structural characteristics using largefootprint lidar.", Remote Sensing of Environment, vol. 79, (2002), p. 305.

Englund, S.R., J.J. O'Brien and D.B. Clark., "Evaluation of digital and film hemispherical photography and spherical densiometry for measuring forest light environments.", Canadian Journal of Forest Research, vol. 30, (2000), p. 1999.

Fitchler, E., Clark, D.A., and M. Worbes, "Age and long-term growth of trees in an old-growth tropical rain forest, based on analyses of tree rings and 14C", Biotropica, vol. 36 (2003) pg 306.

Geron, C., A. Guenther, J. Greenberg, H.W. Loescher, B. Baker, and D.A. Clark., "Biogenic volatile organic compound emissions from a rain forest in Costa Rica.", Atmospheric Environment, vol. 36, (2002), p. 3793.

Loescher, H.W., I.S. Powers, and S.F. Oberbauer., "Spatial variation of throughfall volume in an old-growth tropical wet forest, Costa Rica.", Journal of Tropical Ecology, vol. 18, (2002), p. 397. Loescher, H.W., S.F. Oberbauer, H.L. Gholz and D.B. Clark., "Environmental controls on net ecosystem-level carbon exchange and productivity in a Central American tropical wet forest.", Global Change Biology 9:396-412., vol. 9, (2003), p. 396.

Lovelock CE, SR Wright, KA Nichols, "Using glomalin as an indicator for arbuscular mycorrhizal hyphal growth: an example from a tropical rain forest soil.", Soil Biology and Biochemistry., vol., (), p. . Submitted

Lovelock, C.E., S. Wright, D.A. Clark, and R.W. Ruess., "Soil stocks of glomalin produced by arbuscular mycorrhizal fungi across a tropical rain forest landscape.", Journal of Ecology, vol. , (), p. . in revision

Oberbauer, S.F., H. Loescher, and D. B. Clark, "Effects of climate factors on daytime carbon exchange from an old-growth forest in Costa Rica.", Selbyana, vol. 21, (2000), p. 66.

O'Brien, J. J. and S. F. Oberbauer, "An inexpensive, portable method for measuring soil moisture.", Soil Science Society of American Journal, vol. 65, (2001), p. 1081.

O'Brien, J.J., S.F. Oberbauer, and D.B. Clark, in press. "A general model of tree xylem sap flow response to environmental variables in a wet tropical forest", Plant Cell and Environment, vol. , 
Schwendenmann L., E. Veldkamp, T. Brenes, J.J. O'Brien, J. Mackensen., "Spatial and temporal variation in soil $\mathrm{CO} 2$ efflux in an old-growth neotropical rain forest, La Selva, Costa Rica.", Biogeochemistry, vol. 64, (2003), p. 111

Schwendenmann, L., and E. Veldkamp., in press. "Dynamics of dissolved organic carbon, dissolved organic nitrogen and dissolved inorganic nitrogen in a tropical wet forest.", Ecosystems, vol.,

Veldkamp, E. and J. J. O'Brien, "Calibration of a frequency domain reflectrometry sensor for humid tropical soils of volcanic origin.", Soil Science Society of America Journal, vol. 64:, (2000), p. 1549.

Veldkamp, E., A. Becker, L. Schwendenmann, D.A. Clark, and H. Schulte-Bisping, "Substantial labile carbon stocks and microbial activity in deeply weathered soils below a tropical wet forest.", Global Change Biology, vol. 9, (2003), p. 1171.

Wood,T., D. Lawrence, and D. A. Clark., "Determinants of leaf litter nutrient cycling in a tropical rain forest: fertility versus topography ", Ecosystems, vol. , (), p. . Submitted

Wood,T., D. Lawrence, and D. A. Clark., "Precipitation drives variation in leaf litter nutrients of a Costa Rican rain forest. .", Ecology, vol. , (), p. . Submitted

\section{II.5. Publications-Chapters, theses}

Becker, A., "Comparative study of soil carbon stocks and microbial biomass under old-growth forest and in old pasture, on two tropical soils. Master's Thesis." , bibl. M.S. Thesis, U. Göttingen, Germany., (2000).

Boehm, M., "Landscape-scale variation in soil respiration in a tropical lowland rain forest." , bibl. M.S. Thesis, U. Göttingen, Germany., (2000).

Clark, D.B, "Factores edificos y la distribucion de plantas a nivel del paisaje en bosques húmedos neotropicales." , bibl. IICA, San Jose, Costa Rica, (2002) M. Guariguata and G. Kattan, "Ecologïa de Bosques Lluviosos Neotropicales,"

Drake, J.B., "Estimation of tropical forest aboveground biomass using large-footprint lidar." , bibl. Ph.D. Dissertation, University of Maryand, College Park, Maryland, USA., (2001).

Heincke, M., "Spatial and temporal variation in dissolved organic nitrogen (DON) down the soil profile, in a tropical lowland rain forest. Master's Thesis." , bibl. M.S. Thesis, U. Hohenheim, Germany., (1999).

Loescher, H.W., "Ecosystem-level responses of carbon and energy from a tropical wet forest in Costa Rica." , bibl. Ph.D. dissertation University of Florida., (2002). 
Murillo Cruz, A., and M. Fallas Dotti., "Georectificacicn de alta precisiçn de im genes del sat, lite IKONOS y su aplicacicn a estudios de ecologia forestal en la Estacicn Biolegica La Selva." , bibl. Undergraduate Thesis, School of Forestry, Universidad Nacional de Costa Rica, (2001).

O'Brien, J. J., "The effects of climate on the growth and physiology of tropical rain forest canopy trees." , bibl. Ph.D. Dissertation. Florida International University, Miami FL., (2001).

Peterson, B.E., "Recovery of forest canopy heights using large-footprint lidar." , bibl. Master's Thesis. Department of Geography. University of Maryland, College Park., (2000).

Solano Valverde, V., "Estudio de la diversidad, abundancia y distribuciønde palmas en bosques primarios y secundarios de la regicn Hu,tar Norte, Sarapiqui" , bibl. Undergraduate Thesis, Universidad Nacional, Costa Rica., (2000).

\section{II.6. Presentations}

We made considerable efforts to disseminate information about the project through scientific presentations, seminars, and course presentations. A list of the scientific presentations follows:

$[\mathrm{AB}=$ Anya Becker, $\mathrm{CL}=$ Catherine Lovelock, DAC $=$ Deborah A. Clark, DBC $=$ David B. Clark, $\mathrm{DL}=$ Deborah Lawrence, $\mathrm{EV}=$ Edzo Veldkamp, $\mathrm{HO}=$ Harlyn Ordoñez, $\mathrm{HL}=$ Henry Loescher, $\mathrm{JB}=$ Joseph O'Brien, $\mathrm{JE}=$ Javier Espeleta, $\mathrm{JM}=$ Jens Mackensen, LS = Luitgard

Schwendenmann, $\mathrm{MC}=$ Molly Cavaleri, $\mathrm{MK}=$ Markus Kleber, $\mathrm{MR}=$ Mike Ryan, $\mathrm{PO}=$ Paulo Olivas, SFO $=$ Steven F. Oberbauer, TB $=$ Tania Brenes, $\mathrm{TW}=$ Tana Woods, only first authors/presenters are given.]

Research talk, Ecological Society of America, Savannah GA, August 2003 (CARBONO) (DAC) Research talk, BES Symposium, Association for Tropical Biology, Aberdeen, Scotland, July

2003 (CARBONO) (LS)

Research seminar, STRI, Barro Colorado Island, Panama, July 2003 (CARBONO) (LS)

TV interview for a program on global change, Costa Rican television (Canal 7), July 2003

(TREES/CARBONO) (DBC)

Research talk at Instituto Nacional de Pesquisas da Amazônia, Manaus, Brazil, July 2003

(TREES/CARBONO) (DAC)

Research talks (two) to INPA/Smithsonian graduate field course on Amazonian ecology, Manaus, Brazil, July 2003

(TREES/CARBONO) (DAC)Research talk to OTS Graduate Field Ecology course and La Selva REU group, June 2003 (CARBONO) (JE)

Research talk to OTS Graduate Field Ecology course and La Selva REU group, June 2003

(TREES/CARBONO) (DAC)

Invited research talk, NASA Workshop (Multi-Dimensional Forested Ecosystem Structure:

Requirements for Remote Sensing Observations), Annapolis MD, June 2003 (DBC)

Research Poster, NASA Workshop (Multi-Dimensional Forested Ecosystem Structure:

Requirements for Remote Sensing Observations), Annapolis MD, June 2003 (SFO)

Research Poster, NASA Workshop (Multi-Dimensional Forested Ecosystem Structure:

Requirements for Remote Sensing Observations), Annapolis MD, June 2003 (DBC - with

Carlomagno Soto and Luis Alfaro)

Research talk, Harvard University, May 2003 (CL). 
Research talk to Pepperdine College undergraduate course, plus Dyer Earthwatch group, May 2003 (TREES/ CARBONO) (DAC)

Research talk, Escuela de Biologia, Universidad de Costa Rica, San José, Costa Rica, April 2003

(LS)

Research Poster, Interactions Between Increasing CO2 and Temperature in Terrestrial

Ecosystems Workshop, April 2003 (MC)

Invited talk, OTS Course for LatinAmerican Decisionmakers, La Selva, Costa Rica, May 2003

(TREES/ CARBONO) (JE)

Research talk to OTS Undergraduate Abroad course, La Selva, April 2003 (Remote

sensing/TREES/ CARBONO) (DBC)

Research talk to OTS Undergraduate Abroad course, La Selva, April 2003 (TREES/ CARBONO)

(DBC)

Invited speaker, Marcia Monroe Conery Memorial Lecture,Tulane University, April 2003

TREES/ CARBONO) (DAC)

Research poster, OTS 40th Anniversary Symposium, San José, Costa Rica, April 2003

(CARBONO/TREES) (Luis Diego Alfaro, Carlomagno Soto, DBC)

Research poster, OTS 40th Anniversary Symposium, San José, Costa Rica, April 2003

(CARBONO) (SFO)

Research poster, OTS 40th Anniversary Symposium, San José, Costa Rica, April 2003

(CARBONO) (LS)

Invited talk, OTS 40th Anniversary Symposium, San José, Costa Rica, April 2003 (TREES/

CARBONO) (DAC)

Invited talk, Escuela de Biología, Universidad de Costa Rica (Spanish), San José, Costa Rica,

April 2003 (TREES/ CARBONO) (DAC)

Article based on interview with DBC, February 2003, in Costa Rica newspaper El Financiero

(TREES/ CARBONO) (DBC)

Research talk to OTS English-language graduate course, La Selva, Feb. 2003 (TREES/

CARBONO) (DAC)

Research talk to OTS English-language graduate course, La Selva, Feb. 2003 (TREES/

CARBONO) (DBC)

Research talk to OTS U.S. Decisionmakers course, La Selva, Feb. 2003 (TREES/ CARBONO)

(DAC)

Research orientation walk for OTS English graduate course, La Selva, Feb. 2003 (TREES/

CARBONO) (DAC)

Research orientation walk for Stanford alumni, La Selva, Feb. 2003 (TREES/ CARBONO)

(DAC)

Research talk to Dartmouth College undergraduate course, La Selva, Feb. 2003 (TREES/

CARBONO) (DAC)

Research talk to Dartmouth College, La Selva, Feb. 2003 (TREES/ CARBONO) (DBC)

Research talk to Queen's University (Canada) undergraduate course, La Selva, Feb. 2003

(TREES/ CARBONO) (DAC)

Research talk to the OTS Spanish-language graduate field course, La Selva, Feb. 2003 (TREES/

CARBONO) (DBC)

Research talk to the OTS Spanish-language graduate field course, La Selva, Feb. 2003 (TREES/

CARBONO) (DAC)

Research talk (/Orientation Day) to the OTS Spanish-language graduate field course, La Selva,

Feb. 2003 (TREES/ CARBONO) (DBC) 
Television interview for young people's show for Latin American distribution (Canal 23, Costa Rican television) (Jan. 2003) (TREES/CARBONO) (DBC).

Invited speaker, research talk to Winrock International, Washington DC (Dec. 2002) (remote sensing) (DBC)

Research talk to Carleton College undergraduate course, La Selva, Dec. 2002 (TREES/

CARBONO) (DAC)

Research talk to Carleton College undergraduate course, La Selva (Dec. 2002) (remote sensing) (DBC)

Research presentation to Andrew Acho, World Director for Environmental Strategies, Ford Motor Company, Dec. 2002 (DBC)

Research talk, Smithsonian Environmental Research Center, November 2002 (CL)

Research talk to OTS USAP undergraduate course, La Selva, Nov. 2002 (TREES/ CARBONO) (DAC)

Research talk to OTS USAP undergraduate course, La Selva (Nov. 2002) (remote sensing) (DBC)

Invited speaker, Pittsburgh Ecoforum Eminent Biologists Lecture Series, Pittsburgh,

Pennsylvania, Nov. 2002 (DAC)

Invited speaker, Ecology Seminar Series, U. Pittsburgh, Nov. 2002 (DAC)

Invited speaker, Public Seminar Series of the Centro Nacional de Alta Tecnologia (CENAT), Costa Rica, Nov, 2002 (DAC)

Invited Speaker, Duke Ecology Seminar Series, Duke University, October 2002 (DBC)

Keynote address, Coalition for Excellence in Tropical Biology annual symposium, Miami FL

October 2002 (SFO)

Invited Speaker, Duke School of the Environment Seminar Series, Duke University, October 2002 (DBC)

Research talk to UNA forestry course, La Selva, Oct. 2002 (DBC)Invited Speaker, Conservation International, Washington DC, October 2002 (DBC)Research talk, OTS Latinamerican Wildlands course, September 2002 (DBC)

Research Poster, International Workshop on Quantifying Terrestrial Carbon Sinks: Science,

Technology, and Policy, Wengen, Switzerland, September, 2002 (LS)

Invited symposium speaker, Global Change and Tropical Forests, ATB, August, 2002 (DAC) Invited symposium speaker, Remote Sensing and Tropical Forests, ATB, August, 2002 (DBC) Research talk, Australian National University, August, 2002 (CL)

Research talk to NC State Forestry course, La Selva, August 2002 (DBC)

Research poster and invited workshop participant, LBA All-Scientists Meeting, Manaus, Brazil, July, 2002 (DAC)

Research Poster, 2nd LBA Scientific Conference, Manaus, Amazonas, Brazil, July, 2002 (LS). Research talk to OTS Latin American Decisionmakers Course, La Selva, April 2002 (DBC) Research talk, OTS Undergraduate Semester Abroad Program, La Selva, Costa Rica, May 2002 (DAC)

Invited speaker, OTS Latin American Decisionmakers Course, La Selva, Costa Rica, April 2002 (DBC)

Research talk, La Selva Seminar Series, La Selva, Costa Rica (March 2002) (SFO)

Invited Speaker, GCOS Workshop for Designing Regional Monitoring Programs for Climate and Carbon for Central America and the Caribbean, San José, Costa Rica, March 2002 (DAC) Keynote Speaker, International Association of Vegetation Science, Puerto Alegre, Brazil, March 2002 (DBC). 
Research talk, Annual Meeting of the Society for Tropical Ecology, Göttingen, Germany, February 20-23, 2002 (LS)

Research talk, OTS English-language graduate ecology course, Feb. 2002 (DBC)

Invited Speaker, Distinguished Tropical Biologist, Florida International University, January 2002 (DAC)

Invited Speaker, Symposium on Long-Term Ecological Research, University of Puerto Rico, January 2002 (DAC)

Invited to give testimony, Commission on the Environment and Agriculture, Costa Rican

National Legislature, November 2001 (DAC)

Research poster, International Workshop on Ecological Aspects of Dissolved Organic Matter in

Terrestrial Ecosystems, Wissenschaftszentrum Schloss Thurnau, Germany, October 9-11, 2001 (LS)

Invited talk, Global Change Interdepartmental Seminar, University of Colorado-Boulder, October 2001 (DBC)

Multiple lectures, field walks, TREES, to the OTS 3M course, September 2002 (DBC and DAC)

Poster, International Workshop on Ecological Aspects of Dissolved Organic Matter in Terrestrial

Ecosystems, Wissenschaftszentrum Schloss Thurnau, Germany, October 9-11, 2001

poster in pdf-format (at http://www.gwdg.de/ lschwen) (LS, EV, AB, MK, G. Gerold)

Poster, Meeting of the German Soil Science Society (DBG), Vienna, Austria, September 1-9,

2001, poster in pdf-format (at http://www.gwdg.de/ /schwen) (LS, EV, TB, JM, G.

Gerold)

Research talk, Meeting of the German Soil Science Society (DBG), Vienna, Austria, September

1-9, $2001(\mathrm{EV}, \mathrm{AB}, \mathrm{LS}, \mathrm{MK})$

Research talk, Ecological Society of America, Madison, Wisconsin, August 2001 (DAC)

Research talk, Ecological Society of America, Madison, Wisconsin, August 2001 (SFO)

Research talk, Ecological Society of America, Madison, Wisconsin, August 2001 (JO'B)

Poster, Ecological Society of America, Madison, Wisconsin, August 2001 (TW, DL, DAC)

Invited symposium talk, ESA, Madison, WI, 2001, August 2001 (DBC)

Invited Speaker, National Academies of Science-sponsored Members-Only Breakfast, U.S.

House of Representatives, July 2001 (DAC)

Invited Speaker, USDA Forest Service International Programs Seminar, July 2001 (DAC)

Invited Speaker, National Legislature of Costa Rica, Earth Day Round Table, April 2001 (DAC)

Invited Speaker, Jane and Whitney Harris Ecology Lecture, International Center for Ecology, St.

Louis, Missouri, April 2001 (DAC)

Invited Speaker, Organization for Tropical Studies Assembly of Delegates, La Selva, Costa Rica, March 2001 (DAC)

Invited Professor, Tropical Forest Ecology graduate shortcourse, U. Turku, Finland, Oct. 2000

(DAC)

Research Talk, Max Planck Institute for Biogeochemistry, Jena, Germany, Oct. 2000 (DAC)

Research talk, Association for Tropical Biology/International Botanical Congress, St. Louis, MO 1999 (DBC)

Research talk, University of Göttingen, Göttingen, Germany, October 2000 (DAC)

Research talk, Ecological Society of America, Annual Meeting; Snowbird UT, August 2000, (HL, SO, DBC, DAC)

Research talk, Ecological Society of America, Annual Meeting, Snowbird UT, August 2000, (DAC, LS, EV, JM, TB, SO) 
Research talk, Ecological Society of America, Annual Meeting, Snowbird UT, August 2000, (DBC, DAC, SO, EV)

Research talk, Ecological Society of America, Annual Meeting, Snowbird UT, August 2000, (LS, $\mathrm{EV}, \mathrm{TB}, \mathrm{JM}, \mathrm{DAC}, \mathrm{DBC}, \mathrm{SO})$

Research talk, Ecological Society of America, Annual Meeting, Snowbird UT, August 2000, (JB, $\mathrm{SO})$

Research Lecture, INPA/Smithsonian/OTS Graduate Field course in Amazonian Ecology, for Latinamerican students, June 2000, Manaus, Brazil (DBC)

Poster, LBA All-Scientists Meeting, Belem, Brazil, June 2000 (DAC, SO,DC,EV,JB,HL,LS).

Poster, LBA All-Scientists Meeting, Belem, Brazil, June 2000 (LS, EV).

Invited Speaker, 'Biometry-based estimates of forest NEP: an evaluation of methods and results

across AmeriFlux sites, U. Michigan Biological Station, May, 2000.' (DAC)

Research Lecture, OTS Graduate Field course in Amazonian Ecology, for Latinamerican students, May 2000, Iquitos, Peru (DAC)

Invited Speakers, Smithsonian Tropical Research Institute, March 2000 (DAC, DBC)

Invited Speaker, OTS course in tropical ecological issues for U.S. Decisionmakers (largely

congressional staffers), Costa Rica, March 2000 (DBC)

Research Talk, Soil Science Society of America, Annual meeting, November 1999, Salt Lake

City, UT (EV).

Invited speaker, U. Hohemheim symposium, November 1999, Hohemhiem, Germany (EV, LS).

Poster, Annual meeting of the German Soil Science Society, September 1999, Hanover, Germany (EV, LS).

Research talk, Ecological Society of America, Annual Meeting, Spokane Washington, August 1999, (HL, SO)

Poster, Ecological Society of America, Annual Meeting, Spokane Washington, August 1999 (HL, $\mathrm{SO}, \mathrm{JO})$

Poster, Association for Tropical Biology, Annual Meeting, St Louis, Missouri, August 1999

(DAC)

Poster, American Geophysical Union 1999 (DBC)

Research Lecture, OTS Graduate Field course in Amazonian Ecology, for Latinamerican students, May 1999, Iquitos, Peru (DBC)

Research talk, Annual Meetings of the Ecological Society of America 1998, Baltimore (DAC)

Poster, American Geophysical Union 1998 (http://www.inform.umd.edu/geog/vcl/lscan.html)

(DBC)

Poster, Annual Meetings of the Ecological Society of America 1998, Baltimore (DBC)

Invited Speaker, INPA seminar series, Brazilian National Amazonian Research Institute, Manaus, Brazil, July 1998 (DAC)

Television interview, Amazonas Television, Manaus, Brazil, July 1998 (DAC)

Research Lecture, OTS Graduate Field course in Amazonian Ecology for Latinamerican students, July 1998, Manaus, Brazil (DAC)

Invited Speaker, Women in Science Program, Duke University April 1998 (DAC)

Schnexnayder Lecture in Biology, Louisiana State University, Nov. 1998 (DBC)

Invited Speaker, Tropical Forest Canopy Workshop, Panama, March 1997 (DAC)

Earth, Oceans, Space Seminar Series, U. New Hampshire, October 1996 (DAC)

Departmental Seminar Series, U. Missouri-St. Louis, October, 1996 (DAC)

Invited Participant, Ameriflux meeting, St Louis, MO, October 1996 (HL)

Invited Participant, Ameriflux meeting, St Louis, MO, October 1997 (HL) 
Invited Participant, Fluxnet meeting Missoula MT, June 1998 (HL)

Poster, Annual Meetings of the Ecological Society of America 1998 (HL)

Invited Participant, Ameriflux meeting, St Louis, MO, October 1998 (HL)

Invited Participant, Ameriflux meeting, St Louis, MO, October 1996 (SFO)

Invited Participant, TECO meeting, Washington DC, November 1996 (SFO)

Invited Seminar Series, Florida Atlantic University, April 1998 (SFO)

Invited Seminar, Florida International University, September 1998 (SFO)

Invited Speaker, 4th International Canopy Conference, Selby Botanical Garden, November 1998, (SFO)

Invited presentation, NATO Advanced Study Institute, Chateau de Bonas, France, June 1997 $(\mathrm{EV})$

Plus dozens of lectures to graduate and undergraduate field courses (in English and Spanish) at the La Selva Biological Station, Costa Rica, 1996-2002 (DAC and DBC)

\section{II.7. Report Overview}

The remainder of this report contains section reports addressing and organized around the specific project objectives:1) Ecosystem carbon, water, and energy fluxes 2) Whole tree reponses to climate 3) Assessment of components of net primary productivity 4) Soil carbon stocks and fluxes. The fift objective, Process modeling was integrated into sections 1 and 2 , but some of that work is still in progress. Each section contains what are largely stand-alone reports based on paper addressing the key aspects of the objectives investigated within the project, including both published and unpublished materials. 


\section{STUDY SITE}

This study was conducted at the La Selva Biological Station, Puerto Viejo de Sarapiqui Costa Rica $\left(10^{\circ} 25^{\prime} 51^{\prime \prime N}, 84^{\circ} 00^{\prime} 59^{\prime \prime} \mathrm{W}\right.$ and elevation 80-150 m.a.s.l.). La Selva Biological Station is located in the northeast of the country and lies within the transitional zone between the Cordillera Central and the coastal plain. The forest has been classified as a wet tropical (Hartshorn and Peralta 1988) with high species diversity. Despite having $42 \%$ of the basal area in one species, Pentaclethra macroloba, the forest contains over 320 trees species (Hartshorn and Hammel 1994) with a density/diversity of $200 \mathrm{stems} / \mathrm{species} \mathrm{ha}^{-1}$ (diameter $>10 \mathrm{~cm}$ ). Mean forest height is 20$25 \mathrm{~m}$ with emergents exceeding $55 \mathrm{~m}$. Gaps can extend to the ground with a mean density of 0.1 ha ha ${ }^{-1}$ in various stages of recovery, making the overall canopy very aerodynamically rough. Incident mean daily solar radiation (long-term average from 1993-1998) is $14.9 \mathrm{MJ} \mathrm{m}^{-2} \mathrm{~d}^{-1}$ with an extremely large range from 0.4 to $31.3 \mathrm{MJ} \mathrm{m}^{-2} \mathrm{~d}^{-1}$. Mean annual temperatures were $24.6{ }^{\circ} \mathrm{C}$ for the period from 1982-1998 (OTS unpublished weather records). Mean annual precipitation is $4000 \mathrm{~mm}$, with a short dry period from December to end of May (Sanford et al., 1994) with no single month receiving less than $100 \mathrm{~mm}$. The daily distribution of precipitation during both the wet and dry season is variable. Soils range from relatively fertile Inceptisols along riverine areas to low $\mathrm{pH}$, low phosphorus Ultisols (Sollins et al. 1994) in upland areas.

Surface winds are dominated by the moisture laden NE trades originating from the Bermuda High incident with the Caribbean Sea coastline. Most (85\%) of the daytime, the annual mean direction of surface wind is $90^{\circ}$ due to the clockwise attenuation of these NE trade winds with altitude. The seasonal wet (June to end of November) and dry periods are controlled by the movement of the equatorial low-pressure trough, i.e., the Eastern Pacific intertropical convergence zone (ITCZ). During the dry season, the sub-tropical Hadley cell dominates general circulations, while the tropical cell (Sanford et al. 1994) dominats the wet season circulations. However, wet season precipitation along eastern Costa Rica is predominately from moisture laden, seasonal low-pressure troughs traveling east-west and originating over west Africa (Barry and Chorley 1987). Other circulations may influence wet season climate include temporales or nortes - polar air masses which move down the North American continent generating depressions and rain, chiefly occurring from November-to December (Schlutz et al . 1998), and veranillostemporary and often irregular movement of the South Pacific anticyclone northward causing the equatorial low pressure trough north of Costa Rica, thus creating a short dry period, typically for 7-to-10 days in September or October. See Sanford et al. (1994) and Holdridge et al. (1971) for further site information and Waylen et al. (1996) and Hassenrath (1988) for general climatology.

La Selva is located at $10^{\circ}$ Latitude, consequently there is little diurnal change in sunlight over the course of the year, ca. 40-minute total difference between solstices, making the times of sunrise and sunset to vary annually by approximately 20 minutes. However, the duration of crepuscular light was frequently lengthened by morning or evening cloudiness. 


\title{
IV. ECOSYSTEM CARBON, WATER, AND ENERGY FLUXES
}

\section{Methods}

\author{
IV.1. $\mathrm{CO}_{2}$ FLUXES
}

A 42 m tower (Upright Inc. Selma, CA) was used to access the canopy environment and support meteorological instrumentation, and eddy covariance and a profile system. Several criteria were used to position the tower in the center of an old growth forest at La Selva. After accounting for stability effects, and assessing the output from a source area model (Schuepp et al. 1990), under stable conditions $95 \%$ of the cumulative flux was derived within $1.2 \mathrm{~km}$ of the tower with a horizontal windspeed of $3 \mathrm{~m} \mathrm{~s}^{-1}$. The tower was then sited to minimize; any edge effects, below canopy advection either to- or from the site, and any effects solely contributed by any pockets of swamp forest. Access to the tower was by foot along approximately $2.5 \mathrm{~km}$ of trial.

\section{Meteorological Data}

Microclimate data were collected continuously at the tower top at $42 \mathrm{~m}$. Measured variables included; incident radiation (Li-190, LI-COR Inc. Lincoln, NE) photosynthetic photon flux density (PPFD, Li-200X), air temperature and relative humidity (CS500, Campbell Scientific, Logan UT) installed in a radiation shield, aspirated temperature (100 $\Omega$ platinum RTD, Omega Engineering, Stamford CT) and bulk rainfall (TE525 metric, Texas Electronics). At ground level, atmospheric pressure (PB105, Vaisala, Sweden) and, in each of three $1 \times 1 \mathrm{~m}$ plots, volumetric soil water content though the top $30 \mathrm{~cm}$ of soil (frequency domain reflectometery, CS615, Campbell Scientific) were measured. To assess zeroplane displacement (d), or the mean level of momentum absorption, an array of 3-cup anemometers (Model 03103-L, R.M. Young, Traverse City, MI) were mounted along the tower on a log scale at 35.5, 31.6, 28.2, and $25 \mathrm{~m}$ above the ground, and estimated by determining the $y$-intercept by eq. 1 .

$$
\log Z=\int_{0}^{Z_{m}} \log \left(\overline{u^{\prime}}\right)+y_{0}
$$

Where, $\mathrm{Z}$ is height above the ground $(\mathrm{m})$, and $\mathrm{u}$ is the 30 minute average of horizontal wind velocity at each height $\left(\mathrm{cm} \mathrm{s}^{-1}\right)$.

Roughness length $\left(\mathrm{z}_{0}\right)$ was estimated using $\mathrm{d}$ and can be represented by eq. 2 .

$$
z_{0}=\left(z_{m}-d\right)\left(\exp \frac{u^{*}}{u_{m}^{\prime} k}\right)
$$

Where, $\mathrm{z}_{\mathrm{m}}$ is the measurement height $(\mathrm{m}), \mathrm{u}^{*}$ is friction velocity $\left(\mathrm{m} \mathrm{s}^{-1}\right), \mathrm{u}_{\mathrm{m}}$ is horizontal wind velocity at measurement height $\left(\mathrm{m} \mathrm{s}^{-1}\right)$, and $\mathrm{k}$ is the von Karmen constant $(0.41$, dimensionless).

All instruments were cleaned and leveled as necessary, on a bi-monthly basis, and recalibrated as per manufacturers' instructions. At times when PPFD sensor was inoperational, PPFD was estimated by regression analysis developed with incident radiation. Likewise, when power outages occurred, aspirated temperature was estimated from regressions developed with the CS500 sensor. In both cases, the regressions had $\mathrm{R}^{2}$ of $>0.98$, and the amount of data replaced was $<0.05 \%$. Data were collected at an execution interval of 5 seconds and compiled in 30-minute averages with dataloggers (CR10 and 21X, Campbell Scientific).

Long term term meteorological data are available for the site, where incident light has been measured since 1992, and air temperature and bulk precipitation, since 1961 
(www.ds.duke edu). However, direct comparison of temperature between the OTS records and aspirated temperature measured at the CARBONO tower showed a systematic bias of the OTS air temperatures of $\sim 1^{\circ} \mathrm{C}$ higher than those found through direct comparison to making the longterm annual mean closer to $23.6^{\circ} \mathrm{C}$.

\section{NEE measurements}

The continuing development of the eddy-covariance (EC) technique has increased the accuracy and reliability of measurements over non-simple terrain (Baldocchi et al 1996, Goulden et al. 1996). The EC system was used to directly estimate the portion of NEE that is contributed by turbulent exchange. At times, the below canopy environment was not subject to turbulent transfer. Therefore, a profile system was used to estimate the rate of change of $\mathrm{CO}_{2}$ below canopy. Based on turbulent dynamics, equation 1 will be used to evaluate NEE to climatic variables, and is defined by;

$$
N E E_{\mathrm{CO} 2}=\overline{W^{\prime} \mathrm{CO}_{2}{ }^{\prime}}+\int_{0}^{z} \frac{\partial C \mathrm{O}_{2}}{\partial t} \partial z_{m}
$$

Where, NEE is net ecosystem exchange, $\mathrm{w}$ is vertical windspeed, $\mathrm{m} \mathrm{s}^{-1}, \mathrm{CO}_{2}$ is $\mu \mathrm{mol} \mathrm{CO} \mathrm{Cmol}^{-1}$, and $z_{m}$ is measurement height $(\mathrm{m})$. The first term is the eddy covariance (EC), the prime denotes deviations from the mean, and overbar indicates a time average. The second term is storage term, which in general is thought to be equal to zero over a 24 -hour period, but can be significant over a 1-hour interval. The micrometeorological convention is used here with negative values corresponding to uptake by the forest.

A 3-D sonic anemometer (K-probe, Applied Technology Inc., Boulder CO) to measure wind velocities in each polar coordinate and sonic temperature ( $w, v, u$, and $t$, respectively), and gas inlet were mounted atop the $42 \mathrm{~m}$ tower to estimate EC. Infrared gas analyzers (IRGA, model Li-6262, LI-COR Inc. Lincoln NE) were pressure and temperature controlled at ground level inside a climate-controlled structure. Flow rates were maintained by air movers (KNF Neuberger, Trenton NJ) and mass flow controllers (Model series 200, 0-10 lpm, Teledyne Hastings Inc. Los Angles CA). The NOAA flux program (Baldocchi and Meyers 1988, McMillen 1988) with a $400 \mathrm{~s}$ digital recursive running mean with a fixed lagtime was used to collect raw EC data files. IRGA DAC channels were digitized by the ATI sonic, 12-bit, A-to-D board, and co-variances, wind and scalar statistics and coordinate rotations processed were in real time at $10 \mathrm{hz}$. Protocols for accuracy, precision, quality control and assurance were used as defined by the AmeriFlux science plan (http://cdiac.esd.ornl.gov/programs/ameriflux/scif.htm).

It is essential that the response of all instruments is as fast as, or faster than, the turbulence that is carrying the bulk of mass and energy. This occurs between frequencies of 1-10 hz, e.g., within the inertial sub-range. While the sonic anemometer operates at these speeds, the response time for the IRGAs is slower, ca. 8-9 hz. To account for this frequency loss, Fast Fourier Transfer (FFT) analyses were done in which the portion of attenuation shown by the co-spectral density in the inertial sub-range was compared with the total spectra. This ratio for w't' was considered ideal, since temperature was the scalar estimated at $10 \mathrm{hz}$ solely by the sonic anemometer. This ratio was then compared to that of $\mathrm{w}^{\prime} \mathrm{CO}_{2}$ ' to estimate a correction factor, eq. 4. 


$$
C_{f}=\frac{\sum_{0.1}^{1} n S_{w^{\prime} C O 2^{\prime}} * w^{\prime} \mathrm{CO}^{-1} / \sum_{0.001}^{10} n S_{w^{\prime} \mathrm{CO} 2^{2}} * w^{\prime} \mathrm{CO}^{-1}}{\sum_{0.1}^{1} n S_{w^{\prime} \theta^{\prime}} * w^{\prime} \theta^{-1} / \sum_{0.001}^{10} n S_{w^{\prime} \theta^{\prime}} *^{*} w^{\prime} \theta^{-1}}
$$

Where, $\mathrm{C}_{\mathrm{f}}$ is the correction factor, $\theta$ is sonic temperature, and $\mathrm{nS}_{\mathrm{w}^{\prime} \mathrm{x}} / \mathrm{w}$ ' $\mathrm{X}$ ' is spectral density multiplied by the natural frequency and normalized by the mean variance.

FFT analysis was also used to assess whether the dissipation rate of turbulent kinetic energy (apparent in the wind statistics) followed similar trends found over other forests and were actually attenuated in the inertial sub-range, e.g., the Kaimal relationship, $-2 / 3$ slope within the inertial sub-range in a log-log plot (Kaimal and Finnigan 1994). This assists in the interpretation of how and when the canopy was coupled to the atmosphere, the turbulent structure and the appropriateness of measurement.

$\mathrm{CO}_{2}$ profile measurements were collected from 6 inlets at $0.5,7.3,11.95,16.55,21.2$, and $27.6 \mathrm{~m}$. A datalogger (21X, Campbell Scientific) was used to operate solenoids that switched the flow (ca. $3 \mathrm{lpm}$ ) from each inlet through the IRGA (Li-6262) for 5 minutes during each 30 minute period, and to collect the raw data. Co-located with each inlet were platinum resistance thermometers (100 $\Omega$ PRT, m68, Omega Engineering, Stamford, CT) housed in a radiation shield. Thus, when sampling occurred, the air flow acted to aspirate the PRTs. The temperature and humidity profiles were used to account for changes in mass flow due to changes in density (Webb et al. 1980). Below canopy storage was calculated from line-averaged profile measurements using Eq. 1 and it was assumed that this profile was similar across the EC flux source area. Both EC and profile measurements began in April 1998 and continued through the end of December 2000. These measurements were relatively continuous, however, gaps in the dataset occurred for periods (2-14 days) when either power failure or instrumentation malfunctions occurred. Profile data was screened for validity using the same criteria as the EC data with the exception that profile data includes periods of rain. All IRGA calibrations occurred at the same schedule, i.e., every 2-3 days. Improved precision in calibration was achieved since February 1999 by plumbing nitrogen through the IRGA reference cell as a zero reference.

To test the effects of PPFD on daytime uptake a model was fitted to the response of net ecosystem exchange and incident light, eq 5.

$$
N E E_{\text {day }}=R_{E}+\frac{\phi \alpha P_{\max }}{\phi \alpha+P_{\max }}
$$

Where, NEE is the net ecosystem $\mathrm{CO}_{2}$ exchange as calculated by Eq.1, $\mathrm{P}_{\max }$ is maximum ecosystem $\mathrm{CO}_{2}$ uptake rate, $\mu \mathrm{mol} \mathrm{CO}_{2} \mathrm{~m}^{-2} \mathrm{~s}^{-1}, \mathrm{R}_{\mathrm{E}}$ is ecosystem respiration rate, $\mu \mathrm{mol} \mathrm{CO}_{2} \mathrm{~m}^{-2} \mathrm{~s}^{-1}$, $ø$ is PPFD, $\mu \mathrm{mol} \mathrm{m} \mathrm{m}^{-2} \mathrm{~s}^{-1}$, and $\alpha$ is apparent quantum efficiency, $\mathrm{dCO}_{2} / \mathrm{d} \varnothing$.

To test the effects of temperature on nocturnal efflux a model was fit to the response of net ecosystem exchange and aspirated, or soil temperature, eq 6.

$$
N E E_{\text {night }}=R_{0} \exp ^{\left(b^{*} \text { temperature }\right)} \quad \text { Eq. } 6
$$

Where, $\mathrm{R}_{0}$ is the base respiration rate when temperature is $0, \mu \mathrm{mol} \mathrm{CO} \mathrm{CO}_{2} \mathrm{~m}^{-2} \mathrm{~s}^{-1}$, and temperature is ${ }^{\circ} \mathrm{C}$.

The GLM procedure was used to examine second and first order effects of variables on daytime uptake and nocturnal efflux, respectively (SAS v. 8.01, Cary, NC). Environmental variables included light, temperature, and VPD, and class variables included season and year. 
Sigma plot (v. 5.0, SPSS Inc., Richmond CA) was used to model the relationships between NEE and environmental variables.

\section{Data screening}

Many eddy-covariance studies establish a friction velocity $\left(\mathrm{u}^{*}\right)$ threshold $\left(\sim 0.2 \mathrm{~m} \mathrm{~s}^{-1}\right)$, below which is assumed laminar flow conditions, thus questioning the assumptions for turbulent exchange. Under these conditions data are removed making the remainder of the dataset more robust. $\mathrm{A} \mathrm{u}^{*}$ threshold is determined by either examining the residuals from the daytime energy balance against $\mathrm{u}^{*}$, or the nocturnal EC flux against $\mathrm{u}^{*}$. In either case, the apparent change in slope from low u* values to high denotes the threshold. In contrast, Law et al. (1999) found their nocturnal EC data more robust and in better agreement with ground-based chamber measurements below a $\mathrm{u}^{*}$ threshold of $0.25 \mathrm{~m} \mathrm{~s}^{-1}$. No $\mathrm{u}^{*}$ threshold was used here for the EC data. EC data were screened for validity and removed when; i) data was outside a measure of normalcy, in this case, the time-averaged variance of wind statistics and scalars were used, ii) rain events occurred, iii) 30-minute data collection periods were incomplete, iv) out-of-range signals were present from either the sonic anemometer or the IRGA. Profile data were removed when: i) data was outside a measure of normalcy, i.e., outside $\pm 3 \mathrm{SD}$, ii) 30 -minute data collection periods were incomplete, and iii) out-of-range signals were present from the IRGA.

\section{Leaf area estimation}

Leaf area index (LAI) of at La Selva and other wet tropical forests is uncertain because no direct (destructive) measurements of LAI have been made on a stand-level. Randomly sampled photographic estimates of LAI using WINPHOT (Ter Steege 1996) were made each year during each season (wet and dry) across 18 randomly stratified 0.5 ha plots (for description of statistical design for plot layout see Clark and Clark 2000). Within each plot, 6 photographs were made during each sampling date under diffuse light conditions at the same randomly chosen points. Because these estimates were derived optically with no means of direct calibration (i.e., through destructive sampling), these values should be viewed qualitatively, season-to-season differences being relative to each other. The forest at La Selva is dynamic (Denslow and Hartshorn, 1994), thus, the precision of the estimates made at the plot-level was also decreased with frequent tree and branch falls, potentially skewing the data. Seasonal differences in LAI at La Selva were expected because $8 \%$ of the trees are dry season deciduous, $28 \%$ of trees produce annual leaves, many of which produce at the onset of the wet season (Frankie et al. 1974). Though there are many tree species are facultatively deciduous losing a quarter to half of their leaves during dry events (Richards 1996). The periodicity of leafing from most of the canopy tree species at La Selva show seasonal tendencies, though actual amount of leaf loss and production is an active area of research (Newstrom et al. 1994).

\section{Results}

Spectra

There was a $-2 / 3$ relationship in the inertial sub-range during periods of both stable and unstable atmospheric conditions, indicating a transfer of energy to the canopy with shear forces dominating (Figure 1), although the spectral density was less during stable conditions, as were the EC flux measurements. Buoyancy forces produced energy in the vertical wind velocities, w, at night as indicated by the positive $1: 1$ slope between wavenumbers 0.0001 and 0.1 . A typical shift in the spectral peak between stable and unstable conditions was found, similar to others elsewhere (Kaimal and Finnigan 1994, Anderson et al. 1986). At times, Kelvin-Helmontz 


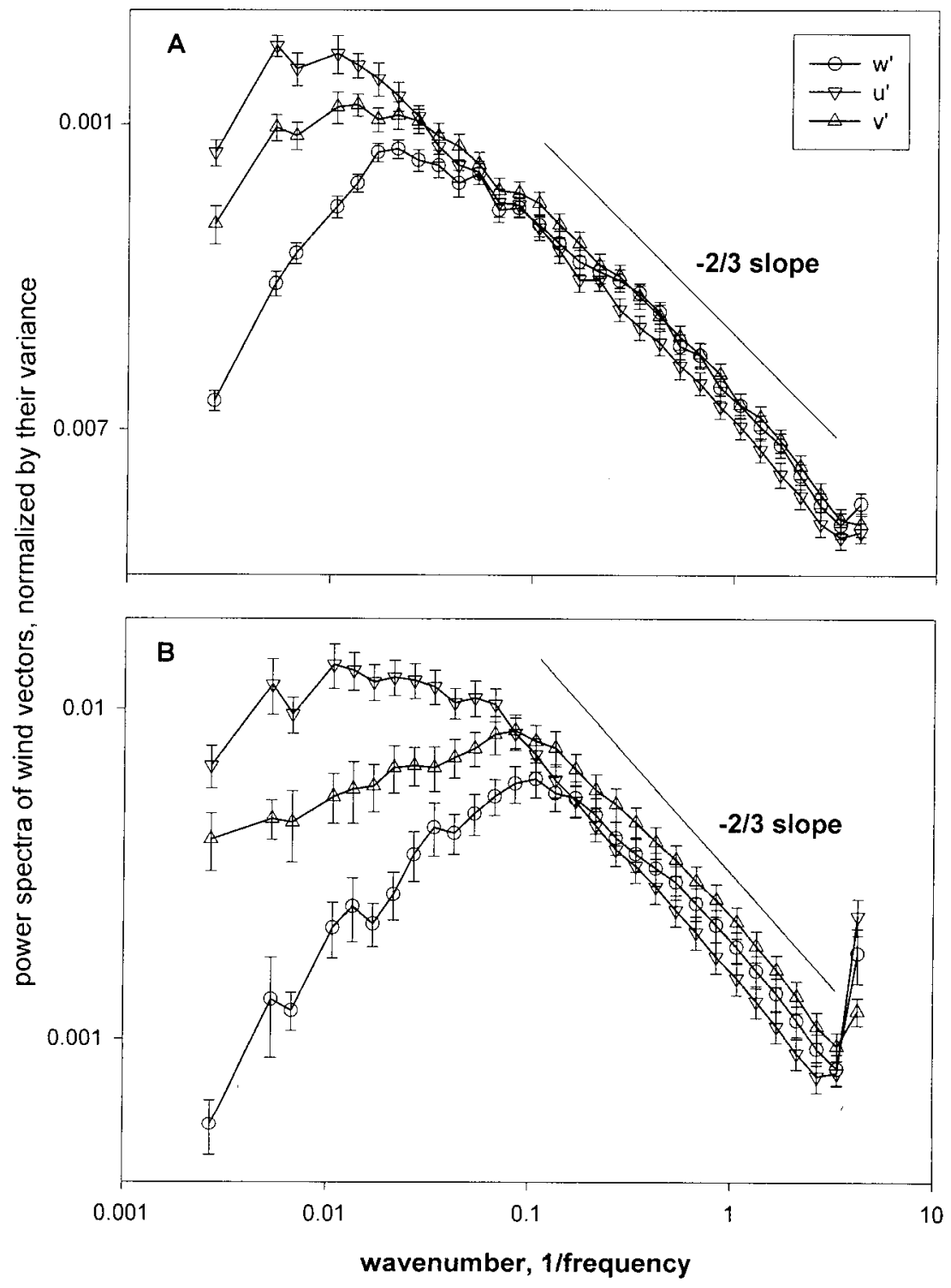

Figure 1. The relationship between the normalized power spectra for the three wind vectors against the wavenumber. Data are averaged from 73 half hour time periods from January 10 to Februray 28th, 1999. All half hours intervals are from A) mid-day, unstable conditions, begining either at 12:00 noon or 12:30 p.m, and B) mid-night, stable conditions, begining either at 23:00 or 23:30 p.m. Graph is plotted in a log-log scale. Error bars are +/- $1 \mathrm{SE}$. 
gravity waves were observed leading to an associated spectral peak (data not shown), similar to those described by Lee and Barr (1998). These gravity waves were observed intermittently during different nocturnal 30-minute intervals, sometimes during several intervals in one night, and most frequently during hours 2230 and $0400 \mathrm{~h}$. Gravity waves are likely associated within specific laminar flows in the nocturnal boundary layer and were only observed when these flows passed through the flux field. The spectra-based correction factor ranged from 1.18 to 1.08 (Figure 2), and varied with changes in stability.

Zero-plane displacement, roughness length and frictional velocity Variation in zero-plane displacement (d) and aerodynamic roughness $\left(z_{0}\right)$ for momentum was also observed with changes in stability (Table 1). During unstable periods where the MoninObukov length (L) was $<-0.5 \mathrm{~m}, \mathrm{~d}$ increased to $\sim 2.7 \mathrm{~m}$, depicting a long roughness length even for a forest environment, and a mean level of drag $\left(\mathrm{z}_{0}\right.$ of $\sim 18 \mathrm{~m}$ ) penetrating $\sim 5 \mathrm{~m}$ below mean canopy height. Aerodynamic roughness sharply decreased in length from unstable conditions to slightly unstable $(-0.1>\mathrm{L}>-0.5)$, and neutral conditions $(0.1>\mathrm{L}>-0.1)$ indicating the quick formation of stratified laminar flow, and below canopy decoupling from the environment above. The relationship between $\mathrm{u}^{*}$ and daytime uptake was linear, $\mathrm{R}^{2}=0.3$, as well as the relationships between daytime uptake and ratios of shear:bouyancy, e.g. Richardson number, Monin-Obukov length, or the kinetic energy budget. However, no relationship was found between $\mathrm{u}^{*}$ and the residuals from the energy budget under any stability conditions for the La Selva dataset. There was a general increase in the nocturnal above canopy flux with $\mathrm{u}^{*}$, though no threshold could be determined, and when all the nocturnal EC data was averaged across $\mathrm{u}^{*}$ classes, the relationship became strongly linear with no apparent asymptote, $\mathrm{R}^{2}=0.98$ (Figure 3 ). Below canopy flux was generally higher below $\mathrm{u}^{*}$ values of $0.1 \mathrm{~m} \mathrm{~s}^{-1}$, but with no clear trend with $\mathrm{u}^{*}$ values $>0.1 \mathrm{~m}$ $\mathrm{s}^{-1}$. Because a $\mathrm{u}^{*}$ threshold could not be determined, none was used for either daytime or nocturnal flux estimates. Friction velocity was generally $>0.3 \mathrm{~m} \mathrm{~s}^{-1}$ in unstable conditions, and was generally $<0.2 \mathrm{~m} \mathrm{~s}^{-1}$ in neutral and stable conditions (Table 1).

The EC flux measurements from La Selva were representative of exchange between the canopy and the atmosphere because of a consistent energy cascade in the inertial sub-range present in the power spectra under both stable and unstable conditions. Measurement height was at least $4 z_{0}$ above d in unstable conditions, and at least $3 z_{0}$ above d under all other stability classes.

\section{Diurnal pattern in $\mathrm{CO}_{2}$ flux}

The diurnal pattern in $\mathrm{CO}_{2}$ flux that is contributed by the change in storage was consistent throughout the year (Figure 4a). The greatest changes in the storage flux were during the early morning hours (Figure $4 \mathrm{~b}$ ), when below canopy $\mathrm{CO}_{2}$, respired from the night before, was ejected from the air-column and/or re-synthesized through photosynthesis. This morning ejection of $\mathrm{CO}_{2}$ was observed in both the EC and profile datasets when downward sweeps of air were countered by ejection of the canopy below canopy airspace. This event occurred sporadically, and was only observed when either a direct downward sweep occurred in the flux field, or when large earlymorning convection eddys passed through the flux field already carrying ejected and enriched $\mathrm{CO}_{2}$ from below canopy. Morning ejections occurred spatially heterogeneously across a landscape during early morning convective building of the boundary layer, and likely purge below canopy air at a scale of 0.1-3 ha ${ }^{2}$. Some of these data were not present in the mean or variance estimates because they were removed from the dataset, i.e., they were outside the 
Table 1. Aerodynamic roughness length $\left(\mathrm{z}_{0}\right)$ and zero-plane displacement (d) estimates according to stability class from La Selva Biological Station, Sarapiqui, Costa Rica. L is Monin-Obukov length, $d$, and $z_{0}$ estimates are median values $\pm 95 \% \mathrm{CI}, \mathrm{u}^{*}$ values are median $\pm 1 \mathrm{SE}$. $\mathrm{d}$ estimates were all significant with $\mathrm{p}<0.005$.

\begin{tabular}{llll}
\hline Stability class & $\mathbf{z}_{\mathbf{0}}$ & $\mathbf{d}$ & $\mathbf{u}^{*}$ \\
\hline Unstable, $\mathrm{L}<-0.5$ & $2.73 \pm 1.25$ & $18.2 \pm 4.9$ & $0.35 \pm 0.17$ \\
Slightly unstable, $-0.1>\mathrm{L}>-0.5$ & $0.61 \pm 0.09$ & $37.8 \pm 0.2$ & $0.34 \pm 0.05$ \\
Neutral, $0.1>\mathrm{L}>-0.1$ & $0.07 \pm 0.05$ & $38.3 \pm 0.8$ & $0.11 \pm 0.02$ \\
Stable, $\mathrm{L}>0.1$ & $0.41 \pm 0.11$ & $30.6 \pm 0.5$ & $0.22 \pm 0.02$ \\
\hline
\end{tabular}

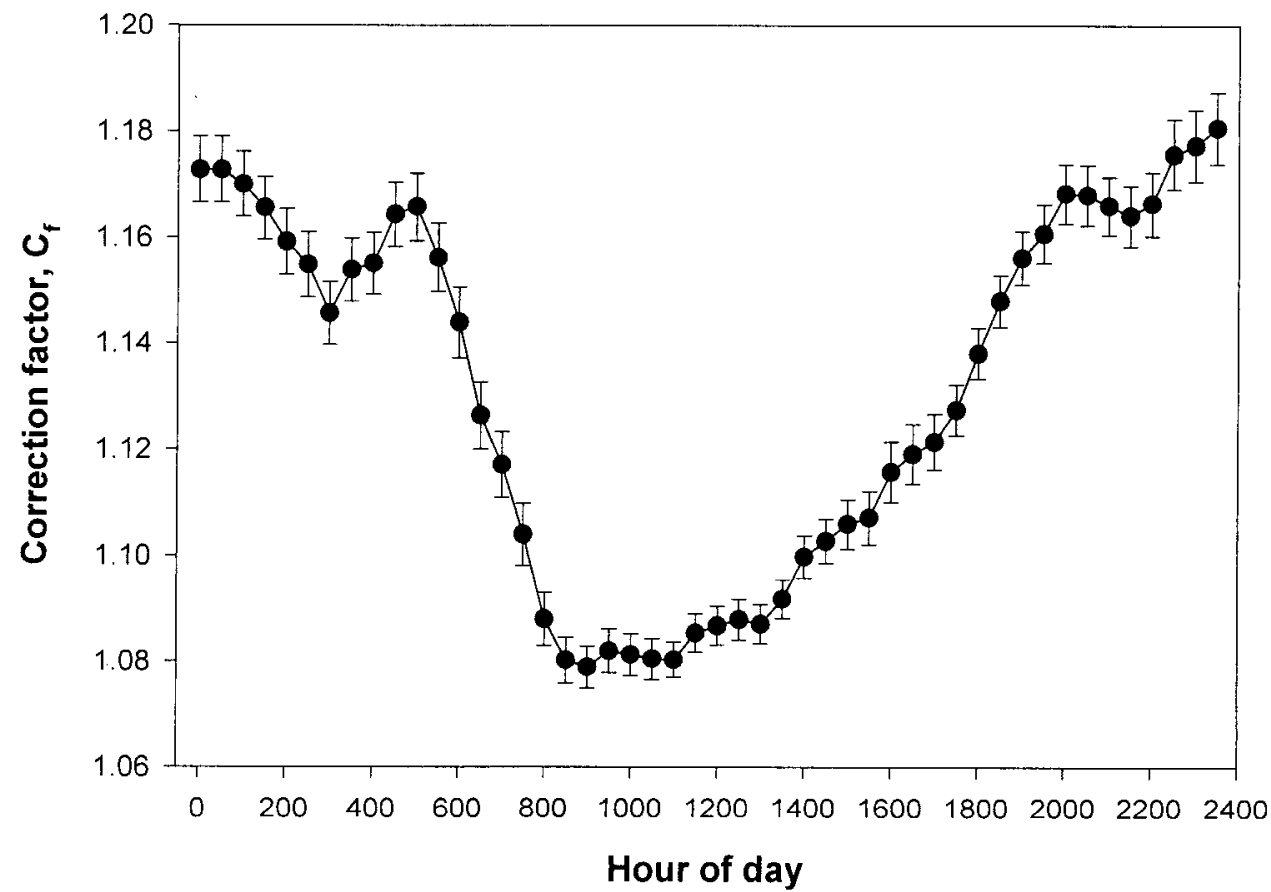

Figure 2. Diurnal timeseries of the spectra-based correction factor for $\mathrm{CO}_{2}$ from La Selva , as calculated by eq. 2. Data are bin -averaged over 1.5 hours, centered on the graphed 30 minute interval. Data are from all years, 1998-2000. Error bars are $+/-1 \mathrm{SE}$. 


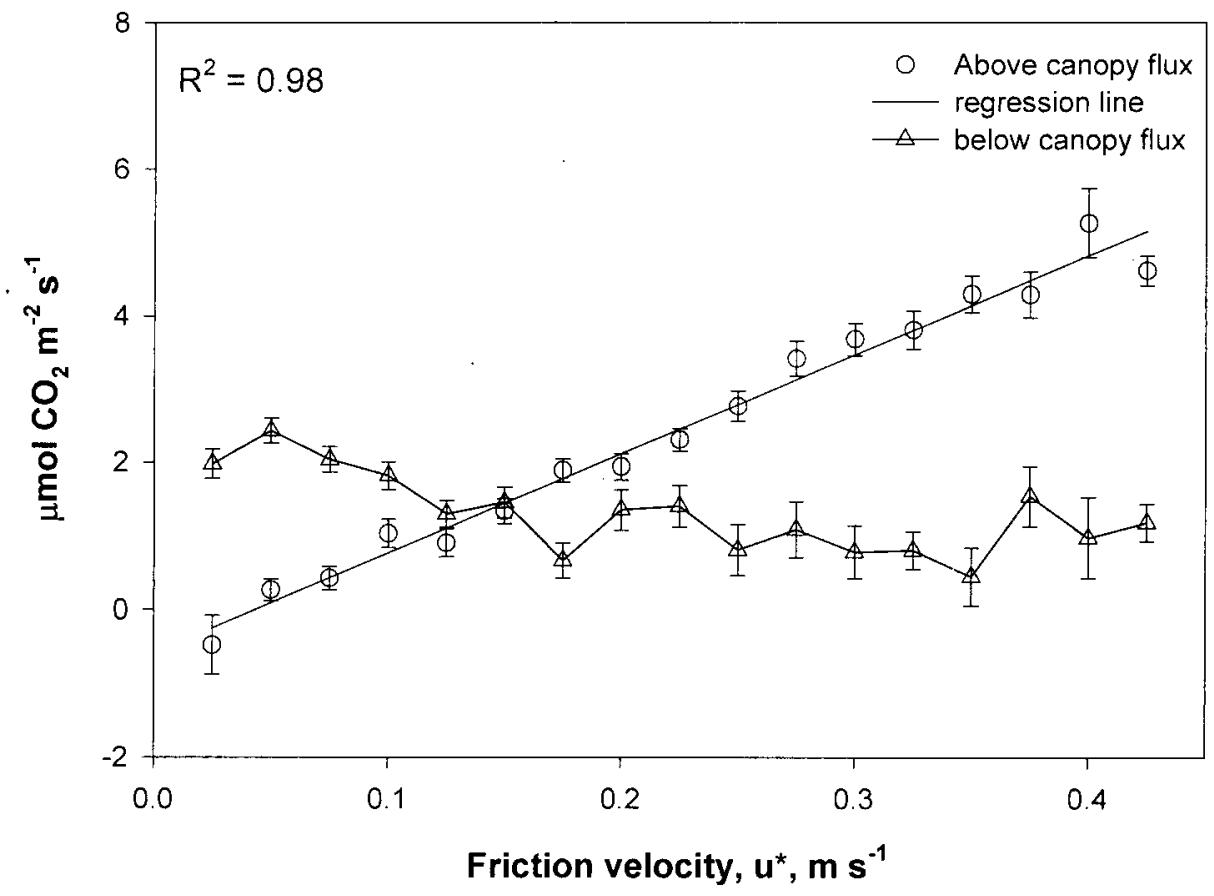

Figure 3. The relationship between above- and below canopy nocturnal flux and $u^{*}$. Values of the nocturnal flux were averaged across intervals of $0.025 \mathrm{~m} \mathrm{~s}^{-1}$. Error bars are $+1-1 \mathrm{SE}$. 


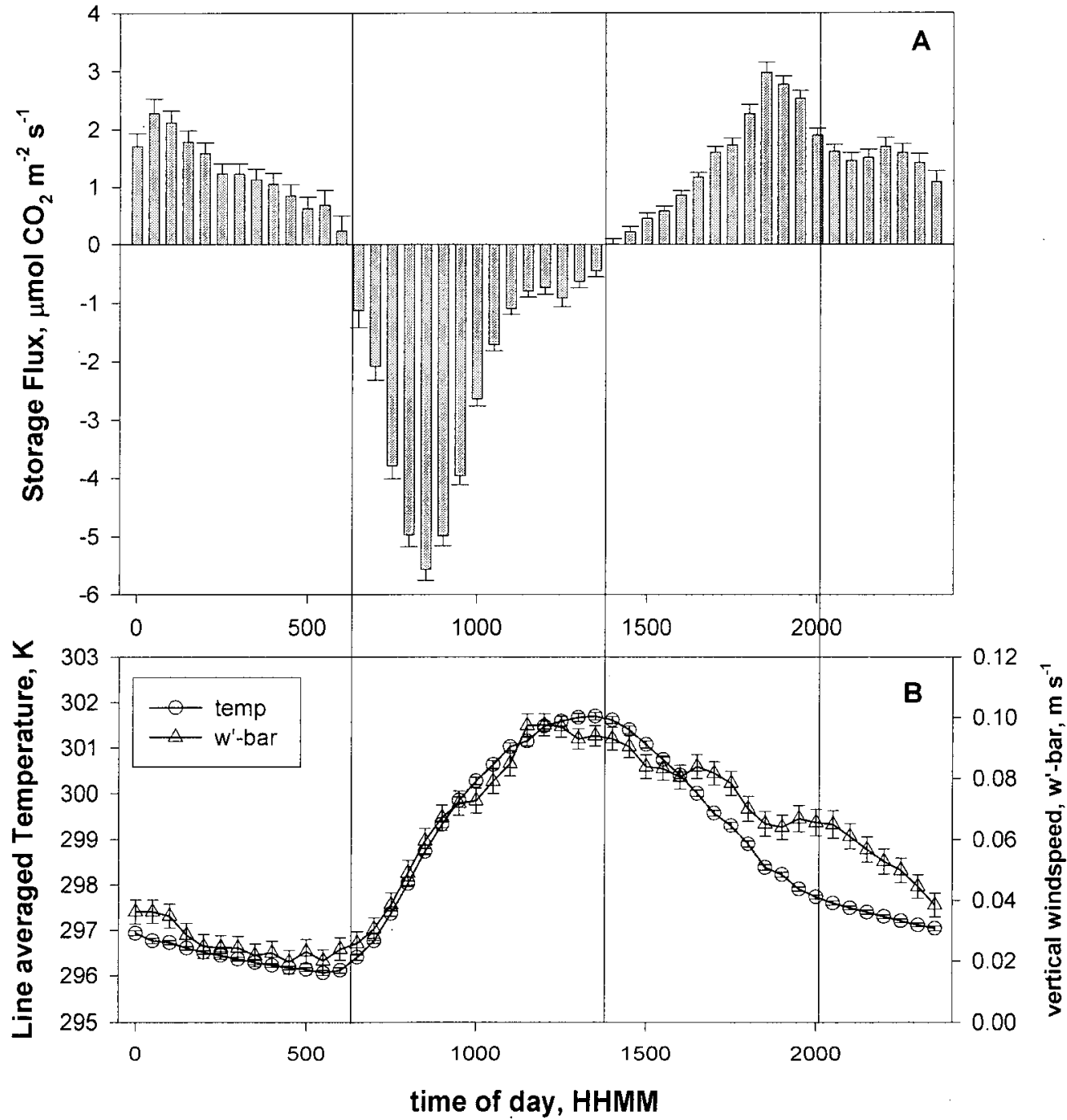

Figure 4. Diurnal characteristics of $A$ ) the contribution of NEE of $\mathrm{CO}_{2}$ by the change in storage, and $B$ ) line averaged temperature and non-rotated vertical velocity from La Selva from years $1998-2000$.. All data are bin averaged over a 90 minute period centered on the 30 minute inverval indicated. Error bars are +/- $1 \mathrm{SE}$. 
measure of normalcy. Hence, the total effect of morning ejections on NEE may not be fully quantified and may be an important larger scale transfer of morning $\mathrm{CO}_{2}$ to the atmosphere.

Maximum uptake from storage was $-5.6 \mu \mathrm{mol} \mathrm{CO}_{2} \mathrm{~m}^{-2} \mathrm{~s}^{-1}$. This occurred during midmorning when the convective boundary layer was developing, as shown by increasing mean vertical windspeed (Figure 4), and when the below-canopy airspace was well mixed. Uptake from storage decreased throughout the afternoon, until mid-afternoon, $\sim 1400 \mathrm{~h}$, when efflux from below canopy occurred. This also coincided the peak in the diurnal course of below canopy temperature (Figure 4). Efflux from storage increased to a peak just after sunset, $1830 \mathrm{~h}$. The contribution to nocturnal efflux from the change in storage was variable ranging from 0.7 to 2.97 $\mu \mathrm{mol} \mathrm{CO} \mathrm{Cm}^{-2} \mathrm{~s}^{-1}$, but centered around $1.6 \pm 0.13 \mu \mathrm{mol} \mathrm{CO} \mathrm{CO}^{-2} \mathrm{~s}^{-1}$, and generally decreased throughout the course of the night following the decreases in temperature and vertical velocity. However, vertical velocity and below canopy temperature patterns diverge between the hours of 1630 and 0130 suggesting that a portion of the flux remains unquantified due to advection.

The estimated $\mathrm{CO}_{2}$ uptake derived from eddy-covariance was negatively correlated with photon flux density (PPFD, Pearson's $\mathrm{r}=-0.7$, Figure 5a), with mean maximum uptake being $\sim 18$ $\mu \mathrm{mol} \mathrm{CO} \mathrm{Cm}^{-2} \mathrm{~s}^{-1}$, coinciding with peak irradiance. Nocturnal efflux remained fairly constant and centered around $4.5 \mu \mathrm{mol} \mathrm{CO}_{2} \mathrm{~m}^{-2} \mathrm{~s}^{-1}$. During 30-minute intervals where gravity waves were observed, measurements tended to be lower, e.g. at 2230 and 0400 (Figure 5). On average, $33 \%$ of the nocturnal flux was contributed by the below canopy-, and $67 \%$ by the above canopy flux. After the morning period when the below canopy $\mathrm{CO}_{2}$ was either re-fixed or purged, the daytime uptake was dominated by above canopy fluxes. A coarse estimate of the amount of recycled $\mathrm{CO}_{2}$ can be estimated using periods when little or no large-scale ejection would occur, where the recycled $\mathrm{CO}_{2}$ is the difference between the sum of the nocturnal efflux integrated over the whole night, and sum of the morning below canopy, re-fixed $\mathrm{CO}_{2}$. On average, $32 \%$ of the total nocturnal flux was recycled by below canopy elements. This estimate was remarkably similar to those from isotopically derived estimates re-fixed $\mathrm{CO}_{2}$ from the Ducke forest $(39 \%$, Sternberg et al. 1997), and within the bounds of estimates from an experimental treatment from another neotropical forest (31-38\%, Sternberg et al. 1989).

\section{Environmental controls on NEE}

Daytime uptake-A general linear model was used to test first and second order effects of year, season, incident light, temperature and vapor pressure deficit on daytime uptake. Some secondorder interactions were significant. A seasonal effect on light was significant $(\mathrm{p}<0.02)$. Light, temperature, and VPD were each significantly different from each year $(p<0.0001, p<0.0001$, and $\mathrm{p}<0.0009$, respectively). And light and- temperature, and- VPD were also significant ( $\mathrm{p}<$ 0.0001 and $\mathrm{p}<0.0001$, respectively). While no statistical significance was found for other seasonal effects, we cannot entirely dismiss that they may exist for carbon exchange. The GLM explained $\sim 72 \%$ of the total variation with all main effects, except season, significant ( $p$ $<0.0001$ ), and light accounting for $\sim 50 \%$ of the variation (Figure $6 \mathrm{a}$ ).

The net daytime uptake fit the light response function, eq 6, (main effects) and explained $\sim 50 \%$ of the variation. When the same data were compared with air temperature and VPD, a negative linear relationship was apparent, each explaining approximately the same amount of variation, $\sim 20 \%$. But temperature, light and VPD are all autocorrelated, as evidenced by the significance of their 2-way interactions. Thus, when the residuals from the light response function, eq 5, were plotted against temperature (Figure 6b) an optimal temperature range emerges for uptake, i.e. $20-26^{\circ} \mathrm{C}$, with an increasing number of positive residuals with higher 


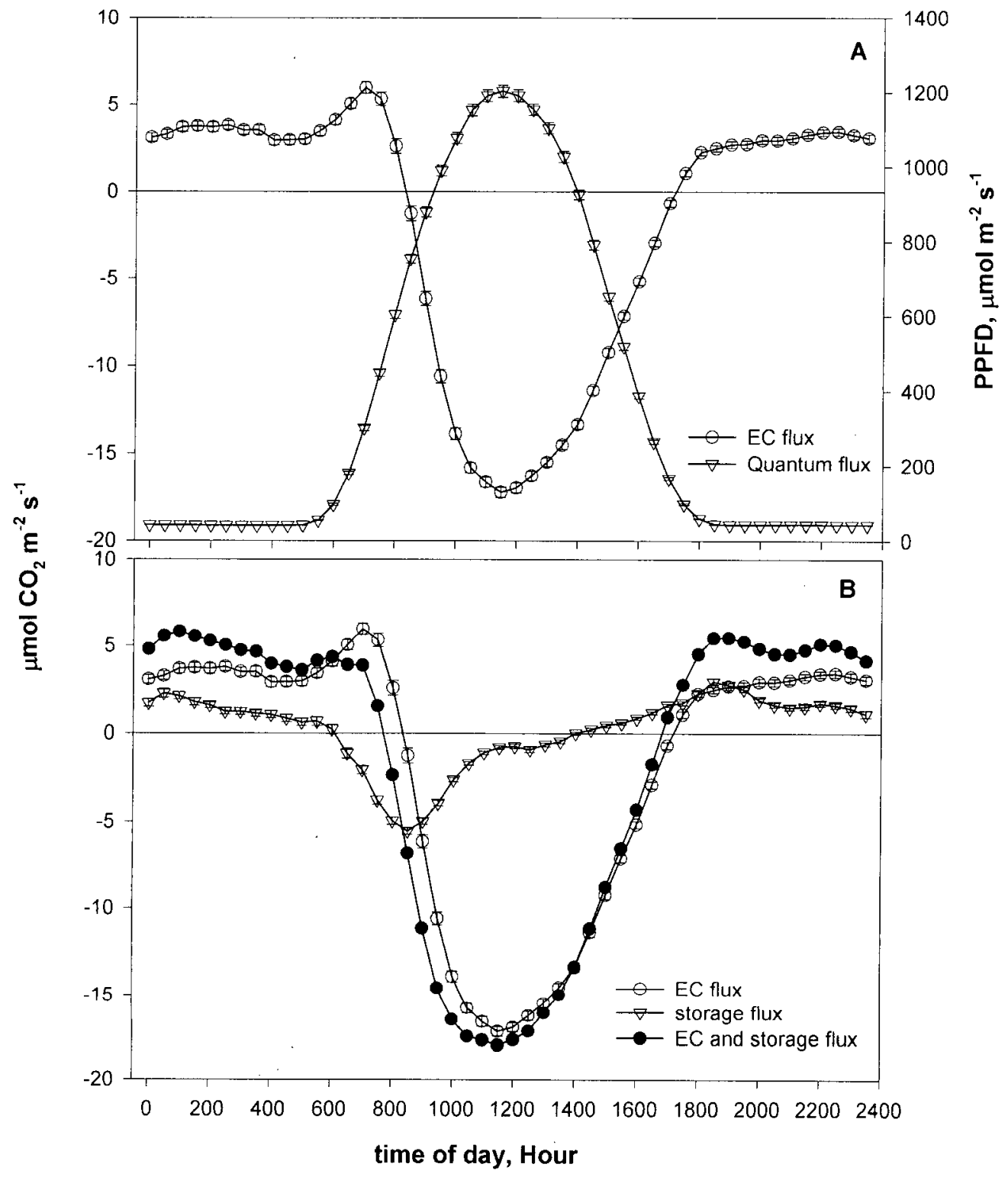

Figure 5. The mean diurnal pattern of $A$ ) above canopy flux and PPFD, and B) below canopy flux, above canopy flux and the combined flux from La Selva. 

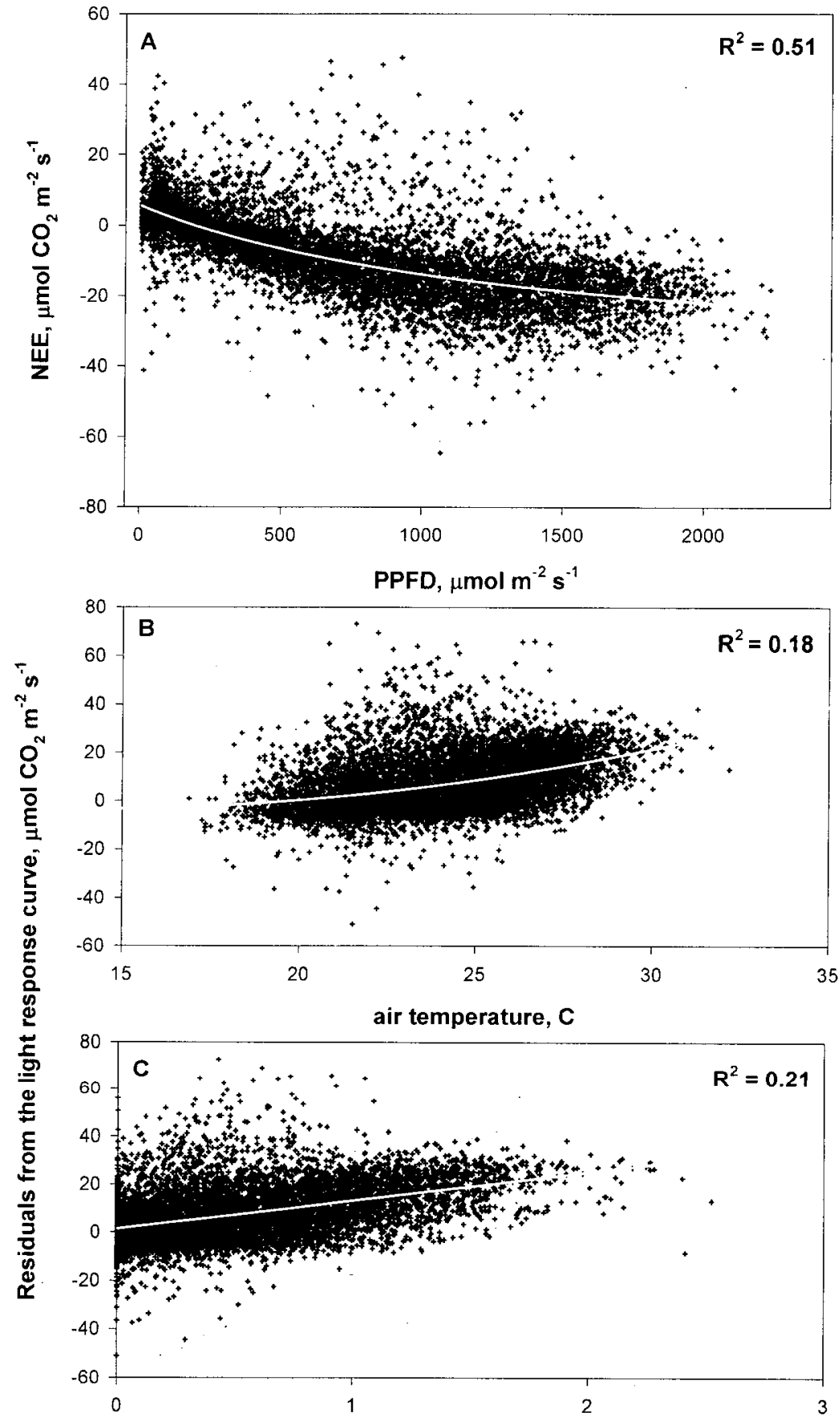

Figure 6. Flux reponse to PPFD with nonlinear model fit (top), with scattergrams of residuals from light model plotted versus air temperature (middle) and VPD (lower). 
temperature indicating a negative effect of higher temperature on daytime uptake. Likewise, greater VPD values show an increase in positive residuals (Figure 6c), also indicating a negative effect on daytime uptake.

Because temperature and VPD are auto-correlated, and the residuals from Figure $6 \mathrm{~b}$ cannot be explained by VPD, and vice versa, it is assumed that the detectable effect of temperature on daytime uptake was entirely due to VPD response. Statistical support for this assumption can be found in Ott (1993) and, statistically, all effects that have included VPD had slightly higher p-values, though, we cannot entirely discount the potential effects of temperature that maybe unobserved in this dataset.

The physical control of uptake can also be seen through the changes in efficiency (slope) in the light response to daytime uptake. Because second-order effects, including light, year and VPD (in that order) were significant, for each year the light response curve separated into arbitrary VPD classes (0-0.5, 0.51-1.00, and $>1.0 \mathrm{kPa}$, Figure 7) and parameter estimates can be found in Table 2. The light response function becomes almost linear with significant differences in slope, demonstrating reduced ability to capture carbon with increases in VPD. During 1998, $P_{\max }$, and $R_{E}$ were significantly lower than those found in year 1999, and the estimate of apparent quantum efficiency, $\alpha$, in year 2000 was greater than those found from the other two years. Light compensation point varied between years and ranged from 110 to $207 \mu \mathrm{mol} \mathrm{CO} 2 \mathrm{~m}^{-2} \mathrm{~s}^{-1}$.

Nocturnal efflux-_Using eq. 6, no relationship between the 30-minute nocturnal efflux data and temperature was found, although the majority of the data showed an efflux of carbon to the atmosphere, with a mean efflux of $4.82 \pm 0.6$ (mean $\pm 1 \mathrm{SD}$ ). Nocturnal flux generally decreased throughout the course of the night along with decreasing temperature. The power spectra from the nocturnal flux indicated a transfer of mass and energy, but the relative flux was small, and the source area quite long $(1.5-2 \mathrm{~km})$. The source area from the storage flux was more localized and only accounted for half of the above canopy flux (Figure 5). The nocturnal environment below canopy was quite different from and subject to changes in density driven adiabatic flows. The nocturnal $\mathrm{CO}_{2}$ profiles were variable, with the greatest variation occurring during periods with the greatest $\mathrm{d} \rho_{\mathrm{air}} / \mathrm{dT}$

$A Q_{10}$ relationship emerged when the nocturnal estimates were averaged for each $30 \mathrm{~min}$ period over the entire sampling period (data from Figure 5) and compared to temperature (Figure 8). All measures of nocturnal temperature were highly correlated $\left(\mathrm{R}^{2}>0.9\right.$ for all soil, above canopy air and profile temperatures). The relationships for both soil temperature and below canopy, line averaged temperature against nocturnal efflux were significant $(\mathrm{p}<0.001$ for all parameters), and resulted in $Q_{10}$ values of 1.27 and 1.79 , and $R^{2}$ of 0.19 and 0.17 , respectively. This approach does not fully quantify the total nocturnal flux, because these measures were biased by the number of estimates made under low $\mathrm{u}^{*}$, and because independent measures of soil efflux range from 2.7 to $4.2 \mu \mathrm{mol} \mathrm{CO} \mathrm{Cm}^{-2} \mathrm{~s}^{-1}$. Interaction effect with soil water could not be tested on this scale because the nocturnal bin-averaged estimates were not different from each other and were $\sim 0.9 \mathrm{v} \mathrm{v}^{-1}$.

A secondary reason to establish a nocturnal temperature response was to provide a means to fill gaps in the data when estimating annual NEE. Because this $\mathrm{Q}_{10}$ response only explains $<$ $20 \%$ of the variation, the approach that Mahli et al (1998) used to establish a nocturnal flux from a humid tropical forest presents another option. Mahli et al. (1998) used a base ecosystem respiration rate with a small temperature adjustment for foliar respiration. If total nocturnal flux is the sum of above-and below canopy elements, then the greatest precision for mean above 


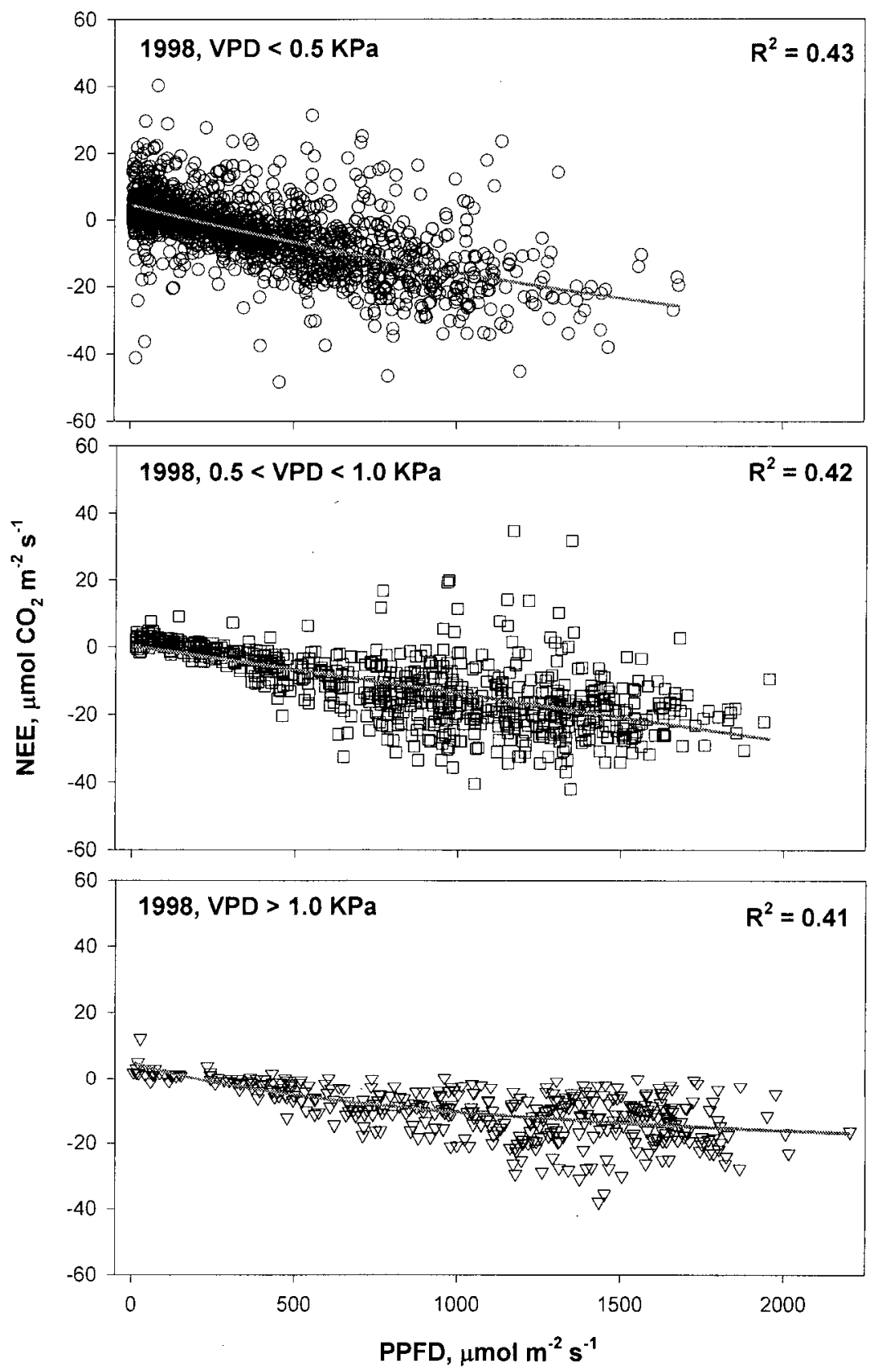

Figure 7. Net ecosystem exchange of carbon as a function of PPFD across a gradient of vapor pressure deficits for years 1998, 1999 and 2000 from La Selva, Costa Rica. 


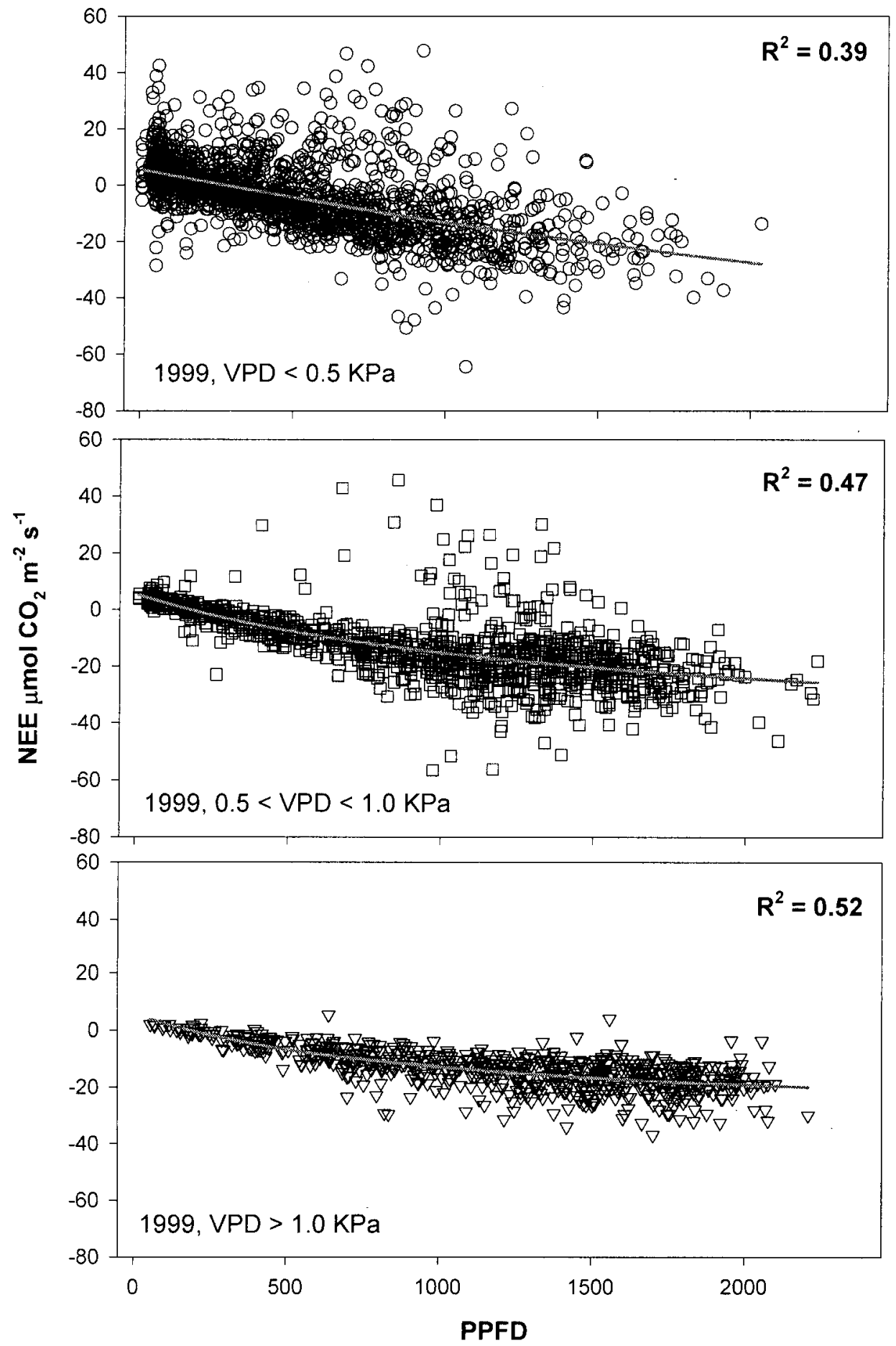

Figure 7. continued 


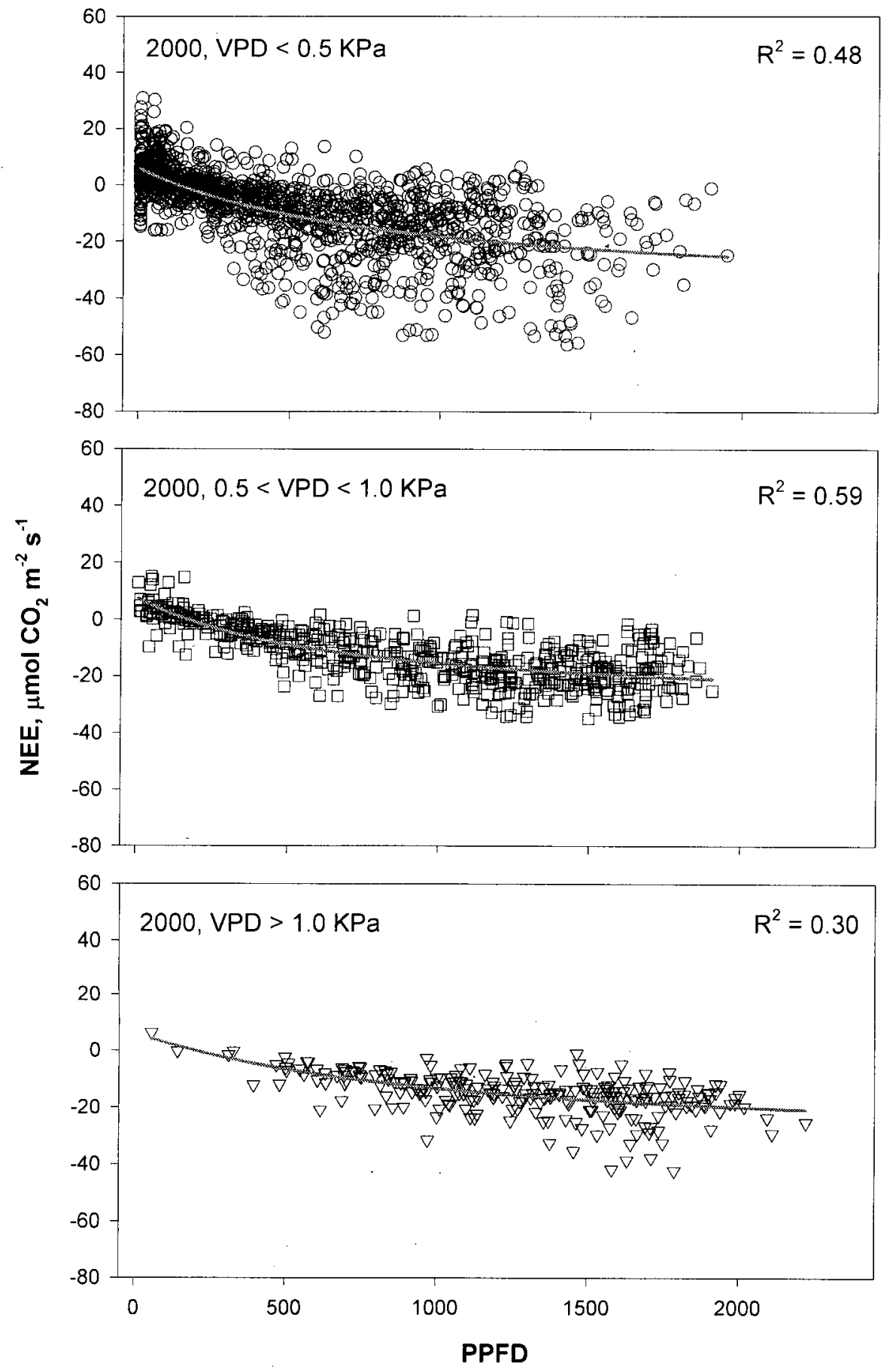

Figure 7. Continued 


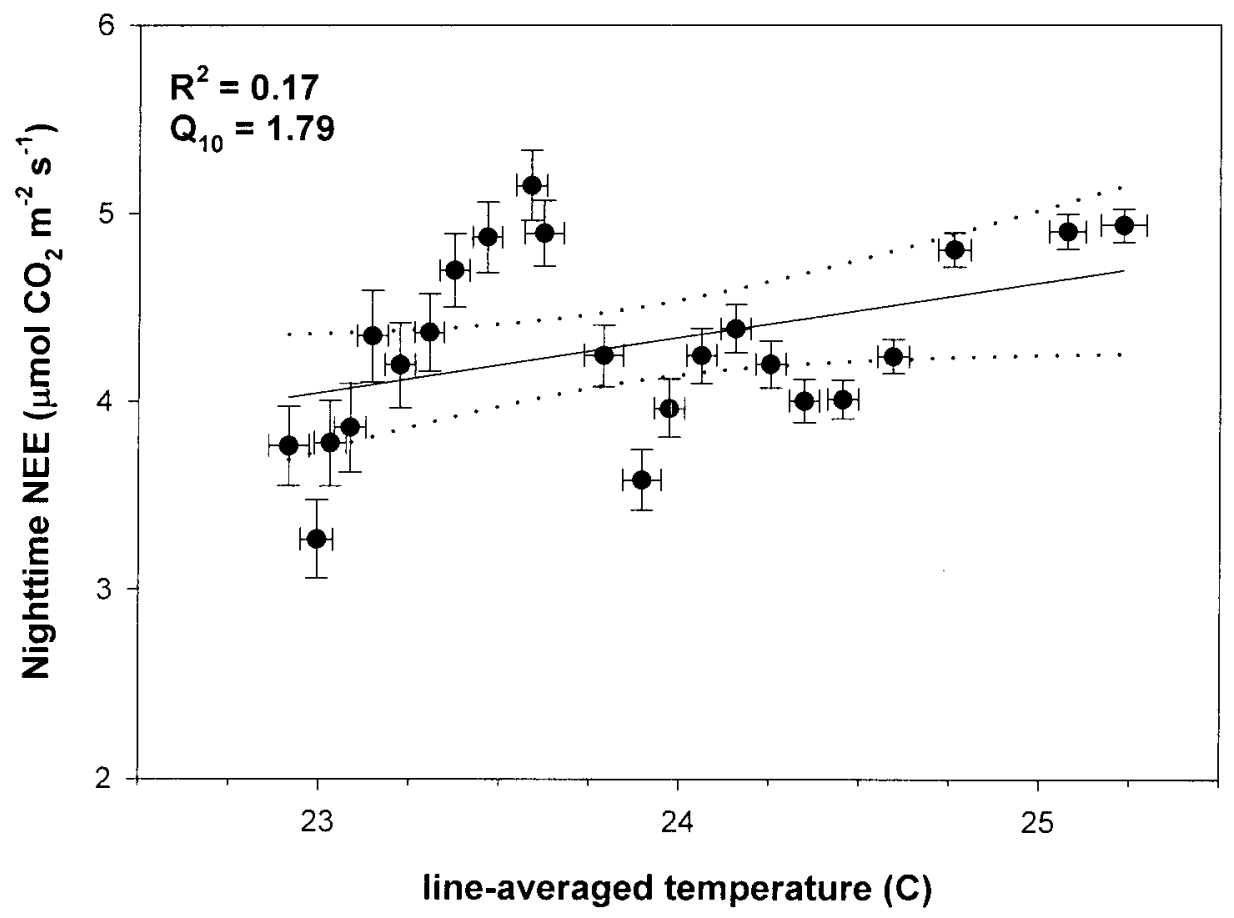

Figure 8. The relationship between nighttime NEE and line-averaged (below canopy) temperature. Nighttime NEE estimates are from the diurnal pattern in Figure 5. Temperature is an average from six measurements through the canopy profile from 27 to $0.5 \mathrm{~m}$ (see methods). 
canopy flux is at or above $\mathrm{u}^{*} 0.4 \mathrm{~m} \mathrm{~s}^{-1}$, and mean below canopy flux at low $\mathrm{u}^{*}$ values. Thus a base respiration flux estimated by this approach is 6.98, where $4.83 \pm 0.21$ and $2.15 \pm 0.11 \mu \mathrm{mol}$ $\mathrm{CO}_{2} \mathrm{~m}^{2} \mathrm{~s}^{-1}$ (mean $\pm 1 \mathrm{SE}$ ) are contributions from above- and below canopy fluxes, respectively. Supporting this approach is the mean nocturnal flux being within the $95 \%$ confidence interval from $\mathrm{R}_{\mathrm{E}}$ (eq. 5) using all the daytime data (Table 2). However, most individual year $\mathrm{R}_{\mathrm{E}}$ estimates were $1-1.5 \mu \mathrm{mol} \mathrm{CO}_{2} \mathrm{~m}^{-2} \mathrm{~s}^{-1}$ less than the base respiration estimate.

\section{Interannual variability in net carbon exchange}

To place bounds on the net annual carbon exchange for this wet tropical forest two approaches were used. First, meteorological data was used to drive the results found using eq.5 (for each year and VPD class), with a fixed nocturnal flux of $6.89 \mu \mathrm{mol} \mathrm{CO} \mathrm{Cm}^{2} \mathrm{~s}^{-1}$, and, second, the same dataset was used, but measured data was substituted when available. There is greater uncertainty in the nocturnal flux estimate because of the significant difference found in the above-canopy estimates at low and high $\mathrm{u}^{*}$ values. Since the filled dataset contains $80 \%$ of the data below a u* of $0.4 \mathrm{~m} \mathrm{~s}^{-1}$, it is biased towards a low nocturnal flux estimate. Hence, a correction factor was applied to this data. The nocturnal correction factor is a function of 3 components, the amount of time with significant respiration, the fraction of measured time under low $\mathrm{u}^{*}$ conditions (in this case $<0.4 \mathrm{~m} \mathrm{~s}^{-1}$ ), and the difference in $\mathrm{CO}_{2}$ flux between low and high $\mathrm{u}^{*}$ values, Figure 3 .

It was necessary to take this gap-filling approach because much of the EC data was rejected with the screens mentioned earlier. For example, during 1999, EC data was collected on $92 \%$ of the days. However, for over $18 \%$ of this time, rain events occurred, and $50 \%$ of the remaining data were removed due to measurements being skewed or out-of-range, leaving $33 \%$ of usable data.

Using these approaches, the results suggest that there were marked differences in the annual NEE among years (Figure 9). For years 1998, 1999, and 2000, the correction factor was $3.28,3.87$ and $2.77 \mathrm{t} \mathrm{Cha}^{-1} \mathrm{y}^{-1}$, respectively, placing bounds on each of the annual estimates for these years, -0.33 to $1.67,-2.05$ to 0.42 , and -6.31 to $-5.43 \mathrm{t} \mathrm{C} \mathrm{ha}^{-1} \mathrm{y}^{-1}$, respectively. Annual NEE was near neutral to a strong source in 1998. The uptake of annual carbon was higher in years 1999 and 2000 with year 1999 being near neutral to a small sink, and year 2000 being a strong sink year. Each of these annual budgets was also calculated using the nocturnal respiration estimate as calculated by the $\mathrm{Q}_{10}$ response, eq. 6. Accepting that the $\mathrm{Q}_{10}$ estimates are not fully quantifying the nocturnal flux, this method increased the net flux into the ecosystem (greater gains) by $\sim 4.2 \mathrm{tC} \mathrm{ha}^{-1} \mathrm{y}^{-1}$ for each of the years.

\section{Discussion}

\section{Characteristics of the La Selva canopy}

We assume the NEE measurements from La Selva were robust and represent the nature of $\mathrm{CO}_{2}$ exchange between the canopy and the atmosphere on the basis of two requirements generally prescribed for eddy covariance: (1) we found a consistent energy cascade in the inertial sub-range in the power spectra under both stable and unstable conditions (Kaimal and Finnigan 1994), and (2) the measurement height was at least 1.8 times $d$, in fact, at least 8 times $z_{0}$ above $d$ in unstable conditions and $6 \mathrm{z}_{0}$ above $\mathrm{d}$ under all other stability classes (i.e., Schmid et al. 2000, Montieth and Unsworth 1985). We did not expect to see a well-developed energy cascade during nighttime conditions. It is likely that this was due to roughness induced turbulence in the nighttime flows. 


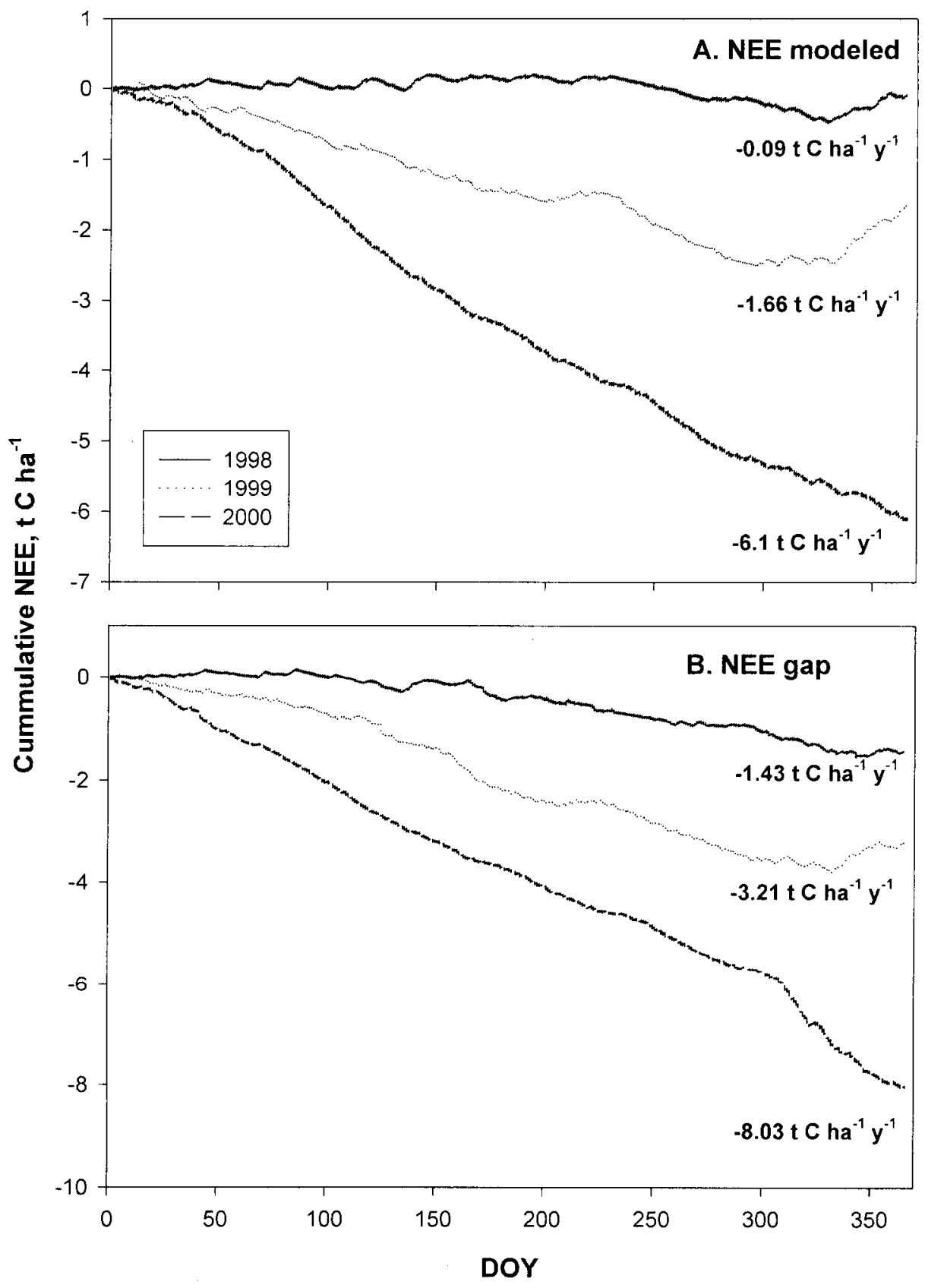

Figure 9. Cumulative NEE from La Selva, Costa Rica from 1998-2000. Estimates were calculated using $A$ ) the results from the light response equation across VPD classes and a fixed estimate for nighttime respiration, and B) direct estimates of daytime and nighttime NEE but with gaps filled using data from NEE modeled. 
Table 2. Parameter estimates and statistics from the light response function, eq. 5, across VPD pooled classes and year, and year (mean $\pm 1 \mathrm{Cl}, * \mathrm{p}$-value). *All parameter estimates were at least significant to $\mathrm{p}<0.0001$ with an $\alpha=0.05$, unless otherwise noted. $\mathrm{p}<0.0001 .{ }^{\mathrm{a}}$ denotes a significant difference between 1998 and $1999,{ }^{\mathrm{b}}$ between 1998 and $2000,{ }^{\mathrm{c}}$ between 1999 and 2000.

\begin{tabular}{|c|c|c|c|c|c|c|}
\hline VPD & year & $\mathbf{P}_{\max }$ & $\alpha$ & $\mathbf{R}_{\mathbf{E}}$ & $\mathbf{R}^{2}$ & $\begin{array}{c}\text { Light compensation } \\
\text { point }\end{array}$ \\
\hline $0-0.50$ & 1998 & $-106.58 \pm 34.7<0.002$ & $0.026 \pm 0.003$ & $4.51 \pm 0.35$ & 0.44 & \\
\hline $0.51-1.00$ & & $-43.6 \pm 4.92$ & $0.0356 \pm 0.007$ & $4.5 \pm 1.13$ & 0.45 & \\
\hline$>1.0$ & & $-32.4 \pm 3.7$ & $0.0317 \pm 0.010 .0019$ & $5.33 \pm 1.90 .005$ & 0.35 & \\
\hline pooled & & $-40.8 \pm 3.95^{\mathrm{a}}$ & $0.0346 \pm 0.0043^{\mathrm{b}}$ & $5.07 \pm 0.6^{\mathrm{a}}$ & 0.49 & $146 \pm 1.6$ \\
\hline $0-0.50$ & 1999 & $-142.4 \pm 63.9<0.03$ & $0.0217 \pm 0.002$ & $5.77 \pm 0.44$ & 0.39 & \\
\hline $0.51-1.00$ & & $-52.4 \pm 5.34$ & $0.0344 \pm 0.0052$ & $5.52 \pm 0.99$ & 0.47 & \\
\hline$>1.0$ & & $-37.8 \pm 1.79$ & $0.0377 \pm 0.0083$ & $5.92 \pm 1.730 .0006$ & 0.52 & \\
\hline pooled & & $-55.01 \pm 5.78^{c}$ & $0.0311 \pm 0.0035^{\mathrm{c}}$ & $6.42 \pm 0.66$ & 0.50 & $207 \pm 2.2$ \\
\hline $0-0.50$ & 2000 & $-44.8 \pm 5.23$ & $0.054 \pm 0.009$ & $6.02 \pm 0.94$ & 0.48 & \\
\hline $0.51-1.00$ & & $-39 \pm 3.0$ & $0.058 \pm 0.016$ & $7.85 \pm 2.13$ & 0.59 & \\
\hline$>1.0$ & & $-40.1 \pm 7.2$ & $0.039 \pm 0.0360 .067$ & $6.57 \pm 8.80 .22$ & 0.30 & \\
\hline pooled & & $-37 \pm 2.07$ & $0.058 \pm 0.0085$ & $6.33 \pm 0.83$ & 0.51 & $110 \pm 1.3$ \\
\hline
\end{tabular}


using Monin-Obukov theory (Leclerc et al. submitted), and have been measured over uniform canopies with short aerodynamic roughness. As roughness lengths become greater $(>1 \mathrm{~m})$, the effect on turbulence in the well-mixed layer and applicability of Monin-Obukov theory become questionable (Nakamura and Mahrt 2001, Ayotte et al. 1999, Raupach and Finnigan 1997). Under these conditions, $\mathrm{u}^{*}$ becomes homogenized over a broader range of turbulence lengths and potentially has less explanatory power (Nakamura and Mahrt 2001). At La Selva, there were insufficient data to assess if the linear relationship between $u^{*}$ and $\mathrm{NEE}_{\text {night }}$ existed at values $>0.45 \mathrm{~m} \mathrm{~s}^{-1}$, or if the relation reached some asymptote. Data that would have contributed toward developing a $\mathrm{u}^{*}$ filter may also have been screened out by other criteria.

\section{Environmental controls on NEE}

The average-diurnal pattern in NEE (Figure 5) is strongly symmetrical around the hour of 1130. On average, the storage term contributed $33 \%$ to $\mathrm{NEE}_{\text {night }}$. The power spectra for nighttime eddy covariance indicated a transfer of mass and energy, but the flux was relatively small and the source distance quite long $(1.5-2 \mathrm{~km})$. The nighttime environment below the canopy is quite different from that at the tower top and subject to diabatic flows controlled by changes in air density and topography (Mahrt 1992) making the source area for the storage flux more localized. The greatest variation in nighttime $\mathrm{CO}_{2}$ profiles occurred during periods with the most rapid changes in $\mathrm{T}_{\mathrm{a}}$. However, the diurnal patterns in $\mathrm{CO}_{2}$ profiles and respective storage fluxes were relatively consistent throughout our measurement period. After the morning reassimilation of stored $\mathrm{CO}_{2}$ was dissipated, the $\mathrm{NEE}_{\text {day }}$ was dominated by above-canopy fluxes.

A coarse estimate of the amount of recycled $\mathrm{CO}_{2}$ can be obtained as the difference between integrated $\mathrm{NEE}_{\text {night }}$ and the morning storage flux. This calculation provides a value of $32 \%$ for the fraction of integrated $\mathrm{NEE}_{\text {night }}$ that was recycled below $42 \mathrm{~m}$, similar to isotopicallyderived estimates of re-synthesized $\mathrm{CO}_{2}$ from the Ducke forest near Manaus, Brazil (39\%, Sternberg et al. 1997) and within the range from another neotropical forest (31-38\%, Sternberg et al. 1989).

The lack of finding a response between 30 -min averages of $\mathrm{NEE}_{\text {night }}$ and temperature was likely due to the combination of i) different sources of variation in $\mathrm{NEE}_{\text {night }}$ attributed to varying controls on partitioned respiration (Davidson et al. 1998). For example, soil respiration in the tropics can be largely influenced by soil water status as well as water (Schwendenmann et al. submitted) and foliar respiration may be influenced by nitrogen flushes and available photosynthate, ii) there was only a small annual nighttime temperature range $\left(<9^{\circ} \mathrm{C}\right)$, iii) the above-canopy source area is distinct from that of the below-canopy environment (Raupach et al. 1992 ), iv) the fact that $80 \%$ of flux estimates were made under conditions with low $u^{*}$ values (< $0.4 \mathrm{~m} \mathrm{~s}^{-1}$ ), thus biasing and underestimating nighttime turbulent exchange, or v) any carbon being exported from the system, as in below-canopy advection or large morning ventilation events, that currently cannot be quantified (Wilson et al. 1998, Mahrt 1992).

Errors in our finding a weak relationship between $\mathrm{NEE}_{\text {night }}$ estimates that were averaged diurnally (Figure 5) and $\mathrm{T}_{\mathrm{a}}$ (Figure 8) include those mentioned above. The relationship found in Figure 8 likely underestimates the $\mathrm{NEE}_{\mathrm{night}}$, for example; average soil respiration estimates from ultisol soils ranged from 3.3 to $4.3 \mathrm{mmol} \mathrm{CO}_{2} \mathrm{~m}^{-2} \mathrm{~s}^{-1}$, Schwendenmann et al. submitted). Moreover, when we recalculated annual $\mathrm{NEE}_{n i g h t}$ using the nighttime respiration function in Figure 8 it resulted in a significant decrease in $\mathrm{NEE}_{\text {night }}$, and hence increased annual NEE into the forest by $\sim 4.2 \mathrm{t} \mathrm{C} \mathrm{ha}^{-1} \mathrm{y}^{-1}$ for each of the years.

We also explored the potential of below canopy nighttime flow in contributing towards error in NEE estimates. For below canopy flow to develop at La Selva conditions must; develop 
a strong change in temperature upslope, become density stratified with height, overcome below canopy resistance to flow, and have net vertical windspeed into the forest. We speculate, however that this error does not contribute greatly to our observed annual flux, because of; a small change in temperature over a large upslope area, large below canopy resistance (e.g. leaf area and tree stems), and dilution of carbon from the addition of above canopy air moving below canopy and downslope (e.g., the measured above canopy non-rotated vertical windspeed is approximately the same as below canopy flow, $\sim 0.05 \mathrm{~m} \mathrm{~s}^{-1}$, see Figure 4). Because the temperature gradient upslope is not likely to change between years (even with a warmer ENSO), we expect that the magnitude of this error will also not differ greatly. This unresolved issue and those mentioned above are concerns for many tower-based flux sites; they are an active area of research, and remain, in general, as potential sources of error for NEE $\mathrm{Night}_{\text {(Massman and Lee }}$ 2001).

Because global temperatures have increased over the past 20 years (National Academy of Science 2000), there is increased focus on the role temperature on carbon dynamics in the tropics. Kindermann et al. (1996) modeled the effects of increased temperature on carbon stores and with even small increases in temperature $\left(\sim 0.5^{\circ} \mathrm{C}\right)$, large effluxes of carbon to the atmosphere are expected, and it is hypothesized most of this carbon will be from the tropics (Trumbore et al. 1996). At La Selva, large year-to-year fluctuations in aboveground biomass increments have been negatively correlated to the mean nighttime temperature and the inter-annual fluctuations in atmospheric $\mathrm{CO}_{2}$ concentrations from the past 16 years (Clark et al. in review). This suggests that temperature imposes control on NEE from tropical forests and play an active role in mitigating global atmospheric $\mathrm{CO}_{2}$ concentrations. In this study, we found a temperature response in uptake that we cannot dismiss is entirely due to a VPD, and a nighttime response only when entire dataset was used and examined on a diurnal basis. Interestingly, both Grace et al. (1996) and Malhi et al. (1998) did not report any nighttime temperature response using just their eddy-covariance data from Amazonian forests. Ecosystem respiration is a combination of microbial decomposition, and metabolic activity of roots, stems and leaves, each with potentially different responses to temperature. It may be, that if all these processes are taken in concert, coupled with our small ranges in nighttime temperature, ecosystem level respiration from these tropical forests may only be apparent when examined at these longer (i.e., annual) time scales.

We found strong interannual changes in apparent forest-level quantum efficiency $(\alpha)$ estimated from the eddy-flux data. These may indicate large adjustments in forest structure and physiology in response to the climatic variation among our study years. For example Waring et al. (1995) concluded that seasonal differences in both LAI and canopy-level quantum efficiency largely controlled productivity from Harvard forest. In our study, the estimated $\alpha$ for year 2000 was significantly higher than those from the preceding two years (Table 2) and approached the theoretical maximum for $\mathrm{C}_{3}$ leaves (Lloyd et al. 1995, Farquhar et al. 1980). Whereas, the eLAI from 1998 was significantly higher than values found from 1999 and 2000 (Table 3). eLAI values increased only during the dry season in 2000 from values found in 1999 . The fact that neither the between year eLAI values- nor $\alpha$ followed the same trends observed in the cumulative annual flux, (Figure 9) suggests that interactions between leaf production, turnover, and plasticity, and climate control annual NEE in this tropical wet forest.

Some Neotropical tree species exhibit strong leaf plasticity and quickly increase leaf production and turnover with increases in incident light (Oberbauer and Strain 1985, Chazdon 1986). The mean daily insolation was significantly higher during 1999, than years 1998 and 2000. A greater $\alpha$ in year 2000 can be explained if leaf set was established in- and was 
Table 3. Annual and seasonal differences in estimated leaf area index (eLAI) $\mathrm{m}^{2} \mathrm{~m}^{-2}$ from La Selva, Costa Rica.

\begin{tabular}{ll}
\hline Season Year & Mean (median) $\pm \mathbf{1 ~ S E}$ \\
\hline Dry 1998 & 3.85 \\
Wet 1998 & 4.85 \\
Dry 1999 & $2.71(2.52) \pm 0.13$ \\
Wet 1999 & $3.76(3.84) \pm 0.11$ \\
Dry 2000 & $3.48(3.51) \pm 0.07$ \\
Wet 2000 & $3.43(3.30) \pm 0.13$ \\
\hline
\end{tabular}


responsive to the increased insolation 1999. Granted, this is speculation and it is possible that a greater $\alpha$ is due to a mechanism not yet recognized.

The effect of VPD suggests physiological or physical control on NEE day. Physiological control is accomplished by stomatal regulation direct response to hydrologic limitation, e.g., high VPDs or decreases in soil moisture availability. The location of the hydraulic limitation in the La Selva forest is not known, e.g. soil, xylem, leaf. Physical control can be though modification of the canopy architecture through leaf-drop, leaf folding or changes in leaf orientation. When temporally integrated, forest canopies do not fully saturate even at full insolation (Ruimy et al. 1995, Wang and Polglase 1995): Changes in leaf angle or leaf closure in the upper canopy allows penetration of light to deeper canopy layers, allowing for increased carbon gain in the lower canopy, thereby offsetting the full effect of leaf closure or changes in orientation at an individual scale when examining the light response at the ecosystem level. However, only $8 \%$ amount of the time were VPD values $>1 \mathrm{Kpa}$, and during $97 \%$ of the daytime (when net radiation was $>40$ $\mathrm{w} \mathrm{m}^{-2}$ ) latent heat fluxes were greater than sensible heat fluxes $(\beta<1$, unpublished data), strongly suggesting that the La Selva canopy had access to abundant soil water. The only exceptions were in the 1998 dry season, when $30 \%$ of daytime VPDs were $>1 \mathrm{Kpa}$, precipitation was the lowest ever recorded $(68,38,126 \mathrm{~mm}$ monthly total rainfall - January, February and March, respectively), and daily mean $\mathrm{T}_{\mathrm{a}}$ was $\sim 1^{\circ} \mathrm{C}$ above the long-term average (data compared to OTS records), suggesting that water limitation, higher VPDs, and perhaps higher temperatures negatively affected $\mathrm{NEE}_{\text {day }}$ during this time.

The 1998 dry season was at the end of the 1997-1998 warm-phase El Niño Southern Oscillation (ENSO). During November and December 1998, a cold-phase (la Niña) ENSO brought greater precipitation, cooler temperatures, and lower mean daily incident radiation (and PPFD) with several days receiving $<5 \mathrm{MJ} \mathrm{d}^{-1}$. Overall, 1998 was warmer and drier during the dry season, with more precipitation, cooler temperatures and reduced light during the latter part of the year (compared to the other two years of data). The greater eLAI (Table 3) coupled with lower $\alpha$, a greater portion of time with VPDs $>1 \mathrm{KPa}$ in the dry season, and lower mean daily insolation (13.3 $\mathrm{MJ} \mathrm{d}^{-1}$, Table 4) likely led to the La Selva forest being close to carbon neutral in 1998 (Figure 9).

During 1999, the daily incident radiation was well above the mean (16.82 $\left.\mathrm{MJ} \mathrm{d}^{-1}\right)$, but with daily averages in November and December below the long-term average, at $\sim 12 \mathrm{MJ} \mathrm{d}^{-1}$ due to a prolonged temporal, suggesting that the effects of increased annual incident radiation outweighed those of reduced eLAI and a prolonged temporal, making this forest a moderate sink of carbon.

We did not find evidence of seasonal effects on NEE. Even though the seasonal displacements of the ITCZ bring changed Hadley cell circulations, changes in individual climatic factors may not necessarily occur in concert. For example, at the beginning of each season the initial passing of the ITCZ can be intermittent and can have multiple 'false starts' (Hastenrath 1991). Moreover, the northern most progression of the ITCZ is just north of Costa Rica and its movement can often be erratic causing prolonged periods of dry weather during the wet season (Sanford et al. 1994). Other regional climatic anomalies can occur, during 1998 and 1999, heavy rains persisted from December and into January, even after the passing of the ITCZ. In 1998, this was brought about by a cold-phase ENSO event, and in 1999 by a prolonged temporal.

The climatic trends observed during the $97 / 98$ ENSO were typical for this region (Waylen et al. 1996b, Cavazos and Hastenrath 1990), as were the conditions observed during temporales (Sanford et al. 1994). The 97/98 ENSO, however brought the highest temperatures in the 19-year 
Table 4. Meteorolgical data for years 1998-2000 from La Selva Biological Station, CR. Data are means $\pm 1 \mathrm{SE}$.

For each year, cumulative meteorological data was used with a general linear model to test for between year statistical

significance. Wherein, the slopes of the cumulative meteorological data equal the annual means. For each year the

slopes were highly linear, $\mathrm{R}^{2} \geq 0.98, p<0.001$.

\begin{tabular}{|c|c|c|c|c|}
\hline Time period & $\begin{array}{l}\text { mean air } \\
\text { temperature, }{ }^{\circ} \mathrm{C}\end{array}$ & $\begin{array}{l}\text { mean minimum } \\
\text { temperature, }{ }^{\circ} \mathrm{C}\end{array}$ & $\begin{array}{l}\text { mean soil } \\
\text { temperature, }{ }^{\circ} \mathrm{C}\end{array}$ & $\begin{array}{l}\text { mean daily } \\
\text { insolation, MJ } \\
\mathrm{d}^{-1}\end{array}$ \\
\hline 1998 & $\mathrm{a} 24.23 \pm 0.015$ & $24.03 \pm 0.015$ & ${ }^{\mathrm{a}} 23.43 \pm 0.018$ & a $13.3 \pm 0.24$ \\
\hline 1999 & $23.4 \pm 0.014$ & $23.19 \pm 0.014$ & $21.29 \pm 0.023$ & b $16.82 \pm 0.28$ \\
\hline 2000 & $23.66 \pm 0.016$ & $23.44 \pm 0.016$ & $21.24 \pm 0.022$ & ${ }^{c} 14.97 \pm 0.26$ \\
\hline January 1998 & 25.09 & 24.8 & 23.55 & $12.51 \pm 0.12$ \\
\hline February 1998 & 25.48 & 25.23 & 24.46 & $12.7 \pm 0.15$ \\
\hline March 1998 & 25.44 & 25.17 & 24.36 & $13.3 \pm 0.17$ \\
\hline
\end{tabular}

Note $;{ }^{a},{ }^{b}$, and ${ }^{c}$ denote significant difference $(a=0.5, p<0.0001)$ for 1998,1999 and 2000 from the other two years, respectively 
(Timmermann et al. 1999, Corti et al. 1999). The La Selva results may have implications for interpreting the effects of climate change in ecosystem carbon storage by showing that this tropical wet forest oscillates between being a source and sink for carbon. This supports the modeled findings of Tian et al. (1998) who concluded that extremes in inter-annual tropical NEE are controlled, in part, by macro-level changes in climate, which in turn are driven by the timing, frequency and magnitude of ENSO events.

Another possible explanation for the observed productivity and large interannual variation is that there is a large fraction of this forest is under regeneration. There is a high frequency of treefall gaps, even though La Selva is below most hurricane pathlines. For example, if tree turnover time is $118 \mathrm{y}$ and gap birth rate is $0.96 \% \mathrm{ha}^{-1} \mathrm{y}^{-1}$ (Denslow and Hartshorn 1994), and minimum gap size is $40 \mathrm{~m}^{2}$ (Sanford et al. 1986), then conservatively, $46 \%$ of the land area is under constant regeneration. This fraction of recovering forest on the landscape scale has also been directly estimated. Clark et al. (1996) showed that half of the canopy was $<23 \mathrm{~m}$ tall, and $\sim 12 \%$ is $\leq 14 \mathrm{~m}$ tall. Because these studies were conducted at one point in time, only general statements can be made about the temporal controls on gap formation and size distribution, i.e., wet verses dry conditions, species propensity to fall, aspect, mortality, etc. It is likely that both the gap birth rate and minimum size increases under climatic conditions imposed by the ENSO (warm and cold phase). An indication of which are the increased mortality rates from $2.03 \%$ for 1969-1982 (Lieberman et al. 1990) to 4.77\% for 1997-1998 (Clark, Clark, Oberbauer and Veldkamp, unpublished data) in upland (utilsol) plots. Regardless, fractions of this forest are accumulating biomass, the potential result of which is from a temporally and spatially variable, gap-disturbance regime.

\section{Comparisons with other tropical sites}

The pattern and magnitude of the diurnal NEE flux at La Selva were similar to those estimated by eddy flux studies at three tropical moist forest sites in the Brazilian Amazon (Reserva Ducke (N. Central Amazon) - Fan et al. 1990; Jarú (S. Central Amazon) - Grace et al. 1995b; Cuieiras (N. Central Amazon - Mahli et al. 1998). Mean maximum NEE day rates estimated for these three forests were $\sim 18-20 \mu \mathrm{mol} \mathrm{CO} \mathrm{m}^{-2} \mathrm{~s}^{-1}$, and mean $\mathrm{NEE}_{\text {night }}$ values were estimated to be $\sim 5-7 \mu \mathrm{mol} \mathrm{CO} 2 \mathrm{~m}^{-2} \mathrm{~s}^{-1}$ (Table 5). In particular, the La Selva 2000 data are remarkably similar to those from Cuieiras (Mahli et al. 1998).

This suggests that these may have similar controls on maximum uptakes rates from tropical forests even though there are marked differences in stand characteristics. Mahli et al. (1998) hypothesized that cloudiness was a strong determinate of insolation and hence NEE $_{\text {day, }}$ and this is also a reasonable possibility at La Selva. VPD was found to play a stronger role in carbon gain at the other tropical sites (Mahli et al. 1998) than we found at La Selva. Each of these other sites receive $<2500 \mathrm{~mm} \mathrm{y}^{-1}$ of precipitation with lower soil water availability (Hodnett et al. 1996, Tomasella and Hodnett 1996), so there are greater hydrologic constraints on $\mathrm{NEE}_{\text {day }}$ (Mahli et al. 1998, Williams et al. 1998). The range in $\alpha$ from La Selva, includes the average value from the other three sites. It is likely that this between-year variation in $\alpha$ is real, and that $\alpha$ is a strong determinate of annual NEE in these tropical forests (Table 5).

Reduction in leaf carbon gain can occur when leaves are wet, lowering rates of $\mathrm{CO}_{2}$ diffusion into the leaf by a factor of $10^{4}$ (Jones 1992), and thus reduced photosynthesis (Ishabashi and Terashima 1995). Smith and McClean (1989) also found that photosynthesis was significantly reduced in wet leaves that had a wettable cuticle, but increased on leaves that had non-wettable cuticles. The ratio of species with wettable:non-wettable leaves are not know at La 
Table 5. Across site comparison of stand attributes from four neotropical eddy covariance studies.

\begin{tabular}{|c|c|c|c|c|c|}
\hline site & unit & La Selva & Ducke & Jarú & Cuieiras \\
\hline location & Lat. & $10^{\circ} 26^{\prime} \mathrm{N}$ & $2^{\circ} 57^{\prime} \mathrm{S}$ & $10^{\circ} 04^{\prime} \mathrm{S}$ & $2^{\circ} 35^{\prime} \mathrm{S}$ \\
\hline & Long. & $83^{\circ} 59^{\prime} \mathrm{W}$ & $59^{\circ} 57^{\prime} \mathrm{W}$ & $61^{\circ} 56^{\prime} \mathrm{W}$ & $60^{\circ} 06^{\prime} \mathrm{W}$ \\
\hline Length of study period & days & 1006 & 12 & 55 & 365 \\
\hline $\begin{array}{l}\text { Mean annual } \\
\text { temperature }\end{array}$ & ${ }^{\circ} \mathrm{C}$ & 25 & $26^{\mathrm{a}}$ & $25^{\mathrm{a}}$ & 27.8 \\
\hline Annual rainfall & $\mathrm{mm}$ & 4000 & $2400^{\mathrm{b}}$ & $1450^{\mathrm{a}}$ & $2400^{b}$ \\
\hline Holdridge life zone & Forest type & Tropical wet & Tropical moist & Tropical moist & Tropical moist \\
\hline Above ground biomass & Mt C ha-1 & $160.5( \pm 18)$ & $300-350$ & $140-180$ & $300-350$ \\
\hline *Estimated LAI & $\mathrm{m}^{2} \mathrm{~m}^{-2}$ & $2.7-4.9$ & $5-6$ & 4 & $5-6$ \\
\hline Estimated quantum yield & $\begin{array}{l}\mu \mathrm{mol} \mathrm{CO}_{2} \mu \mathrm{mol} \\
\text { photon }^{-1}\end{array}$ & $0.022-0.058$ & 0.051 & 0.025 & 0.048 \\
\hline Mean Nighttime NEE & $\mu \mathrm{mol} \mathrm{CO}_{2} \mathrm{~m}^{-2} \mathrm{~s}^{-1}$ & 6.89 & 6.0 & 6.4 & 6.5 \\
\hline peak Daytime NEE & $\mu \mathrm{mol} \mathrm{CO}_{2} \mathrm{~m}^{-2} \mathrm{~s}^{-1}$ & -18 & -19 & -15 & -17 to -21 \\
\hline $\begin{array}{l}\text { Light compensation } \\
\text { point }\end{array}$ & $\mu \mathrm{mol} \mathrm{m} \mathrm{m}^{-2} \mathrm{~s}^{-1}$ & $147-208$ & 120 & 130 & 80 \\
\hline Annual NEE & Mt C ha ${ }^{-1} y^{-1}$ & ${ }^{\mathrm{c}}-0.09$ to -6.1 & -2.2 & -1.0 & -5.9 \\
\hline Source & & This study & $\begin{array}{l}\text { Fan et al. } \\
1990\end{array}$ & $\begin{array}{l}\text { Grace et al. } \\
1995 \mathrm{~b}\end{array}$ & $\begin{array}{l}\text { Mahli et al. } \\
1998\end{array}$ \\
\hline
\end{tabular}


have over estimated as a result. La Selva experiences rain for $18 \%$ of the time annually, as compared to only $13 \%$ and $8 \%$ at Jarú and Ducke, respectively (data from 1994-96,

http \..www.abracos.com).

Our estimates of annual GPP (Table 6) span that found in North central Amazon (e.g. Cuieiras). If we view NEE as a surrogate for net ecosystem production, then high ratios of NEE:GPP are thought to exist only with forests rapidly accumulating carbon, e.g., compare 0.02 for old-growth Pseudotsuga menziesii to 0.29 for rapidly growing pine stand (Waring and Schlesinger 1985). The NEE:GPP ratios were 0.18 and 0.194 for La Selva and Cuieiras, respectively, indicating that these systems can be very productive compared to other forests, during 2000 and 1995, respectively. All of the tropical sites cited here are considered "oldgrowth", assumed to be near steady state among years with respect to carbon. However, none of these sites, from Costa Rica to Brazil, support this view, indicating that tropical forests may be accruing as much as $6 \mathrm{t} \mathrm{Cha}^{-1} \mathrm{y}^{-1}$ (averaging $\sim 2 \mathrm{t} \mathrm{Cha}^{-1} \mathrm{y}^{-1}$ ). However, it is important to point out that there are systematic errors inherent in the current state of eddy covariance studies. Some examples include carbon lost to night-time cold-air drainage (as discussed earlier), carbon lost in venting events (particularly soil $\mathrm{CO}_{2}$ ) during strong storms or early in the morning before turbulent flow is established, and loss of volatile organic compounds. These systematic errors tend to inflate NEE, since the carbon is measured when it enters the system but not when it leaves.

But where within the ecosystem is this carbon accumulating and at what temporal scale can we assess this? To increase our confidence in these estimates and controls continued studies are needed across temporal and spatial scales. Other studies have had to rely on models to balance the internal cycling of carbon, and by residuals, attribute large fluxes of carbon below ground. For example, at Cuieiras $27 \%$ of NPP ( $72 \%$ of NEE, $13.8 \%$ of GPP) is partitioned to below ground biomass and increases in soil organic matter to balance the annual $\mathrm{C}$ budget (Mahli et al. 1999). While, this may be the case, it is unlikely that greater fluxes of coarse woody debris and its respective carbon are labile enough to account for the residual below ground carbon flux. Scientists have yet to demonstrate this possibility in situ.

Table 6. Between year measures of productivity and ecosystem efficiency from La Selva, Costa Rica and Cuieiras, Brazil. Data from La Selva are from eq.5 across VPD classes and a fixed nighttime NEE, as noted in the text. Units of GPP and NEE are expressed as MT C. ha ${ }^{-1} y^{-1}$.

\begin{tabular}{llcll}
\hline site & \multicolumn{3}{c}{ La Selva, Costa Rica } & Cuieiras, Brazil \\
\hline year & 1998 & 1999 & 2000 & 1995 \\
GPP & 28.41 & 30.6 & 33.9 & 30.4 \\
NEE & -0.09 & -1.66 & -6.1 & -5.9 \\
NEE:GPP & 0.004 & 0.055 & 0.18 & 0.194 \\
\hline
\end{tabular}

Note: The Cuieriras dataset is from Mahli et al. 1998, and Mathi and Grace 2000. Data from La Selva is based on $\mathrm{NEE}_{\text {modcled }}$

\section{Conclusions}

Diurnal patterns of NEE followed similar trends found elsewhere, with turbulent fluxes dominating the $\mathrm{NEE}_{\text {day }}$, and storage fluxes contributing largely in the early morning hours. $\mathrm{NEE}_{\text {day }}$ was largely a function of both abiotic (PPFD, VPD and temperature) and biotic (quantum efficiency and eLAI) controls. PPFD, quantum efficiency, and eLAI differed between years. VPD limited $\mathrm{NEE}_{\text {day }}$ when values were above $>1 \mathrm{KPa}$, but this only occurred over a small 
percentage of the time. There was a positive relation between temperature and nighttime respiration based on diurnal averages of all $\mathrm{NEE}_{\text {night }}$ measurements, and it indicated a $\mathrm{Q}_{10}$ of 1.79. No such temperature response to $\mathrm{NEE}_{\text {night }}$ was found using 30-min data. Annual NEE estimates used a fixed $\mathrm{NEE}_{\text {night }}$ value. There was a wide range between $\mathrm{NEE}_{\text {gap }}$ and $\mathrm{NEE}_{\text {modeled }}$ within each year. Regardless of the calculation method used, our estimates of NEE derived from the eddy flux studies indicated large interannual changes in forest NEE at La Selva, with the warm El Niño year 1998 showing much less uptake, and perhaps net source status, compared to the other two years, and with 2000 showing significantly higher uptake.

In this study it became apparent that interpretation of the ecophysiological controls on tropical wet forest interannual NEE is strengthened when examined across varying temporal and spatial scales. This approach will be crucial in further identifying-- and increasing the precision of our understanding of -- these controls, and enhancing our ability to predict the cycling of carbon under the potential of climate change. 


\section{IV.2. Canopy Throughfall}

\section{Introduction}

Understanding how water and nutrients in aqueous solutions move through forested systems enhances our understanding of ecosystem-level processes such as energy partitioning, streamflow, and productivity (Waring \& Running 1998). This becomes particularly important when modelling these processes across spatial and temporal scales under different climate scenarios. Throughfall and canopy interception of rainfall are key elements in any forest hydrological and nutrient cycle. Quantification of throughfall and associated nutrient losses start with collection of throughfall volume that includes both 'free' throughfall and canopy drip, here, referred to collectively as throughfall. Interception, throughfall rates, and movement of nutrients are usually based on regression analyses, whose key assumption is independence of samples. However, spatial independence of collected throughfall is rarely established, nor is the assumption of spatial independence verified statistically.

Many studies have examined throughfall and interception through the use of models to explain water usage, storage and flow with little attention paid to spatial controls, for example; physical models (Gash 1979, Liu 1992, Rutter et al. 1975, Ubarana 1996) empirical models (Massman 1983), and stochastic models (Calder 1986). Examining the sources of variation is key to understanding the spatial distribution and independence of throughfall, and has not received much attention in the literature. Rather, previous studies have focused on the variation in throughfall volume within each collector (Lloyd \& Marques 1988) and have found that throughfall volume from an individual collector increased with distance from nearest tree bole (Beier et al. 1993). Many of these studies have been conducted in architecturally simple, evenage stands (Bruijnzeel \& Wiersum 1987, Liu 1998) and have shown high within-collector variability (Lloyd \& Marques 1988, McDowell 1998). Lloyd et al. (1988) demonstrated difficulty applying both the Gash (1979) and Rutter et al. (1975) models to tropical forests, which exhibited higher spatial variability than many other temperate forests (Jackson 1971). Jackson (1971) calls for large sample size to reduce error associated with high spatial variability. Whereas Lloyd et al. (1988) found better precision in their throughfall estimates with random placement of--and relocations of-- collectors along transect with 1-m intervals rather than a plot $(20 \times 4 \mathrm{~m})$ with $1 \times 1 \mathrm{~m}$ grids. They did not however, attempt to identify specific controls on their sources of variability. Moreover, throughfall estimation assumes that canopies are locally uniform in distribution of leaf area and water retention properties. At what spatial scale does this occur? For this reason, identifying sources of spatial variability in throughfall volume from wet tropical forests can assist in the interpretation of model results, and increase both the precision and accuracy of direct methods of estimation. The objectives of this study were the following: to determine throughfall volume amounts and interception of bulk precipitation events in a wet tropical forest, to determine the spatial autocorrelation of throughfall, and to examine relationships between canopy structure and throughfall.

\section{Study Site}

This study was conducted in concert with ongoing carbon balance studies (CARBONO PROJECT) at the La Selva Biological Station, Costa Rica $\left(10^{\circ} 26^{\prime} \mathrm{N}, 83^{\circ} 59^{\prime} \mathrm{W}\right.$, and elevation 80-150 masl). In the Holdridge classification system, La Selva is wet tropical forest (Hartshorn \& Peralta 1988). Annual bulk precipitation is ca. $4000 \mathrm{~mm}$ year ${ }^{-1}$ with no single month receiving less than $100 \mathrm{~mm}$ (Sanford et al. 1994). While the distribution of precipitation during both the wet and dry seasons is variable, the first three months of 1998 were drier than the average, 
possibly due to the warm-phase of the El Niño Southern Oscillation, see Figure 1. Mean annual air temperature is ca. $26^{\circ} \mathrm{C}$. The annual mean above-canopy wind direction is at $90^{\circ}$ due to the attenuation of the NE surface winds with altitude. Stand structure is outlined in Table 1. While landscape variation of forest structure and above-ground biomass has been studied (Clark and Clark 2000), little is known concerning the distribution of leaf area, leaf size and shape in the tropics. Detailed information on this site is found in Sanford et al. (1994), and on general climatology in Waylen et al. (1996) and Hassenrath (1988).

\section{Methods}

Thirty-six collectors were placed on radial transects extending away from a center at distances of $20 \mathrm{~m}, 40 \mathrm{~m}$, and $60 \mathrm{~m}$ to determine volumetric throughfall quantities (excluding stemflow) and canopy interception. Each transect was repeated every $30^{\circ}$ to maximize the distance classes of the matched pairs (Figure 2). A tipping bucket rain gauge (model TE-252, Texas Electronics) mounted on top of a meteorological tower in the center of the collection area, measured incoming rainfall so that all collectors captured the same rain event. To test for spatial autocorrelation, an additional 20 collectors were laid out $5 \mathrm{~m} \mathrm{~N}$ and $5 \mathrm{~m} \mathrm{E}$ of all the collectors in the NE quadrant (Figure 2).

Collectors consisted of funnels with a surface area of $95 \mathrm{~cm}^{2}$ attached to 3.791 jugs. To prevent splash-out, a $30 \mathrm{~mm}$ high PVC ring was fixed to the perimeter of each funnel. Each collector stood $0.37 \mathrm{~m}$ above the ground under differing canopy heights and plant structures. Throughfall was collected manually, and collectors were leveled and cleaned of litter after each rain event. A rain event was defined by periods of complete drying of the upper canopy after a period of bulk precipitation. Below canopy leaves were also typically dry, even though the relative humidity was $>90 \%$. Epiphytes and canopy root mats may have remained moist and not entirely dry. Typically, rain events occurred daily in the late afternoon after a morning of convective building of the boundary layer, and often continued into the night. Evaporative losses from the canopy during a rain event were insignificant because; it was assumed that air became saturated with water vapor soon after an event began (preconditions of high relative humidity, Figure 1), and much of the rain fell either during late afternoon or evening when the net radiation was low. Collections were made during the wet season and began on July 7, 1998 and ended on August 14, 1998.

Because variation in throughfall increased with both intensity and duration of the rainfall event, the data were log-transformed to homogenize the variance, Eq. 1.

$\log (\mathrm{L})=\mathrm{a}[\log (\mathrm{BP})]+\mathrm{b}$

Eq. 1

Where,

$\mathrm{L}=$ estimated mean throughfall, $\mathrm{mm}$, and

$\mathrm{BP}=$ bulk precipitation, $\mathrm{mm}$, and

$\mathrm{a}+\mathrm{b}=$ are empirical coefficients.

Both interception and spatial variability were estimated from throughfall measurements. Data was regressed using Eq. 1 with interception estimated by the $\mathrm{x}$-axis intercept where the $\mathrm{y}$ axis is equal to zero. Interception defined here is the maximum 'free' water holding capacity by the canopy, including the water more tightly held by arboreal soil and root mats. Stemflow was not measured, nor was any attempt made to estimate changes in interception over temporal scale, i.e., modeling changes in water holding capacity. Minimal evaporation between collections was assumed because relative humidity was near $100 \%$ at ground level during the collection period 


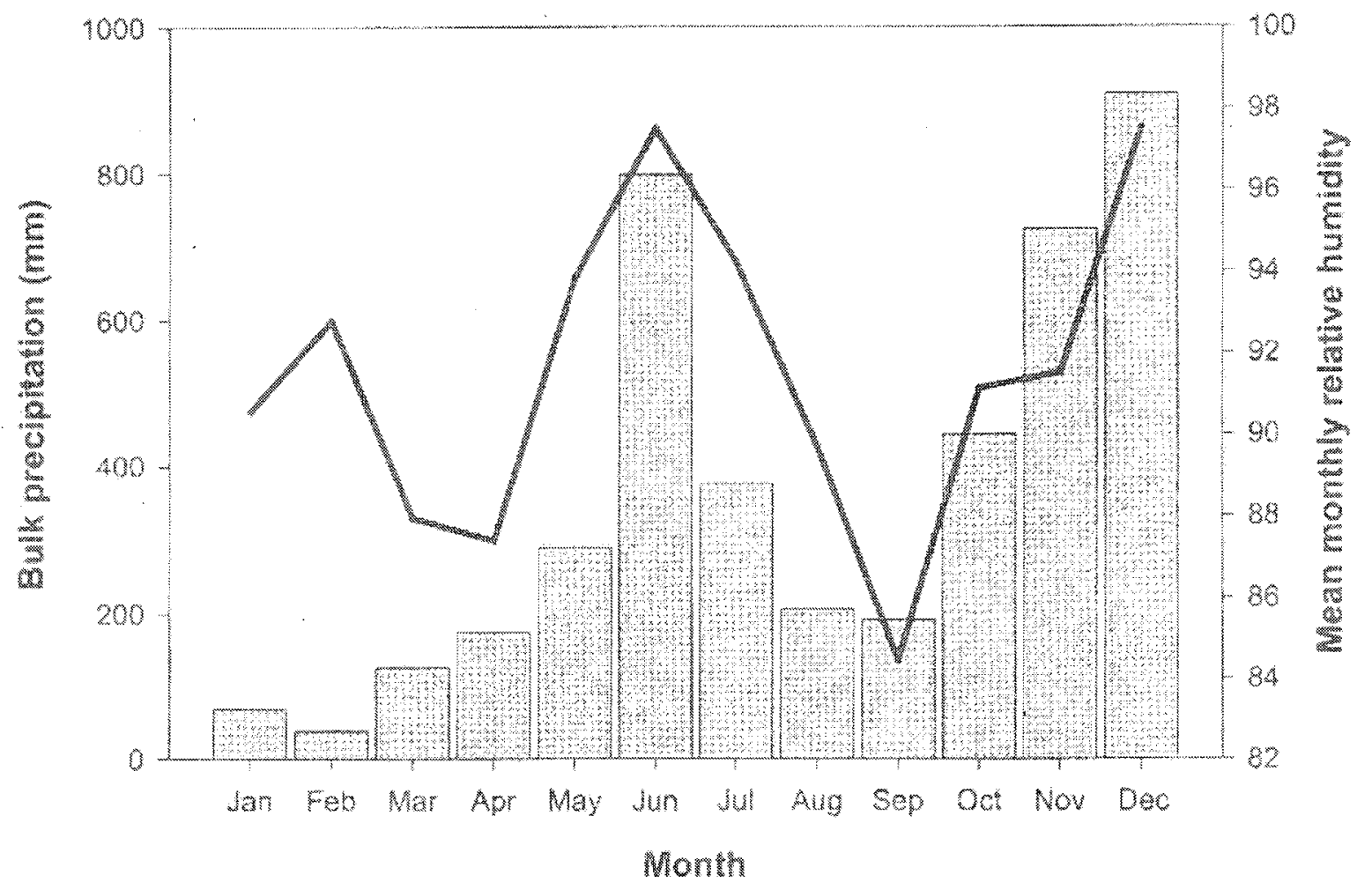

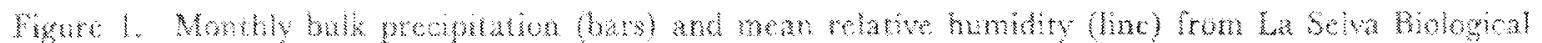

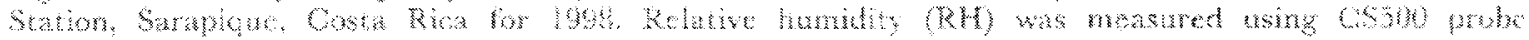

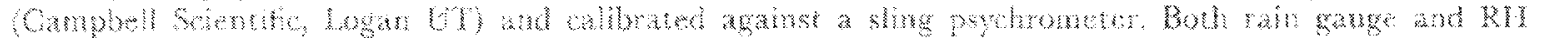

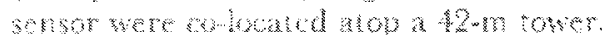




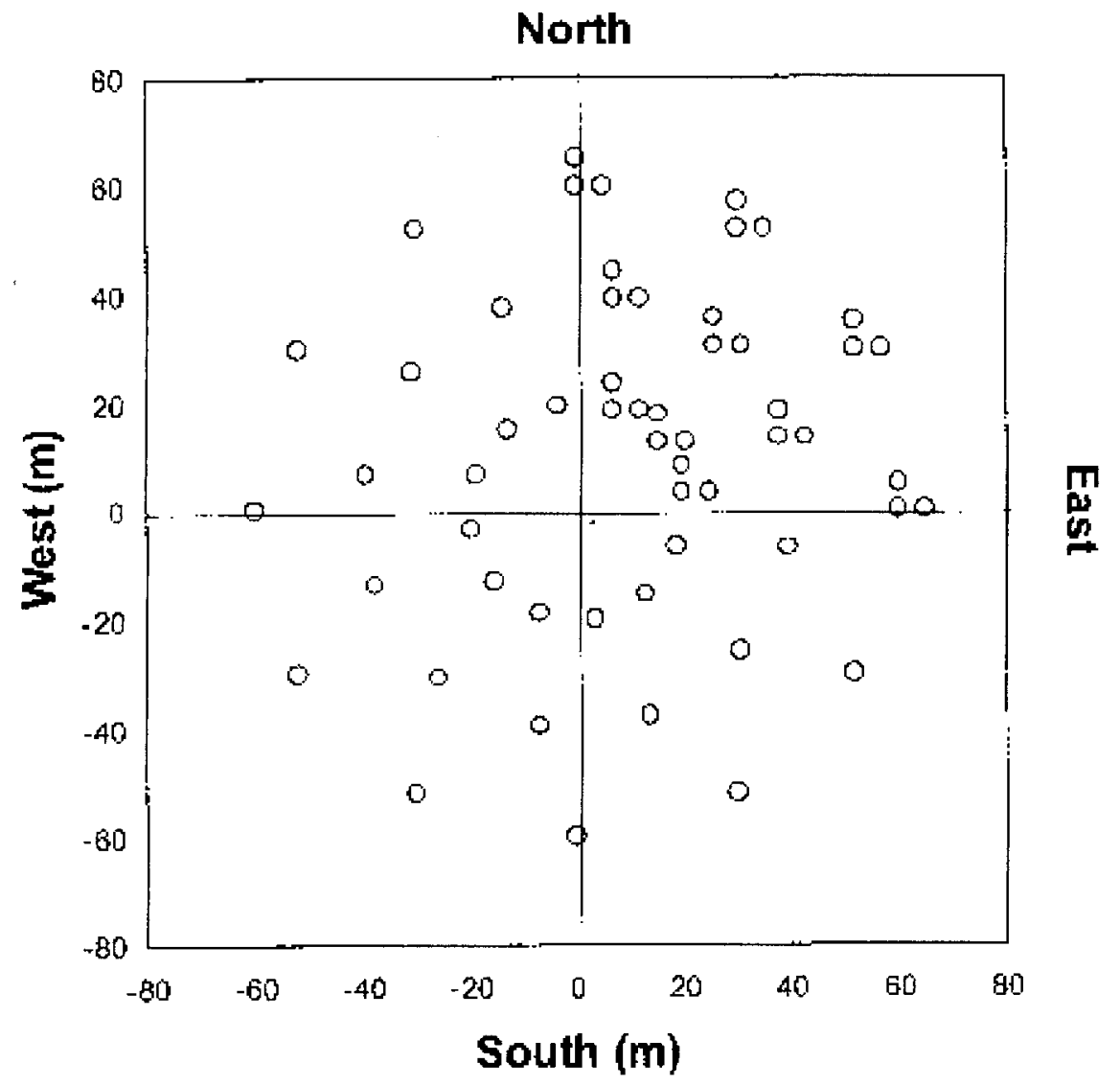

ial havout of the thoughtall collectors. Inits are in metres. 
Variograms were used to test for spatial autocorrelation in the throughfall data, for reviews of geostatistics see, Goovaerts 1998, Trangmar et al. 1987, Webster 1985. Variograms are a geostatistical technique to detect spatial autocorrelation between mapped samples of a quantitative variable (e.g. throughfall). In a variogram, the averaged squared difference in the value of a variable between all pairs of points is computed across distance intervals (lag classes). The output is presented graphically as a plot of the average semi-variance versus distance class. The semi-variance will converge on total variance at distances for which values are no longer spatially autocorrelated (this is referred to as the range and is measured in units of distance). Thus, semi-variance takes on values from 0 to the total variability in the data set (i.e., the upper limit of semi-variance values will depend upon the units of measurement). Three parameters estimated from the variogram describe spatial autocorrelation in the data: the range, the sill (the sill is the asymptotic value of semi-variance at the range), and the Y-intercept or nugget variance, which describes sampling error or variation at distances below those separating the closest pairs of samples. Empirical variograms were computed in Splus software (SPATIALSTATS package, Mathsoft Inc., Seattle WA) with 5- meter lag classes. The range, sill, and nugget variance were estimated from theoretical models that were fitted to the empirical variograms using nonlinear least squares methods. Two different functional models, spherical and Gaussian, were fit to each variogram and the goodness-of-fit was assessed using the residual sum of squares. To assess the potential variability within each-and across all event(s), the mean throughfall values from each collector were used. Variograms were constructed with a minimum of 20 pairs of collection points in each $5 \mathrm{~m}$ distance class (lag interval). The range distance (i.e., the distance beyond which samples are spatially independent) was estimated from the empirical variogram by fitting Gaussian and spherical theoretical models. Goodness-of-fit was assessed using the residual sum of squares.

To further explain the spatial variability of throughfall, descriptions of the canopy cover above collectors were made at each site. The distance to nearest vegetation directly above each collector was measured (measuring tape was used for distances $<2 \mathrm{~m}$, optical rangefinder for distances $>2 \mathrm{~m}$ ). Leaf area was estimated using a spherical densiometer because of ease and expense. Even though this technique may seem primitive to some, Englund el al. (2000) found good agreement between LAI values estimated by both spherical densiometry and hemispherical photography. These measurements were taken in each cardinal direction $(\mathrm{N}, \mathrm{E}, \mathrm{W}$, and $\mathrm{S}$ ) above each collector, and averaged to obtain mean estimates. This technique was developed at La Selva Biological Station, and improves the prescision of the estimate, see Englund et al. 2000.

\section{Results}

For both mean and cumulative throughfall, samples separated more than $43 \mathrm{~m}$ apart (the range) were statistically independent (Figure 3). Interception was calculated both with the total dataset (Figure $4 \mathrm{a}$ ), and with collectors $\geq 43 \mathrm{~m}$ apart (Figure $4 \mathrm{~b}$ ). Thus, estimated canopy interception was 1.88 and $1.54 \mathrm{~mm}\left(\mathrm{r}^{2}=0.94, \mathrm{P}<0.0001\right.$ and $0.97, \mathrm{P}<0.0001$, respectively $)$. A weak relation was found between percent canopy cover and throughfall volume, (Figure 5, $\mathrm{r}^{2}=0.11, \mathrm{P}$ $<0.02$ ). The coefficient of variation among collectors was ca. 24 , which stabilized after 15 collectors (Table 2). No relationship was found between throughfall volume and distance to nearest leaf above the collector $\left(\mathrm{r}^{2}=0.04, \mathrm{P}=0.19\right)$ or distance to nearest plant $\left(\mathrm{r}^{2}=0.002, \mathrm{P}=\right.$ 0.75 ) with the nearest leaves and plants located in the understory. 


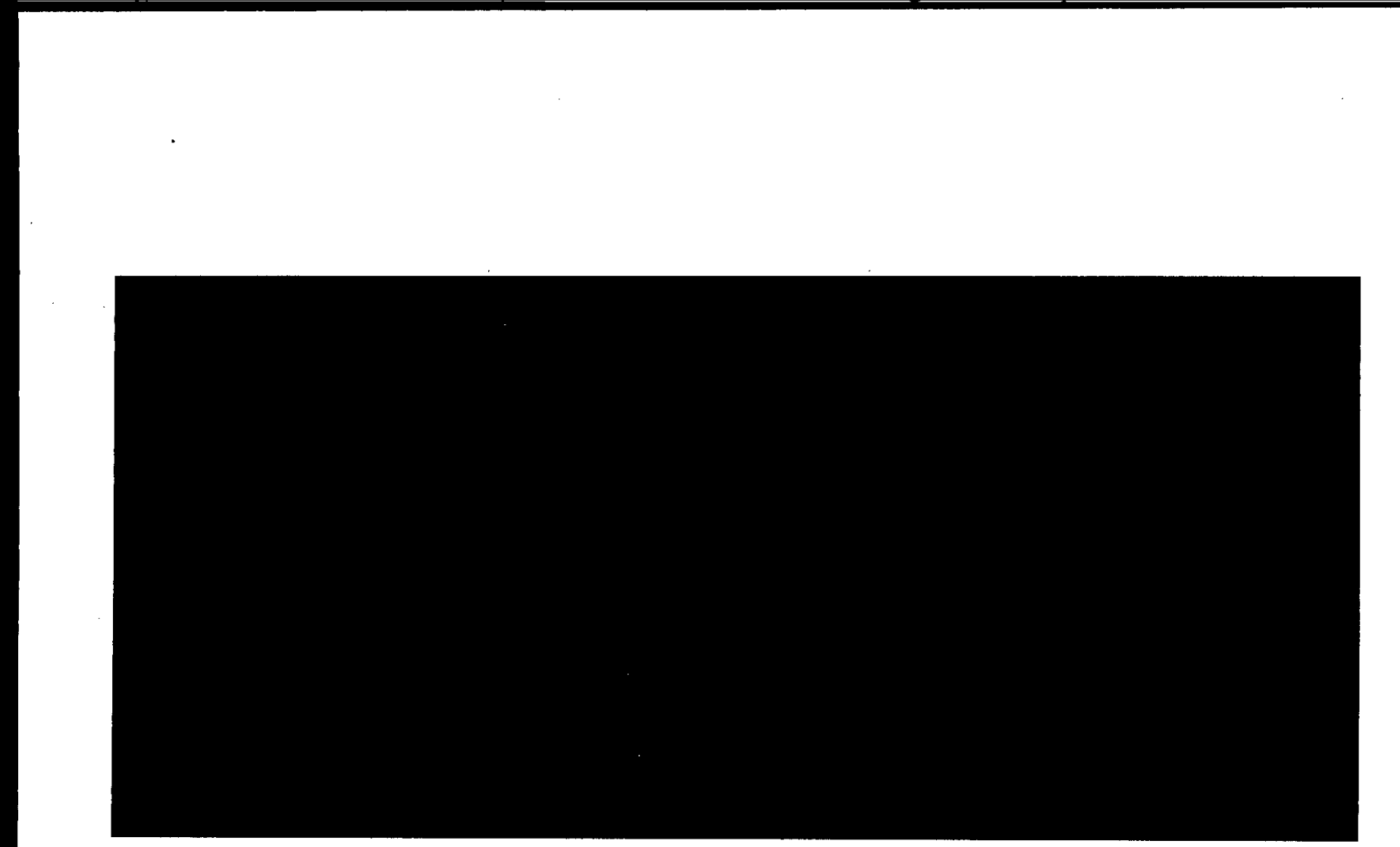





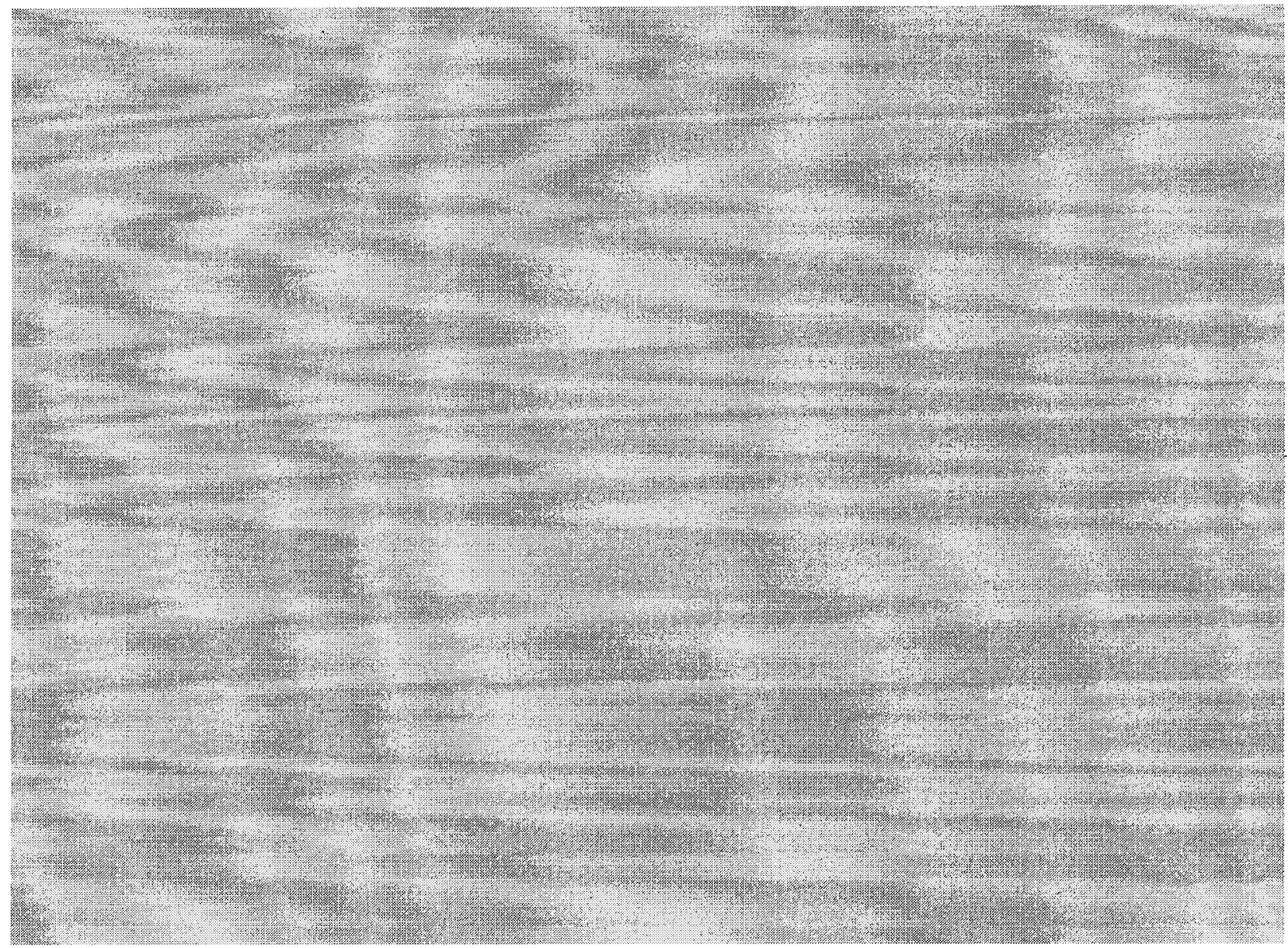




\section{Discussion}

Numerous studies have estimated either canopy interception for hydrological budgets, or nutrient additions from wet deposition (Clark et al. 1998, Liu 1998, Lloyd et al. 1988). It is difficult to account for the inherent variability of interception and throughfall in scaling of these processes to the stand-level, as evidenced in Table 2 . To reduce the spatial variance, many previous studies have worked on relatively simple systems in terms of plant or canopy architecture.

Furthermore, determination of wet deposition rates in throughfall and interception estimates assume statistically independent samples from a random placement of collectors, for example (Clark et al. 1998, Parker 1985). Independence should be estimated to better interpret the results from these studies. This study now provides a procedure by which independence can be determined in forested systems. For placement of collectors in this particular wet forest independence is achieved at $43 \mathrm{~m}$. The significance of this distance becomes apparent when mapped spatially (Figure 6), and it appears to be due to large areas dominated either by individual tree canopies or by treefall gaps. This relationship likely holds true for other tropical wet forests with similar stand attributes, where treefalls are the major source of disturbance, and occur in similar density.

The influence of tree canopies and gaps was also found on light transmission at La Selva, Costa Rica. Independence was found to be $20 \mathrm{~m}$ for light interception as measured at $2 \mathrm{~m}$ in height (Clark et al. 1996). We expected the spatially variability of light to be greater than that of throughfall for several reasons. Because light interception (direct beam) decreases exponentially with height within forests (Beer-Lambert Law), the effect of the intercepting biomass on light is greater. Moreover, The frequency, duration and area of direct beam sunflecks lead toward increase the spatial heterogeneity and variability. Whereas, throughfall volume is more dependent on the water holding capacity of the intercepting biomass and is likely linear once canopy capacitance is filled. Thus, decreasing its spatial variability, assuming the horizontal distribution of biomass is uniform with height. Because the range for light and throughfall volume was more than double ( $20 \mathrm{~m}$ and $43 \mathrm{~m}$, respectively), the variability in throughfall volume in a wet tropical lowland forest is more influenced by canopy architecture and the lack of overstorey (gaps) than light. A relationship was found between percent-cover and throughfall $\left(\mathrm{r}^{2}\right.$ $=0.11, \mathrm{P}=0.02$ ) suggesting that interception is a function of ecosystem surface area (Waring $\&$ Schlesinger, 1985) which in this case includes both leaf and epiphytic components. It is also important to note, that while epiphytic plants may not have contribute greatly to the attenuation of light below canopy, they may increase the ecosystem surface area substantially.

There is large variability in throughfall volume between collectors. Collection of throughfall in a single collector can exceed the bulk precipitation due to 'funneling', and likewise 'caps' above the collector can limit throughfall. Examination of the coefficient of variation shows that the variation in throughfall estimates stabilizes after 15 collectors, estimates of the mean are within $25 \%$ of the 'true' mean, and additional collectors do not contribute to precision of the mean (Table 2).

\section{Conclusions}

Spatial independence can be established for a wet tropical system where distance between collectors should be $>45 \mathrm{~m}$. Canopy gaps and individual tree canopies influenced this distance. The variability in throughfall volume in a wet tropical lowland forest is more influenced by canopy architecture and the lack of overstorey (gaps) than light. When estimates were made from spatially independent collectors interception decreased by $19 \%$. This result may not be 


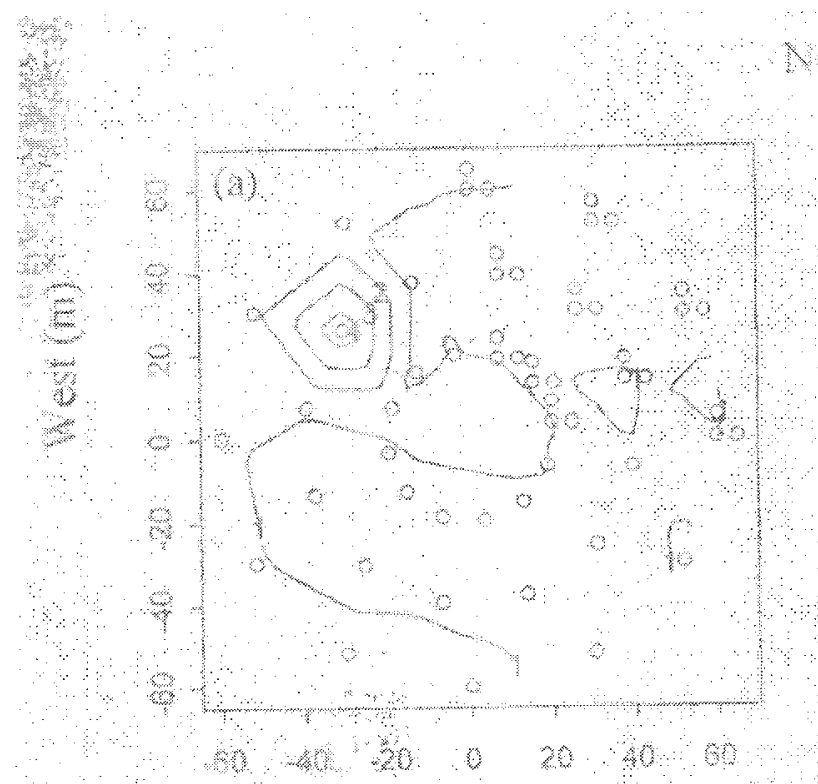

Noth

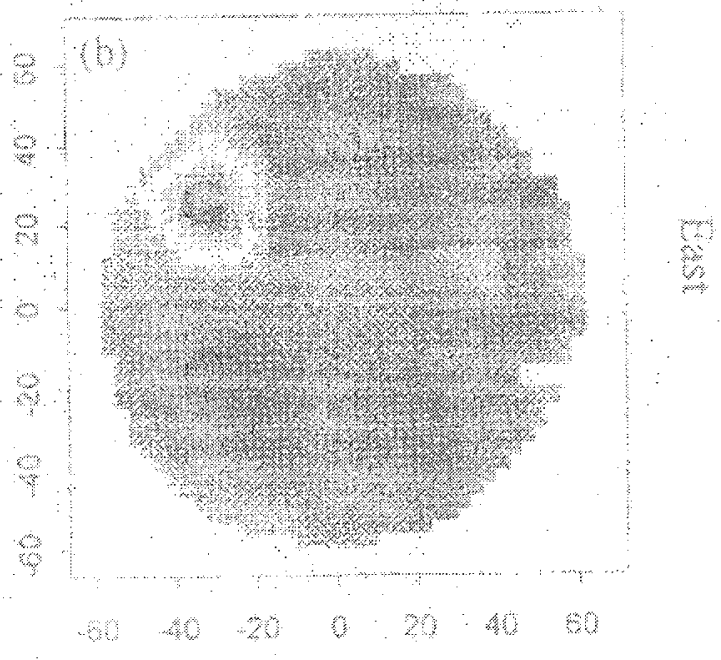

somm $(m)$

\section{syst}

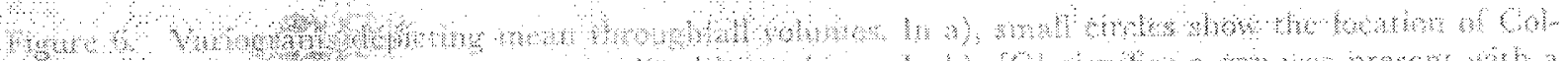

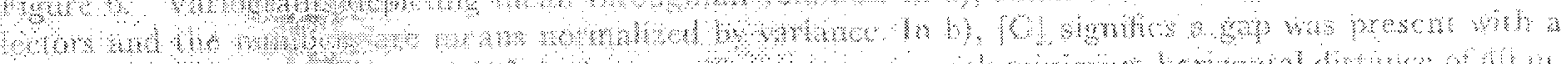

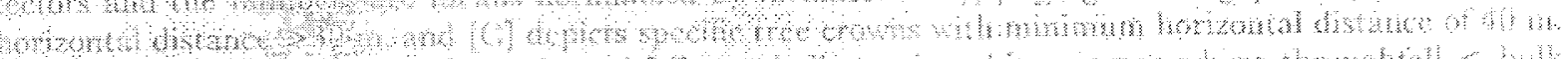

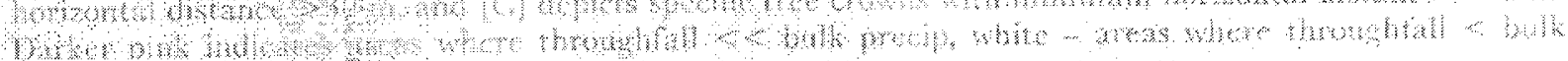

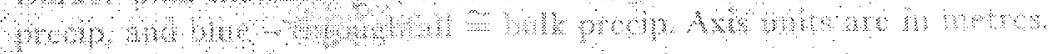


significant, because $95 \%$ confidence intervals as estimated on a log-log plot increases greatly as the regression approaches the zero intercept 


\section{IV.3. Water and Energy Fluxes}

\section{Introduction}

The energy balance of tropical forests is complex due to feedback mechanisms among radiation, cloud formation and precipitation (Wielicki et al. 2002, Hartman et al. 2001, Sohn and Smith 1992). This complexity extends to the potential role of the tropical energy balance in affecting tropical and global climates and general and anomalous circulations (Kelly and Randall 2001, Timmerman et al. 1999, Chen and Van den Dool 1999, Fasullo and Webster 1999, Larson et al. 1999). Much of our understanding of these dynamics has relied on model results, which have shown large spatial and temporal variability in both sensible and latent energy budgets (Kelly and Randall 2001, Raman et al. 1998, Hulme and Viner 1998, Shuttleworth 1988). In situ studies have either scaled leaf level measurements to whole canopies (Bigelow 2001, Avissar 1993, Roberts et al. 1993), or have estimated the energy balance components using eddy covariance over short periods (e.g., 8 d, Shuttleworth et al. 1984, 1 y Malhi et al. 2002). Quantifying the variation of energy balance parameters and their biophysical controls over longer periods (e.g., years) should allow for better predictions of runoff and improved models of regional and global climate.

Both physical and physiological factors influence forest energy fluxes, including incident radiation, surface albedo, rain, interception, canopy capacitance, and aerodynamic ( $\mathrm{g}_{\mathrm{a}}$ ) and bulk surface $\left(g_{b}\right)$ conductances. Incident radiation in the tropics varies less seasonally than that at higher latitudes, and values at the surface are more related to cloudiness than changes in solar zenith angle. General circulation models tend to underestimate net radiation in the tropics because of uncertainties in estimating surface albedo and cloud cover (Cramer et al. 1999, Ruimy et al. 1999). Forest surface albedos range from $0.1-0.2$, with annual and seasonal differences affecting the available energy. Large variability in annual rainfall totals have been observed in the tropics and are thought to be influenced by El Niño-Southern Oscillation (ENSO) and other anomalous circulations. This in turn affects the amounts of water available for evapotranspiration. A general observation is that $\sim 50 \%$ of annual rainfall is re-circulated to the atmosphere through transpiration and evaporation of intercepted water, with the other $50 \%$ as runoff (Shuttleworth 1989). This implies that local hydrology is strongly effected by how energy is partitioned at the surface.

Canopy conductances for tropical forests have been estimated using both ecophysiological and micrometeorological approaches. Ecophysiologists estimate bulk surface conductance $\left(\mathrm{g}_{\mathrm{b}}\right)$ by scaling leaf-level or sap-flow measurements to the canopy (Whitehead 1998, Dolman et al. 1991), while micrometeorologists model $\mathrm{g}_{\mathrm{b}}$ in relation to meteorological parameters (Wright et al. 1996). Aerodynamic conductance is generally calculated as a function of horizontal windspeed, zero-plane displacement, and roughness length (Denmead and Bradley 1985). Evapotranspiration from tropical forests is generally thought to be strongly dependent on aerodynamic conductance, because of the high rainfall and the significant proportion of the time when the canopy is wet, reducing the importance of $\mathrm{g}_{b}$ in evapotranspiration (Shuttleworth 1989).

Our overall research objective was to define the surface controls on the energy fluxes from a wet tropical forest in Costa Rica. Analyzed controls included the temporal partitioning of $R_{n}$, below-canopy energy fluxes as compared to the overall surface energy fluxes, and the affect of $g_{a}, g_{b}$ and $R_{n}$ on evapotranspiration.

\section{Methods}

Meteorological Data 
All measurements were collected from September 1997 to December 2000.

Instrumentation for measuring air temperature, relative humidity, bulk precipitation, and net radiation were mounted at the top of a $42 \mathrm{~m}$ tower (Upright, Inc., Selma, CA). Prior to March 1 1999, air temperature $\left(\mathrm{T}_{\mathrm{a}}\right.$ ) was measured with a CS500 probe (Campbell Scientific, Inc., Logan UT) installed within a radiation shield, and linearly back-corrected to fit the response of the aspirated temperature sensor $\left(\mathrm{R}^{2}=0.98\right)$. After March $1,1999, \mathrm{~T}_{\mathrm{a}}$ was measured with platinum resistance temperature detector ( $100 \Omega$ platinum RTD, Omega Engineering, Stamford, CT) mounted in an aspirated shield. Rainfall was measured with a tipping bucket rain gauge (model TE525, metric, Texas Electronics, Dallas TX). From August 1, 1997 to March 1, $1999 \mathrm{R}_{\mathrm{n}}$ was measured with a Fritschen-style sensor (model Q*7.1, Radiation Energy Balance Systems, Seattle, WA). Net radiation, $\mathrm{R}_{\mathrm{n}}$, was measured from March 1, 1999 to December 2000, with a closed-cell thermopile-style sensor (NR-lite, Kipp and Zonen, Delft, the Netherlands). All data collected with the Q-*7.1 were linearly back-corrected to fit the response of the NR-lite $\left(\mathrm{R}^{2}=\right.$ $0.97)$ and corrected for advected sensible heat across the sensor faces. Another net radiometer (model CNR1, Kipp and Zonen, Delft, the Netherlands) was also used to estimate albedo during February-April, July, and September 2000.

Soil heat flux plates (model HFT-3, Radiation Energy Balance Systems) were installed at a depth of $5 \mathrm{~cm}$, in each of three $1 \times 1 \mathrm{~m}$ plots $>20 \mathrm{~m}$ distance apart near the base of the tower. Atmospheric pressure was measured at $\sim 3 \mathrm{~m}$ (PB105, Vaisala, Helsinki, Finland). All meteorological data were collected at 5-sec intervals and compiled as 30-min averages with a datalogger (CR10X, Campbell Scientific Inc., Logan, UT). Instruments were cleaned, leveled as necessary, and recalibrated according to manufacturers' instructions.

\section{Energy Flux Estimates}

Ecosystem-level energy balance was estimated by

$$
R_{n}-\lambda E-H-G=C_{p} \rho_{a} \int_{z_{1,5}}^{z_{27}} \frac{\partial \theta_{p}}{\partial t} d z+S_{w i} C_{p w} L_{a r c a} \int_{Z_{10,5}}^{Z_{27}} \frac{\partial \theta_{p}}{\partial t} d z+\lambda E_{B C:} \quad \text { Eq. } 1
$$

assuming horizontal homogeneity in source area, $\mathrm{R}_{\mathrm{n}}$ is net radiation, $\lambda \mathrm{E}$ is the latent heat flux, $\mathrm{H}$ is the sensible heat flux, and $\mathrm{G}$ is the soil heat flux (all units are $\mathrm{W} \mathrm{m}^{-2}$ ). The right-hand terms are the non-turbulent heat fluxes ( $\mathrm{W} \mathrm{m}^{-2}$, i.e., change in below-canopy heat profiles), where the first term is the change in sensible heat in the air column $\left(\mathrm{H}_{\mathrm{BC}}\right)$, the second term is the change in sensible heat in the leaf biomass $\left(\mathrm{H}_{\text {leaf }}\right)$, the third term is the change in latent heat flux in the air column $\left(\lambda \mathrm{E}_{\mathrm{bc}}\right)$, such that $\mathrm{C}_{\mathrm{p}}$ is specific heat capacity of air $\left(\mathrm{J} \mathrm{kg}^{-1} \mathrm{~K}^{-1}\right), \rho_{\mathrm{a}}$ is the density of air $(\mathrm{kg}$ $\left.\mathrm{m}^{-3}\right), \mathrm{Z}_{\mathrm{x}}$ is measurement height $(\mathrm{m}), \theta_{\mathrm{p}}$ is the potential temperature from profile measurements $\left({ }^{\circ} \mathrm{C}\right), \mathrm{S}_{\mathrm{wt}}$ is the specific weight of leaf water $\left(\mathrm{kg} \mathrm{m}^{-2}\right.$ leaf area), $\mathrm{C}_{\mathrm{pw}}$ is the heat capacity of water $(\mathrm{J}$ $\mathrm{kg}^{-1} \mathrm{H}_{2} \mathrm{O} \mathrm{K}^{-1}$ ), and $\mathrm{L}_{\text {area }}$ is the one-sided leaf area based on LAI from polyculture plantations at $\mathrm{La}$ Selva $\left(4.5 \mathrm{~m}^{2} \mathrm{~m}^{-2}\right.$, S. Bigelow and J.Ewel, pers. comm.). Changes of sensible heat in the leaf biomass were included in Eq. 1 because leaves have small thermal inertia but significant amounts of water. It was assumed that the temperature profiles were similar throughout the flux source area.

Net ecosystem exchange of sensible heat was estimated by the combination of turbulent and storage fluxes (Eq. 2a), and the turbulent latent energy exchange was calculated as a residual flux Eq. 2b, such that,

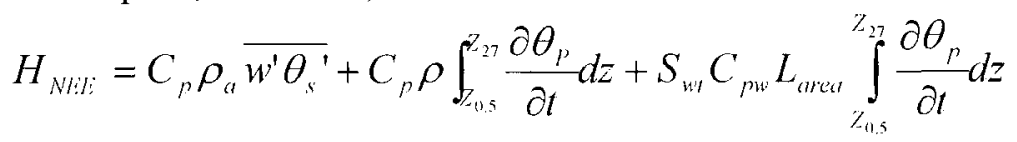




$$
\lambda E=R_{n}-H_{N E I I:}-\int_{2,5}^{2_{27}} \frac{\partial q}{\partial t} d z
$$

where $\mathrm{w}^{\prime}$, and $\theta_{s}{ }^{\prime}$ are the deviations of instantaneous values from a running mean of vertical windspeed $\left(\mathrm{m} \mathrm{s}^{-1}\right)$ and $\theta_{\mathrm{s}}$ as a function of the speed of sound and changes in air density (excluding water vapor, i.e., potential temperature), $\overline{w^{\prime} \theta^{\prime}}$ is the turbulent exchange of sensible heat flux as estimated by eddy covariance method, and $\mathrm{q}$ is the specific humidity $\left(\mathrm{mmol} \mathrm{mol}^{-1}\right)$.

The eddy covariance system was comprised of a sonic anemometer (K-probe, Applied Technologies, Inc., Boulder, CO) and a laptop computer. The sonic anemometer measured the wind velocities in three dimensions at $10 \mathrm{~Hz}$, where $w$ is vertical windspeed, and $u$ and $v$ are the two horizontal windspeed components, as well as, $\theta_{\mathrm{s}}$. Covariance fluxes were calculated in real time at $10 \mathrm{~Hz}$ using a software program (McMillen 1988), which also collected raw eddy covariance data files. Protocols for accuracy, precision, and quality control and assurance were used as defined by the AmeriFlux Science Plan

(http//cdiac.esd.oml.gov/programs/ameriflux/scifhtm).

The non-turbulent (storage) fluxes were estimated by the changes of heat through the forest profile in both the air column below $42 \mathrm{~m}$ and in the foliage. Mean specific humidity was sampled from 6 inlets at $0.50,7.30,11.95,16.55,21.20$, and $27.60 \mathrm{~m}$ on the tower. Solenoids switched the flow $(\sim 3.0 \mathrm{lpm})$ from each inlet through an infra-red gas analyzer (model Li-6262, Li-Cor, Lincoln, NE) for 5 min during each 30-min period, data were only used for the final 4min in the 5-min interval. For $\mathrm{H}_{\mathrm{BC}}$, the profile temperature, $\theta_{\mathrm{P}}$, was measured with platinum RTDs housed in radiation shields and co-located with each inlet; when sampling occurred, the airflow acted to aspirate the platinum RTDs. 


\section{Evapotranspiration Models}

Evapotranspiration estimates were partitioned into whole forest transpiration and the evaporation of intercepted precipitation. $\lambda \mathrm{E}$ was modeled using the Penman-Monteith equation (Montieth and Unsworth 1990),

$$
\lambda E_{p m n}=\frac{\Delta R_{n}+\rho_{u} C_{p}\left[e_{s}\left(T_{u}\right)-e_{u}\left(T_{u}\right)\right] g_{a} f}{\left[\Delta+\gamma\left(1+\frac{g_{u}}{g_{b}}\right)\right]}
$$

where $\lambda \mathrm{E}_{\mathrm{pm}}$ is latent energy flux $\left(\mathrm{W} \mathrm{m}^{-2}\right), \Delta$ is the is the rate of increase in saturated water vapor pressure with temperature $\left(\mathrm{kPa} \mathrm{K}^{-1}\right), \mathrm{e}_{\mathrm{s}}$ is the saturated water vapor pressure at $\mathrm{T}_{\mathrm{a}}, \mathrm{e}_{\mathrm{a}}$ is the ambient water vapor pressure $(\mathrm{kPa}), \mathrm{g}_{\mathrm{a}}$ is the aerodynamic conductance $\left(\mathrm{mol} \mathrm{m}^{-2} \mathrm{~s}^{-1}\right), \lambda$ is the latent heat of vaporization $\left(\mathrm{J} \mathrm{kg}^{-1}\right), \gamma$ is the psychometric constant at $25^{\circ} \mathrm{C}\left(0.0665 \mathrm{kPa} \mathrm{K}^{-1}\right), \mathrm{g}_{\mathrm{b}}$ is the bulk canopy conductance $\left(\mathrm{mol} \mathrm{m}^{-2} \mathrm{~s}^{-1}\right)$. To change units of energy to depth, $\lambda \mathrm{E}_{\mathrm{pm}}$ was multiplied by a conversion factor that included molar volume $\left(f, \mathrm{~mol} \mathrm{~m}^{-3}\right)$ and weight $\left(\mathrm{kg} \mathrm{mol}^{-1}\right)$. The use of the notation $\lambda \mathrm{E}$ denotes energy flux $\left(\mathrm{W} \mathrm{m}^{-2}\right)$, and ET, water depth ( $\mathrm{mm}$ per unit time), hence Evapotranspiration depth estimated by $\mathrm{Eq} 3$ is noted in the text as $\mathrm{ET}_{\mathrm{pm}}$.

As a positive momentum flux into the canopy was assumed hence, aerodynamic conductance was estimated by

$$
g_{a}=\frac{k^{2} u}{\left[\ln \left(\frac{z_{42-d}}{z_{m}}\right)\right]^{2}+\ln \left(\frac{z_{42-d}}{z_{m}}\right)\left[\ln \left(\frac{z_{m}}{z_{42}}\right)+\Psi_{m}-\Psi_{h}\right]}
$$

where $\mathrm{k}$ is Von Karmen's constant $(0.40)$, d is the zero-plane displacement $(\mathrm{m}), \mathrm{z}_{\mathrm{m}}$ is the aerodynamic roughness length (m), and $\Psi_{\mathrm{m}}$ and $\Psi_{\mathrm{h}}$ are the diabatic correction factors (dimensionless) for momentum and sensible heat, respectively (Yasuda 1988, Arya 1988). Zeroplane displacement and aerodynamic roughness changed with stability and were empirically estimated for this study period (Loescher et al. 2003). Diabatic correction factors are a function of stability, where in stable conditions,

$\Psi_{M}=\Psi_{H}=6 \ln (1+\zeta)$

Eq. 5

and in unstable conditions,

$\Psi_{H}=-2 \ln \left[\frac{1+(1-16 \zeta)^{0.5}}{2} ; \Psi_{M}=0.6 \Psi_{H}\right.$

Eq. 6

where $\varsigma$ is a stability parameter, and

$\varsigma=-\frac{z_{42}-d}{L}$

$\mathrm{L}$ is the Monin-Obukov length, ratio of convective to mechanical turbulent production,

$L=\frac{u^{* 3} \rho_{a} C_{p} T_{u}}{k g H}$

Eq. 8

with $\mathrm{u}^{*}$ defined as friction velocity $\left(\mathrm{m} \mathrm{s}^{-1}\right)$ and $\mathrm{g}$ the acceleration due to gravity $\left(\mathrm{m} \mathrm{s}^{-2}\right)$.

Bulk canopy conductance, $g_{\mathrm{b}}$ was estimated by,

$g_{h}=\frac{g_{a}}{\frac{\Delta H}{C_{p} \lambda E}-1}+\frac{\lambda E}{\rho_{a} D_{42}}$

where $\mathrm{D}_{42}$ is the specific humidity deficit at measurement height $\left(\mathrm{kg} \mathrm{kg}^{-1}\right)$. 
Both $g_{a}$ and $g_{b}$ were empirically modelled by using relationships with horizontal windspeed (for $\mathrm{g}_{\mathrm{a}}$ ), and $\mathrm{R}_{\mathrm{n}}$ and the vapor pressure deficit (VPD), (Martin et al. 1997, Wright et al. 1996) for use in Eq. 3. $g_{b}$ was normalized to unity, and the upper limit to $R_{n}$ determined (e.g. Jarvis 1976, Livingston and Black 1987). This limit function was used to estimate a theoretical maximum, $g_{\max }$, by increasing $\mathrm{g}_{b}$ as though $\mathrm{R}_{\mathrm{n}}$ was not limiting. Then $\mathrm{g}_{\max }$, in turn, was related to VPD, assuming that maximum conductance would take place with 0 VPD and high $R_{n}$. A dimensionless decoupling coefficient, $\Omega$, was used to determine the relative effects of $g_{a}$ and $g_{b}$ on evapotranspiration (Jarvis and McNaughton 1986);

$$
\Omega=\frac{\frac{\Delta}{\gamma}+1}{\frac{\Delta}{\gamma}+1+\frac{g_{a}}{g_{h}}}
$$

A second method of modeling $\lambda E$, the Priestly-Taylor equation, was used to compare with the Penman-Monteith results. The Priestly-Taylor equation (Eq. 11) simplifies the transfer process that is explicit in Eq. 3, and in doing so, is thought to be appropriate for large-scale, wellwatered vegetative canopies, like those typically found in the wet tropics (Priestly and Taylor 1972), and is defined as,

$$
\lambda E_{P T}=\alpha R_{n}\left[\frac{\Delta}{\Delta+\gamma}\right]
$$

where $\alpha$ is a coefficient estimated by fitting the model results to measures of $\lambda \mathrm{E}$ from Eq. $2 \mathrm{~b}$. Monteith (1981) estimated an average $\alpha$ on a theoretical basis as 1.26, but values observed over rough canopies have varied greatly (Jones 1992).

To determine annual ET, evaporation of intercepted water by the canopy was modeled using a Rutter-type model (Calder et al. 1986). Canopy water storage increased exponentially with precipitation to a maximum capacitance $\left(\mathrm{C}_{\max }\right)$. The rate by which the canopy filled with water was estimated by a unitless fill constant (a value of 0.28 for this constant was used from a broadleaf plantation forest at La Selva, Bigelow 2001). An empirical estimate of $1.53 \mathrm{~mm}$ was used for $\mathrm{C}_{\max }$ (Loescher et al. 2002). The stemflow component of interception was ignored because it was assumed to be a small volumetric flux, i.e., $<2 \%$ of rain, (Schroth et al. 1999, Neal et al. 1993). If modeled $E T_{p t}$ was greater than the remainder of canopy free water, the remaining depth was included as transpiration, $\mathrm{ET}_{\mathrm{pt}}$.

\section{Results}

\section{Above-Canopy Environment}

The stability index, $\varsigma$ differed only with incident radiation, and did not differ with year or season. On a diurnal basis, $\varsigma$ was neutral $(\sim 0 \mathrm{~m})$ during the night, and decreased during the day time until 1400 when the boundary layer became weakly unstable $(\varsigma \sim-125 \mathrm{~m}$ Figure 1$)$. After $1400 \mathrm{~h}, \varsigma$ sharply increased, and the boundary-layer became weakly stable $(\sim 100 \mathrm{~m})$ at $1600 \mathrm{~h}$, but then returned to neutral conditions by nightfall. Friction velocity ( $u^{*}$ ) was $\sim 0.1 \mathrm{~m} \mathrm{~s}^{-1}$ during the night and increased during the morning hours with convective turbulence. Diurnal patterns of $\mathrm{u}^{*}$ followed that convective activity throughout the day, which tended to decrease after solar noon and continued to decrease throughout the afternoon (Figure 1). The decrease in afternoon $\mathrm{u}^{*}$ is thought to be due to increases in cloud cover and the lack of growth in the convective boundary layer, which in turn caused mid-afternoon windstalls. These conditions agree with observations over Amazonian forests (Nobre et al. 1996). 


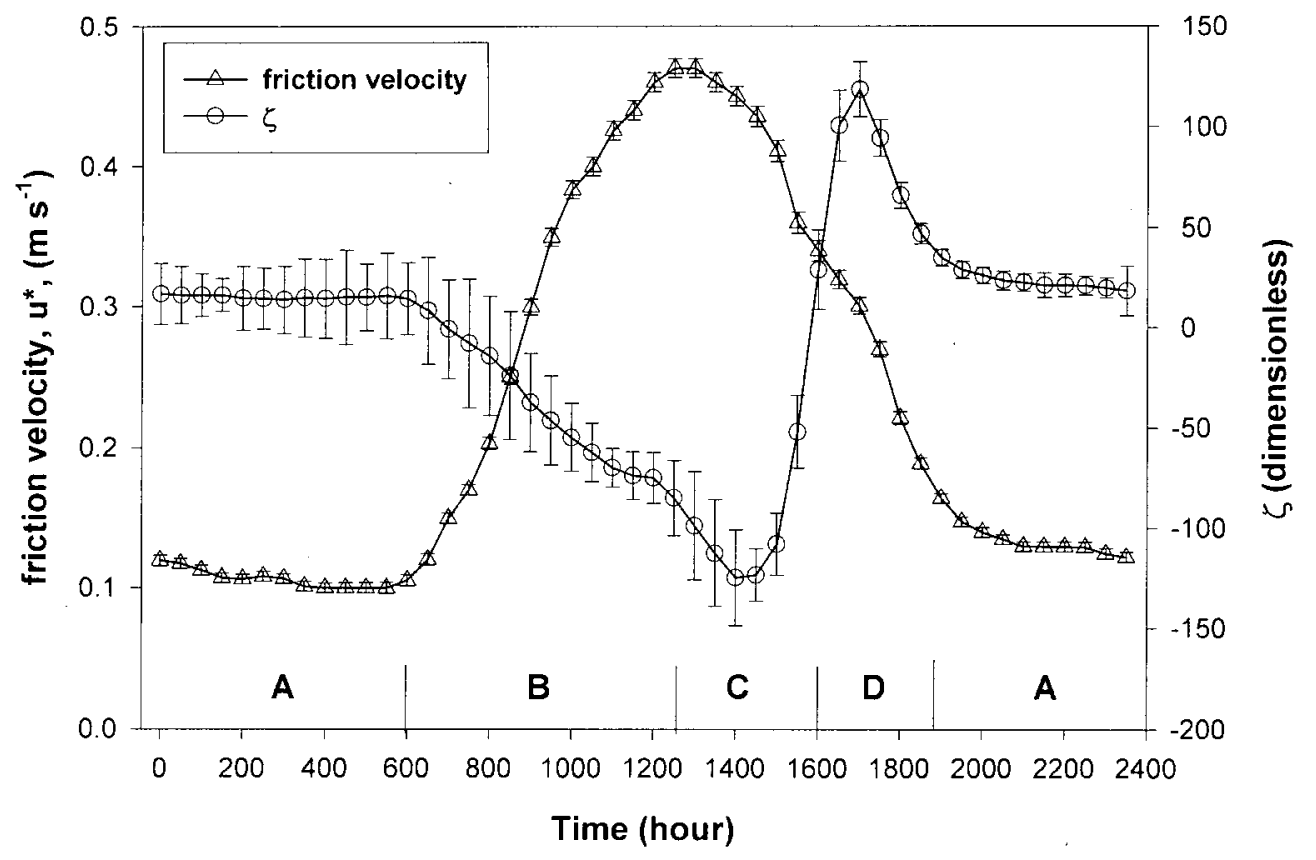

Figure 1. Diurnal patterns of friction velocity and the stability parameter over an old growth wet tropical forest. Data are averages using all data from 1998-2000. Intervals A, B, C, and D indicate neutral, unstable, weakly unstable, and weakly stable boundary conditions, respectively. Error bars are $\pm 1 \mathrm{SE}$. 
Total daily $\mathrm{R}_{\mathrm{n}}$ ranged from 1.47 to $27.54 \mathrm{MJ} \mathrm{d}^{-1}$ during the measurement period, and differed among years (using a general linear model with an alpha $=0.05, \mathrm{p}<0.0001$, Figure 2) with mean daily totals for $1998-2000$ of $13.31 \pm 0.028,17.48 \pm 0.050$, and $15.33 \pm 0.040 \mathrm{MJ} \mathrm{d}^{-1}$ (mean $\pm 1 \mathrm{SE}$ ), respectively. $R_{n}$ also varied significantly with season $(p<0.0001)$. Mid-day albedo did not change seasonally, and ranged from $0.118-0.135$.

\section{Energy Fluxes}

Diurnal temperature and water vapor profiles in the canopy (Figure 3) followed trends similar to those of other forests (Shaw et al. 1988). Heating of the canopy air column during the day increased with height, i.e., there was a positive temperature gradient. However, negative temperature (counter) gradients were often observed between 21 and $27 \mathrm{~m}$, where the leaf area was concentrated. Cooling during the night often produced neutral or slightly negative gradients, often with warmer temperatures at ground levels. Negative or neutral water vapor gradients were observed all times, with negative gradients present during non-rain days between 11 and $21 \mathrm{~m}$ height.

Soil heat fluxes followed very similar diurnal patterns throughout the year, and ranged \pm $16 \mathrm{~W} \mathrm{~m}^{-2}$ at any point in time, with negative flux into the system during the daytime (Figure $4 \mathrm{~A}$ ). On a day-to-day basis, the contribution of $\mathrm{G}$ varied little, and though the soil thermal properties for these soils were not known, the change in annual $\mathrm{G}$ was expected to be negligible. At night, $\lambda \mathrm{E}_{\mathrm{BC}}$ was $\sim 3-5 \mathrm{~W} \mathrm{~m}^{-2}$, larger $\lambda \mathrm{E}_{\mathrm{BC}}$ occurred in the early morning hours, presumably from convective winds mixing the below-canopy airspace and evaporating free water. $\lambda E_{B C}$ flux continued to be positive throughout the afternoon, but was more variable, with mean daytime values ranging from $\sim 6-7 \mathrm{~W} \mathrm{~m}^{-2}$. This flux remained positive throughout the day across all years. Mean nighttime storage of sensible heat $\left(\mathrm{H}_{\mathrm{BC}}+\mathrm{H}_{\text {leaf }}\right)$ ranged from ca. -1 to $-14 \mathrm{~W} \mathrm{~m}^{-2}$, and became negative in the early hours as the air space increased in temperature. The maximum average $\mathrm{H}_{\mathrm{BC}}+\mathrm{H}_{\text {leaf }}$ was $\sim 18 \mathrm{~W} \mathrm{~m}^{-2}$, which occurred at $\sim 0800 \mathrm{~h}$ when the convective boundary layer was developing. $\mathrm{H}_{\mathrm{BC}}+\mathrm{H}_{\text {leaf }}$ decreased and became negative at $\sim 1400 \mathrm{~h}$, which coincided with a late afternoon weakly stable/unstable boundary layer (Figure 1). The below-canopy environment continued to lose sensible heat until $\sim 1900 \mathrm{~h}$, when neutral canopy conditions prevailed. The maximum daytime soil flux lagged peak fluxes of $\lambda \mathrm{E}_{\mathrm{BC}}$ and $\mathrm{H}_{\mathrm{BC}}+\mathrm{H}_{\text {leaf }}$ by $\sim 7.5$ h. The total storage flux (Figure 4B) became negative (out of the ecosystem) at $\sim 1600$ corresponding to the decrease in $\mathrm{H}_{\mathrm{BC}}+\mathrm{H}_{\text {leaf }}$. During nighttime neutral conditions, the flux was $8-10 \mathrm{~W} \mathrm{~m}^{-2}$. The daytime minima were ca. $-5 \mathrm{~W} \mathrm{~m}^{-2}$ and the peak efflux was $30 \mathrm{~W} \mathrm{~m}^{-2}$, which occurred during weakly stable conditions (Figure 4B).

The average $30-\mathrm{min} \lambda \mathrm{E}$ was greater than $\mathrm{H}_{\mathrm{NEE}}$ for all daytime hours and across seasons and years (i.e., $\mathrm{H} / \lambda \mathrm{E}=\beta<1.0$, Figure 5). The largest relative contribution of $\mathrm{H}_{\mathrm{NEE}}$ occurred between 0900 and $1200 \mathrm{~h}$ (Figure 5), coinciding closely with the observed diurnal pattern of $\mathrm{T}_{\mathrm{a}}$. A statistical (linear) model that included second-order effects of year, season, VPD and $\mathrm{R}_{\mathrm{n}}$, explained $79 \%$ of the total variation in $\mathrm{H}_{\mathrm{NEE}}+\lambda \mathrm{E}$. Because $\mathrm{R}_{n}$ and VPD are auto-correlated and VPD did not explain any additional variation, it was removed from the linear model. $R_{n}$ alone accounted for $69 \%$ and $68 \%$ of the variation in $\mathrm{H}_{\mathrm{NEE}}$ and $\lambda \mathrm{E}$, respectively.

\section{Modeled Conductance and Evaporation}

$\mathrm{g}_{\mathrm{a}}$ was linearly correlated with horizontal windspeed (Figure 6A). Values of $\psi_{H}$ and $\psi_{M}$ were small and all other parameters were relatively constant. The upper boundary of normalized $\mathrm{g}_{b}$ was a square hyperbolic function to $\mathrm{R}_{\mathrm{n}}$ (Figure $6 \mathrm{~B}$ ). $\mathrm{g}_{\max }$ was expected to be negatively related 


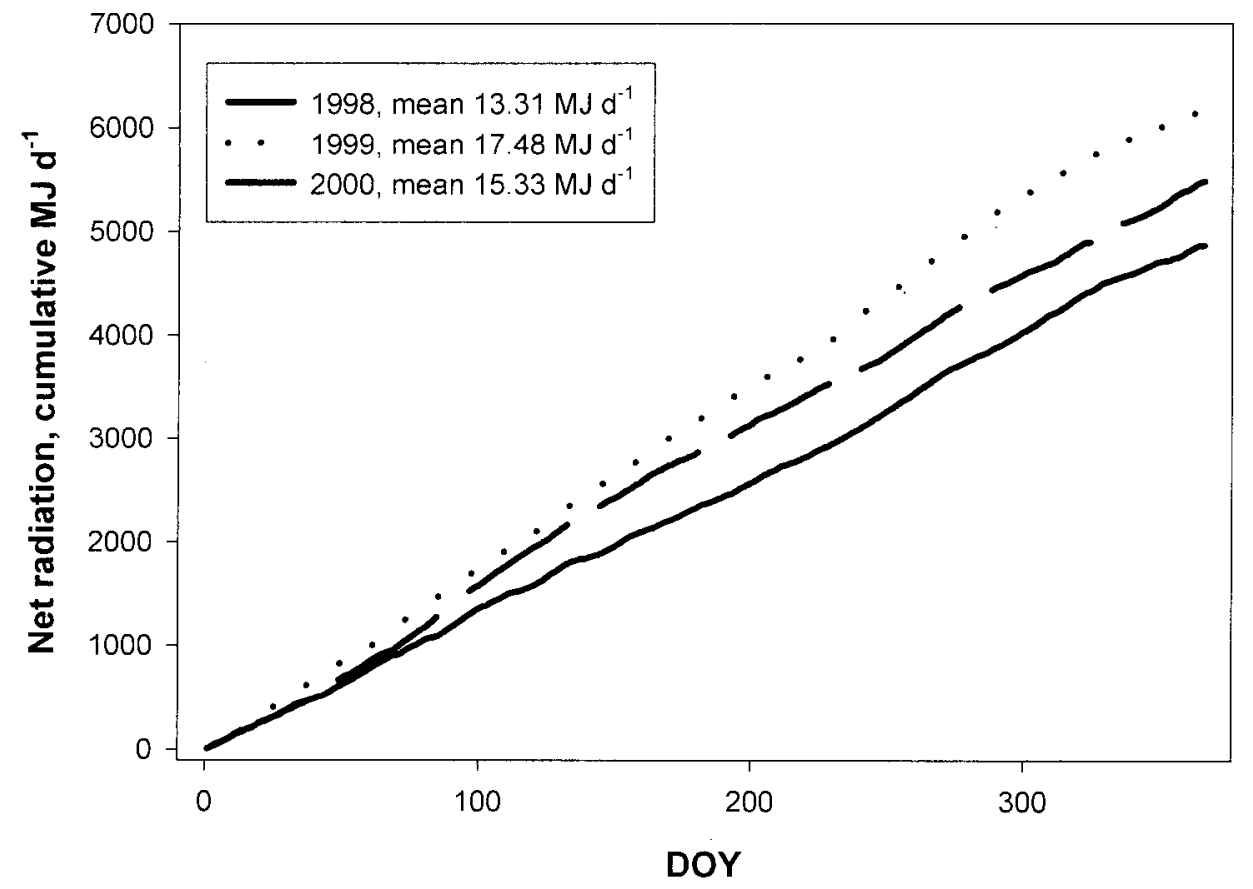

Figure 2. Cumulative net radiation for 1998-2000 over and old-growth forest in La Selva, Costa Rica. Daily means were derived using first-order regression. Each year was significantly different at the $\alpha=0.05$ level, $\mathrm{p}<0.001$, and $\mathrm{R}^{2}>0.99$. 

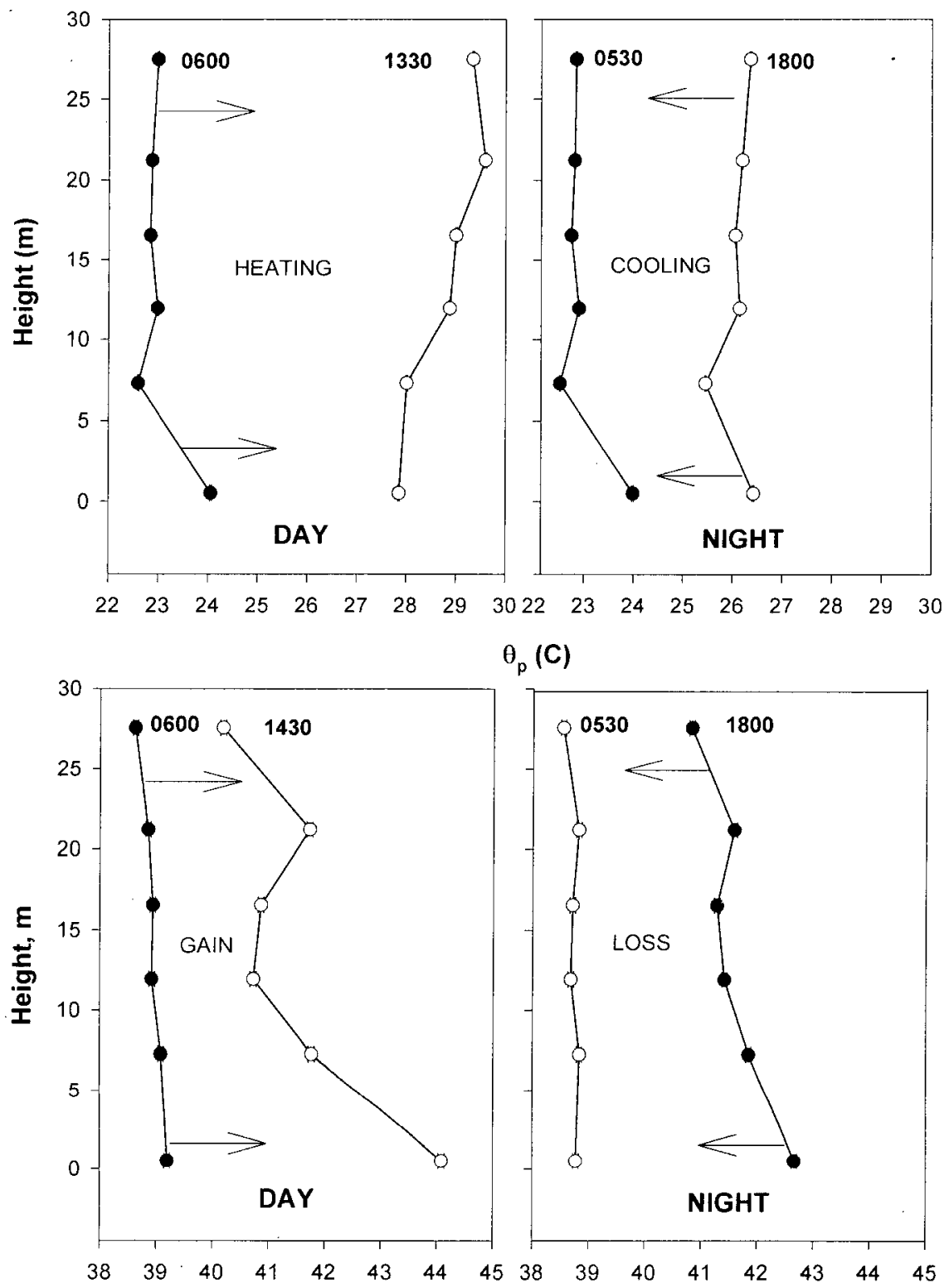

$\theta_{\mathrm{p}}$ (C)

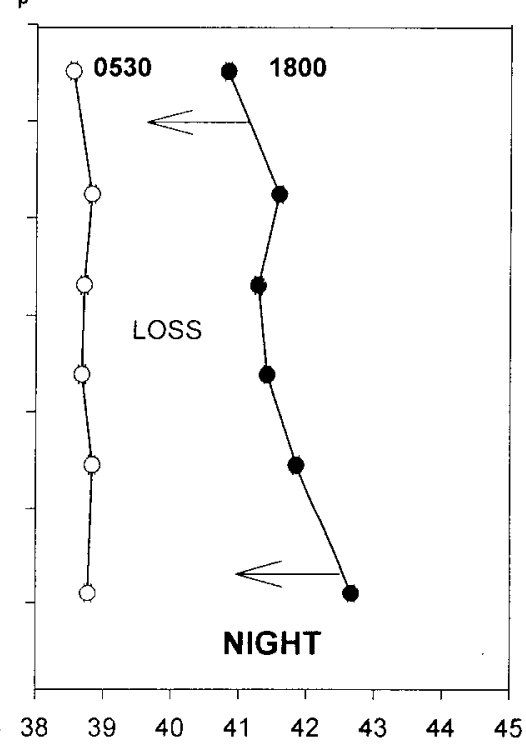

water vapor $\left(\mathrm{mmol} \mathrm{mol}^{-1}\right)$

Figure 3. Representative diurnal changes in below-canopy temperature and water vapor profiles from an old-growth forest, La Selva, Costa Rica. Data are median values for all of 1999. Standard errors were $<0.05^{\circ} \mathrm{C}$ and $<0.1$ for $\theta$ and $\mathrm{q}$, respectively. 


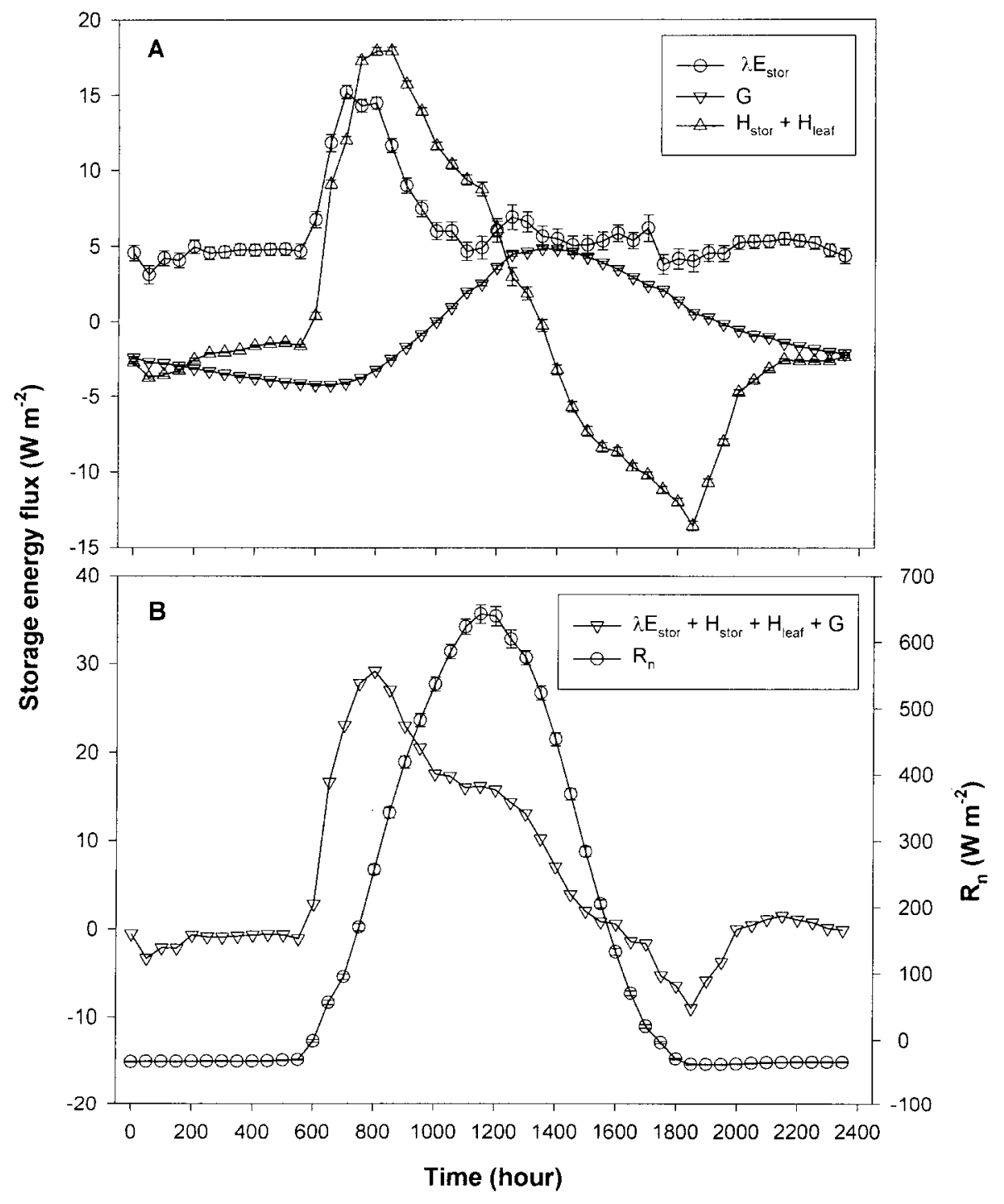

Figure 4. Diurnal patterns of below-canopy storage energy fluxes from an old-growth wet tropical forest in Costa Rica. Where A) are each of the components of the energy flux, and B) are the sum of the components. Contrasted with $R_{n}$. Data are mean values from 1998-2000 with error bars $\pm 1 \mathrm{SE}$. 


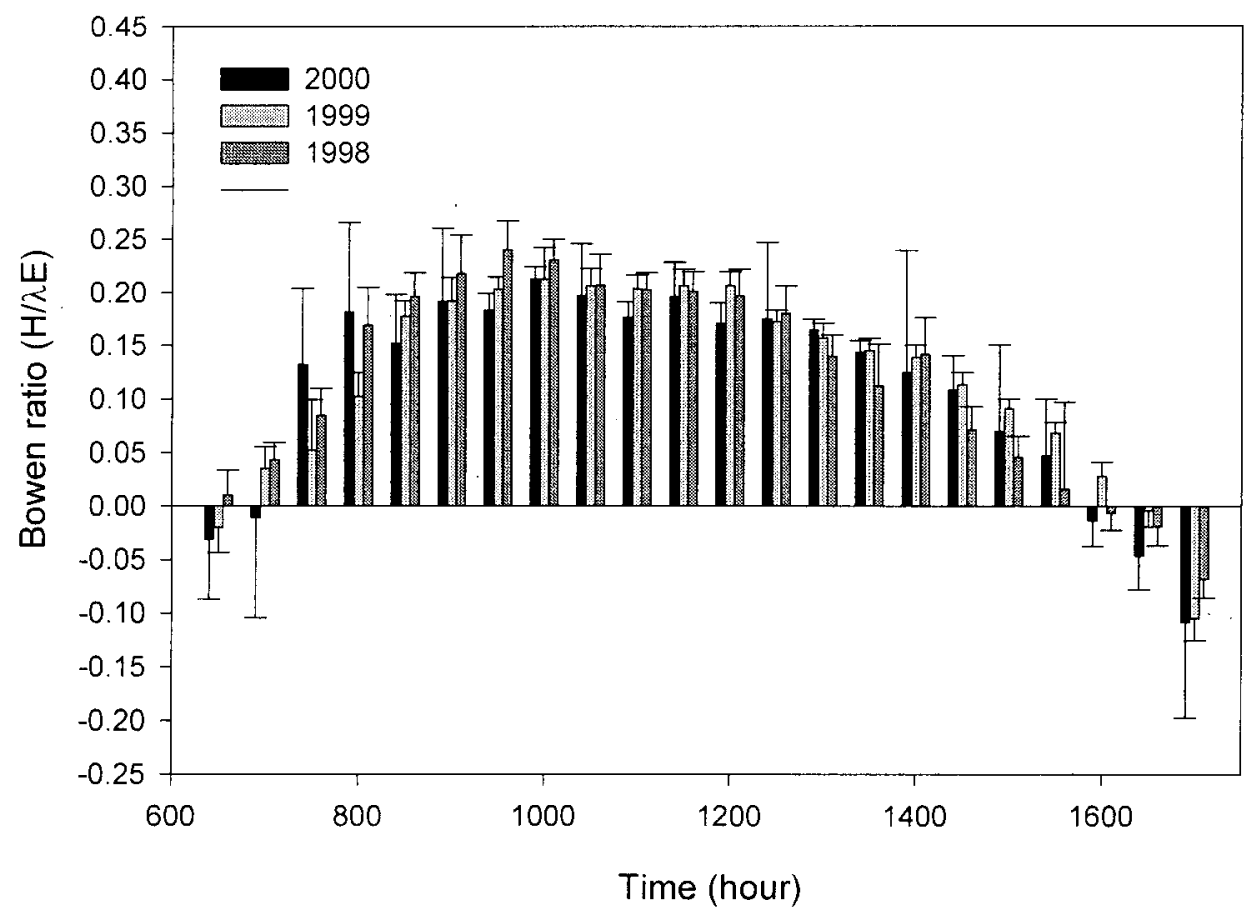

Figure 5. Daytime Bowen ratios for each year. Estimates of $\lambda E_{\text {turh }}$ were calculated by $E q 2 b$. Data are median values ( $\pm 1 \mathrm{SE}$ ) with $R_{n}>40 \mathrm{~W} \mathrm{~m}^{-2}$. 

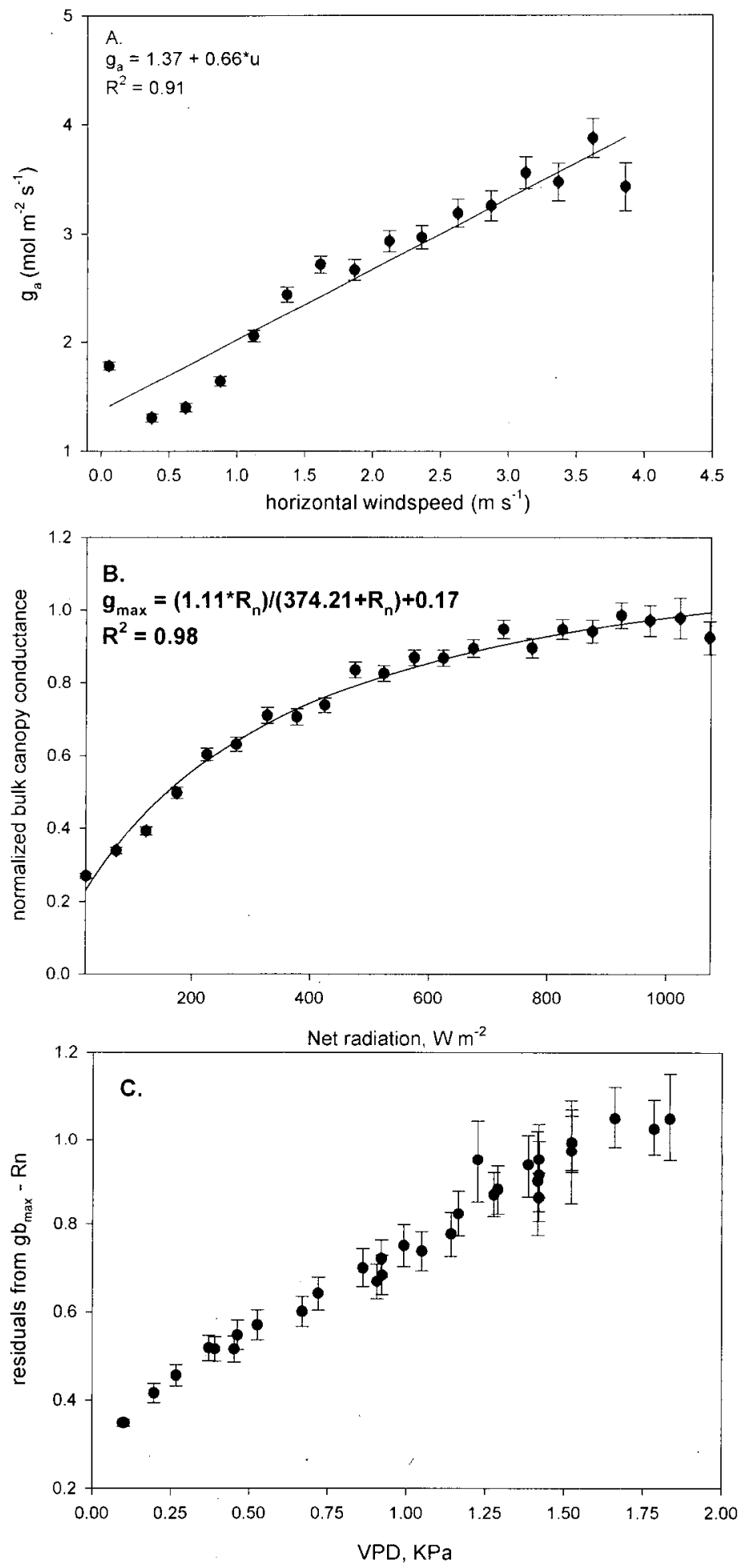

Figure 6. Empirical relationships of both aerodynamic and bulk conductance used to model $\mathrm{ET}_{\mathrm{pm}}$. Independent variables were averaged at different intervals, i.e., $0.25 \mathrm{~m} \mathrm{~s}^{-1}, 50 \mathrm{~W} \mathrm{~m}^{-2}$, and $0.025 \mathrm{kPa}$, for $\mathrm{A}, \mathrm{B}$, and $\mathrm{C}$, respectively. All data were median values with $\pm 1 \mathrm{SE}$. 
This relationship was not found, so an upper limit for $g_{\max }$ as a function of VPD could not be determined (Figure 6C). $g_{b}$ was modeled only as a function of $R_{n}$, in concurrence with statistical results from a first-order regression. The minimum $\mathrm{g}_{\mathrm{a}}$ was $1.0 \mathrm{~mol} \mathrm{~m} \mathrm{~m}^{-2} \mathrm{~s}^{-1}$, which increased to $>$ $2.0 \mathrm{~mol} \mathrm{~m}^{-2} \mathrm{~s}^{-1}$ during mid-day (1000-1500 h, Figure 7A). Estimated values of $\mathrm{g}_{\mathrm{b}}$ followed a similar diurnal pattern as $\mathrm{R}_{\mathrm{n}}$, and at dawn, $\mathrm{g}_{\mathrm{b}}$ was $\sim 1 \mathrm{~mol} \mathrm{~m}^{-2} \mathrm{~s}^{-1}$ until $0800 \mathrm{~h}$, then steadily increased till noon, and decreased during the later afternoon, and approached $0.1 \mathrm{~mol}$ $\mathrm{m}^{-2} \mathrm{~s}^{-1}$ at dusk (Figure 7B). Modeled values of $\mathrm{g}_{\mathrm{a}}$ and $\mathrm{g}_{\mathrm{b}}$ behaved similarly to those derived using Eqs. 4 and 9 (Figure 7 ). $\Omega$ ranged from $\sim 0.6$ during the night to $\sim 0.85$ by $0830 \mathrm{~h}$. For the majority of daytime hours (0600-1600), $\Omega$ was $>0.75$ (Figure $7 C$ ).

Both the Penman-Monteith and Priestly-Taylor equations performed well in estimating $\lambda E$, (Figure $8 \mathrm{~A}$ ). The slopes of all the regression lines were $\sim 1.0$. The Penman-Monteith equation explained $95 \%$ of the observed variation in $\lambda \mathrm{E}$, with the variation being equally distributed and increasing with increasing energy (Figure 8A). There was no significant difference between using the Penman-Monteith equation for wet and dry canopy conditions. In contrast, the simpler Priestly-Taylor relationship accounted for $\geq 98 \%$ of the observed variation (Figure 8B). While there was also no significant difference in the use of the Priestly-Taylor equation to estimate $\lambda E$ for wet and dry canopy conditions, it did seem to overestimate $\lambda E$ when $\mathrm{R}_{\mathrm{n}}$ was $<500 \mathrm{~W} \mathrm{~m}^{-2}$ under dry canopy conditions (Figure $8 \mathrm{C}$ ). Annual ET PT ranged from 1892 $\mathrm{mm}$ in 1998 to $2294 \mathrm{~mm}$ in 1999, and from $54 \%$ to $66 \%$ of bulk precipitation (Table 1). Mean daily $\mathrm{ET}_{\mathrm{PT}}$ rates were also lower in 1998 and greatest in 1999 (5.2 to $6.3 \mathrm{~mm} \mathrm{~d}^{-1}$, respectively). Results using the Penman-Monteith model were not significantly different than the PriestlyTaylor model. Interception loss was greatest in 2000, with an annual total of $708 \mathrm{~mm}$, accounting for $18 \%$ of bulk precipitation.

\section{Discussion}

\section{Ecosystem Energy Dynamics}

Daytime profiles of temperature and water vapor in the upper canopy were often counter to the above-canopy gradients as a result of winds that did not fully penetrate the canopy. The top of the canopy, between $21-27 \mathrm{~m}$, acted as a physical barrier to the removal of transpirated moisture from below. As a result, the negative $\lambda \mathrm{E}_{\mathrm{BC}}$ at night was due to adiabatic cooling and consequent condensation. Storage fluxes can contribute substantially to the overall ecosystem energy flux when $R_{n}$ is small or during the night. On a diurnal basis, this was a very small component ( $2 \%$ ). Mahli et al. (2002) did not find this to be the case from a seasonally humid forest in Amazonia, storage fluxes calculated by the residual from the energy balance accounted for as much as $30 \%$ of overall flux on an hourly basis. This suggests a strong contrast between tropical wet and seasonally humid forests.

Bowen ratios $(\beta)$ were consistently $<1$ indicated that water was not limiting $\lambda E$ at any time during the year. Soils in the wet tropics generally do not exert hydraulic limitations on $\lambda \mathrm{E}$ (De Bruin 1983). This is likely also the case at La Selva, where soils have high water-holding capacity and high hydraulic conductivity (Weitz et al. 1997, Sollins et al. 1994). The neglibile response of $\lambda \mathrm{E}$ and $\mathrm{g}_{\mathrm{b}}$, to $\mathrm{VPD}$, further suggests that water was not limiting in this forest. Pentaclethra macroloba, the dominant tree species ( $42 \%$ of the basal area) is known to close its stomata and leaves in the late afternoon $(\sim 1530 \mathrm{~h})$. However, changes in either $\mathrm{H}_{\mathrm{NEE}}$ or $\lambda \mathrm{E}$ due to associated changes in $\underline{P . \text { macroloba }}$ physiology were not detected. This result suggests that either single species do not control energy partitioning, their controls cannot be detected at the ecosystem-level in heterogenous tropical wet forests with the eddy-covariance technique, or that 


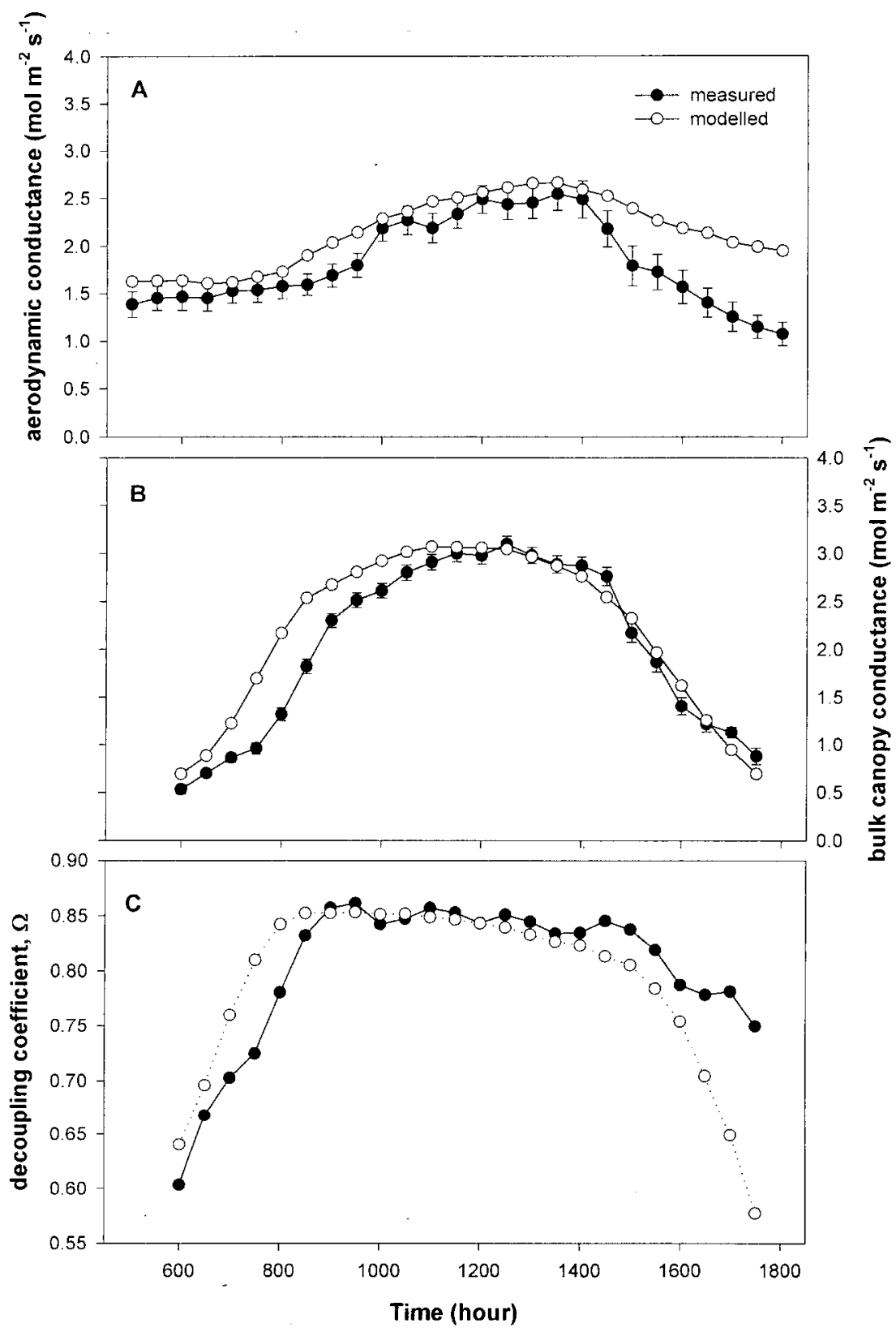

Figure 7. The diurnal relationship of A) aerodynamic conductance, B) bulk canopy conductance, and $\mathrm{C}$ ) the decoupling coefficient calculated by eddy covariance data and modeled based on Figure 7 from an old-growth wet tropical forest, Costa Rica. All data are median values from 1997-2000. Error bars in graphs A and B are \pm 1 SE. SE for graph C are typically $<0.006$. 
Table 1. Evaporative fluxes for La Selva, Costa Rica calculated using the Priestly-Taylor equation. Units for total $R_{n}$ are $J{ }^{-1}$, and $E T_{p t} / R_{n}$ is the fraction of the total annual energy needed to evaporate $E T_{p t}$ of $R_{n}$. Evaporation of intercepted water is noted as $E_{i}$. Units

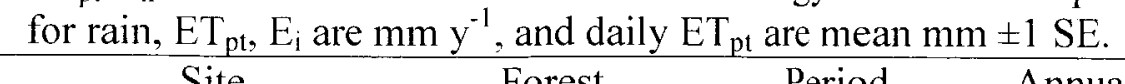

\begin{tabular}{|c|c|c|c|c|c|c|c|c|c|}
\hline Site & Forest & Period & Annual & Annual & Annual & Annual & Annual & Annual & Annual \\
\hline & & & Rain & $\mathrm{ET}_{\mathrm{pt}}$ & $\mathrm{ET}_{\mathrm{pu}} / \mathrm{R}_{\mathrm{n}}$ & $\mathrm{E}_{\mathrm{i}}$ & $E T_{p t} /$ rain & $\mathrm{E}_{\mathrm{i}} / \mathrm{ET}_{\mathrm{pt}}$ & $\mathrm{E}_{\mathrm{i}} /$ rain \\
\hline This study & old-growth & 1998 & 3495 & 1892 & 0.95 & 564 & 0.55 & 0.30 & 0.17 \\
\hline This study & $"$ & 1999 & 3475 & 2294 & 0.88 & 587 & 0.66 & 0.26 & 0.17 \\
\hline This study & " & 2000 & 4127 & 2230 & 0.97 & 708 & 0.54 & 0.32 & 0.18 \\
\hline${ }^{\mathrm{a}} \mathrm{La}$ Selva, Costa Rica & old-growth & Aug 82-Mar 83 & 4620 & 2172 & 1.25 & 760 & 0.47 & 0.35 & 0.17 \\
\hline${ }^{\mathrm{b}}$ La Selva, Costa Rica & 3 plantations & Dec 94-Nov 95 & 3156 & $1318-1509$ & $0.79-0.90$ & $74-375$ & nd. & $0.06-0.25$ & nd. \\
\hline `Janlappa, Java & secondary & Aug 80-Jul 81 & 2892 & 1481 & 0.96 & 595 & 0.52 & 0.41 & 0.21 \\
\hline${ }^{\mathrm{d}}$ Cuieiras, Brazil & old-growth & Sept 95-Aug 96 & 2089 & 1124 & 0.65 & nd. & 0.66 & nd. & nd. \\
\hline${ }^{\mathrm{c}}$ Ducke, Brazil & old-growth & $8 \mathrm{~d}$ in Sept 83 & nd. & nd. & 0.92 & nd. & 0.48 & 0.30 & nd. \\
\hline
\end{tabular}

References: ${ }^{\mathrm{a}}$ Luvall $1984,{ }^{\mathrm{b}}$ Bigelow 2001, ${ }^{\mathrm{c}}$ Calder et al. $1986,{ }^{\mathrm{d}}$ Malhi et al. 2002, ${ }^{\mathrm{c}}$ Shuttleworth et al. 1984, 1988. nd denotes no data. 
Table 2. Annual fraction of time that the canopy was wet at two heights in the canopy.

\begin{tabular}{lll}
\hline year & \multicolumn{2}{l}{ Height of leaf wetness sensor } \\
& $25 \mathrm{~m}$ & $2 \mathrm{~m}$ \\
\hline 1998 & 0.42 & 0.59 \\
1999 & 0.17 & 0.57 \\
2000 & 0.23 & 0.48 \\
All year & 0.32 & 0.57 \\
\hline
\end{tabular}


the time of day when P. macroloba closes its leaves and stomata is inconsequential to the abovecanopy energy fluxes.

\section{Conductances and Other Limits to Annual Energy Fluxes}

The general diurnal patterns found for $g_{a}$ and $g_{b}$ are similar to those reported for other tropical forests (Bigelow 2001, Wright et al. 1996, Shuttleworth 1984). We found higher late afternoon $g_{b}$ rates for the old-growth forest than those found for three monocultural plantations at La Selva ( 0.5-0.8 mol m $\mathrm{m}^{-2} \mathrm{~s}^{-1}$, Bigelow 2001). Our higher observed afternoon $\mathrm{g}_{b}$ was likely an integrated response of all species, suggesting that the gas exchange measurement acquired with cuvettes from these plantations do not fully capture the response from old-growth forests. Moreover, our $g_{b}$ estimates were also higher than Wright et al. (1996) values from a tropical humid forest in Brazil. The lower $\mathrm{g}_{\mathrm{b}}$ estimates found by Wright et al. (1996) were due to VPD constraints on $g_{b}$, that were not found in this study. For the most part, VPDs at La Selva were relatively low, $<1.5 \mathrm{kPa}$. VPDs may, however, affect energy flux at the leaf-level in the upper canopy, but were not detected by the methods used here, suggesting that the lack of ecosystemlevel response to the observed VPDs may be due to increased transpiration in the lower canopy, thereby offsetting any leaf-level effects in the upper canopy. We found significant differences in observed $g_{b}$ among years and seasons that followed the same trends as $R_{n}$. Between year differences in $R_{n}$ explained much of the interannual variability observed in measured and modeled $\lambda \mathrm{E}$ from La Selva. Increased rainfall in 2000 increased the absolute amount of interception, but not the fraction of rainfall intercepted.

The direct effects of $g_{b}$ on $\lambda E$ could not be determined because these variables were not be independently measured. However, increasing values of $\Omega$ (from 0.6 to $\sim 0.85$ ) during the early morning indicate that before 0900 were only times when strong physiological control on $\lambda \mathrm{E}$ occurs, likely due to the opening and closing of stomata and leaves. Values of $\Omega>0.75$ suggest that mid-day $\lambda \mathrm{E}$ is controlled more by $\mathrm{R}_{\mathrm{n}}$ and $\mathrm{g}_{\mathrm{a}}$, than $\mathrm{g}_{\mathrm{b}}$. $\mathrm{g}_{\mathrm{a}}$ explained $44 \%$ of the variation in $\lambda E$ during times when both conductances were used to calculate $\mathrm{ET}_{\mathrm{PM}}$ (i.e., dry canopy conditions). The importance of $g_{a}$ in controlling ET $_{P M}$ increased further because of the very high precipitation at La Selva, where $32 \%$ of the time, the upper canopy was wet.

The Priestly-Taylor relationship for well-watered conditions described the $\lambda E$ dynamics of this tropical forest quite well, in particular for wet canopy conditions (Figure 8C). However, Priestly-Taylor relationship tended to overestimate the observed $\lambda E$ flux for dry canopy conditions with $R_{n}<500 \mathrm{~W} \mathrm{~m}^{-2}$. Because the assumption that the $\alpha$ coefficient applies for optimal conditions (free water and maximum $R_{n}$ ) but not for hyperbolic change in $g_{b}$ with increasing $\mathrm{R}_{n}$ (e.g., Figure $6 \mathrm{~B}$ ), the fraction of available energy used for $\mathrm{ET}_{\mathrm{PT}}$ was similar yearto-year suggesting a thermodynamic constraint on $\mathrm{H}$ that limits maximum daily temperature (Calder 1986). Wright et al. (1996) and Calder et al. (1986) also found that potential evapotranspiration accounted for a large fraction of $R_{n}(>0.80)$ from a humid Amazonian and Javanese forest, respectively, as did Bigelow (2001) for the monocultural plantations at La Selva (0.79-0.90).

In a previous study in the old-growth forest at La Selva, Luvall (1984) determined that the energy required for evapotranspiration exceeded $R_{n}$ by $25 \%$. Although this seems counterintuitive, it may very well be true. This phenomenon has been observed over crops (Ham and Hielman 1991) as well as other tropical forests (Jones 1992, Shuttleworth 1989, Calder 1986). The likely explanation is that additional energy is locally advected into the flux field from surrounding and contrasting land use types, or from rapid movement of frontal systems (Newson 


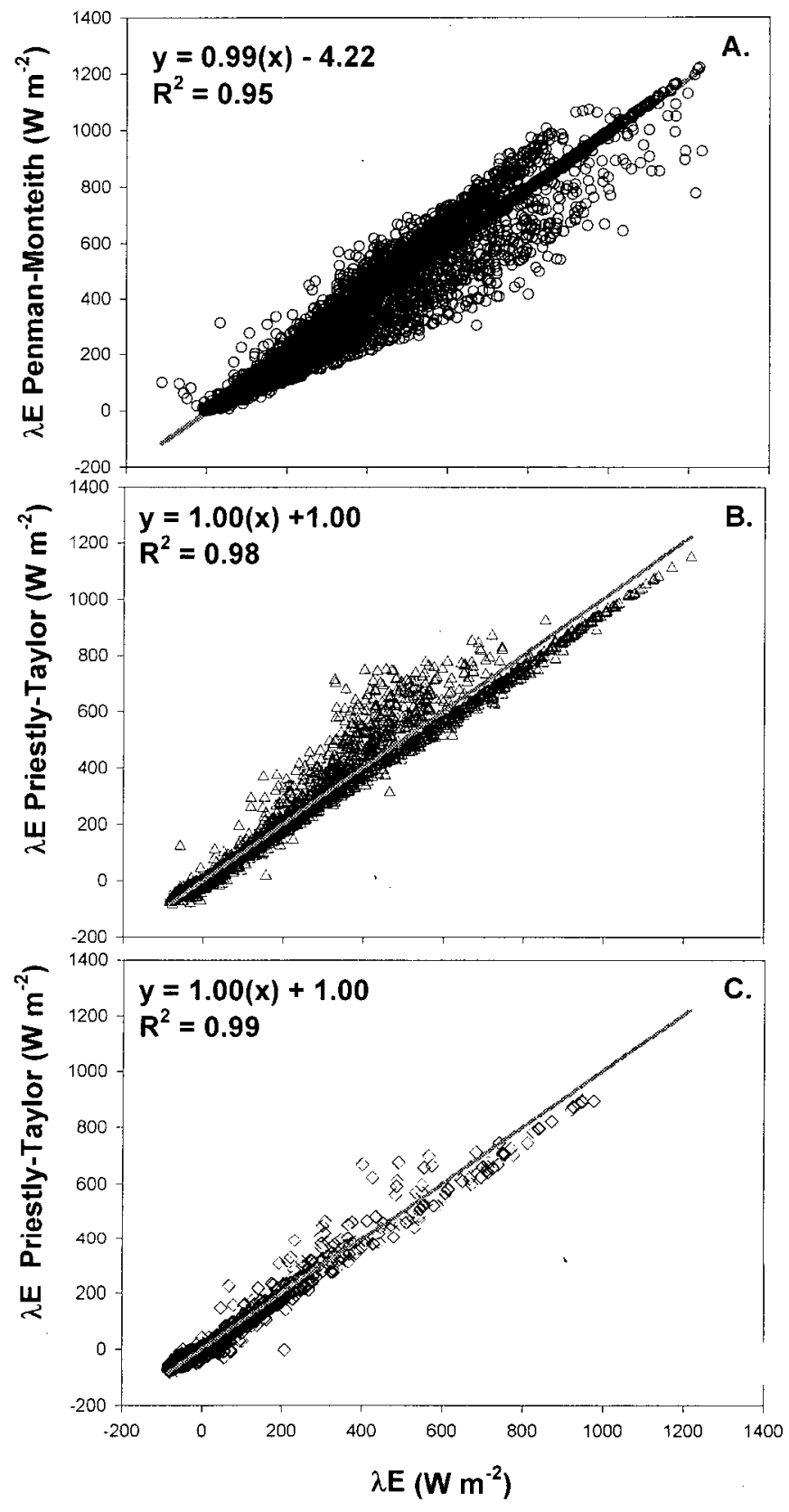

Figure 8. Relationship between empirical and modeled estimates of the latent energy, where A) is modeled using a Penman-Monteith equation, and B) using Priestly-Talyor equation with a dry canopy, and C) using a Priestly-Taylor equation with a wet canopy. All graphs used data from 1998-2000. An $\alpha$ of 1.24 was found for graphs B and C. All slopes were significant, $p<0.0001$. $\mathrm{y}$-intercepts had p-values of $0.003,0.04$ and 0.04 for A, B and C, respectively. 
and Calder 1989). This is certainly possible at La Selva, where mean daytime wind direction is $90^{\circ}$ and the fetch is $\sim 2 \mathrm{~km}$, beyond which the landscape is dominated by pastures, crops and patches of secondary forests extending for $\sim 60 \mathrm{~km}$ to the Caribbean shore. Advection of drier air masses with greater evaporative demand is possible, particularly during Luvall's study in the early 80's when much of the land in the Costa Rican coastal plain was being converted from forests to agriculture (Table 1). ET $\mathrm{PT}_{\mathrm{PT}}$ estimates reported here did not exceed available $\mathrm{R}_{\mathrm{n}}$, suggesting advection was not significant. We cannot rule out the possibility however, that advection contributed additional energy.

The magnitude of canopy capacitance is in large part a function of physical surface area of a canopy (Waring and Schlesinger 1985). At La Selva, high epiphytic loads, bromeliad tanks and arboreal soil mats can contribute capacitance and may not have been fully accounted for in our estimates. We used a fixed estimate of capacitance of $1.53 \mathrm{~mm}$ (Loescher et al. 2002). The fraction of intercepted rainfall was consistent from 1998 to 2000, as was Luvall's study. This suggests that the canopy surface area at La Selva is often saturated, that the relative annual amount of interception is constant, and that changes in leaf surface area were not detectable over our measurement period.

This old-growth wet tropical forests fairly consistently retained and recycled $\sim 50 \%$ of the annual bulk precipitation. For a given amount of $\mathrm{R}_{\mathrm{n}}$, limited water losses to the atmosphere appears to be imposed by forest structure and function. Unknown, is if the $50 \%$ limit on bulk precipitation holds true for other tropical wet forests with differing age and structure. Annual $R_{n}$ and bulk precipitation are likely correlated to some degree. Data presented here suggest that 88 $97 \%$ of $R_{n}$ estimates an upper bound on the partition of bulk precipitation from tropical forests having rainfall $>2800 \mathrm{~mm} \mathrm{y}^{-1}$ (Table 1 ). Not known--is how this fraction may change with climate changes. For example, if changes in climate increased $R_{n}$ relative to precipitation, there would likely be ample water available for ET. In contrast, the amount of available energy would likely limit annual ET if annual precipitation increased relative to $R_{n}$, with a resultant increase in runoff.

In conclusion, the relatively constant understory temperatures with a modest diurnal range led to storage fluxes contributed very little $(\sim 2 \%)$ to the overall daily energy fluxes. Daytime $\lambda E$ was always greater than sensible heat, suggesting that the trees in this forest have sufficient ground-water reserves to minimize hydraulic stress. Conductances followed similar trends reported from other tropical forests, but were higher in magnitude. $R_{n}$ was the largest determinant for the annual energy flux for this wet tropical forest, as demonstrated by both models. This was primarily because $\Omega$ was high and $g_{b}$ exerted little control during daytime hours when fluxes were at their greatest. Both the Penman-Monteith and Priesty-Taylor models performed well. The Priestly-Taylor model is more appropriate for wet canopy conditions that prevail for much of time. This tropical wet forest behaved more like a classical well-watered agronomic crop rather than many other forests that respond to hydraulic limitations. 


\section{Introduction}

\section{IV.4. Aerosol Carbon fluxes}

Determining the factors that control the carbon balance for ecosystems around the globe has been the subject of intense research efforts. Many studies have focused primarily on the controls of the biologically-active component in the atmosphere, $\mathrm{CO}_{2}$ (Clark et al. 1999, Law et al. 2000, Valentini et al. 2000, Loescher et al. 2003). While the deposition of biologicallyinactive particulate carbon to the overall carbon balance may be small, concentration of carbon aerosols in the atmosphere and deposition to forests can potentially affect biological processes exchanging $\mathrm{CO}_{2}$. Organic sources carbonaceous aerosols can counteract the warming due to greenhouse gases and cool the atmosphere (Penner et al. 1998) by scattering incoming solar radiation and changing cloud properties (Grant et al. 1999, Penner et al. 2002). Alternatively, black carbon aerosols from fossil fuels can heat the air mass in the convective boundary-layer (Chuang et al. 2002). At the leaf-level, particulates can stress plants and limit its ability to capture carbon (Hosker and Lindberg 1982, Smith and Jones 2000, Jacobson 2001) and limit light availability by increasing substrate for algae and microbes on leaves. Despite these feedbacks on productivity, estimates of deposition, fate, and transport are not well represented globally, and development of global deposition models is still nascent.

Atmospheric composition and chemistry, and global climate are shaped in part, by the production and removal of aerosols within the troposphere (Koutrakis and Sioutas 1996, Charlson et al. 1992). Aerosols can be solid or liquid particulate matter suspended in the atmosphere, e.g., dust, ash, and smoke. But aerosols can also be formed through complex and often unknown chemical reactions between different gas species and particulates (Friedlander 1977, Seinfeld 1986, Williams and Loyalka 1991). Aerosols have direct effects both on the global radiation balance and on global atmospheric chemistry (IPCC 1995). Quantitative understanding of the environmental sources and sinks of these aerosols, and their various interactions contribute to changes in biogeochemical processes and climate, and are key for making reliable predictions of future concentrations of $\mathrm{CO}_{2}$ in atmospheric and estimating uptake of total carbon by terrestrial ecosystems.

Tropical forests account for large fractions of global gross primary productivity, carbon stored in aboveground terrestrial biomass, and global soil carbon, $\sim 35 \%,>50 \%$, and $\sim 20 \%$, respectively (Melillo et al. 1993, Dixon et al. 1994). Annual net carbon exchange from a wet tropical forest has recently been shown to have large interannual variability (Loescher et al. 2003 ), and is thought to modulate the interannual variation in atmospheric $\mathrm{CO}_{2}$ concentrations (Clark et al. 2003, Clark and Clark 1992, 1994). Moreover, the interannual variation in atmospheric $\mathrm{CO}_{2}$ concentrations was negatively correlated with warm-phase E1 Nino Southern Oscillations (ENSO, Clark et al. 2003, Ogren et al. 1996). Differences among annual light regimes are in part responsible for the observed differences in annual net carbon exchange (NEE) and is hypothesized that the magnitude and frequency of cloud formations play an additional role (Loescher et al. 2003, Malhi et al. 1998).

Aerosols play an important role in the response of tropical forests to increasing global temperatures. Wet tropical forests were predicted to become a major source of atmospheric $\mathrm{CO}_{2}$ due to increased respiration (Kindermann et al. 1996). Aerosols can exacerbate carbon losses by reducing available light for photosynthesis, or they can ameliorate carbon losses by reducing the amount of net radiation available for sensible heat (Jacobson 2001). To date, aerosol observations over tropical rainforests are rare, and no in situ field data on carbonaceous aerosols have been collected over tropical wet forest canopy. 
The potential role aerosols play in modifying micro- and macro-level climate, and the subsequent consequences on tropical forest productivity and atmospheric $\mathrm{CO}_{2}$ remain to be determined. The objective of this study was to measure the carbonaceous aerosol concentrations in- and estimate deposition through- the roughness sub-layer within the atmospheric boundarylayer to a wet tropical forest canopy.

\section{Aerosol properties}

Aerosols can be solid or liquid particles and are formed through gas-to-particle conversion processes in the surrounding air. The physical and chemical characteristics of aerosols are dependent on formation mechanisms and sources, and are classified as either originating from natural or anthropogenic sources. The transport of aerosols $<0.1 \mathrm{~mm}$ occur by Brownian diffusion, and at times, coagulate to form larger aerosols $(>0.1 \mathrm{~mm})$, which become subject to atmospheric mixing processes. Above the forest canopy, aerosols are usually produced in adjoining and different land use classifications and horizontally advected to the forested ecosystem. Below-canopy aerosols are a combination of above canopy aerosols that have settled and the fractionation of dead organic matter. Often, small, low energy circulations occur under the canopy that may transport aerosols through convection (daytime) or adiabatic flows (nighttime). Large fractions of the total aerosols present in the atmosphere are removed during rain events.

Mechanisms of formation affect the size distribution and lifetimes of aerosols (Charlson et al. 1992). Aerosols generally range from 0.01 to $100 \mu \mathrm{m}$ in diameter, with particles ranging in size from 0.01 to $0.1 \mu \mathrm{m}$ defined as the 'nucleation' range. Nucleation size aerosols have lifetimes generally $<1 \mathrm{~h}$ because of rapid coagulation with larger particles or serve as condensation nuclei for cloud or fog droplets. Nucleation size aerosols, however can also persist if removal mechanisms are weak (Lodge 1989). Aerosols ranging from 0.1 to $2.5 \mu \mathrm{m}$ are in the 'accumulation' range and primarily consist of elemental and organic carbon. Aerosols in this range have two physical forms, a chemically-active gas phase and a droplet phase. In general, aerosols in the accumulation range are too small to precipitate out by gravity and too large to coagulate onto larger particles. Thus, they have lifetimes in the atmosphere on the order of days and can be transported over long distances. Aerosols $>2.5 \mu \mathrm{m}$ are considered 'coarse' and are formed by a variety of biological, geological, and anthropogenic origins e.g., pollen and spores, decomposition of leaf litter, weathering of parent material, wind impaction, volcanic ash, trash and tire abrasion, biomass burning. Gravitational settling is one of the mechanisms removing these aerosols from the troposphere.

\section{Methods and Materials}

Aerosol measurement

Carbonaceous aerosols, the combination of organic and black carbon, were measured from a $42 \mathrm{~m}$ tower (Upright Inc., Selma, CA) during the wet season (November - December, 1998). Aerosol samples were collected using an eight-stage cascade impactor (model Mark I, Thermo-Andersen, Waltham MA), and separated by size class; 9.0 - 5.8, 5.8 - 4.7, 4.7 - 3.3, 3.3 $-2.1,2.1-1.1,1.1-0.65$, and $0.65-0.1 \mu \mathrm{m}$. Operation was followed as described in USEPA 1998. The eight-stage impactor was connected to a single head pump with $10 \mathrm{lpm}$ of sampling air pulled continuously across the filters. Each sample was collected on carbonless, quartz, high purity, binder-free (QMA) filters. Before application, these filters were heat treated to remove trace organic impurities. Care was taken to prevent filters from contamination before and after sampling. The impactor ports from each stage were checked daily for debris and cleaned if 
necessary. The flow meters were calibrated using a NIST standard bubble meter (model Gilabator-2, Sensidyne Inc., Clearwater, FL). Quantity of aerosols on each filter was estimated using a carbon analyzer (model LECO-WR12, Laboratory Equipment Corp., St. Joseph, MI), with a detection limit of $0.6 \mathrm{ppm} \mathrm{C}$, and precision of $0.001 \%$. Samples were combusted in a high-temperature resistance furnace, $850^{\circ} \mathrm{C}$, and the carbon on the filter oxidized to $\mathrm{CO}_{2}$, which in turn, was quantified by infrared absorption. The LECO analyzer was calibrated using standards following the appropriate EPA protocol (USEPA 1998).

The impactor was positioned at three vertical positions on the $42 \mathrm{~m}$ tower (Upright Inc., Selkirk CA) at 42,21 ( zero plane displacement), and $2 \mathrm{~m}$. Sampling was integrated over an entire $24 \mathrm{~h}$ interval; weather permitting, with a total of 28 days sampled between November 24 and December 28, 1998. On two extreme weather occasions, sampling integrated over $48 \mathrm{~h}$. Meteorological data were collected continuously at the tower top, included; aspirated air temperature ( $\mathrm{T}_{\mathrm{a}}, 100 \Omega$ platinum RTD, Omega Engineering, Stamford, $\mathrm{CT}$ ), and bulk rainfall (TE525 metric, Texas Electronics, Dallas, TX). Atmospheric pressure (PB105, Vaisala, Helsinki, Finland) was monitored at ground level. All of the meteorological were collected at an interval of $5 \mathrm{sec}$ and compiled as 30-min averages with dataloggers (CR10X and 21X, Campbell Scientific Inc., Logan, UT). Instruments were cleaned, leveled as necessary, and recalibrated according to manufacturer's instructions.

Estimates of aerosol concentrations were normalized on the basis of total rainless ('dry') hours sampled, because of daily rain events during our sampling intervals, and precipitation removes aerosols from the atmosphere such that,

$C_{n}=C_{i} \cdot \frac{M_{v}}{V_{a}} \cdot \int_{i=0}^{1=24} \frac{h_{d}}{h_{s}}$

$\mathrm{C}_{\mathrm{n}}$ is the normalized aerosol density per mol air sampled ( $\left.\mu \mathrm{g} \mathrm{C} \mathrm{mol}{ }^{-1}\right), \mathrm{C}_{\mathrm{i}}$ is the carbon weight of the sample $(\mu \mathrm{g}), V_{a}$ is the total air volume sampled $\left(\mathrm{m}^{3}\right), \mathrm{M}_{v}$ is the molar volume of air $\left(\mathrm{m}^{3} \mathrm{~mol}^{-}\right.$ $\left.{ }^{1}\right), h_{d}$ is the fraction of sampling time without precipitation, and $h_{s}$ is the entire sampling time ( $t$ is hours, i.e., $24 \mathrm{~h}$ ). Because carbonaceous aerosols are being added to- and removed from the atmosphere during the measurement period, functional relationships $\mathrm{C}_{n}$ were estimated to reflect changes in sink-source status.

The tracer continuity equation can be integrated to define a deposition velocity, and can be used to estimate the deposition of carbonaceous aerosol to the forest canopy with aerosol being the tracer in this case,

$F_{c}=C_{n} \cdot V_{d}$

Eq. 2

where $F_{c}$ is deposition to the canopy $\left(\mu \mathrm{g} \mathrm{m}^{-2} \mathrm{~s}^{-1}\right), \mathrm{V}_{\mathrm{d}}$ is the deposition velocity to the canopy ( $\mathrm{mol}$ $\mathrm{m}^{-2} \mathrm{~s}^{-1}$ ), and here is estimated using three different ways. Assuming spatial homogeneity in transfer properties, $V_{d 1}$ and $V_{d 2}$ were estimated using conductance terms in series analogous to the inverse of electrical resistances, and $V_{d 3}$ was estimated more traditionally by incorporating deposition processes of gravitational settling, diffusion, impaction and interception, such that,

$V_{d 1}=\frac{1}{\frac{1}{g_{a}}+\frac{1}{g_{h}}} \cong V_{d 2}=\frac{1}{\frac{1}{g_{a}}+\frac{1}{g_{m}}} \cong V_{d 3}$

Eq. $3 a$ 
$V_{d 3}=\left[V_{g}+\frac{1}{\frac{1}{g_{a}}+R_{s}}\right] M_{v}$

Eq. $3 b$

where $g_{a}$ is aerodynamic conductance in the roughness sub-layer $\left(\mathrm{mol} \mathrm{m}^{-2} \mathrm{~s}^{-1}\right), \mathrm{g}_{\mathrm{b}}$ is the bulk canopy conductance ( $\left.\mathrm{mol} \mathrm{m} \mathrm{m}^{-2} \mathrm{~s}^{-1}\right), \mathrm{g}_{\mathrm{m}}$ is the canopy conductance due to momentum transfer, $\mathrm{V}_{\mathrm{g}}$ is gravitational setting of particulate $\left(\mathrm{mol} \mathrm{m}^{-2} \mathrm{~s}^{-1}\right), \mathrm{R}_{\mathrm{s}}$ represents the collection efficiency of the canopy due to diffusion, impaction and interception $\left(\mathrm{mol} \mathrm{m}^{-2} \mathrm{~s}^{-1}\right)$, and $\mathrm{M}_{\mathrm{v}}$ is the molar volume $\left(\mathrm{mol} \mathrm{m}^{-3}\right)$.

Aerodynamic conductance in a well-mixed layer was estimated by,

$$
g_{a}=\frac{k^{2} u}{\left[\ln \left(\frac{z_{42-d}}{z_{m}}\right)\right]^{2}+\ln \left(\frac{z_{42}-d}{z_{m}}\right)\left[\ln \left(\frac{z_{m}}{z_{42}}\right)+\Psi_{m}-\Psi_{h}\right]}
$$

where $\mathrm{k}$ is Von Karmen's constant ( 0.40 dimensionless), $\mathrm{u}$ horizontal windspeed $\left(\mathrm{m} \mathrm{s}^{-1}\right), \mathrm{Z}_{\mathrm{x}}$ is measurement height $(\mathrm{m}), \mathrm{d}$ is the zero-plane displacement $(\mathrm{m}), \mathrm{Z}_{\mathrm{m}}$ is the aerodynamic roughness length, and $\Psi_{\mathrm{m}}$ and $\Psi_{\mathrm{h}}$ are the diabatic correction factors $(\mathrm{m})$ for momentum and sensible heat, respectively (Yasuda 1988, Arya 1988). Zero-plane displacement and aerodynamic roughness changed with stability and were empirically estimated for this study site (Loescher et al. 2003). Diabatic correction factors are a function of stability, where in stable conditions,

$\Psi_{M}=\Psi_{H}=6 \ln (1+\zeta)$

Eq. 5

and in unstable conditions,

$\Psi_{H}=-2 \ln \left[\frac{1+(1-16 \zeta)^{0.5}}{2} ; \Psi_{M}=0.6 \Psi_{H}\right.$

Eq. 6

with $\zeta$ is a stability parameter; a ratio of convective to mechanical turbulent production,

$\zeta=-\frac{z_{42}-d}{L} ; L=\frac{-\rho_{a} C_{p} T_{1} u^{* 3}}{g k H}$

Eq. 7

and $\mathrm{L}$ is the Monin-Obukov length $(\mathrm{m}), \rho_{\mathrm{a}}$ is the density of air $\left(\mathrm{kg} \mathrm{m}^{-3}\right), \mathrm{C}_{\mathrm{p}}$ is the specific heat capacity of air $\left(\mathrm{J} \mathrm{kg}^{-1} \mathrm{~K}^{-1}\right), \mathrm{T}_{\mathrm{a}}$ is in Kelvin $(\mathrm{K}), \mathrm{u}^{*}$ is a velocity scale derived from the square root of Reynold's stresses $\left(\mathrm{m} \mathrm{s}^{-1}\right)$, $\mathrm{g}$ is acceleration due to gravity $\left(\mathrm{m} \mathrm{s}^{-2}\right)$, and $\mathrm{H}$ is the sensible heat flux density $\left(\mathrm{J} \mathrm{m}^{-2} \mathrm{~s}^{-1}\right.$, Montieth and Unsworth 1990).

The $g_{b}$ and $g_{m}$ describes the transfer process at the boundary between the canopy and the atmosphere, and incorporates influences from both physiological and structural controls. Traditionally, $g_{b}$ has been estimated by scaling leaf-level measurements of stomatal and boundary-layer conductances to the canopy-level (e.g., Bigelow 2001). This is difficult to accomplish in structurally diverse and complex natural tropical forests. Moreover, $P$. macroloba is known to close its stomata and leaves in the late afternoon $(\sim 1530 \mathrm{~h})$. So the use of $g_{b}$ assumes the transfer process is directly related to the transfer of sensible and latent heat $(\mathrm{H}$ and $\lambda \mathrm{E}$, respectively) and indirect responses due to the diurnal shift, lower into the canopy, of momentum flux. Other studies have relied on only the use of $\mathrm{g}_{\mathrm{a}}$ due to lack of direct measurements of $\mathrm{H}$ and $\lambda \mathrm{E}$, or have relied on model results. On the other hand, $\mathrm{g}_{\mathrm{m}}$ directly estimates the transfer at theoretical boundary (i.e., d) through the momentum flux, but also indirectly integrates the diurnal change in d due to $P$. macroloba the closing of the leaves in the canopy. Bulk canopy conductance $\left(g_{b}\right)$ was estimated by, 


$$
g_{b}=\frac{g_{a}}{\frac{\Delta H}{C_{p} \lambda E}-1}+\frac{\lambda E}{\rho_{a} D_{42}}
$$

where $\Delta$ is the rate of change in the saturation of specific humidity with temperature $\left(\mathrm{kPa} \mathrm{K}^{-1}\right)$, and $\mathrm{D}_{42}$ is the specific humidity deficit at the tower top, $42 \mathrm{~m}\left(\mathrm{~kg} \mathrm{~kg}^{-1}\right)$. Because $\mathrm{H}, \lambda \mathrm{E}$, and $\mathrm{D}_{42}$ are close to zero during nighttime hours, we assumed a base nighttime $g_{b}$ of $0.35 \mathrm{~mol} \mathrm{~m}^{-2} \mathrm{~s}^{-1}$ and contributed this to a forest structure.

Canopy conductance due to momentum transfer, $\mathrm{g}_{\mathrm{m}}$ was estimated as,

$$
g_{m}=\frac{M_{v} u^{* 2}}{u}
$$

An eddy covariance method was used to estimate $\mathrm{H}, \mathrm{u}^{*}$, and $\lambda \mathrm{E}$ contributed by turbulent exchange and changes in scalar concentration below the top of the tower. Because the belowcanopy environment was not always subject to turbulent transfer (i.e., well-mixed conditions), a profile system was used to estimate the rate of change of $\mathrm{H}$ and $\mathrm{q}$ below the canopy,

$$
\begin{aligned}
& H=\overline{w^{\prime} \theta^{\prime}}+\int_{Z_{0.5}}^{Z_{2} 7} \frac{\partial[\theta]}{\partial t} \partial Z_{27} \\
& u^{*}=\overline{w^{\prime} u^{\prime}} \\
& \lambda E=\overline{w^{\prime} q^{\prime}}+\int_{Z_{0.5}}^{Z_{27}} \frac{\partial[q]}{\partial t} \partial Z_{27}
\end{aligned}
$$

where $\overline{w^{\prime} \theta}, \overline{w^{\prime} u^{\prime}}$ and $\overline{w^{\prime} q^{\prime}}$ are the turbulent exchanges of water vapor and heat as estimated by eddy covariance method, and the second term in eqs. 10 and 12 is the storage flux in the air column. $w^{\prime}$ is the vertical windspeed with cross wind components rotated to $0\left(\mathrm{~m} \mathrm{~s}^{-1}\right), \theta^{\prime}$ virtual temperature $\left({ }^{\circ} \mathrm{C}\right)$, $\mathrm{u}^{\prime}$ is horizontal windspeed $\left(\mathrm{m} \mathrm{s}^{-1}\right)$, $\mathrm{q}^{\prime}$ specific humidity $\left(\mathrm{mmol} \mathrm{mol}{ }^{-1}\right)$ and primes denote instantaneous values from a running mean, overbar. A 3-D sonic anemometer (K-probe, Applied Technologies Inc., Boulder $\mathrm{CO}$ ) was used to measure wind velocities in each polar coordinate $(\mathrm{w}, \mathrm{v}, \mathrm{u})$ and sonic temperature $(\theta)$ at $42 \mathrm{~m}$. Infrared gas analyzers (IRGA, model LI6262 , LI-Cor Inc.) were used to measure q, controlled for pressure and temperature at ground level inside a climate-controlled structure. Flow rates were maintained by pumps (KNF Neuberger, Trenton, NJ) and mass flow controllers (Model series 200, 0-10 lpm, Teledyne Hastings Inc., Los Angeles CA). Sampled air for eddy covariance flowed through $\sim 60 \mathrm{~m}$ of tubing ( $4.8 \mathrm{~mm}$ ID Teflon tubing) at a rate of $8 \mathrm{lpm}$ resulted in a lagtime of $\sim 14.2 \mathrm{~s}$. Change in storage was determined with a profile system with samples collected from 6 inlets at $0.5,7.3$, $11.95,16.55,21.2$, and $27.6 \mathrm{~m}$. Functional relationships were derived using sonic data from April to December, 1998. For detailed description of the eddy covariance design for this study site see Loescher et al. 2003, and for general technique Baldocchi et al. 1988.

Settling of particulates due to gravitational forces was calculated as,

$V_{g}=\frac{\rho_{d} d_{p} 2 g C_{c}}{18 r^{\prime}}$

where, $p_{\mathrm{d}}$ is the density of the particle $\left(1 \mathrm{~g} \mathrm{~m}^{-3}\right)$ and $\mathrm{d}_{\mathrm{p}}$ its diameter $(\mathrm{m}), \mathrm{C}_{\mathrm{c}}$ is the a correction due to slip, and $v$ is the kinematic viscosity of air $\left(\mathrm{m}^{2} \mathrm{~s}^{-1}\right)$. The correction factor was estimated by,

$C_{c}=1+\frac{0.133}{d_{p}}\left(1.142+0.558 \exp ^{-0.999 \frac{0.133}{d_{p}}}\right)$

The collection efficiency was estimated by, 


$$
R_{s}=\frac{1}{\varepsilon_{0} u * R_{1}\left(E_{b}+E_{i m}+E_{m}\right)}
$$

such that, $\varepsilon_{0}$ empirical coefficient, $\mathrm{R}_{1}$ is the fraction of particles to adhere to the surface and estimated with an exponential function of the Stokes number $\left(\mathrm{St}=\mathrm{V}_{\mathrm{g}} \mathrm{u}^{*} / 2 \mathrm{~g}\right)$ by $\mathrm{R}_{1}=\exp (-\mathrm{St} 0.5)$. and $E_{b}, E_{i m}$, and $E_{i n}$ are dimensionless efficiencies due to Brownian diffusion, impaction and interception, respectively. $\mathrm{E}_{\mathrm{b}}$ was also based in the Schmidt number, $\mathrm{E}_{\mathrm{b}}=\mathrm{Sc}-0.66$ (Slinn et al 1982). $\mathrm{E}_{\mathrm{im}}$ was also estimated as a function of the Stokes number $\left(\mathrm{St}=\mathrm{V}_{\mathrm{g}} \mathrm{u}^{*} / 2 \mathrm{~g}\right)$, given by,

$$
\begin{aligned}
& E_{\text {trt }}=\left(\frac{S t}{0.8+S t}\right)^{2} \\
& E_{i n}=0.5\left(\frac{d p}{A}\right)^{2}
\end{aligned}
$$

Eq. $16 \mathrm{a}$

Eq. $16 b$

Where $\mathrm{A}$ is a characteristic radius of the canopy, and has been suggested to be 5 for evergreen broadleaved canopies (Zhang et al. 2001). Deposition estimates using $\mathrm{V}_{\mathrm{d} 3}$ were made for each size class and summed together. Use of all three $V_{d}$ estimates used here assume no electrical migrations, and no physical or chemical changes in the aerosol. Carbonaceous aerosols are known to be hydrophilic (i.e., cloud condensation particles) potentially allowing them to persist and be transported long distances. It is unkown how this transformation may contribute to the error in deposition estimates.

\section{Results}

Surface winds originated from two general circulations, $90-130^{\circ}$ direction from the African low pressure troughs and $255-80^{\circ}$ direction from the continental temporale (Figure 1A). Higher winds with less variance occurred from winds originating from the $90-130^{\circ}$ direction (Figure 1B). Correlations between wind direction and aerosol concentration were not made because of long integration times, i.e., $24 \mathrm{~h}$. Mean wind direction was $172^{\circ} \pm 79^{\circ}( \pm 1 \mathrm{SD})$, during the entire sampling period and $152^{\circ} \pm 79^{\circ}$ during daytime hours only, suggesting that in the majority of winds originated from the East to Southeast, over areas with rapid land use change, agricultural lands and rural industry; towns of Puerto Limon ( $97 \mathrm{~km} \mathrm{SE}$ ) and Guápiles (53 km SE), Costa Rica.

No significant differences were found among aerosol size and distribution from the different heights sampled, Figure 2. The distribution was negatively skewed for the range of aerodynamic diameter aerosols measured. The main size constituent was in the class $4.7-3.3$ $\mu \mathrm{m}$ accounting for $\sim 0.70 \mu \mathrm{g} \mathrm{C} \mathrm{mol}{ }^{-1}$, followed by the $5.8-4.7 \mu \mathrm{m}$ class producing $\sim 0.35 \mu \mathrm{g} \mathrm{C}$ $\mathrm{mol}^{-1}$. Concentrations measured at the $21 \mathrm{~m}$ height tended to be less than those measured at the other two heights.

The concentration of aerosols was found to exponentially decay with increasing precipitation, Figure 3. Seemingly incredible, precipitation during the study period averaged 20.4 $\pm 0.45 \mathrm{~mm} \mathrm{~d}^{-1}$, totaling $1221 \mathrm{~mm}$ over $60 \mathrm{~d}$ with a daily maximum of $121 \mathrm{~mm}$. Removal of aerosols occurred rapidly due to large precipitation events, and we were able to measure lower concentrations $\left(<0.10 \mu \mathrm{g} \mathrm{C} \mathrm{mol}^{-1}\right)$ after $75 \mathrm{~mm}$ of rain. Normalized concentrations should be viewed as qualitative estimates. More focus was placed on the functional relationships that allowed us to model the loading to- and removal of aerosols from the atmosphere.

Aerodynamic conductance was strongly linear with horizontal windspeed. L was neutral $(\sim 0 \mathrm{~m})$ during the night, and decreased during the day time until 1400 when the boundary layer 
Table 1. Temporal integrations of carbonaceous dry deposition to a wet tropical forest canopy in Costa Rica using three different means of calculating $\mathrm{V}_{\mathrm{d}}$ from $\mathrm{Eq} 3$. Units are $\mathrm{Kg} \mathrm{ha}^{-1}$.

\begin{tabular}{ccccccccccc}
\hline Interval & \# of DOY & \multicolumn{3}{c}{ Deposition using $g_{\mathrm{a}}$ and $\mathrm{g}_{\mathrm{b}}$} & \multicolumn{3}{c}{ Deposition using $\mathrm{g}_{\mathrm{a}}$ and $\mathrm{g}_{\mathrm{m}}$} & \multicolumn{3}{c}{ Deposition using $\mathrm{V}_{\mathrm{d} 3}$} \\
\hline & & mean & $+1 \mathrm{SE}$ & $-1 \mathrm{SE}$ & mean & $+1 \mathrm{SE}$ & $-1 \mathrm{SE}$ & mean & $+1 \mathrm{SE}$ & $-1 \mathrm{SE}$ \\
\hline Annual & $1-365$ & 2.83 & 2.49 & 3.38 & 4.95 & 7.49 & 3.17 & 9.57 & 9.57 & 9.57 \\
Wet season & $142-365$ & 1.68 & 1.47 & 1.99 & 2.91 & 4.40 & 1.87 & 5.59 & 5.59 & 5.59 \\
Dry season & $1-141$ & 1.16 & 1.03 & 1.38 & 2.04 & 3.10 & 1.30 & 3.98 & 3.98 & 3.98 \\
\hline
\end{tabular}



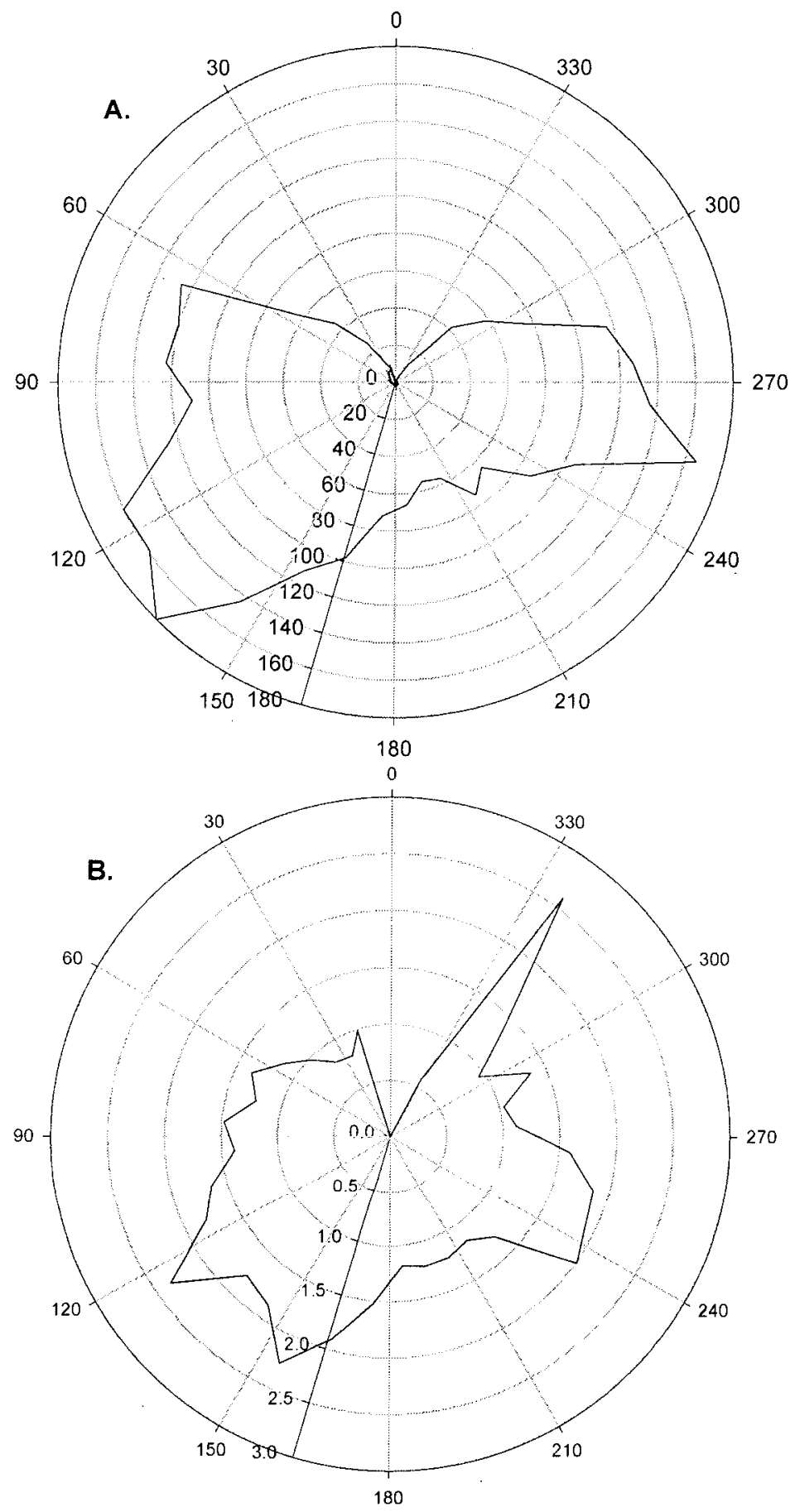

Figure 1. Relationship between wind direction and $A$ ) frequency distribution (number of 30-min periods), and B) u $\sigma \mathrm{u}-1$ during November to December 1998 from La Selva, Costa Rica. 


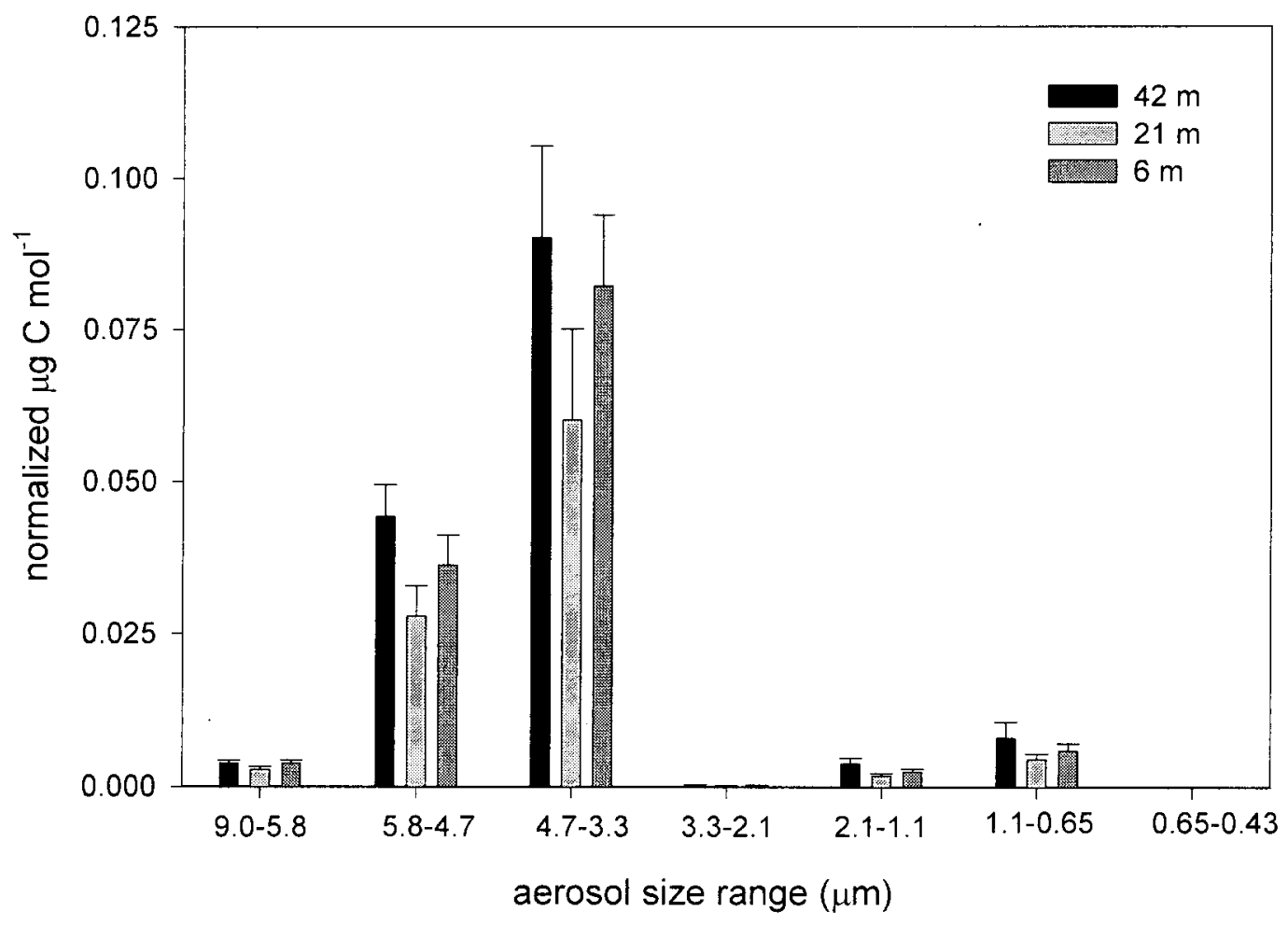

Figure 2. Speciation of aerosol size at different canopy heigths. Data are mean (+1 SE). The range in aerosol size for stages 1-7 are, 9.0 - 5.8, 5.8 - 4.7, 4.7 - 3.3, $3.3-2.1,2.1-1.1,1.1-0.65,0.65-0.43 \mu \mathrm{m}$, respecitvely. 


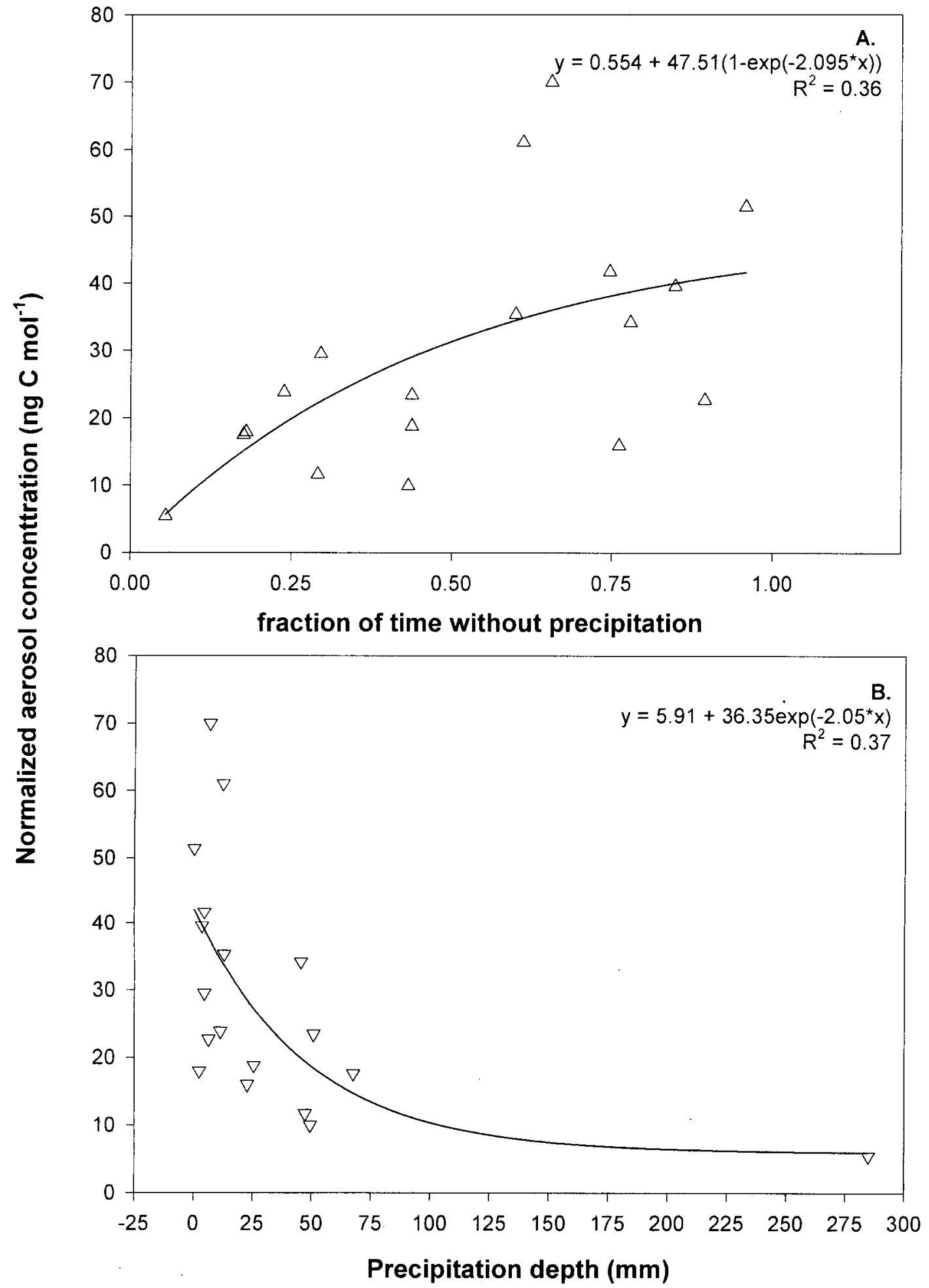

Figure 3 . The relationship between normalize aerosol concentration and $A$ ) fraction of time sampled without rain, i.e., atmospheric loading, and B) the amount of aerosol removal by precipitation. 
became weakly unstable ( $\mathrm{L} \sim-125 \mathrm{~m}$ Figure $4 \mathrm{~A}$ ). After $1400 \mathrm{~h}$, the $\mathrm{L}$ sharply increased, and the boundary-layer became weakly stable $(\sim 100 \mathrm{~m})$ at $1600 \mathrm{~h}$, but then returned to neutral conditions by nightfall.

All conductances $\left(g_{a}, g_{b}\right.$ and $\left.g_{m}\right)$ followed a similar diurnal hyperbolic pattern and increased with unstable boundary layers. $\mathrm{g}_{\mathrm{a}}$ was always $>1.0 \mathrm{~mol} \mathrm{~m}^{-2} \mathrm{~s}^{-1}$ with peak conductance of $\sim 2.50 \mathrm{~mol} \mathrm{~m}^{-2} \mathrm{~s}^{-1}$ at $\sim 1130$, Figure $4 \mathrm{~B}$. During the night, both $\mathrm{g}_{\mathrm{b}}$ and $\mathrm{g}_{\mathrm{m}}$ were $\sim 0.45 \mathrm{~mol} \mathrm{~m}^{-2}$ $\mathrm{s}^{-1}$. Though mid-day peak values of $\mathrm{g}_{\mathrm{m}}$ exceeded $\mathrm{g}_{\mathrm{b}}$ by approximately $24 \%, 3.30$ and $2.50 \mathrm{~mol} \mathrm{~m}^{-}$ ${ }^{2} \mathrm{~s}^{-1}$, respectively. Afternoon decline in conductance values coincided with weakly stable and transitional boundary layers as indicated by changes in $\mathrm{L}$ at $\sim 1430$ to 1630 . The general trend was for $\lambda \mathrm{E}$ to be greater than $\mathrm{H}$ all the time, and energy fluxes were small due to excessive cloudiness, rain and low net radiation during the experimental period (Loescher unpublished data). $V_{d 3}$ rates also followed a diurnal pattern with peak rates occurring mid-day, Figure 5 . $V_{d 3}$ rates were greatest for the three smallest fractions, $0.65-2.1 \mu \mathrm{m}$, with values $\sim 2.34 \mathrm{~mol} \mathrm{~m}^{-2} \mathrm{~s}^{-1}$. $\mathrm{V}_{\mathrm{d} 3}$ rates for the largest size class were the lowest, $9.0-5.8 \mu \mathrm{m}$, and ranged $\sim 1.25-0.84 \mathrm{~mol} \mathrm{~m}^{-}$ ${ }^{2} \mathrm{~s}^{-1}$.

Assuming similar aerodynamic conditions and aerosol characterization for the entire year, mean annual deposition was $\sim 2.9$ or $5.0 \mathrm{Kg} \mathrm{ha}^{-1} \mathrm{y}^{-1}$, dependent on whether $\mathrm{g}_{\mathrm{b}}$ or $\mathrm{g}_{\mathrm{m}}$ was used, respectively, Table 1. In attempt to assess the errors in annual deposition rates, estimates were recalculated using $\pm 1 \mathrm{SE}$ for $\mathrm{g}_{\mathrm{a}}, \mathrm{g}_{\mathrm{b}}$ and $\mathrm{g}_{\mathrm{m}}$, Table 1 . There were less apparent variability in estimates using $g_{a}$ and $g_{b}$, than those using $g_{a}$ and $g_{m}$. Deposition utilizing the more traditional method of assessing velocity deposition, i.e., eq $3 \mathrm{~b}$, was $9.6 \mathrm{Kg} \mathrm{ha}^{-1} \mathrm{y}^{-1}$.

\section{Discussion}

\section{Carbon Concentrations}

We assumed that oceanic air mass was relatively free of carbon compounds, and that the majority of carbon was transported from the $\sim 80 \mathrm{~km}$ of flat coastal landscape east to the shoreline. There were little or no industrial sources of black carbon (e.g., from fossil fuels) other than transportation. This land area however, does contain fragmented forests, agriculture, and abandoned fields typical of a rapidly colonized tropical landscape (Ko et al. 1998, Pontius et al. 2001). Sources of aerosol carbon include year-round agricultural, land clearing, and urban garbage fires, and are major sources in the rural tropics (Yamasoe et al. 2000). This seems particularly the case in this area of Costa Rica. The frequency of biomass burning can increase four-fold from the end of the dry season to the onset of the wet season (April to June, Cooke and Wilson 1996, Liousse et al. 1996). Moreover, there seems to be a positive feedback between tropical fires from agriculture, land use change and forests and the warm-phase of the El Niño Southern Oscillation (Laurance and Williamson 2001).

Since re-suspension of aerosols creates particulates $<1.0 \mathrm{~mm}$ and subject to Brownian motion, and that size distribution did not differ throughout the measurement profile, suggests a well-mixed column of air and that the source of aerosols were imported from surrounding land use types. Mean concentrations at zero-plane displacement height $(21 \mathrm{~m})$ were lower for all particulate sizes than those measured from the other two heights (even though no significant difference was found among heights). This suggests a small and unquantified sink at this height - the height at which momentum is $\sim 0 \mathrm{~m} \mathrm{~s}^{-1}$. This potential sink has ecological importance for the transport and deposition of pollen and spores, and may be more apparent during the pulse of plant reproduction at the end of the dry season (Newstrom et al. 1994). Moreover, deleterious effects from aerosol carbon on plant function may incur additional 

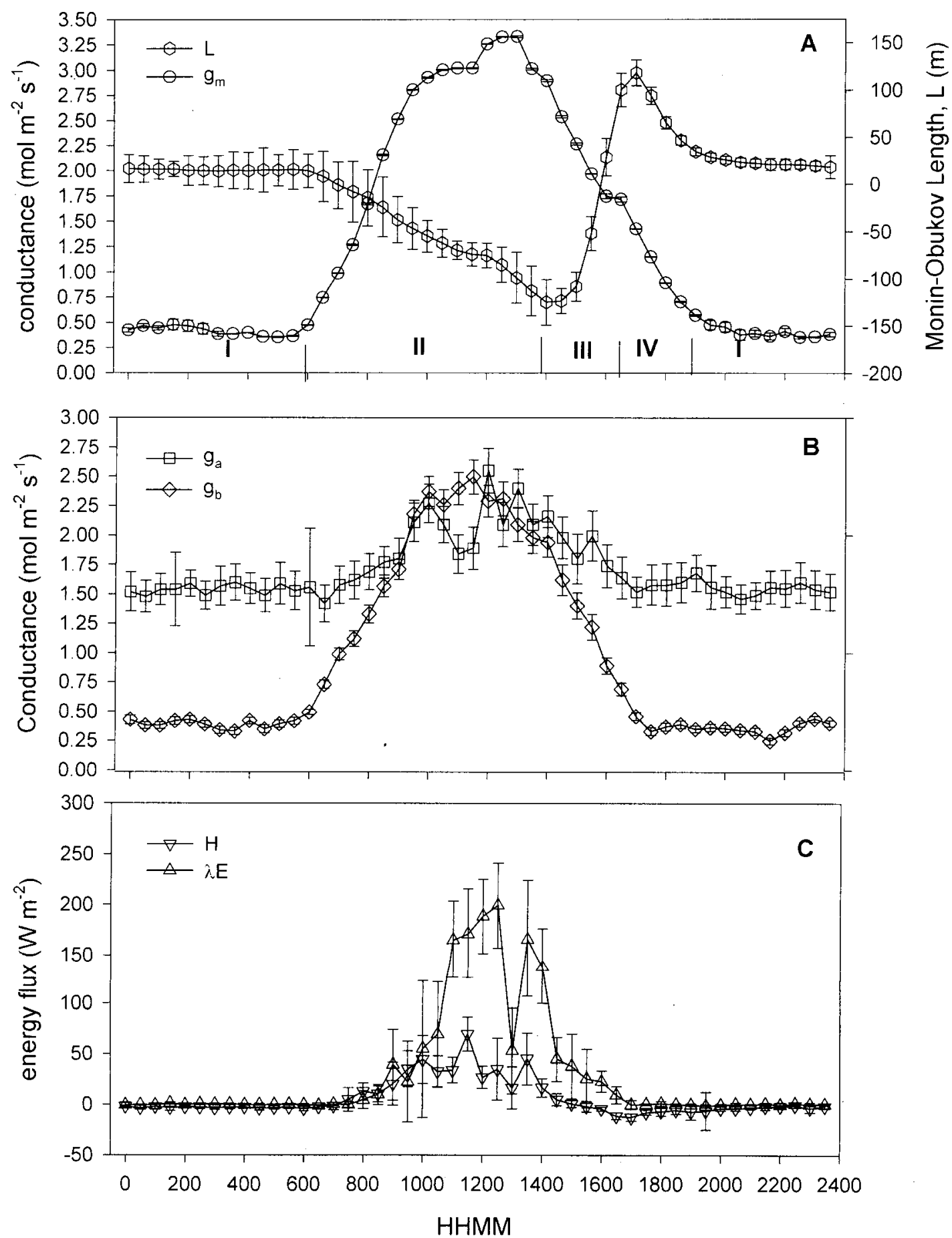

Figure 4. The relationship between A) Monin-Obukov length and canopy conductance due to momentum transfer, $g_{m}, B$ ) aerodynamic, $g_{a}$, and bulk canopy conductance, $g_{b}$, , and C) energy fluxes to time of day. Intervals I, II, III, and IVindicate neutral, weakly unstable, unstable, and weakly stable boundary conditions, respectively. Data are from November 26 to December 28, 1998, and values are median +/- 1 SE 
maintenance and growth costs at the canopy-level (Smith and Jones 2000), particularly for the large mass of epiphytic plants found in this forest (Wolterbeek 2002).

The use of $\sim 24 \mathrm{~h}$ integration times and large precipitation events enabled the determination of loading- and removal of aerosols in the atmospheric environment. A first-order regression could be determined, but it is assumed that these processes have a non-normal distribution (e.g., Wu et al., 1992) and the use of an exponential function is more appropriate (Penner et al. 1993, Wu et al. 1992). We expect that the source and sink relationships differ during the dry season due to additional particulate loading of the atmosphere by seasonal burns in the source area and the lack of precipitation. Further investigation is needed to assess seasonal aerosol source and sink functions to the atmosphere, and their associated errors.

Concentrations of carbon aerosols reported here are as much as 2-orders of magnitude higher than other estimates for Costa Rica, Table 2. Conversely, Cooke and Wilson (1996) found measured concentrations at remote sites to be lower than model estimates. The higher observed concentrations reported here was assumed to be due, in part, to the collection of aerosols in the air mass as it moves from the Caribbean Sea inward. Concentrations of carbon aerosols reported from originating over oceanic air masses incident with northern Ireland (Jennings et al. 1993) were similar as those reported for Costa Rica by Cooke and Wilson 1996 (Table 2), and were of the same magnitude as concentrations found in isolated artic and alpine regions, i.e., $<0.1 \mu \mathrm{g} \mathrm{C}$ $\mathrm{m}^{-3}$ (Lavanchy et al. 1999, Barrie 1986). The range of concentrations found in highly urbanized areas span those found at La Selva, Table 2.

Disagreement between concentration estimates found here and those reported elsewhere can be partially accounted for by the coarse grid scale of models, which likely does not fully account for the spatial heterogeneity in source and sink strengths at ecologically relevant scales. In this case, the use of coarse grid-scales i) averages areas with lower aerosol concentrations (e.g., over the Caribbean Sea), ii) inadequately models precipitation patterns, iii) can not describe the temporal and spatial nature of human decisions to burn biomass, and iv) can not effectively characterizing circulations at the confluence at the two Hadley Cells (i.e., ITCZ), thereby falling short in properly estimating any non-linear physical or ecological function. For example, determining the day-to-day magnitude of heating or cooling of the atmosphere by black- and organic carbon fractions.

Sources of uncertainties between modeled concentration estimates and those reported here are likely to occur elsewhere in tropical. Errors in modeled estimates have been reported to be approximately \pm 3 times (e.g., Wilson and Cooke 1996), however the overall precision and accuracy in model estimates are likely to be lower in the tropics because of less available information on the temporal and spatial variation in the burning of biomass. The lack of information is particularly true in regions were rapid land use change, forest conversion and other rural agronomic practices are occurring.

\section{Deposition}

Both the bulk canopy $\left(\mathrm{g}_{\mathrm{b}}\right)$ and momentum conductance $\left(\mathrm{g}_{\mathrm{m}}\right)$ followed similar diurnal trends. The logarithmic functions expressed in eq. 4 are inherent in $\mathrm{u}^{*}$. Because of large rain events, $>90 \%$ relative humidity, and low $\mathrm{H}$, the right-hand term in eq. 8 is minimized, and the left-hand term is dominated by $g_{\mathrm{a}}$. Many other studies relate bulk canopy conductance to physiological function, for example, scaled stomatal and boundary layer conductance, and scaled sap-flow. Because the response in $g_{b}$ to microclimate variables $\left(g, u^{*}, H, \lambda E, \rho\right.$, and $\left.D\right)$ embody similar bulk transfer terms as those expressed in eq. $3 \mathrm{~b}$, we argue that not all $\mathrm{g}_{\mathrm{b}}$ is related to physiological function, but to other physical and structural elements in the canopy environment 
Table 2. Reported concentrations of carbonaceous aerosols.

\begin{tabular}{|c|c|c|c|}
\hline Study & Location & $\mu \mathrm{g} \mathrm{C} \mathrm{m^{-3 }}$ & $\mathrm{kg} \mathrm{km}^{-2} \mathrm{y}^{-1}$ \\
\hline This Study & Sarapique, Costa Rica & $6.28^{\mathrm{a}}, 24.97 \pm 12.57^{\mathrm{b}}$ & $2.9^{h}, 5.0^{1}, 9.6^{\prime}$ \\
\hline \multirow[t]{2}{*}{ Moraes et al. $2003^{\mathrm{c}}$} & $\begin{array}{l}\text { Caminho do mar, } \\
\text { Cubatao, Brazil }\end{array}$ & $3.20-4.60$ & \\
\hline & $\begin{array}{l}\text { Mogi valley, } \\
\text { Cubatao, Brazil }\end{array}$ & $66.00-114.00$ & \\
\hline Cooke and Wilson $1996^{\mathrm{de}}$ & Costa Rica & $0.10-0.50$ & \\
\hline Liousse et al. $1996^{\mathrm{df}}$ & Costa Rica & $1.00-1.50$ & $1.0-12.0$ \\
\hline \multirow[t]{2}{*}{ Penner et al. $1993^{\mathrm{dg}}$} & Costa Rica & $0.05-0.20$ & \\
\hline & Oki Islands, Japan & $0.446-0.933$ & \\
\hline \multirow[t]{2}{*}{ Penner et al. 1993} & Abastumani, Georgia & $0.71-1.03$ & \\
\hline & Ljubljana, Yugoslavia & $20.00-90.00$ & \\
\hline Jennings et al. $1993^{\mathrm{c}}$ & Mace Head, Ireland & $0.04-0.29$ & \\
\hline Andreae et al. $1984^{c}$ & Manaus, Brazil & $0.33-0.60$ & \\
\hline
\end{tabular}

${ }^{a}$ sum of measured samples

$\mathrm{b}_{\text {annual mean }} \pm 1 \mathrm{SD}$ derived from source-sink functions found in Figure 3

cempirically measured

destimated by an emission inventory coupled with a numerical model

${ }^{\mathrm{e}}$ spatial resolution is $1^{\circ} \times 1^{\circ}$ spatial grid

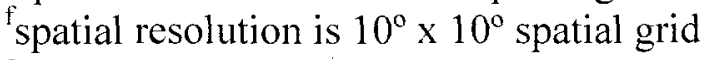

${ }^{\mathrm{g}}$ spatial resolution is $350^{\circ} \mathrm{km} \mathrm{x} 350^{\circ} \mathrm{km}$

h calculated using $\mathrm{V}_{\mathrm{d} 1}$

'calculated using $\mathrm{V}_{\mathrm{d}}$

${ }^{j}$ calculated using $V_{d} 3$ 


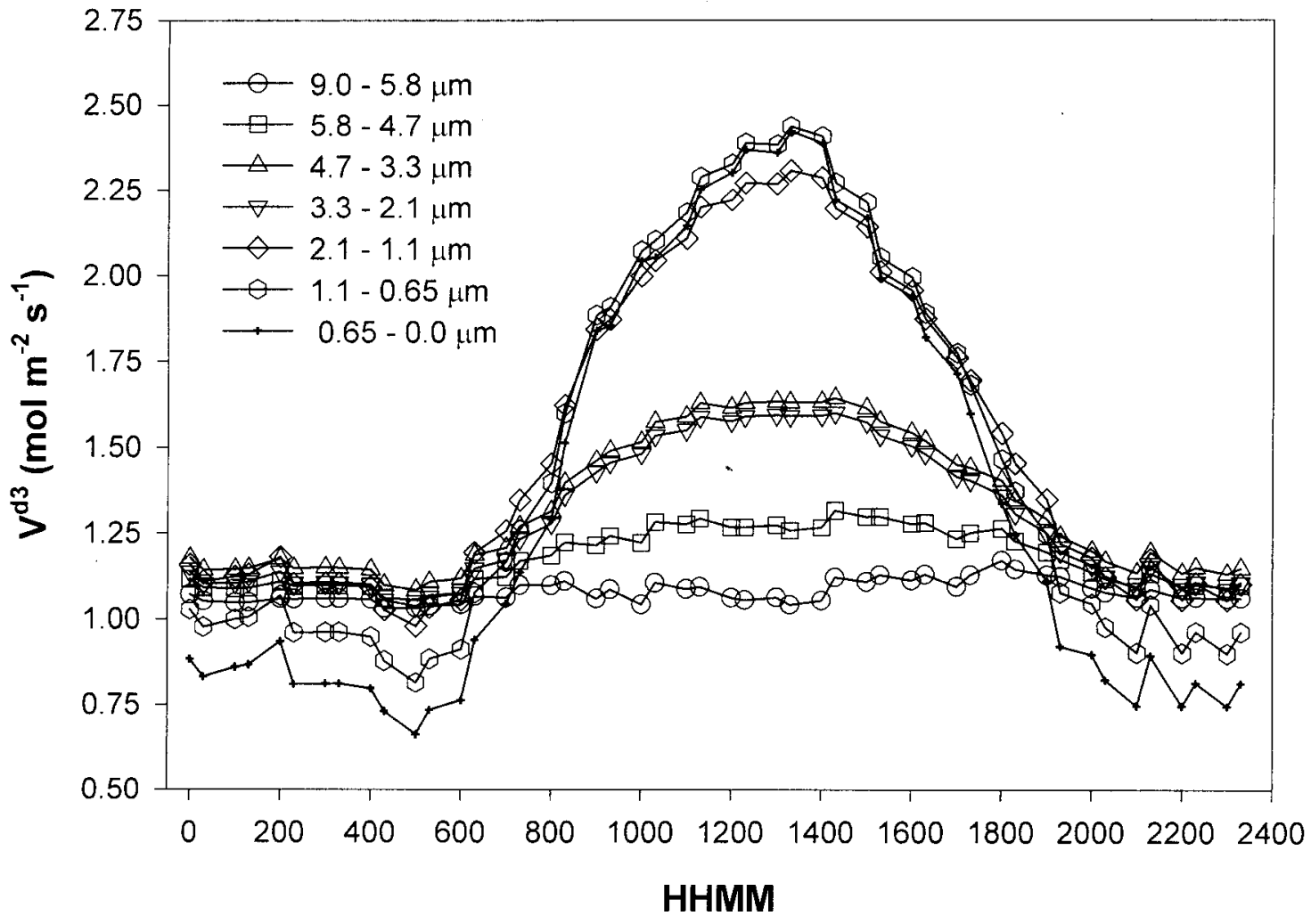

Figure 5. Diurnal traces of velocity deposition calculated by Eq. $3 \mathrm{~b}$ for each of the aerosol size classes. Data were from January 1 - December 31 , 1998. Values were mean with $\mathrm{SE}<0.013 \mathrm{~mol} \mathrm{~m}^{-2} \mathrm{~s}^{-1}$. 
that can affect aerosol deposition. Here, we suggest that the use of $g_{b}$ in estimating above the canopy deposition may provide useful insight because, i) the turbulent mixing length (K-theory) for all homogenously mixed scalars are assumed to are similar, if not related, ii) boundary conditions for particulate deposition is a function of $g, u^{*}, H, \lambda E, \rho$ and $D$, and iii) new studies are showing that $g_{b}$ estimated by sap flow cannot account for all of the bulk canopy conductance-i.e., not all of the conductance is attributed to physiological function (Kurpius and Goldstein 2003). The ensemble effect of $g_{b}$ on deposition is not known, and interpretation of deposition estimates presented here should reflect this uncertainty.

Other reported values of $\mathrm{V}_{\mathrm{d} 3}$ range $0.42-0.84 \mathrm{~mol} \mathrm{~m}^{-2} \mathrm{~s}^{-1}$ in unstable atmospheres and over vegetative canopies with short roughness lengths (Hicks et al. 1982, Sievering 1982, Sievering 1987, Hicks et al. 1989, Gallagher et al. 1997). Estimates of $\mathrm{V}_{\mathrm{d} 3}$ reported here are $\sim 2$ - 3 times higher, due to high roughness elements ( $>2.0 \mathrm{~m}$, Loescher et al. 2003) and high windspeeds. Zhang et al. (2001) also estimated that velocity deposition (calculated similarly to eq. $3 \mathrm{~b}$ ) increased exponentially with increases in roughness and windspeed, and can exceed 2.4 mol m${ }^{-2} \mathrm{~s}-1$. The canopy at La Selva is particularly aerodynamically rough because of numerous emergent trees exceeding $40 \mathrm{~m}$ and high gap density.

Differences between deposition rates estimated by $V_{d 1}$ and $V_{d 2}$ were not significantly different, even though mean estimates differed by $\sim 2.1 \mathrm{~kg} \mathrm{ha}^{-1} \mathrm{y}^{-1}$, Table 1 . The higher estimate of deposition is likely due in part by the $\sim 24 \%$ greater estimate of mid-day values of $g_{m}$ than those using $g_{b}$.

All three of the annual deposition estimates found here are within reported model results (Liousse et al. 1996). Liousse et al. (1996) used a fixed conductance value (derived similarly to $\mathrm{V}_{\mathrm{d} 3}$ ) and function to describe precipitation scavenging and linked their deposition model with a numerical global climate model to estimate $\sim 1.2-12 \mathrm{~kg} \mathrm{ha}^{-1} \mathrm{y}^{-1}$ dry carbon deposition to Costa Rica. Our annual estimates and those reported by Liousse et al. (1996) are likely low for several reasons. First, all model estimates were parameterized with data from the wet season and the dry season dynamics were not properly characterized. Aerosol concentrations in the dry season are likely to be orders of magnitude greater because of the large increase in fire frequency, and the decrease in precipitation thus reducing the amount of scavenging in the atmosphere. Second, the range of aerosols used in Liousse et al. (1996) was a magnitude greater than those reported here, $0-50.0$ and $0-9.0 \mu \mathrm{m}$, respectively. Including aerosol concentrations in the larger size classes $(>9.0 \mu \mathrm{m})$ would increase our dry deposition estimates. Third, model estimates may not adequately estimate surface roughness characteristics resulting in underestimating velocity deposition. Lastly, the large range in Liousse et al. (1996) estimates may be due in part to large spatial integration. The $10^{\circ} \times 10^{\circ}$ grid size may be appropriate for developing regional-to-global deposition budgets, but lacks the resolution for specific ecosystem-level studies, e.g., effects on net primary productivity (NPP), though the range in dry deposition from the Carribean coast to the Central Corridea may be within the order of magnitude reported by Liousse et al. (1996).

The $g_{a}, g_{b}$, and $g_{m}$ at La Selva are likely to be equal in forests along the eastern side of the Central American Corridea and other tropical forests because of similar physical canopy characteristics and patterns in diurnal windspeeds. The magnitude of deposition and $\mathrm{V}_{\mathrm{d} 3}$ estimates at La Selva are due, in part, to high rates of atmospheric loading. This is particularly significant considering the current increases in land use change and source areas in tropical forests. At La Selva, the central mountain system restricts circulations traveling east to west. While regional orographic effects would likely influence deposition in different tropical forests, and re-suspension likely contributes to both changes in size distribution and deposition during the 
Table 3. Reported values of aerodynamic $\left(g_{a}\right)$ and bulk canopy conductance $\left(g_{b}\right)$ from several tropical forests, values are $\mathrm{mol} \mathrm{m} \mathrm{m}^{-2}$

\begin{tabular}{llcc}
\hline \multicolumn{1}{c}{ Study } & \multicolumn{1}{c}{ Location } & $\mathbf{g}_{\mathbf{a}}$ & $\mathbf{g}_{\mathbf{b}}$ \\
\hline This study & La Selva, Costa Rica & $\sim 1.40-2.60$ & $\sim 0.35-2.5$ \\
Loescher et al. in press & La Selva, Costa Rica & $\sim 1.40-2.60$ & $\sim 0.35-3.0$ \\
Malhi et al. 2002 & Ducke Forest, Manaus, Brazil & NR & $0-1.75$ \\
Bigelow 2001 & La Selva, Costa Rica & $1.4-3.0^{\S}$ & $0.2-0.98^{\S}$ \\
Wright et al. 1996 & Ji-Parana Forest, Rondonia, Brazil & NR & $0.129-2.47^{\dagger}$ \\
& Fezenda pasture, Manaus, Brazil & NR & $0.126-1.26$ \\
Grace et al. 1995 & Rondonia, Brazil & $0-4.0$ & $0.4-1.0$ \\
Gash and Shuttleworth 1991 & Ducke Forest, Manaus, Brazil & $0-0.522^{\dagger}$ & $4.17^{\dagger}$ \\
Roberts et al. 1990 & Ducke Forest, Manaus, Brazil & NR & $1.20-1.60^{\dagger}$ \\
Calder et al. 1986 & Java & $4.0-10.0$ & 0.34 \\
Shuttleworth et al. 1984 & Ducke Forest, Manaus, Brazil & $0.522^{\dagger}$ & $0.194-0.321^{\dagger}$ \\
\hline
\end{tabular}

NR, not reported

reported in resistance units $\left(\mathrm{T} \mathrm{L}^{-1}\right)$, conversion into conductance units assumed a molar volume of $0.02398 \mathrm{~m}^{3} \mathrm{~mol}^{-1}$.

$\$_{\text {scaled from leaf-level measurements }}$ 
dry season when litter can dry out. Therefore, actual deposition rates are likely higher than those estimated here when taking into account the increased burning during the dry season, different seasonal rates of aerosol loading to- and removal from the atmosphere, increases in land use change, and macro-level changes in general atmospheric circulations (e.g., ENSO).

Despite the high precipitation, high concentrations of carbonaceous aerosols were found over a wet tropical forest in Costa Rica. Other studies found lower concentrations from a wider range of size classes. Dry deposition estimated by velocities that were analogous to the transfer of gaseous and energy scalars $\left(V_{d_{1}}\right.$ and $\left.V_{d 2}\right)$ were $1 / 3$ to $1 / 2$ lower than those estimates accounting for gravitation, diffusion, impaction and interception $\left(V_{d 3}\right)$. Similar velocity deposition estimates (i.e., $V_{\mathrm{d} 3}$ ) from other studies were lower than those found here, likely due to not fully characterizing roughness effects. Annual dry deposition estimates found here were underestimated because increases in biomass burning -- and estimating atmospheric source-sink status of aerosols during the dry season could not be determined. Other modeled dry deposition estimates were likely also underestimated because they too were parameterized during the wet season and their velocity deposition estimates were low for these tropical forests. Modeled estimates also lack the spatial and temporal resolution to assess the effects of carbonaceous aerosols on productivity and boundary-layer dynamics at ecologically relevant scales.

An aerosol $<1 \mu \mathrm{m}$ in diameter in air can be transported by the flow of gas molecules surrounding it and its motion can be considered by gas kinetics, not violating any assumptions associated with $\mathrm{V}_{\mathrm{d} 1}$ and $\mathrm{V}_{\mathrm{d} 2}$, i.e., respond to micro-scale turbulent eddies (Baron and Willeke 1993, Williams and Loyalka 1991). Transport of larger aerosols is also influenced by turbulence diffusion, but if the aerosols' velocity decelerates by collision with other particles or by gravity (i.e., drag forces); impaction, interception and gravitational settling become important. The transition between exclusively gaseous transfer and deceleration by collision and gravity is the slip flow. There are no clear demarcations of when aerosols enter slip flow, though larger aerosol size and greater density contribute to slip. Estimating the movement of larger particles in air (continuum regime) can be estimated by either gas kinetics or numerical integration of momentum equations, i.e., $\mathrm{V}_{\mathrm{d} 3}$ (Baron and Willeke 1993, Williams and Loyalka 1991). Friedlander (1997) and Lewellen (1985) suggest slip can occur in the diameter range $1-5 \mu \mathrm{m}$, and a density $\sim 1 \mathrm{~g} \mathrm{~cm}^{-3}$, as is the case with carbon. The deposition using $V_{\mathrm{d} 3}$ for aerosols $<4.4$ $\mu \mathrm{m}$ in diameter was $6.75 \mathrm{~kg} \mathrm{ha}^{-1} \mathrm{y}^{-1}$, still $\sim 2-3 \mathrm{x}$ higher than those using $\mathrm{V}_{\mathrm{d} 1}$ and $\mathrm{V}_{\mathrm{d} 2}$ estimated with aerosols in the same size range. Of course this should be viewed qualitatively since $V_{\mathrm{d} 1}$ and $\mathrm{V}_{\mathrm{d} 2}$ estimates are contingent on the distribution and density of aerosols in air. Hence, if the aerosol size distribution and $\mathrm{V}_{\mathrm{d} 1}$ or $\mathrm{V}_{\mathrm{d} 2}$ are known (as is the case with numerous ecophysiological studies, e.g., Bigelow 2001), deposition can be estimated that includes the fraction of aerosols subject to drag forces. 


\section{WHOLE TREE RESPONSES TO CLIMATE VARIATION}

\section{Introduction}

\section{V.1. Sap flow response}

Tropical rainforests are renowned for their high tree species diversity. The diversity of these trees is reflected in their varying life histories, architecture, morphology and physiology, which in turn combine to create a complex forest structure. How these complex characteristics interact to impact whole-tree physiological function is just beginning to be understood. The regulation of transpiration in rainforest trees might be expected to vary strongly among species due to both differences in physiological responses and morphology such as crown architecture, leaf size and shape, among other characteristics. However, Meinzer, Goldstein \& Andrade (2001) and Andrade et al. (1998) showed that in some species, variation in transpiration was governed largely by tree size and hydraulic architecture rather than species-specific physiological differences when measurements were scaled to the level of an entire tree. Nevertheless, the potential variation in physiological responses in trees of the same size could be large. Knowledge of the magnitude of any differences among species responses is necessary before individual tree measurements can be scaled up to the stand level. Accurate estimates of stand level transpiration therefore depend on understanding the source of the majority of variation in transpiration estimates.

Climatic variables that may influence sap flow include radiation, vapor pressure deficit (VPD), soil moisture, rainfall, temperature, wind speed, and leaf wetness. Fetcher, Oberbauer \& Chazden (1994) found VPD greater than one kPa reduced stomatal conductance in Pentaclethra macroloba in Costa Rican rainforests. Meinzer et al. (1993, 1995) and Granier, Huc \& Colin (1992) showed that sap flow of several tree species decreased under conditions of high VPD. Periodic soil moisture limitation might be an important force driving yearly variation of productivity in tropical rainforests and has been shown to limit transpiration in other forests (Granier 1987). Smith \& McClean (1989) showed that wet leaves drastically reduced photosynthesis. Frequent heavy rainfall is characteristic of wet tropical forests and water films on leaves inhibit diffusion of gases in and out of stomata. Wind disrupts the canopy boundary layer, increasing coupling to the bulk atmosphere and boundary layer conductance and dries wet leaves (Jarvis \& McNaughton 1986, Meinzer \& Andrade 1997). These multiple environmental factors have complex interactions with each other and with leaves, crowns and forest canopies. In addition, many of the meteorological variables that affect transpiration rates are typically highly correlated with one another. Some also can interact to have opposite effects on tree physiology. For example, VPD and irradiance often co-vary but have opposite effects on stomatal aperture. Many physical principles and mechanisms driving transpiration at the leaf and crown level are well understood, especially those focusing on the influences of VPD, and irradiance, and more recently hydraulic architecture (Williams et al. 2001). The interaction among these factors with other variables such as leaf wetness, soil moisture and soil temperature and a complicated crown environment are less well understood and are less easy to model physically. Because the integrated impact of multiple variables is what actually drives sap flux responses at the whole tree level, exploiting the underlying structure of covarying weather data to predict whole tree sap flux responses could be an effective approach especially for comparing species specific responses,. Principal Components Analysis (PCA), is often used to detect and interpret underlying structure in multiple covarying variables. Furthermore, PCA reduces the dimensionality of a dataset; a correlated set of data are condensed into a few composite variables that retain most of the information found in the original variables. These factors are independent, eliminating covariance 
among the environmental variables. Just as whole-tree sap flow measurements integrate the many internal factors regulating a tree's transpiration rate, the PCA derived factors are a synthetic representation of the external environmental variables driving transpiration.

Our goals in this study were to develop and test a simple model to predict whole tree water use using a synthetic environmental variable, to contrast the sap flow responses to environmental variables of several tropical tree species, and to explore how different morphological and ecological traits might affect whole-tree water use. We examined the variance in the model coefficients to estimate the magnitude of species specific sap flow responses and tested the efficacy of a single general model versus several species specific models.

\section{Methods}

Climate and Species

We conducted the study at the La Selva Biological Station in northeastern Costa Rica. The site is in an old growth, low elevation $(\sim 35 \mathrm{~m})$ tropical wet evergreen forest. La Selva receives an average of $4414 \mathrm{~mm}$ of rain annually, without a marked dry season (Figure 1). Similarly, monthly temperature variation is minimal.

We focused on ten species with diverse life histories ranging from pioneers to giant emergent trees. These ten species are representatives of four functional groups and show a wide range of morphological and life history traits (Clark \& Clark 1992). The leaf morphology, wood anatomy and growth rates vary among the species, as do leaf and reproductive phenology and tree longevity (Clark \& Clark 1999, Frankie, Baker \& Opler 1974). A summary of the range in traits likely to influence whole tree water use are found in Table 1 . These ten species constitute a large proportion of the forest biomass; one of the species, $P$. macroloba represents $40 \%$ of the timber volume at La Selva (King 1996). With the exception of P. macroloba, which they did not include in their study, all of our study trees were a subset of individuals sampled yearly by Clark \& Clark (1994). We randomly selected four or more individuals of each species with the criteria that the trees had a well-illuminated crown and a stem diameter above buttresses between 30 to $60 \mathrm{~cm}$. Clark \& Clark (1999) showed that the fastest growing individuals occur in this size class, with the exception of $C$. obtusifolia (which grows fastest at a slightly smaller diameter). Measuring sap flow in rapidly growing individuals enabled us to better detect tree responses to weather conditions.

\section{Environmental Variables}

We measured the following micrometeorological parameters on top of a $30 \mathrm{~m}$ antenna mast located in the old-growth forest: solar irradiance (silicon pyranometer, Li-200X, LI-COR Inc, Lincoln, Nebraska, USA), rainfall (TE 525, Texas Electronics, Dallas, Texas, USA), wind speed and direction (RM Young Wind Sentry, Traverse City, Michigan, USA), leaf wetness (247 wetness sensing grid, Campbell Scientific Inc., Logan Utah, USA), air temperature and relative humidity (CS500 probe, Campbell Scientific Inc.). We also measured volumetric soil moisture in the top $30 \mathrm{~cm}$ of soil (CS615 probe, Campbell Scientific Inc.) and soil temperature at $15 \mathrm{~cm}$ using a type-T thermocouple at the tower base. Atmospheric pressure (CS105 barometric pressure sensor, Campbell Scientific Inc.) was measured at a duplicate weather station on top of a $42 \mathrm{~m}$ tower located $\sim 1 \mathrm{~km}$ away. Missing data from the antenna mast were replaced with readings taken from the $42 \mathrm{~m}$ tower. At both stations, a Campbell CR10 datalogger read the sensors every $30 \mathrm{~s}$ and stored 30-min averages. We calculated vapor pressure deficit using the half hour averages of temperature and relative humidity after Campbell and Norman (1998). We synchronized all the datalogger clocks to Central Standard Time. 
Figure 1. The climate diagram of La Selva after Walter (1985). The diagram highlights the minor

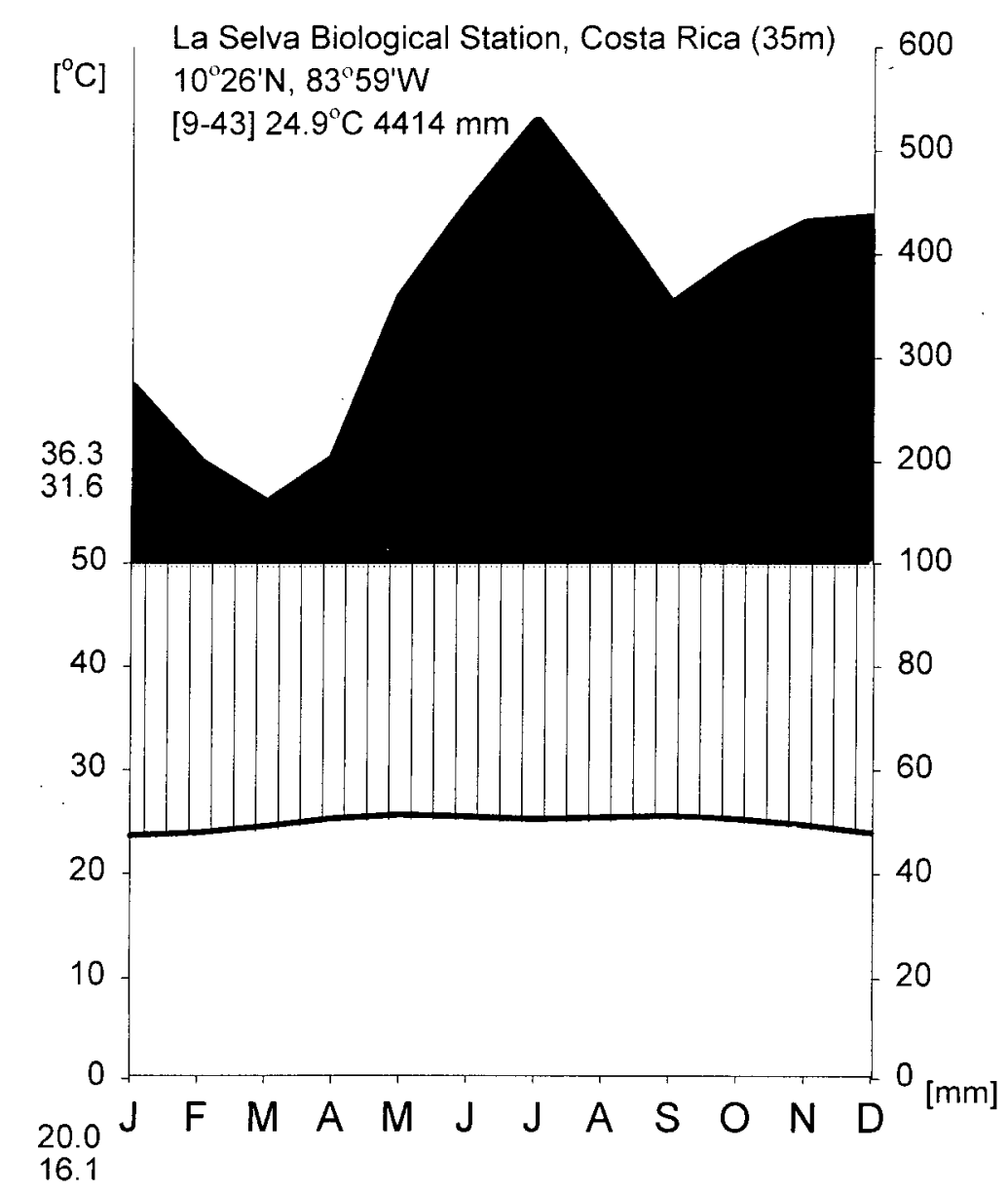

annual temperature variation and extremely wet climate of La Selva. Walter (1985) suggested that overlaid plots of rainfall and temperature with y-axes where $2 \mathrm{~mm}$ of rain equals 1 degree $\mathrm{C}$, gave an indication of potential plant water status through time at a site. The resulting plot should be shaded according to the following rules: when the rainfall line dips below the temperature line, stippled fill between the rainfall and temperature lines indicates a water deficit (not shown), the vertical bars indicate humid conditions where moisture stress is limited, and black fill indicates perhumid conditions, where there is a surplus of water. Throughout the year, monthly averages indicate perhumid conditions prevail at La Selva. 
Table 1. The tree taxa and sample size of individuals studied. Letters in the leaves column refer to simple (S) and compound (C), capital letters indicate leaves or leaflets longer than $5 \mathrm{~cm}$, lower case indicates leaves or leaflets $<5 \mathrm{~cm}$ long. The letters in the functional group column refer to the life history categories of Clark and Clark (1992).

\begin{tabular}{l} 
Family \\
\hline Cecropiaceae \\
Euphorbiaceae \\
Fabaceae
\end{tabular}

Lecythidaceae Olacaceae

Simaroubaceae
Species

Cecropia insignis Liebm.

Cecropia obtusifolia Bertol.

Hyeronima alchorneoides Allemão

Balizia elegans (Ducke) Barneby \& J. W. Grimes

Dipteryx panamensis (Pittier) Record \& Mell

Hymenolobium mesoamericanum H. C. Lima

Pentaclethra macroloba (Willd.) Kuntze

Lecythis ampla Miers

Minquartia guianensis Aubl.

Simarouba amara Aubl.
Leaves Funct Trees Days Group

D 4

D 4

C 4

C 4

B 4

B 4

c B

36

$\begin{array}{ll}4 & 78 \\ 4 & 87\end{array}$




\section{$\underline{\text { Sap Flow Measurements }}$}

We measured sap velocity by installing a single thermal dissipation probe (TDP) consisting of a pair of $30 \mathrm{~mm}$ long needles into the tree trunks (Granier, 1987). We used both commercially manufactured probes (TDP 30, Dynamax Inc., Houston, Texas, USA) and selfmade probes of similar design. Because the trees we used were part of a long-term demographic study, we installed only one probe to minimize tree injury. We inserted the probe needles into two holes $5 \mathrm{~cm}$ apart, drilled into the trunk 1.5 to $3 \mathrm{~m}$ above the ground and any buttresses. We insulated the probes with a $15 \mathrm{~cm}$ diameter polystyrene hemisphere and sealed the probes and the hemisphere to the tree trunk with plastic modeling clay and duct tape. Although the clay around the probes might have caused some error due to heat conductance, the heavy rainfall at the site necessitated sealing the probes to minimize potentially large errors caused by water flowing down the stems and over the probes. An aluminized sheet of plastic bubble-wrap covered the probe and the tree trunk to a point $1.5 \mathrm{~m}$ below the probe. The plastic sheet reduced probe error introduced by sunlight heating the trunk (Gutierrez et al. 1994). A 36 amp-hour $6 \mathrm{~V}$ deep cycle battery coupled to a DC voltage regulator (AVRD regulator, Dynamax Inc.) set at the manufacturer recommended $3 \mathrm{~V}$, provided $0.2 \mathrm{~W}$ of power to heat the sensor and caused a maximum temperature difference of approximately $5-8{ }^{\circ} \mathrm{C}$ between the heated and unheated needles. The probes were left in place for 2 to $8 \mathrm{wk}$ from 1998-2000 and rotated among study trees. Dataloggers (Campbell 21X, CR10, and CR10X) measured the sensors every $30 \mathrm{~s}$ and stored 30-min averages of the probe temperature difference. We calculated sap flow using the function reported by Granier et al. (1992) and recommended by the probe manufacturer. This function integrates sap flow over the probe length and calculates sap flux density $\left(\mathrm{J}_{\mathrm{S}}\right)$ as $\mathrm{kg} \mathrm{H}_{2} \mathrm{O}$ $\mathrm{dm}^{-2} \mathrm{~h}^{-1}$.

TDP estimates of xylem sap velocity can show a large degree of variation depending on probe placement (Jiménez et al. 2000) and error can be introduced from probe insertion into nonconducting xylem (Clearwater et al. 1999). These errors would be superimposed on real differences in the magnitude of $\mathrm{J}_{\mathrm{S}}$ among the species. Because of the potential magnitude of these errors was unknown, we chose to focus on analyzing a standardized sap flux density (SSF) and focusing on the behavior of the $J_{\mathrm{S}}$ as measured by a single TDP. We standardized the $J_{\mathrm{S}}$ data for each tree by subtracting the mean for the entire measurement period from each 30 -minute observation and then dividing the result by the standard deviation (a z-score). This procedure resulted in all $J_{\mathrm{S}}$ measurements having a mean of 0 and a standard deviation of 1 . In cases where an negative values might preclude an analysis such as function requiring the calculation of a natural logarithm, a positive integer was added to all observations, raising the mean to that integer value and reported the value as $\mathrm{SSF}+\mathrm{X}$, where $\mathrm{X}$ represents the value of the integer.

\section{Sap Flow Models}

In order to construct the PCA based model we followed this general procedure: First, we extracted PCA factor scores from all the environmental data, reducing the number of variables to model from nine to three. Second, we generated and saved factor scores from the PCA analysis and matched these data to simultaneous sap flux observations. Finally, we applied a four parameter sigmoid function with a linear correction to predict sap flux based on the factor scores.

We used the PCA module in Statistica (1999 Edition, StatSoft Inc., Tulsa, Oklahoma, USA), to analyze the half-hour micrometeorological data we collected over February 1998 to August 2000 and described above. We applied a varimax rotation to the PCA axes and saved the factor scores. Rotating the axes maximizes the differences in loadings among axes and makes interpretation of the underlying structure easier. The factor scores are the sum of the product of 
the standardized environmental variables and their respective rotated axis factor loadings. Each half-hour observation of the environmental data had an associated factor score and could be matched to sap flux observations taken at the same time. We chose to use a four parameter sigmoid function to model the sap flux data (described in detail below). Empirically, we saw that plots of sap flux versus the factor scores showed an obvious $S$ shaped pattern. We chose a four parameter function for theoretical reasons since each parameter represented an important physiological response. These were the function extrema, where environmental factors had little effect on sap flux, the conditions where there was a linear change of sap flux in response to climatic drivers, and the influence of rainfall on leaves as a physical barrier to water vapor movement out of stomata. Furthermore, we could use the extrema of the function second derivative, where sap flux was initiated and where environmental drivers began to lose effect as points to compare among species.

\section{Sap Flux Lags and Hysteresis}

Because lags between transpiration from the crown and sap flow at the base of tree could complicate modeling of sap flux in relation to canopy microclimate, we examined plots of hysteresis between sap flux and important environmental variables to confirm the presence of lags. We also tested for differences between the timing of maximum sap flow and the environmental variables. Though lags may have been present, we assumed that any lags would be similar among species because the study trees were of similar size and height (Goldstein et al. 1998). We also analyzed integrated $J_{\mathrm{S}}$ over a 24 hour period to compare the impact of lags in modeling the $\mathrm{J}_{\mathrm{s}}$ response to environmental variables.

\section{Transpiration Estimates}

To estimate whole-tree transpiration from TDP measurements, estimates of the active sapwood area are required. Sapwood area is usually determined using a stem core sample extracted at the point of TDP insertion. In order to minimize tree damage, we chose not to determine sapwood depth directly. For two species, Minquartia guianensis and Simarouba amara, we calculated tree transpiration using sapwood area estimates from published diametersapwood relationships (Ryan et al. 1994). For these species we also estimated crown conductance $\left(g_{c}\right)$ after Meinzer \& Andrade (1997). Since we did not measure leaf temperature, we assumed leaf and air temperature were equivalent in our calculations of vapor pressure difference between leaf and air.

\section{Statistical Analyses}

We suspected that differences among species responses might be partly explained by tree canopy idiosyncrasies, therefore we analyzed the model coefficients with a multivariate analysis of covariance (MANCOVA) with SPSS (Release 10.0.5, SPSS Inc., Chicago, Illinois, USA), using liana cover, a crown area index and crown height above neighboring tree canopies as covariates. We measured liana cover by visually assessing the proportion of the crown occupied by lianas in six classes $(0 \%, 0-5 \%, 5-25 \%, 25-50 \%, 50-75 \%,>75 \%)$. We estimated crown area by measuring distance from the edge of the canopy to the trunk in four cardinal directions and then calculated the crown area as if it were an ellipse. We assigned each tree a canopy height index based on a z score calculated from FLI-MAP (fast laser imaging-mobile airborne platform) data collected in September 1997 (US National Aeronautics and Space Administration, unpublished data). The FLI-MAP canopy heights were extrapolated from a digital terrain model generated by LVIS (laser vegetation imaging sensor) data also collected in 1997 (Drake et al. 
2002, Weishampel et al. 2000). Each pixel in the FLI-MAP model represents the elevation of a $0.3 \mathrm{~m}^{2}$ area. To create the height index, we estimated the crown elevation for each individual tree by averaging the pixel values found in a $5 \mathrm{~m}$ radius circle centered on its bole, which would encompass the majority of the crown area. We then calculated the average and standard deviation of pixel values in a $75 \mathrm{~m}$ radius circle centered on the tree bole. The canopy height index, calculated as a $z$ score, indicated whether the tree was embedded in or emergent from the surrounding canopy and therefore estimated potential canopy coupling with the atmosphere. Tall trees had high index values, and trees embedded in the forest canopy had low index values. Two trees were not covered by the FLI-MAP survey; therefore we substituted the species means for these missing values.

\section{Results}

Species Characteristics

Mean values of the species bole diameter, crown area, crown height index, and liana cover differed significantly among species, although with large overlaps (Table 2, Figure 2). For bole diameter, two groups of two species differed from each other: Cecropia obtusifolia and Hyeronima alchorneoides were significantly smaller than Dipteryx panamensis and Lecythis ampla individuals, though neither species within the group differed from each other or any of the other species. Cecropia obtusifolia had a significantly smaller crown than either Dipteryx panamensis or Lecythis ampla individuals, though there were no differences among all other combinations of species. The crown height index differed among four species: Cecropia insignis and Hyeronima alchorneoides crowns were lower in the canopy than Dipteryx panamensis trees, and $C$. insignis crowns were lower than $S$. amara crowns. Liana cover did not differ among nine of the ten species; only Minquartia guianensis had significantly more liana cover than five other species.

\section{Environmental Variables}

Nearly all the weather variables were correlated to some degree (Table 3, Figure 3). Soil temperature and soil moisture were only moderately correlated with air temperature and soil temperature. Rainfall was not correlated with any variable at the half hour time scale. The factor loadings in the PCA mirrored these patterns of correlation. The first three PCA axes explained $77 \%$ of the variance in the complete data set (Table 4 ). The first axis explained $48 \%$ of the variance in the data and was positively correlated with irradiance, VPD, air temperature and wind speed and negatively correlated to relative humidity and leaf wetness. High values of axis 1 scores occurred on sunny, dry, warm, windy days, creating conditions of high evaporative demand, so we referred to this factor as the evaporative demand index (EDI, Table 5). The second axis explained an additional $18 \%$ of variance and was positively correlated to soil moisture and soil temperature, so we referred to it as the soil index. The third axis explained a further $12 \%$ of the variance and was correlated only to rainfall, so we called it the rain index.

\section{Sap Flux Density}

$\mathbf{J}_{\mathrm{S}}$ estimates varied considerably among individuals within species. Maximum sap flux ranged from 2.43 to $6.86 \mathrm{~kg} \mathrm{H}_{2} \mathrm{O} \mathrm{dm}^{-2} \mathrm{~h}^{-1}$ (Table 6). In all species, the highest sap flow occurred around noon, although timing of peak flow varied depending on weather conditions such as rainfall. The pattern of variation in sap flow closely matched the pattern of variation in the EDI, but there was little congruence among the patterns of sap flow and the soil and rain factors. 
Table 2. ANOVA results of comparison of species mean bole and crown characteristics.

Dependent Variable Type III Sum of Squares Mean Square $\quad \mathrm{F} \quad p$-value

Crown Projection

Crown Height Index

$\%$ Liana Cover

Bole Diameter

$\begin{array}{rrrr}90670.66 & 10074.52 & 3.23 & 0.01 \\ 13.16 & 1.46 & 3.86 & 0.00 \\ 16298.35 & 1810.93 & 4.15 & 0.00 \\ 1680.28 & 186.70 & 2.45 & 0.03\end{array}$


Figure 2. Plots of mean bole diameter above buttress (Plot A), crown projection (Plot B), crown height index (Plot C), and liana cover (Plot D) for all ten species. Crown projection was calculated by assuming an elliptical crown and measuring the major and minor axes. The crown height index represented the position of the tree crown relative to crown heights of neighboring trees calculated from remotely sensed data. Positive values indicated emergent trees, values close to 0 or negative indicated crowns at or below mean canopy level. Liana cover was estimated as a percentage of the total crown occupied by liana leaves. The whiskers represent one standard error of the mean. A solid line below the species abbreviations indicates the means did not differ (Tukey's HSD, $p>0.05$ ).
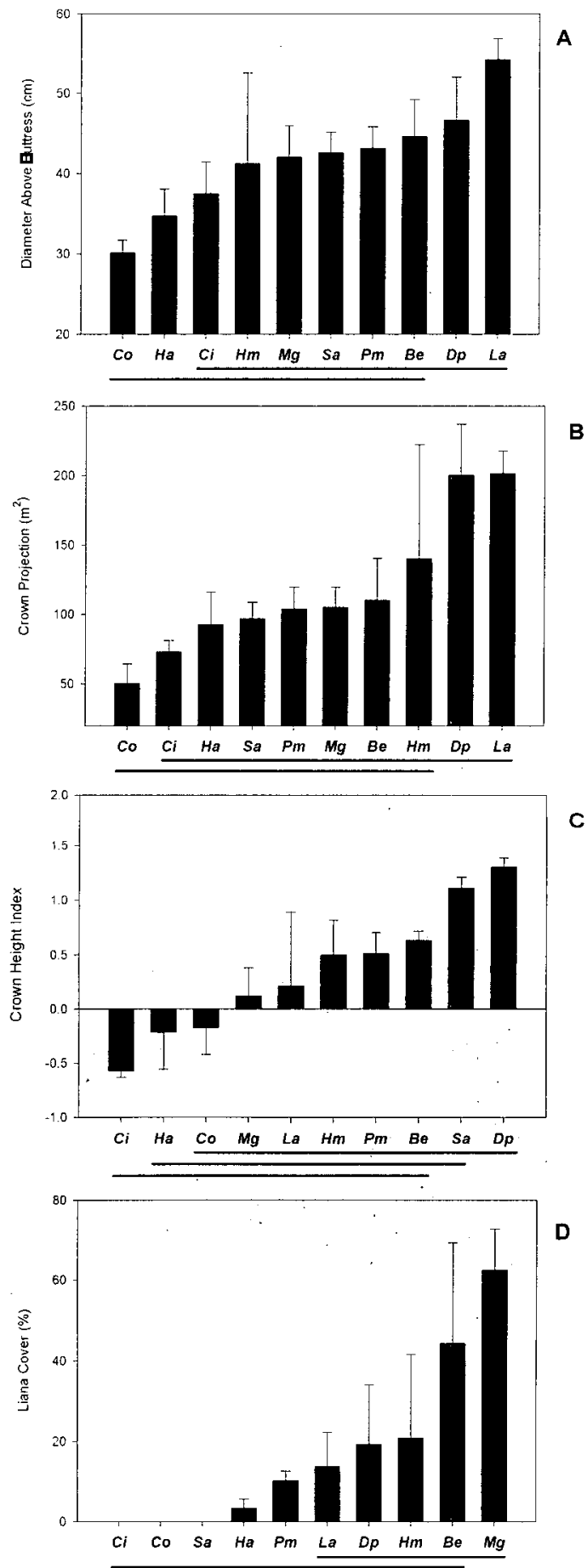
Table 3. Correlations among the half-hour averages of weather variables measured during the study period are shown below. Coefficients less than 0.2 are marked with an $x$.

\begin{tabular}{|c|c|c|c|c|c|c|c|c|}
\hline $\mathrm{N}=40500$ & Irradiance & $\begin{array}{c}\text { Air } \\
\text { Temp. }\end{array}$ & RH & VPD & $\begin{array}{c}\text { Leaf } \\
\text { Wetness }\end{array}$ & $\begin{array}{l}\text { Wind } \\
\text { Speed }\end{array}$ & Rain & $\begin{array}{c}\text { Soil } \\
\text { Moisture }\end{array}$ \\
\hline Soil Temp. & $x$ & 0.51 & $x$ & $x$ & $x$ & $x$ & $x$ & -0.42 \\
\hline Irradiance & & 0.73 & -0.76 & 0.76 & -0.37 & 0.63 & $x$ & $x$ \\
\hline Air Temp. & & & -0.85 & 0.87 & -0.48 & 0.56 & $x$ & -0.24 \\
\hline $\mathrm{RH}$ & & & & -0.99 & 0.53 & -0.65 & $x$ & $x$ \\
\hline VPD & & & & & -0.52 & 0.64 & $x$ & -0.20 \\
\hline Leaf Wetness & & & & & & -0.34 & $x$ & -0.29 \\
\hline Wind Speed & & & & & & & $x$ & $x$ \\
\hline Wind Dir. & & & & & & & $x$ & $x$ \\
\hline Rain & & & & & & & & $x$ \\
\hline
\end{tabular}


Figure 3. Mean 30 minute weather observations for air temperature, leaf wetness, VPD and irradiance over the study period (1997-2000). The high degree of correlation is evident among irradiance (open circles), air temperature (filled squares), and VPD (filled circles). Leaf wetness (open squares) was inversely correlated to each of the previously mentioned variables. Leaves are wetted by heavy dewfall, which occurred nearly nightly, and began drying approximately two hours following sunrise. The vertical dotted line represents noon.

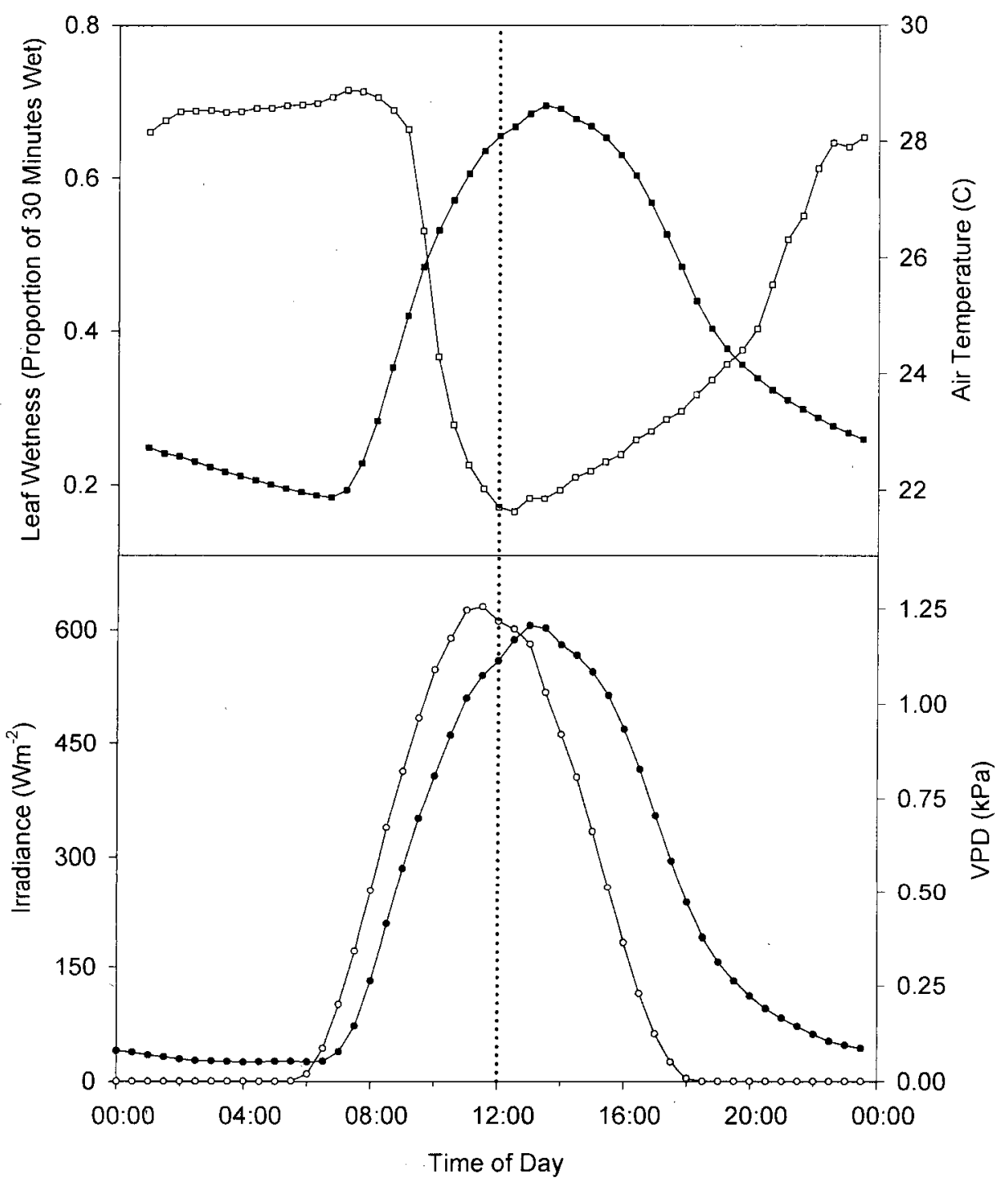


Table 4. Eigenvalues and the variance explained by the first three axes of the PCA on the weather data.

\begin{tabular}{|c|c|c|c|c|}
\hline & & $\begin{array}{l}\% \text { Total } \\
\text { Variance }\end{array}$ & Cumulative & $\begin{array}{l}\text { Cumulative } \\
\% \text { Variance }\end{array}$ \\
\hline Axis Number & Eigenvalue & Explained & Eigenvalue & Explained \\
\hline 1 & 4.32 & 48 & 4.32 & 48 \\
\hline 2 & 1.57 & 18 & 5.9 & 66 \\
\hline 3 & 1.03 & 12 & 6.93 & 77 \\
\hline
\end{tabular}

Table 5. Factor loadings of the environmental variables on the first three PCA axes are shown below. The loadings are analogous to Pearson correlation coefficients. High loadings (greater than 0.6 and underlined) were used in the interpretation and naming of the factors, the names in quotes represent our interpretation of the structure.

$\begin{array}{lccc}\text { Variable } & \text { "EDI" } & \text { "Soil" } & \text { "Rain" } \\ \text { Soil Temperature } & 0.13 & \underline{-0.81} & 0.08 \\ \text { Irradiance } & \underline{0.84} & 0.05 & 0.00 \\ \text { Air Temperature } & \underline{\underline{0.90}} & -0.34 & -0.02 \\ \text { Relative Humidity } & \underline{-0.96} & 0.05 & 0.09 \\ \text { VPD } & \underline{\underline{0.96}} & -0.09 & -0.08 \\ \text { Leaf Wetness } & \underline{-0.62} & -0.37 & 0.14 \\ \text { Wind Speed } & \underline{0.72} & 0.08 & 0.20 \\ \text { Rainfall } & -0.06 & 0.02 & \underline{0.98} \\ \text { Soil Moisture } & -0.10 & \underline{0.83} & 0.12\end{array}$

Table 6. $\mathrm{J}_{\mathrm{s}}$ averaged over the entire measurement period $\left(\mathrm{kg} \mathrm{H}_{2} \mathrm{O} \mathrm{dm} \mathrm{m}^{-2} \mathrm{~h}^{-1}\right)$ for the ten species.

Species

$\mathrm{N}$

Standard

$\begin{array}{ccccc}\begin{array}{c}\mathrm{N} \\ \text { (Trees) }\end{array} & \text { (Half-hour Means) } & \text { Mean } & \text { Error } & \begin{array}{c}\text { Maximu } \\ \mathrm{m}\end{array} \\ 4 & 3564 & 0.84 & 0.61 & 4.22 \\ 5 & 1728 & 0.54 & 0.43 & 5.64 \\ 4 & 2016 & 0.41 & 0.40 & 3.30 \\ 4 & 2784 & 0.94 & 0.67 & 4.77 \\ 4 & 3552 & 0.62 & 0.47 & 3.46 \\ 4 & 4560 & 0.77 & 0.62 & 5.93 \\ 4 & 3696 & 0.82 & 0.57 & 4.94 \\ 4 & 3744 & 0.29 & 0.29 & 2.43 \\ 8 & 6528 & 1.00 & 0.32 & 6.86 \\ 4 & 4176 & 0.41 & 0.33 & 4.45\end{array}$




\section{Sap Flux Lags and Hysteresis}

The time of maximum $\mathbf{J}_{\mathrm{S}}$ was either coincident or occurred after maximum irradiance (Table 7). Maximum $J_{S}$ occurred earlier than maximum VPD in all species. The timing of maximum EDI was either coincident or after maximum $J_{s}$. Plots of half-hour mean $J_{S}$ versus irradiance, VPD, and EDI revealed a counter-clockwise hysteresis for irradiance, but a clockwise hysteresis for VPD and EDI (Figure 4). These patterns were consistent for all species. Hysteresis was eliminated or significantly reduced in the EDI plots. In order to separate the effects of light and evaporative demand we plotted the normalized $\mathrm{J}_{\mathrm{s}}$ response to VPD in a manner similar to Meinzer et al. (1995). Meinzer et al. divided VPD values by simultaneous irradiance measurements to control for the effect of light on the behavior of stomata. When plotting halfhour values, all species showed a unimodal response with a positive skew indicating an initial increase in sap flow with higher VPD, followed by a rapid decline (Figure 5).

\section{Crown Conductance}

Crown conductance was higher in $S$. amara than $M$. guianensis (Figure 6). The pattern of $g_{c}$ against VPD was similar to that of the $\mathrm{J}_{\mathrm{S}}$ response, and $g_{c}$ increased as a quadratic function of VPD (Figure 7). The responses differed slightly between the species, mostly due to the differences in the magnitude of $g_{c}$. The response of $g_{c}$ to irradiance was best explained by a linear function (Figure 7). The slopes differed between the species with $S$. amara having a steeper response function than $M$. guianensis. The differences between these two species likely reflect both differences in sapwood area ( $S$. amara had about twice the sapwood area, Ryan et al. 1994), but also in the crown characteristics. The crowns of $S$. amara trees are much more open and less dense than $M$. guianensis crowns. Furthermore, liana cover was much higher in $M$. guianensis and might affect the crown boundary layer characteristics.

\section{$\underline{\text { Sap Flux Models }}$}

The four parameter function explained $74-94 \%$ of the variation in SSF (Figure 8). We then examined the residuals of this model, and found a negative linear correlation with the rain index, but no correlation with the soil index. Since the soil index was uncorrelated to the residuals of the non-linear function, we did not include it in any further analyses. We included a rainfall correction coefficient to the sigmoid function and re-estimated the parameters. The final form of the model was:

$$
S S F=y_{0}+\frac{a}{1+e^{-\left(\frac{x-x_{o}}{h}\right)}}+c z
$$

The independent variables were the EDI $(x)$ and the rain index scores $(z)$. The estimated parameters were the function low value $\left(y_{o}\right)$, the function high value $(a)$, the inflection point $\left(x_{o}\right)$, the slope of the transition $(b)$, and the correction coefficient for rainfall $(c)$.

This function has two asymptotes, where changes in EDI had little influence on sap flux. Sap flux changed little at night or under dark, still, humid conditions, then increased rapidly in a nearly linear fashion as conditions became warmer, brighter, drier and windier. It approached an upper asymptote when maximum sap fluxes were achieved and higher values of these weather conditions had little effect (Figure 9). Rainfall always reduced sap flow. Since the model showed two asymptotes separated by a nearly linear change in sap flux rates, comparing the maximum and minimum of the second derivative provided an independent point to test for differences among species in initiation and termination of sap flux responses to the climatic conditions. These points occurred where the maximum increase and decrease in transpiration rate 
Table 7. Mean lag (minutes) of environmental values relative to maximum sap flow. The values were calculated as the number of minutes between when the maximum $J_{S}$ occurred minus when the maximum irradiance, VPD, or EDI occurred. Negative values indicate maximum $\mathrm{J}_{\mathrm{S}}$ occurred before the environmental variable. Values with asterisks had mean differences significantly different than $0(p<0.05)$.

Species Irradiance VPD EDI

$\begin{array}{lrrr}\mathrm{Pm} & 73.9^{*} & -28.7^{*} & 15.5 \\ \mathrm{Sa} & 69.4^{*} & -35.4^{*} & 18.7 \\ \mathrm{Be} & 68.7^{*} & -23.3^{*} & 10 \\ \mathrm{Ci} & 4.95 & -109.8^{*} & -39.6 \\ \mathrm{Mg} & 56.5^{*} & -41.3^{*} & -1.8 \\ \mathrm{La} & 9.3 & -75.2^{*} & -38.9^{*} \\ \mathrm{Ha} & 37.8^{*} & -78.26^{*} & -28^{*} \\ \mathrm{Hm} & 29.2^{*} & -77^{*} & -26^{*} \\ \mathrm{Dp} & -21 & -122.3^{*} & -79.5^{*} \\ \mathrm{Co} & 16.4 & -105^{*} & -65^{*}\end{array}$


Figure 4. Plots of half hour mean $\mathbf{J}_{s}$ plotted against irradiance (Plot A), VPD (Plot B), and EDI $($ Plot $\mathrm{C})$. The points in the plots represent 30 minute means, the arrows in the upper left plot $(B E)$ represent the direction where the next consecutive observation in time occurred. The direction of sap flux hysteresis in all species was counterclockwise for irradiance, but clockwise for VPD and EDI. The whiskers are one standard error.

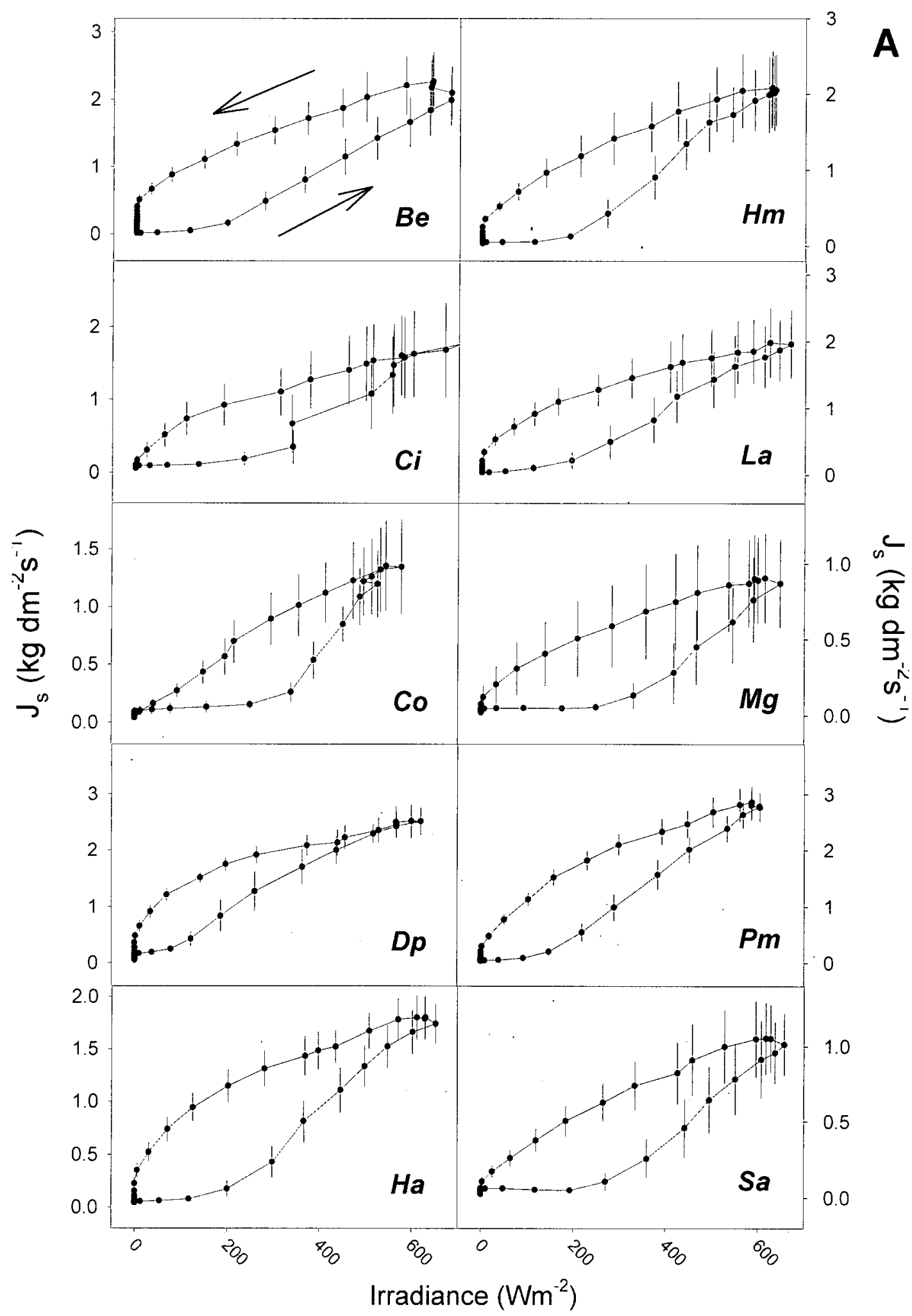


Figure 4B

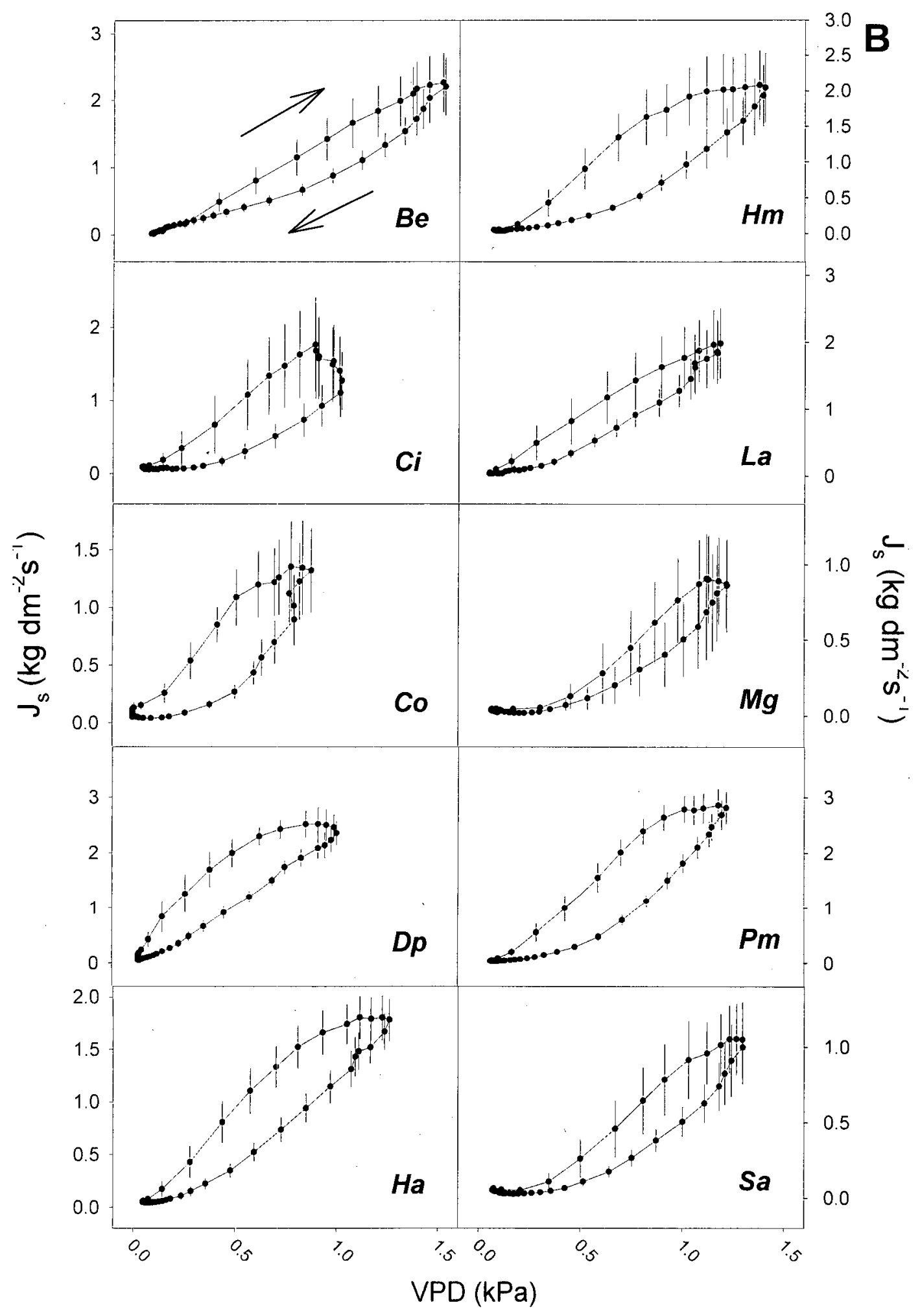


$10 \exists$

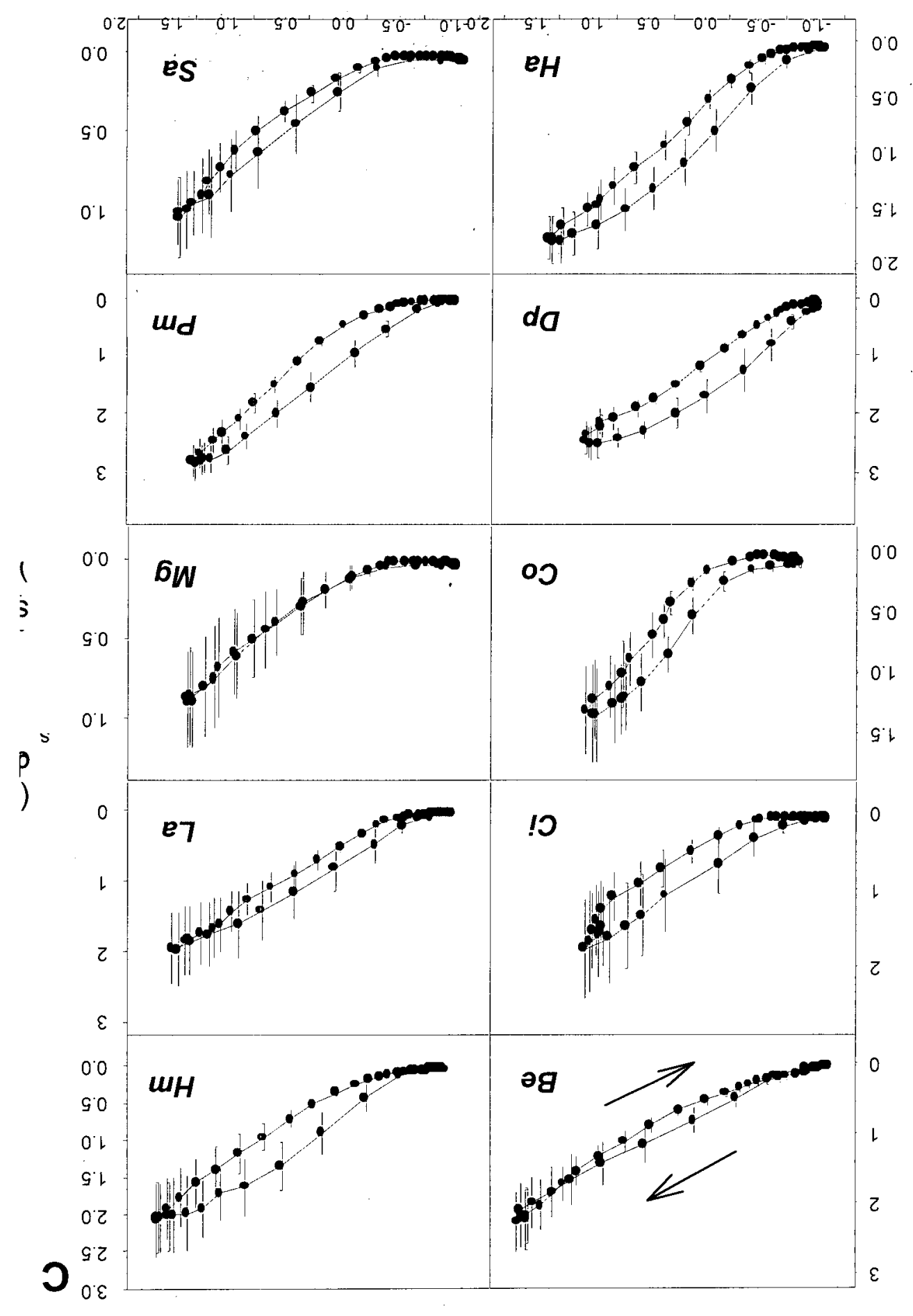


Figure 5. Plots of mean daily $\mathbf{J}_{\mathrm{s}}$ against normalized VPD (VPD/irradiance) over the entire study period. The data are plotted after taking the natural logarithm of the normalized VPD values. Each point represents a half-hour mean from a single tree. All species are plotted together.

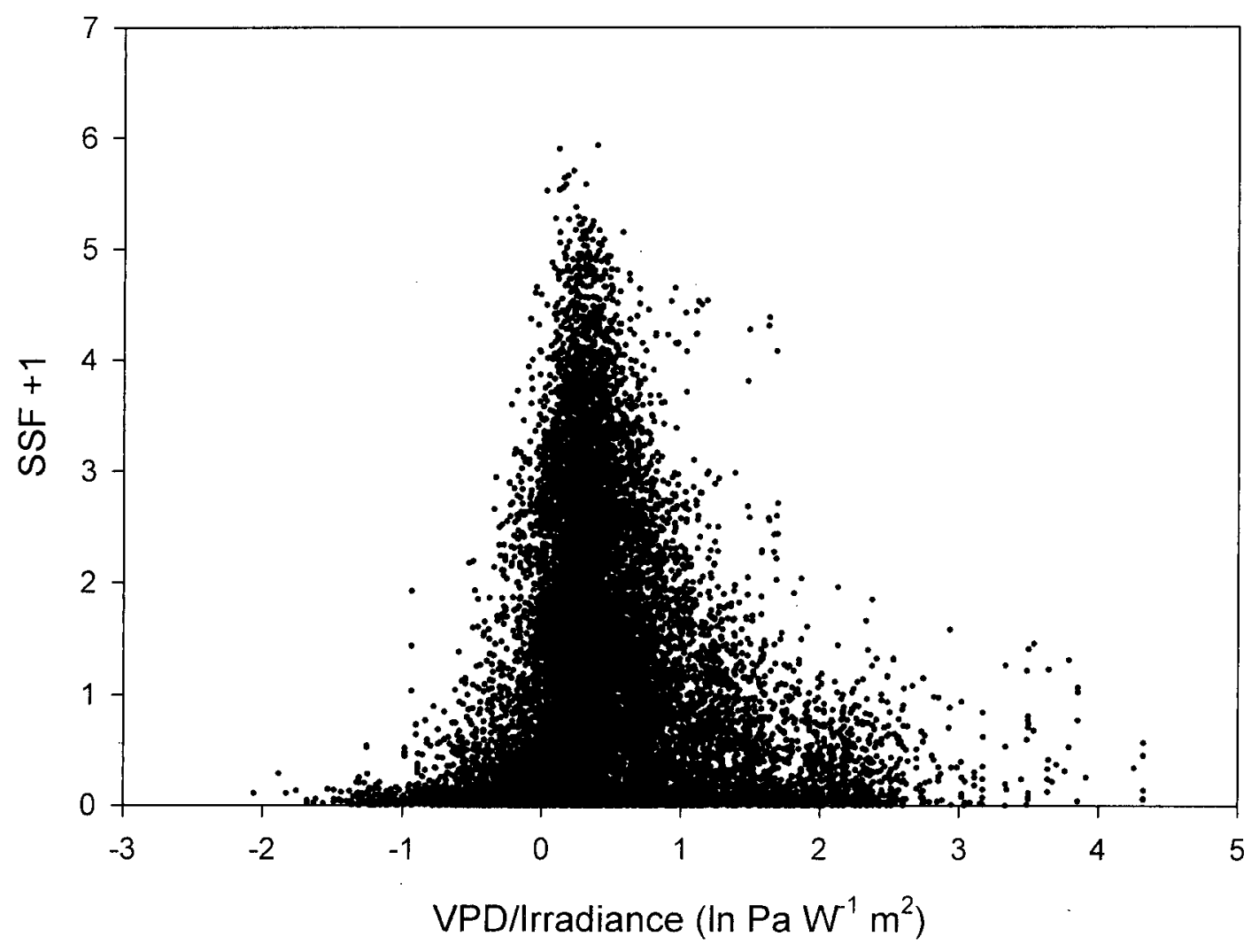


Figure 6. Time course of mean hourly values of $g_{c}$ for $S$. amara (open circles) and $M$. guianensis (filled circles). The means represent 87 days of observations for $S$. amara and 78 days for $M$. guianensis. The whiskers represent one standard error.

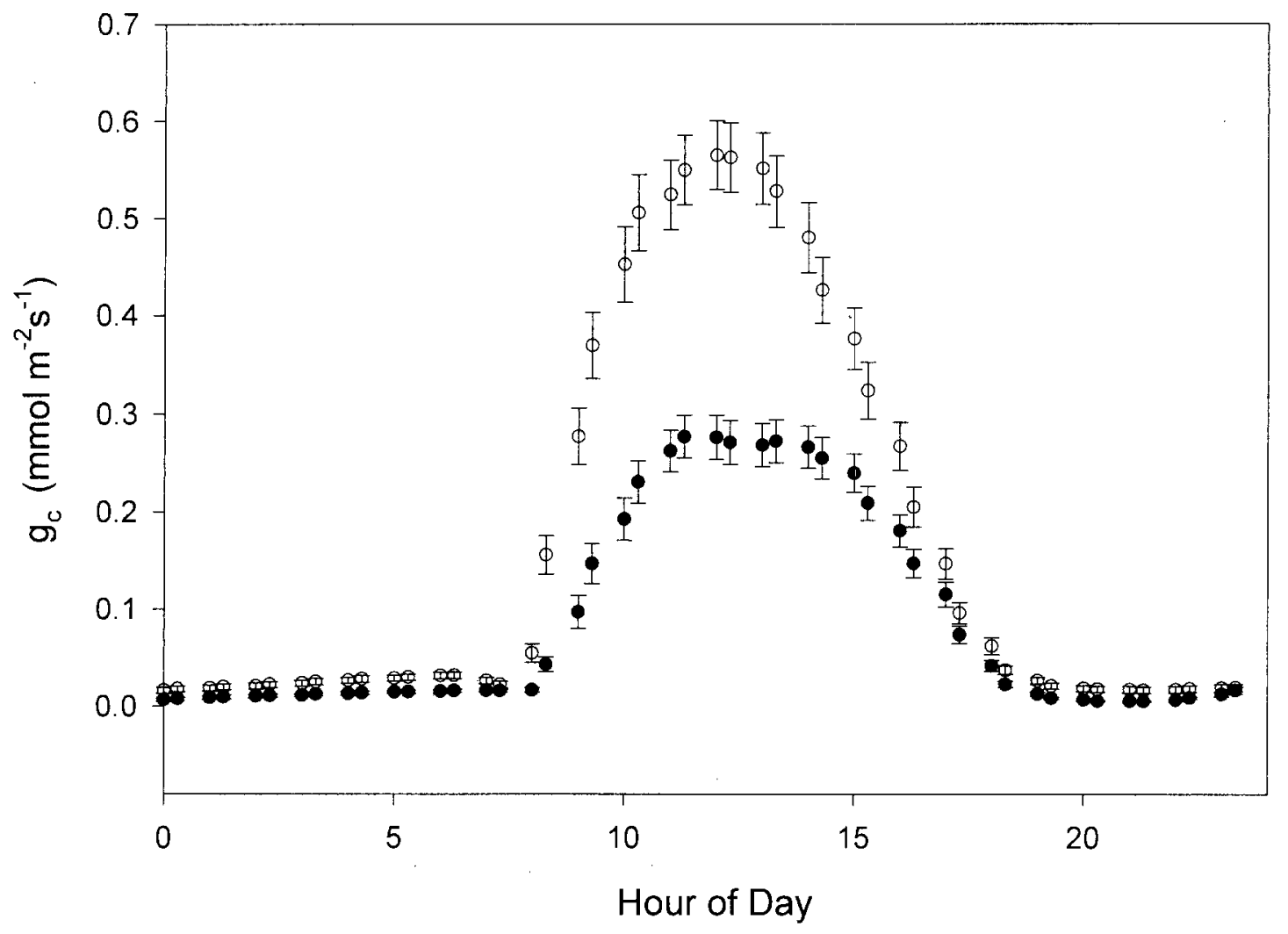


Figure 7. Time course of mean daily $g_{c}$ of $S$. amara (open circles, $\mathrm{n}=87$ days) and $M$. guianensis (filled circles, $\mathrm{n}=78$ days) plotted against matched mean daily values of irradiance and VPD. The $\mathrm{R}^{2}$ values for the regression lines for $S$. amara were 0.40 (VPD) and 0.58 (irradiance). The $\mathrm{R}^{2}$ values for the regression lines for $M$. guianensis were 0.31 (VPD) and 0.45 (irradiance).
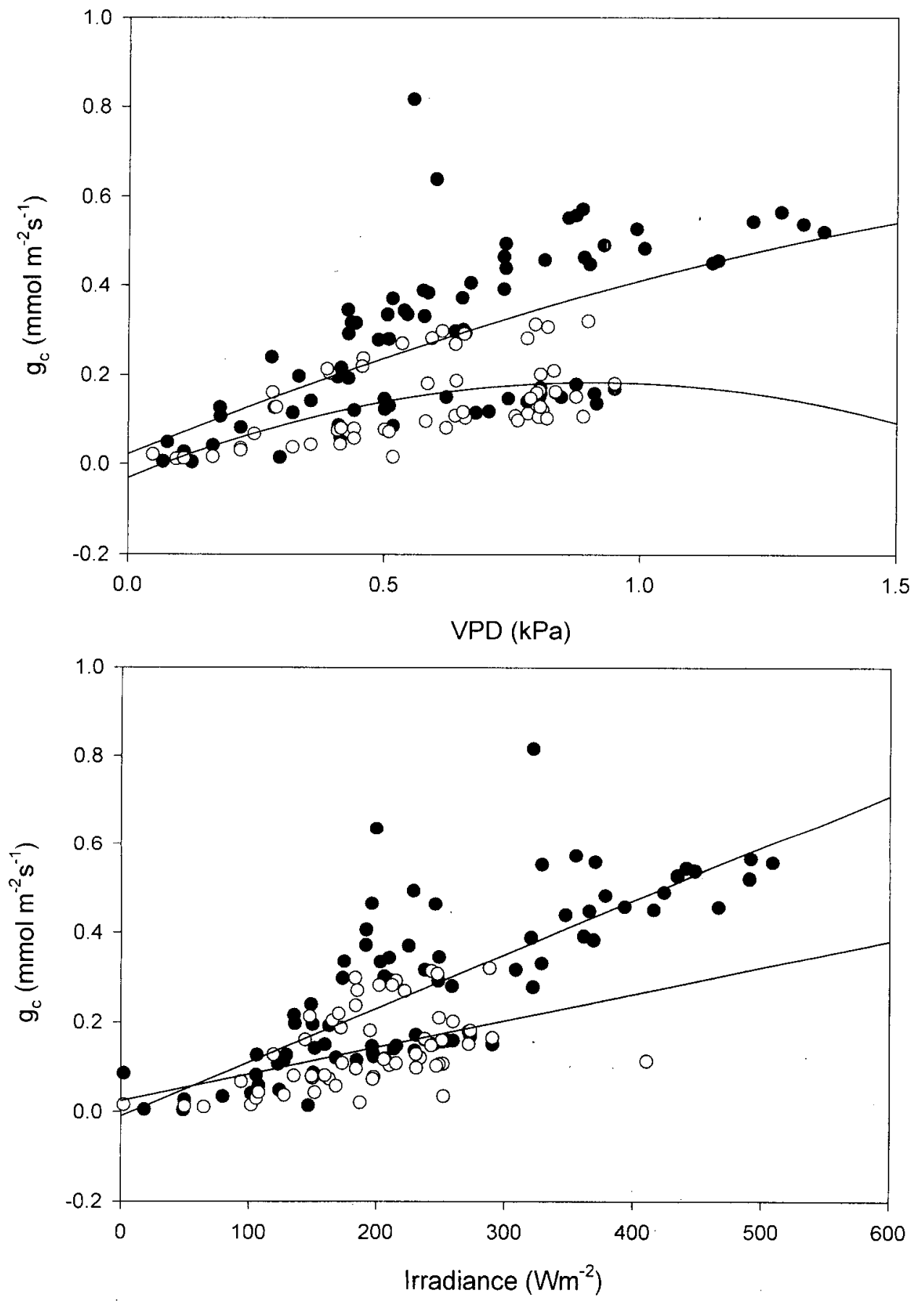
Figure 8. An example of the model fit; the plot shows concurrent observed (solid line) and predicted (dashed line) half-hour mean standardized sap flow in a single $B$. elegans tree over a four day period in October 1998 . The predicted sap flux values were generated using the halfhour EDI and the parameters for Equation 1 as reported in Table 8.

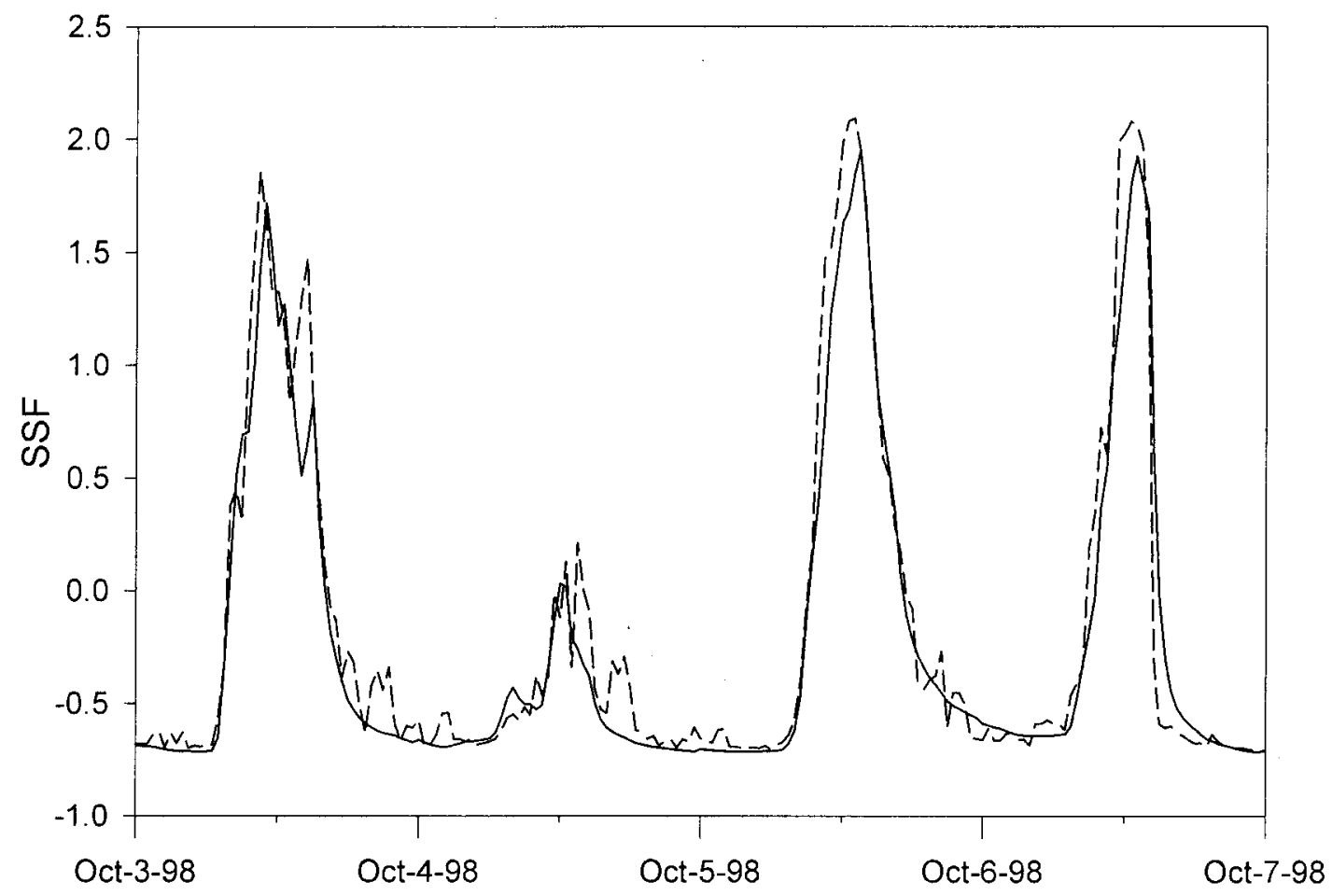


Table 8. Mean values for the dependent variables tested in the MANCOVA. The species codes are the first letters of the genus and species. The symbols in the parameter column refer to those described in Equation 1. Max and Min refer to the EDI values taken at the points where the second derivative of the equation reached maximum and minimum values. The $\mathrm{R}^{2}$ values are only a descriptor of model fit and are not used to make any inferences.

\section{Species}

Parameter $\mathrm{Be} \quad \mathrm{Ci} \quad \mathrm{Co} \quad \mathrm{Dp} \quad \mathrm{Ha} \quad \mathrm{Hm}$ La $\mathrm{Mg} \quad \mathrm{Pm} \quad \mathrm{Sa}$ Overall

$$
\begin{aligned}
& \begin{array}{llllllllllll}
\mathrm{N} & 4 & 5 & 4 & 4 & 4 & 4 & 4 & 4 & 8 & 4 & 47
\end{array} \\
& y_{0} \quad-1.03-0.62-0.55-0.74-0.88-0.91-0.97-0.58-0.73-0.64-0.76
\end{aligned}
$$

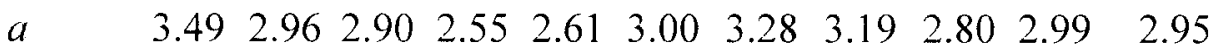

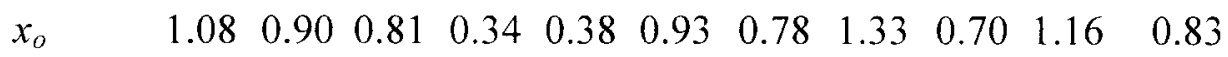

$$
\begin{aligned}
& \begin{array}{lllllllllllll}
b & & 0.77 & 0.37 & 0.28 & 0.31 & 0.37 & 0.55 & 0.54 & 0.41 & 0.40 & 0.45 & 0.44
\end{array}
\end{aligned}
$$

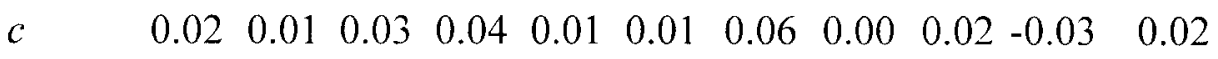

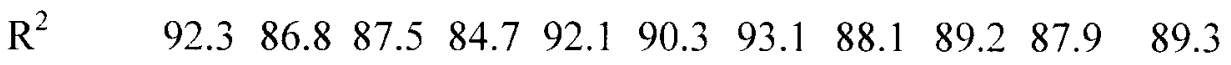

$$
\begin{aligned}
& \begin{array}{llllllllllll}
\operatorname{Max} & 0.05 & 0.40 & 0.43 & -0.07 & -0.12 & 0.20 & 0.06 & 0.79 & 0.17 & 0.56 & 0.24
\end{array} \\
& \begin{array}{llllllllllll}
\text { Min } & 2.11 & 1.38 & 1.17 & 0.73 & 0.86 & 1.64 & 1.48 & 1.85 & 1.22 & 1.74 & 1.39
\end{array}
\end{aligned}
$$

$\begin{array}{llllllllllll}\text { Canopy area } & 110 & 71 & 50 & 200 & 93 & 162 & 202 & 105 & 104 & 97 & 116\end{array}$

$\begin{array}{llllllllllll}\text { Liana cover } & 44 & 0 & 0 & 19 & 3 & 16 & 14 & 63 & 10 & 0 & 15\end{array}$

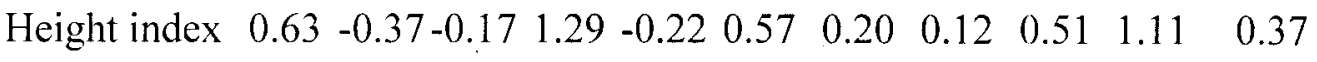


occurred (Figure 9). We also included the EDI values at these extreme points in the analysis of the model parameters among species (Table 8).

We tested the model parameters and crown characteristics for violations of the analysis of covariance assumption of homogeneous slopes by examining the interaction between the species and covariates. None of the tests were significant $(p>0.5)$. The MANCOVA showed that liana cover had a significant positive linear relationship with the model inflection point and the two points where maximum transpiration rate changes occurred (Table 9). Canopy height index exhibited a significant negative relationship with the function maximum values (Table 9). More exposed canopies had lower function maxima, indicating that SSF began to increase at lower values of the EDI. Crown area was not significantly correlated to any of the parameters despite the four-fold range in crown area among species.

After adjusting for the effects of liana cover and crown exposure with the MANCOVA, we found significant differences among the species in the means of four of the model parameters (Table 10). In all cases however, the differences were a continuum with no significant outliers (Table 11). Despite the small differences in a few parameters among a few of the species, the responses to the EDI appear similar among all the species (Figure 10). The B. elegans response curve tended to be flatter than the other species though its slope parameter did not differ from that of $H$. mesoamericanum and L. ampla, which were not statistically different from the rest of the taxa. The upper asymptote in B. elegans was higher than $H$. alchorneoides, though the post hoc tests showed rest of the species overlapped with both. D. panamensis and S. amara showed the same pattern for the value of the lower asymptote; D. panamensis had a lower value than Simarouba but neither differed from the rest. D. panamensis also reached the upper asymptote at lower EDI values than H. mesoamericanum, S. amara and B. elegans, but did not differ from the rest.

To estimate the sensitivity of the sap flow model to the species-specific differences described above, we recalculated parameters, pooling tree measurements at different levels and compared the variance explained. First, we estimated model parameters for each individual and then averaged the $\mathrm{R}^{2}$ by species. We then generated the estimates from a pool of all individuals within a species and finally pooled all individuals from all species. Individual differences accounted for $\sim 3 \%$ of the model efficiency and species level differences accounted for an additional $3 \%$. Pooling all individuals reduced the average variance explained by $\sim 6 \%$ (Table 12).

\section{Discussion}

Our results showed that we could effectively model short-term tree sap flux responses with a sigmoid function using synthetic climatic variables as predictors. Our multivariate approach simplified the model and ensured the independence of the explanatory variables. The model performed well, explaining an average of $74 \%$ to $93 \%$ of the variance in sap flow for the ten species and explained an average of $89 \%$ of the variance across all species. The greatest discrepancies between measured and predicted flux occurred under conditions of low sap flow and at night. Ewers \& Oren (2000) found relatively higher TDP error under conditions of low sap flow and low VPD, suggesting that flux measurement error might partly explain the lower model performance under these conditions. Nevertheless, nighttime stomatal closure also explains why the model consistently overestimated sap flux during the rare nights with high evaporative demand. 
Figure 9. A plot of 44 days of standardized half-hour sap flow observations of a Pentaclethra macroloba tree taken in October 1999 and December 1999- January 2000. The solid line represents the predicted standardized sap flow predicted by Equation 1; the points are the observed half-hour means of standardized sap flow. The arrows indicate the approximate location of the maximum (filled arrow) and minimum (unfilled arrow) values of the function second derivative.

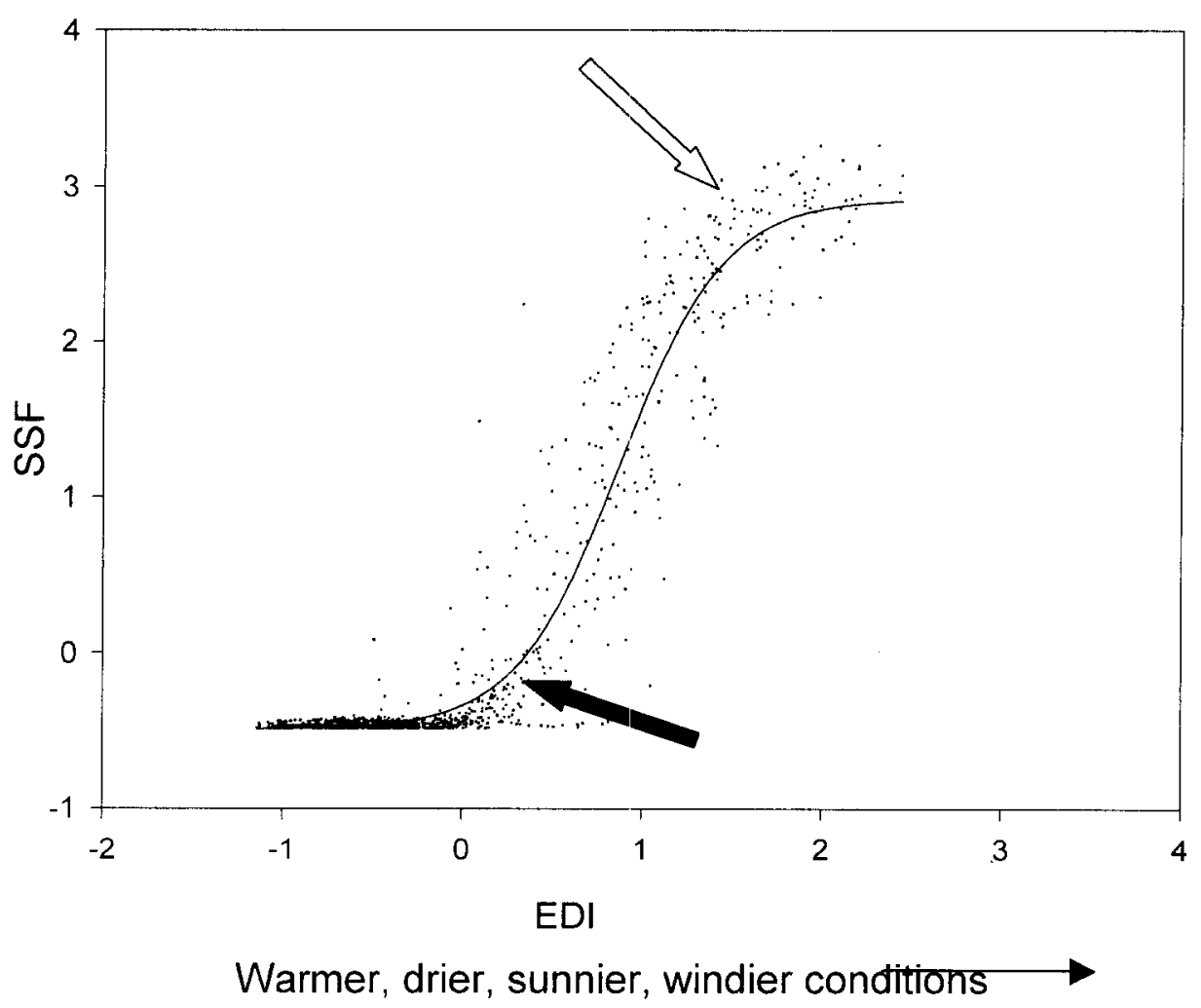


Table 9. The results of the analysis of the covariates and the species main effect on the model parameters. Since the MANCOVA was not significant for crown area, we did not include this variable as a covariate.

\begin{tabular}{cccccc} 
& Pillai's & \multicolumn{1}{c}{ Hypothesis } & Error & \\
Effect & Trace & $\mathrm{F}$ & $\mathrm{df}$ & $\mathrm{df}$ & $p$-value \\
Crown Area & 0.243 & 1.005 & 8 & 25 & 0.457 \\
Liana Cover & 0.438 & 2.439 & 8 & 25 & 0.042 \\
Canopy Height & 0.437 & 2.422 & 8 & 25 & 0.043 \\
Species & 2.292 & 1.428 & 72 & 256 & 0.024
\end{tabular}

Table 10. Univariate ANCOVA results: only dependent variables with significant $F$ tests $(p<0.05)$ are shown. The symbols in the dependent variable column represent the parameters from Equation 1 and the EDI values at the maximum and minimum of the function second derivative.

\begin{tabular}{ccccccc} 
& Dependent & $\begin{array}{c}\text { Sum of } \\
\text { Squares }\end{array}$ & \multicolumn{5}{c}{ Mean } & & \\
Square & & $p$ - \\
Source & Variable & Error & df & Error & F & value \\
Liana Cover & $x_{o}$ & 0.764 & 1 & 0.764 & 8.750 & 0.006 \\
& Min & 0.841 & 1 & 0.841 & 8.389 & 0.007 \\
& Min & .632 & 1 & 0.632 & 5.419 & 0.026 \\
Canopy Height & $a$ & 0.937 & 1 & 0.937 & 7.118 & 0.012 \\
Species & $y_{0}$ & 0.895 & 9 & 0.099 & 2.924 & 0.012 \\
& $a$ & 2.824 & 9 & 0.314 & 2.385 & 0.034 \\
& $x_{o}$ & 2.681 & 9 & 0.298 & 3.410 & 0.005 \\
& $b$ & 0.668 & 9 & 0.074 & 6.396 & 0.000 \\
& Max & 2.559 & 9 & 0.284 & 2.836 & 0.014 \\
& Min & 5.231 & 9 & 0.581 & 4.979 & 0.000
\end{tabular}

Table 11. Results of the post hoc pair-wise Bonferroni t-tests among corrected means. We only compared the dependent variables (DV) with significant mean differences. Species with the same letters in superscript did not differ $(p>0.05)$.

DV Results of Pair-wise Comparisons

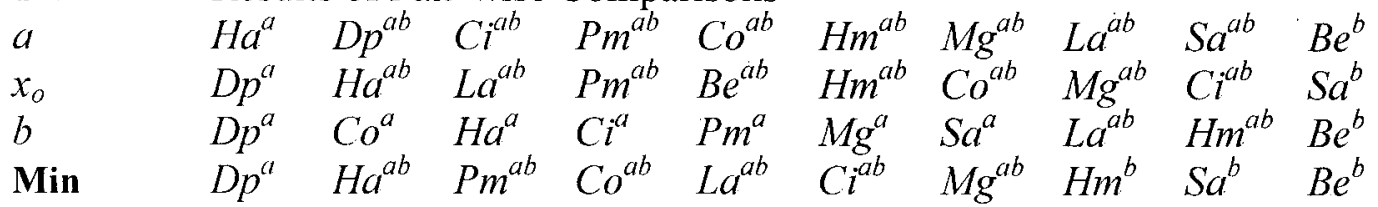


Table 12. The variance explained by the sap flow model (Equation 1) with the parameters estimated from different levels of sample pooling. The first column gives the species name codes. The values in the second column were derived by averaging the $\mathrm{R}^{2}$ of models on data from individual trees. $\mathrm{R}^{2}$ values in the third column were derived from data pooled within each species, and the single $\mathrm{R}^{2}$ value in the fourth column was estimated from the entire set of observations.

$\begin{array}{cccc} & \begin{array}{c}\text { Mean (standard error) } \\ \mathrm{R}^{2} \text { of Models Using }\end{array} & \begin{array}{c}\mathrm{R}^{2} \text { OF MODELS USING } \\ \text { DATA POOLED }\end{array} & \mathrm{R}^{2} \text { of Model Using } \\ \text { Species } & \text { Individual Tree Data } & \text { Within Species } & \text { All Data } \\ \text { Be } & 92.33(0.78) & 90.10 & \\ \mathrm{Ci} & 86.77(2.35) & 86.16 & \\ \mathrm{Co} & 87.50(3.51) & 87.74 & \\ \mathrm{Dp} & 84.71(3.52) & 80.66 & \\ \mathrm{Ha} & 92.54(0.67) & 89.26 & \\ \mathrm{Hm} & 90.32(2.37) & 89.63 & \\ \mathrm{La} & 93.11(0.41) & 85.14 & \\ \mathrm{Mg} & 88.13(2.41) & 82.28 & \\ \mathrm{Pm} & 89.20(1.41) & 88.02 & \\ \mathrm{Sa} & 87.93(1.16) & 85.07 & \\ \text { Mean } & & & \\ \text { Across } & & 86.12 & \\ \text { Species } & 89.25 & \end{array}$


The species we measured had remarkably similar response patterns to the climatic conditions (Figure 10). Although the model parameter means differed among a few of the taxa, the effect size was small as indicated by the minor decrease in model efficacy when we derived parameter estimates from a pool of all individuals (Table 12). These species with widely varying morphology, anatomy, life history and architecture appear to have converged on a common response to environmental conditions. Meinzer et al. (2001) found convergence in the relationship between water transport and sapwood area in species with widely varying xylem morphology. They suggested that the relationship between sap flow and evaporative demand might show a similar universality among species. Our results support this view.

A further reason for the similarity among species responses may be that under some conditions, physiological responses are not the primary determinants of water loss from the canopy. In tropical moist forest in Panama, stomatal responses of trees in gaps were found to be largely uncoupled (sensu Jarvis \& McNaughton 1986) from the whole tree transpiration because canopy conductance was often lower than stomatal conductance (Meinzer et al. 1995, Meinzer \& Andrade 1997). The same uncoupling may have occurred in our study. Consequently, water loss from the canopy may have been strongly influenced by climatic conditions, resulting in similar responses. Because we were unable to compare absolute values of sap flow among species due to our sampling limitations, we cannot say whether the volume of whole tree water use in this wet tropical forest was independent of species. We can say that climate affected sap fluxes similarly among these species. This could be an effect of measurement scale, not a lack of intrinsic differences in physiology (Meinzer et al. 2001, Andrade et al. 1998); nevertheless, the similar responses among species would simplify sampling efforts when estimating stand transpiration.

Elucidation of specific factors driving transpiration of individual trees is typically hampered by covariance and interaction among the environmental drivers. An alternative to our PCA approach is to use physiologically-based functions to fit the data and analyze the responses of the residuals. When we fit a light response model, the model explained $70 \%$ of the variation in the sap flow data (data not shown), considerably less than the sigmoid EDI model. Analysis of the residuals of the light response model still suffered from the covariance problem, which also prevented us from separating the importance of individual environmental variables of the EDI on sap flow. However, through our other analyses, we could infer some mechanisms driving the patterns we observed. $\mathbf{J}_{\mathrm{s}}$ was positively correlated with higher irradiance, VPD, temperature, and wind speed, but negatively correlated to leaf wetness.

While irradiance is known to have positive direct and indirect effects on stomatal conductance, many investigations of water use in trees have shown a decrease in transpiration driven by diminishing stomatal conductance as VPD increases (Monteith 1995, Whitehead 1998). Although we did not measure stomatal conductance, the shape of the $J_{\mathrm{S}}$ response to VPD when normalized by irradiance (see Meinzer et al. 1995) showed that $J_{s}$ initially increased then decreased (Figure 5). This could indicate that a decline in stomatal conductance with higher evaporative demand occurred only after an initial threshold was reached. The positive correlation occurred only under conditions of very high irradiance or very low VPD, both situations where stomatal aperture might be expected to be greater. Meinzer et al. (1995) and Granier et al. (1992) showed the stomatal conductance of three species we studied (S. amara, C. insignis and $C$. obtusifolia) declined with increasing VPD. While the majority of our observations would support their results, there did appear to be significant intervals where VPD did not decrease stomatal aperture if this was the major factor driving transpiration during the initial increase in sap flow seen in Figure 5. Furthermore, Meinzer et al. (1995) showed that in one species, transpiration decreased at high VPD. We never observed this in any of our data, though eddy covariance 
Figure 10. Standardized sap flow (SSF, Y axis) plotted against EDI for each of the ten species. The solid line represents the predicted sap flow of the model calculated from parameters estimated from all individuals pooled within a species. The points are the observed mean halfhour averages of sap flux for all individuals within a species. The letters in the lower right corner of each plot refer to the first letters of the tree genus and species.
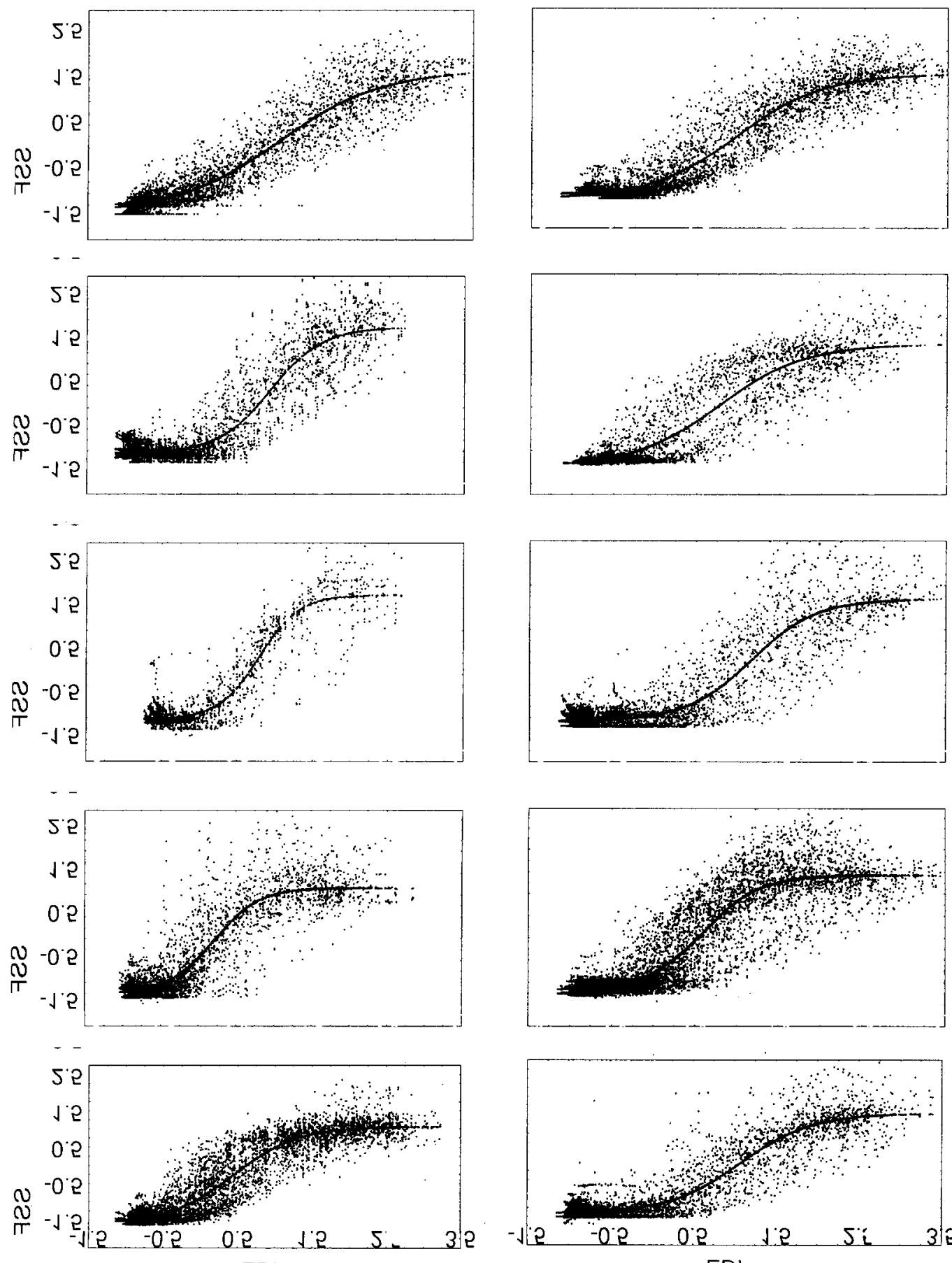

EDI

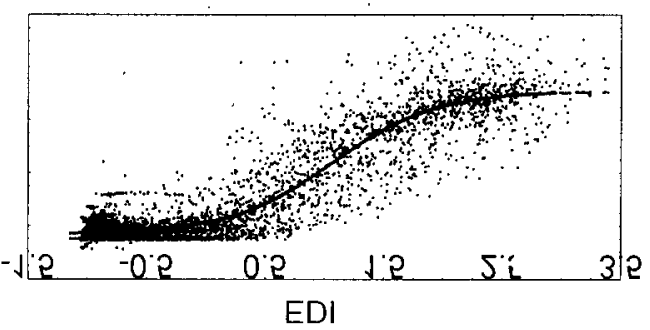


measurements from La Selva over approximately the same period as our study indicated a slight negative effect of high VPD on ecosystem carbon uptake (Loescher et al. 2003). In more seasonal Amazonian forests, VPD has been identified as an important limit on canopy carbon uptake (Grace et al. 1995, Mahli et al. 1998), but the effect might be more subtle at La Selva due to the extremely wet conditions.

Our results also showed that the study trees at La Selva were probably not limited by soil water because $J_{\mathrm{s}}$ did not respond to changes in soil moisture and never decreased under conditions of high evaporative demand. Granier, Lousteau \& Bréda (2000) found a similar response in a study of tree canopy conductance in several different forest types with plentiful soil moisture. However, based on eddy covariance data from Cuieiras, Brazil, Mahli et al. (1998) suggested that gross primary productivity in more seasonal forests was likely limited by soil moisture. Using sensitivity analysis, Williams et al. (1998) identified soil moisture and soil/root hydraulic resistance as two of the primary climatic controls on evapotranspiration for the same site in Brazil.

Liana cover varied among the study trees and across species. Liana presence in a tree crown and the tree's crown position relative to the canopy neighborhood had a significant effect on sap flow responses. Heavy liana cover in the crown delayed the tree sap flow response to conditions of higher evaporative demand, probably through shading by liana leaves. This shading might also explain the negative impact on growth by lianas shown by Clark \& Clark (1990) in several of the taxa we report on here. Trees with emergent crowns reached maximum sap flow under conditions of lower evaporative demand than trees embedded in the canopy. Even though we intended to minimize the variance in crown characteristics through our sampling strategy, tree canopy idiosyncrasies were still an important source of variation in the model parameter estimates. These characteristics would likely become more important as these trees matured, since several species (all the emergent species) we measured had not achieved their full stature.

Many authors have reported lags between sap flow measured at the base of trees and transpiration in the crown (e.g. Landsberg, Blanchard \& Warrit 1976, Granier \& Lousteau 1994, Goldstein et al. 1998, Phillips et al. 1999, but see Ewers \& Oren 2000). The morning lag in $J_{\mathrm{s}}$ in response to light that we observed might be explained by water capacitance in the stem, a slow stomatal response to light, boundary layer dynamics, or diffusion limited by wet leaves. Leaf wetness appeared to be important in explaining the morning lag in $\mathrm{J}_{\mathrm{S}}$ response to irradiance. The diurnal pattern of leaf wetness shows rapid drying of wet leaves occurring over the same period that we observed the lag in $\mathrm{J}_{\mathrm{s}}$ response to light. The afternoon lag in VPD response seen as hysteresis in Figure $4 \mathrm{~b}$ could be driven by stomatal closure either in response to higher VPD, decreasing light levels, or internal cycles. An example of the latter is the clockwork closure of leaflets (and stomata) of P. macroloba in the afternoon while irradiances are still relatively high (Oberbauer, Strain \& Riechers 1987). Interestingly, the combination of morning lags in response to light and afternoon lags in response to VPD resulted in much smaller overall hysteresis when the SSF was plotted against EDI (Figure 4c).

Climate change scenarios suggest that rainfall and soil moisture levels will decline and seasonality will increase in many areas of the Neotropics, although in some areas, such as Central America, rainfall is predicted to increase (Hulme \& Viner 1998). If changing climate dried the soil to the point where water became limited, the upper asymptote in sap flow rates shown by our model might disappear. Soil water limitations would then cause a decrease in transpiration under conditions of high evaporative demand. If conditions became wetter, wet leaves and lower light levels might lower sap flow rates. Morphological and architectural differences among the species might interact differently under these conditions. While we cannot examine these scenarios 
easily, the common sap flow response at the scale we measured (whole tree) did not vary greatly under current conditions. External factors such as liana cover and crown position had more impact on tree water use than species-specific characteristics. Our model of sap flux response to the evaporative demand index proved more effective than individual environmental variables for predicting short-term tree water use across species, but when integrating measurements over an entire day, VPD explains nearly as much variation as the composite index. This is likely because lags and hysteresis among the environmental variables become less important when averaged over a day. Nevertheless, our approach offers a simple way to examine how weather influences short term tree water use responses, to compare these responses among species, and to project sap flux rates through time. The similarity among sap flux responses of the study trees suggests that variation in climate will affect whole-tree photosynthesis of the study species similarly, a finding compatible with the synchronous growth responses of many of these species to climate variation (Clark \& Clark 1994, Clark et al. 2003). Clark \& Clark (1994) showed species growth responses appeared similar but the magnitude of the growth rates varied among the species. Understanding the variability in water use efficiency and carbon allocation among these species would explain their different growth rates and help predict how these forests might respond to climate change. 


\section{V.2. Stem growth and seasonality}

\section{Introduction}

One of the first impacts of projected rapid climate change in the tropics will be altered plant phenology, because phenological events are often triggered by subtle environmental cues (Corlett and Lafrankie 1998). Understanding the interaction between phenology and tree stem growth will be important for predicting how the carbon dynamics and species composition of tropical forests will respond to future climate change.

Seasonal stem growth and leaf exchange are well known phenomena of temperate forests. Rhythmic growth and phenological responses also occur in less seasonal biomes such as wet tropical forests, although these responses can be small or infrequent in comparison. The proportion of species with synchronized phenology in tropical forests is proportional to the strength of environmental cues, primarily rainfall. Seasonally dry forests are often dominated by seasonally deciduous species, whereas in continually moist forests, deciduous species become less common (Frankie et al. 1974, Medina 1983, Kikuzawa 1991, Reich 1995). Nevertheless, annual rhythms of leaf exchange and stem growth exist even in very constant environments, and seasonal cues in the wet tropics do cause annual growth response patterns in some species (Hazlett 1987, Breitsprecher and Bethel 1990, Newstrom et al. 1994, Corlett and Lafrankie 1998, Worbes 1999).

Growth and phenological events can be controlled by endogenous or exogenous factors. The degree of synchrony in phenological responses can give an indication as to the control source: asynchronous responses are likely governed endogenously, whereas concerted responses are initiated by climatic; light or other external stimuli (Borchert 1983, Ashton et al. 1988). Endogenous responses can be secondarily entrained by environmental cues (Borchert 1992). Light and rainfall are most often identified as the climatic factors driving phenological seasonality in the tropics though other species in weakly seasonal environments might not respond at all to small annual variations of light and rainfall (Ashton et al.1988, Wright and van Shaik 1994, Bullock 1997, Borchert 1998, Borchert and Rivera 2001).

The effects of phenology on growth are not well understood in weakly seasonal forests. Although a few studies have examined the seasonality of tree growth and the inferred climatic causes in the tropics (Hazlett 1987, Breitsprecher and Bethel 1990, Bullock 1997), the link between tropical tree phenology and growth in wet forests has not been explicitly explored. In this paper, we describe the patterns of leaf exchange and reproductive phenology and explore the relationship between these phenological events and canopy tree stem growth in a weakly seasonal wet tropical forest.

\section{Methods}

$\underline{\text { Study Site }}$

The study site was a stand of old-growth forest at La Selva Biological Station, Costa Rica $\left(10^{\circ} 26^{\prime} \mathrm{N}, 83^{\circ} 59^{\prime} \mathrm{W}\right)$. The climate and site description of La Selva are reported in detail in McDade et al. (1994). Climate measurements reported here were collected at an on-site weather station maintained by the Organization for Tropical Studies. Rainfall is heavy throughout the year, with two drier periods: February through April, and the month of September. Average daily rainfall decreases by approximately half during the peak drier period when compared to the wettest months (Figure 1). Nevertheless, even in March, the driest month, there is an average of $158 \mathrm{~mm}$ of rain that, according to Walter (1985), indicates a moisture surplus. In comparison, on Barro Colorado Island in Panama, a tropical forest which shares many tree species with La Selva, 
rainfall in March, the driest month, averaged $23 \mathrm{~mm}$ from 1972-1989 (Leigh 1999). Soil moisture in April of 1998 (the driest month of data availability) averaged $0.50 \mathrm{~m}^{3} \mathrm{~m}^{-3}$ which was unlikely to produce moisture stress.

Day length at La Selva varies slightly annually, with about 1.23 hours more daylight in June than in January (Forsythe et al. 1995). Irradiance levels at La Selva are less affected by astronomically-driven changes in day length than by declines in direct irradiance caused by seasonal differences in cloud cover (Figure 2). Yearly temperature variation at La Selva is also relatively small; differences in the average daily maximum and minimum temperatures of the warmest and coldest months are less than $3^{\circ}$ (Figure 3 ). Daily temperature variation is usually less than 10 degrees; in 1999 , the average daily maximum air temperature was $29.7^{\circ}$ and the average daily minimum was $22.0^{\circ}$. Though subtle, the seasonal variation at La Selva is sufficient to provide cues for synchronized phenological events such as flowering and leaf exchange in many tree species (Frankie et al. 1974).

\section{Study Species}

The ten species we chose for this study are a diverse group of canopy and emergent trees, with a range of life history, anatomical and morphological traits (Table 1). Clark and Clark $(1992,1999)$ categorized nine of the ten species into four functional groups based on patterns of establishment and regeneration and five groups based on annual growth increment across sizes classes. We randomly chose individuals from a subset of trees studied by Clark and Clark (1992) with the addition of ten randomly chosen individuals of Pentaclethra macroloba, a forest dominant. Trees we selected had to meet the following criteria: a diameter of $30-60 \mathrm{~cm}$ diameter above buttress and unobstructed or emergent crowns. Trees in this size class have the highest growth rates, with the exception of Cecropia obtusifolia, which had higher growth rates in smaller size classes (Clark and Clark 1999).

\section{Growth Measurements}

Initially, we installed 115 steel band dendrometers (Liming 1957) on ten or more individuals of the ten study species between January and July 1997. Mortality and band damage reduced the final sample size of trees with measurements spanning the full study period to seven to ten individuals (Table 1). The bands were read approximately once a month from the time of installation until March 2000. We used a micrometer caliper to measure the distance between a fixed mark on the band and the dendrometer sleeve, and recorded the distance to the nearest 0.01 millimeters. For this study, we report the results from trees that grew more than $2 \mathrm{~mm}$ in diameter over the entire two-year measurement period.

In May 1999 we installed a second band on three of the already banded individuals of each of the ten species to determine the time required for the bands to settle and give consistent readings. Usually, slack remaining in the bands after installation introduces measurement error that is reduced through time as stem growth removes the slack (Keeland and Sharitz 1993). We read these additional bands simultaneously with the original bands. The data from duplicate band installation indicated that growth readings were not significantly different after one month (Table 2). The lack of discrepancies between the early band readings apparently was due to careful tightening of the bands upon installation and rapid growth rates that quickly removed any residual slack. Though there were no significant differences in band readings after one month, we had left the original bands in place for four to five months before recording growth. Therefore, we felt confident that there was little measurement error due to band settling. 
Figure 1. Climate diagram for the study site after Walter (1985). The diagram highlights the minor annual temperature variation and extremely wet climate of La Selva.

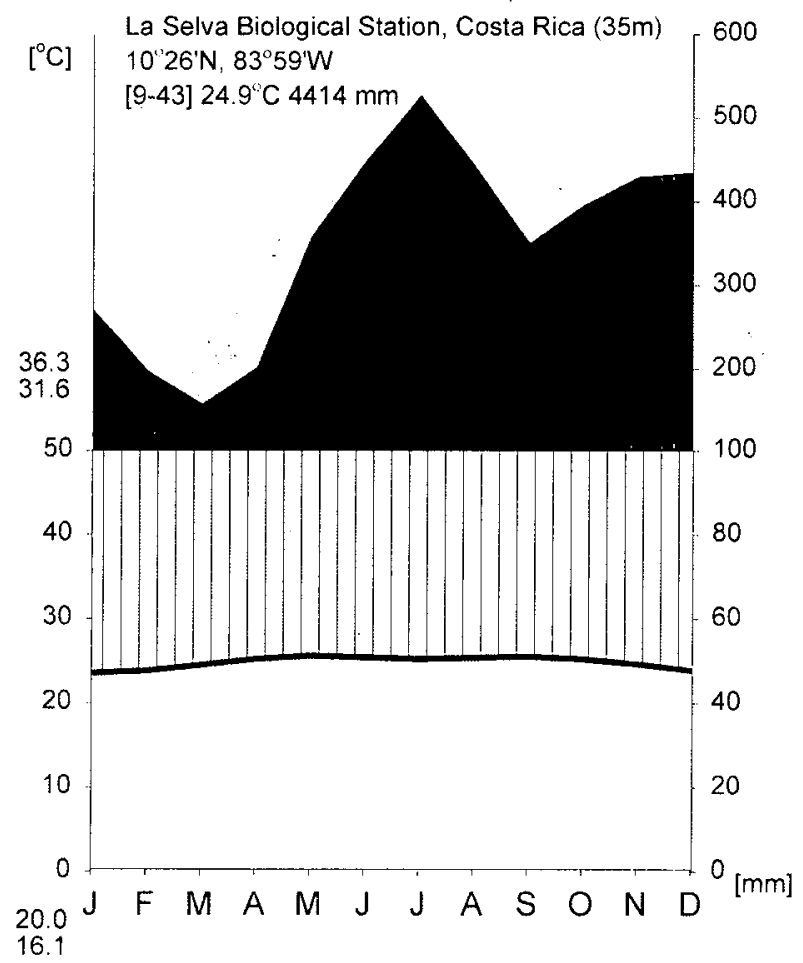


Figure 2. The annual patterns of irradiance (line) and rainfall (bars). The figure displays mean monthly irradiance values and rainfall totals over the study period (1997-2000). The irradiance values are daily averages (calculated from 5:00 to 19:00 Central Standard Time), rather than monthly totals, to allow for the inclusion of data from months with some missing daily observations.

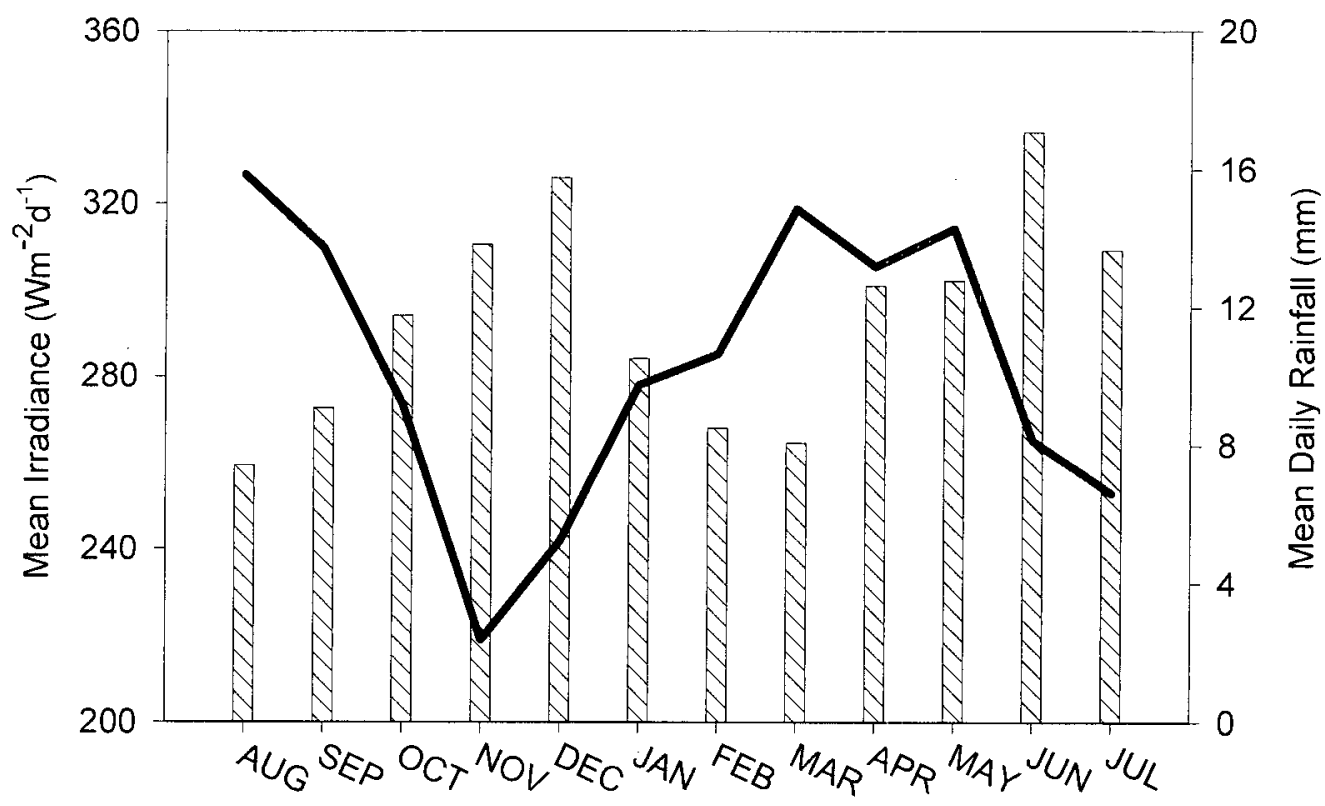


Figure 3. Annual temperature variation at La Selva over the study period. The lines represent the average maximum and minimum daily temperature of months measured from 1997-2000.

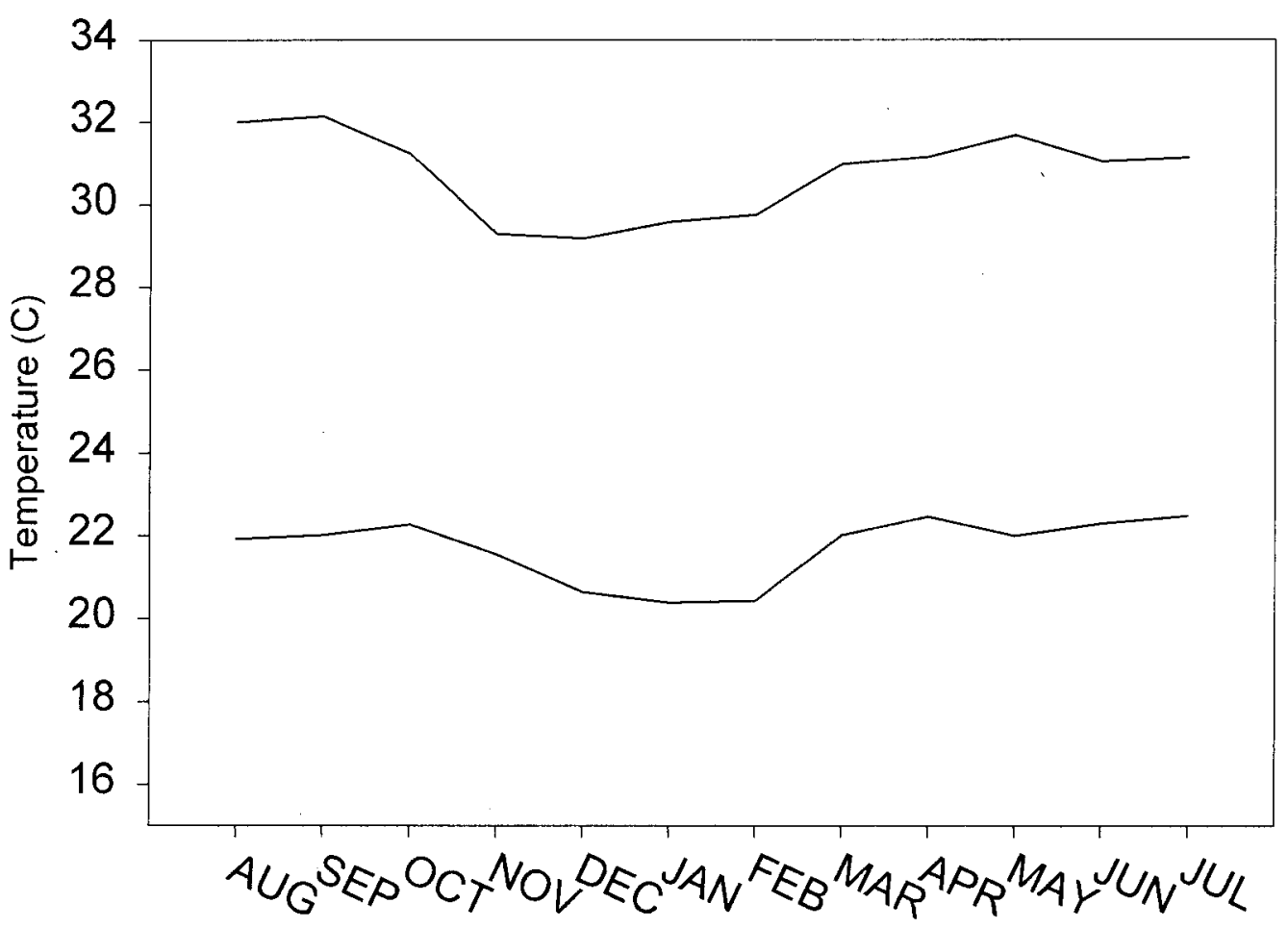


Table 1. Species from the La Selva old-growth forest included in this study. Leaf morphology refers to whether the leaves were simple (s) or compound (C) and relative size. Capital letters indicate leaves or leaflets greater than two $\mathrm{cm}$, lowercase indicates leaves or leaflets smaller than two $\mathrm{cm}$. Stature refers to whether mature trees are generally emergent $(\mathrm{E})$ or contiguous $(\mathrm{C})$ with the average forest canopy. $\mathrm{N}$ equals the number of trees included in the analysis.

\begin{tabular}{llll}
\multicolumn{1}{c}{ Species } & Leaf Morphology & Stature & N \\
\hline Cecropiaceae & S & C & 9 \\
\hline Cecropia insignis Liebm. & S & C & 7 \\
Cecropia obtusifolia Bertol. & & & \\
Euphorbiaceae & S & E & 9 \\
Hyeronima alchorneoides Allemão & & & \\
Fabaceae & c & E & 10 \\
Balizia elegans (Ducke) Barneby \& J. W. Grimes & C & E & 9 \\
Dipteryx panamensis (Pittier) Record \& Mell & c & E & 10 \\
Hymenolobium mesoamericanum H. C. Lima & C & C & 10 \\
Pentaclethra macroloba (Willd.) Kuntze & & & \\
Lecythidaceae & S & E & 9 \\
Lecythis ampla Miers & & & \\
Olacaceae & C & 9 \\
Minquartia guianensis Aubl. & S & & \\
Simaroubaceae & & C & 9
\end{tabular}

Table 2. Repeated measures ANOVA results of the duplicate band installation. While there was a significant within-subjects effect (month), there were no differences among any combination of within and between subject effects, indicating that there were no differences between the band readings.

\begin{tabular}{lccccc} 
Effect & Pillai's Trace & F & Hypothesis df & Error df & Sig. \\
\hline Month & 0.452 & 4.610 & 5 & 28 & 0.003 \\
Month * Species & 1.415 & 1.400 & 45 & 160 & 0.066 \\
Month * Band & 0.071 & 0.427 & 5 & 28 & 0.826 \\
Month * Species * Band & 0.332 & 0.253 & 45 & 160 & 1.00
\end{tabular}


Phenology

We assessed leaf and reproductive phenology when the bands were read. Using binoculars, we visually estimated the proportion of the crown occupied by four classes of leaves and reproductive structures: mature dark green leaves, young (red or light green) or unexpanded leaves, and flowers and fruit. For each class, we assigned an index from 0 to 3 based on the percentage of the full crown potential occupied by each class. We scored a 0 for a bare crown, a 1 for $0-25 \%, 2$ for $25-50 \%$ and a 3 for $>50 \%$ cover of the crown occupied by each class. We could not visually assess the phenology of $P$. macroloba due to its dense canopy. For the Cecropia species, we could not differentiate between flowers and fruit and scored them as one.

Data analysis

In order to correct for differences in the day of the month sampled, we linearly interpolated adjacent sampling values to the diameter on the $19^{\text {th }}$ of each month as the dependent variable. By choosing diameter on this date as the dependent variable, we maximized the time period with continuous data. To test for seasonal growth patterns, we applied a repeated measures ANOVA to monthly growth increment over two years where we had complete records for at least nine individuals within each species. For deciduous species, we tested the relationship between phenology and growth using logistic regression. The independent variable was crown phenological index of the previous month and the dependent was a score of whether the current month's growth increment was greater or less than the yearly average growth.

\section{Results}

Patterns of phenology

The ten species fell into two main leaf phenological categories: those with evergreen or deciduous crowns. Two sub-categories differentiated by timing of leaf exchange occurred within each main category (Table 3 ). We also categorized the species into three reproductive categories (Table 3). The four deciduous species were leafless at least once a year: B. elegans, $D$. panamensis, H. mesoamericanum, and $L$. ampla (Table 3 ). Individuals of these species were generally leafless for a month or less and species differed in the synchronization of leaf shedding: $D$. panamensis and L. ampla individuals tended to drop leaves in concert (Pearson Chi-Square $22.17, p=0.023$ and $42.66, p<0.000$ respectively), whereas individuals of $B$. elegans and $H$. mesoamericanum dropped leaves independently of each other (Pearson Chi-Square 12.64, $p=0.317$ and $16.40, p=0.129$ respectively) (Figure 5). Only individuals of H. mesoamericanum trees shed all their leaves more than once a year, and an individual tree could be leafless at almost any time of year. Dipteryx panamensis and L. ampla trees lost leaves during the driest months from February to May. Most, but not all, of B. elegans trees exchanged their leaves from June to September. The degree of synchrony in leaf shedding of $B$. elegans was intermediate between that of H. mesoamericanum and D. panamensis.

One evergreen species, Simarouba amara, flushed more new leaves from January to April when light levels were highest and rainfall lowest (Figure 4). The remaining species, $M$. guianensis, P. macroloba, H. alchorneoides and the two Cecropia spp., flushed and produced new leaves continuously and were evergreen (Table 3 ).

The ten species flowered in three general patterns: supra-annual, continual, and annual (Newstrom et al. 1994). Species with annual flowering patterns tended to flower at particular times of year (Figure 6). The timing of flowering in C. insignis, D. panamensis, L. ampla and $S$. amara occurred immediately following the months with highest light and lowest rainfall. Two taxa, H. mesoamericamum and $M$. guianensis flowered supra-annually, though the degree of 
Table 3. Phenological groups of the ten tree species.

\begin{tabular}{|c|c|c|c|c|}
\hline \multirow[b]{2}{*}{ Species } & \multirow{2}{*}{$\begin{array}{c}\text { Phenological } \\
\text { Functional Group }\end{array}$} & \multirow{2}{*}{$\begin{array}{l}\text { Timing of } \\
\text { Leaf Exchange }\end{array}$} & Synchrony of & \\
\hline & & & Leaf Exchange & Flowering \\
\hline$\overline{\text { C. insignis }}$ & Evergreen & Continuous & & Annual \\
\hline C. obtusifolia & Evergreen & Continuous & & Continual \\
\hline M. guianensis & Evergreen & Continuous & & Supra-annual \\
\hline P. macroloba & Evergreen & No Data & & No Data \\
\hline H. alchorneoides & Evergreen & Continuous & & Annual \\
\hline S. amara & Evergreen & Annual & Synchronous & Annual \\
\hline D. panamensis & $\overline{\text { Deciduous }}$ & Annual & Synchronous & Annual \\
\hline L. ampla & Deciduous & Annual & Synchronous & Annual \\
\hline$\overline{B . e l e g a n s}$ & Deciduous & Annual & Asynchronous & Annual \\
\hline H. mesoameric & Deciduous & Sub-annual & Asynchronous & Supra-annual \\
\hline
\end{tabular}


Figure 4. Seasonal leaf cover for species showing seasonal patterns of leaf drop or flushing. The proportion of individuals of deciduous species with canopies occupied by greater than $75 \%$ leaf cover of mature leaves (solid bars) or evergreen species with $25 \%$ or more cover of newly expanded leaves (open bars).

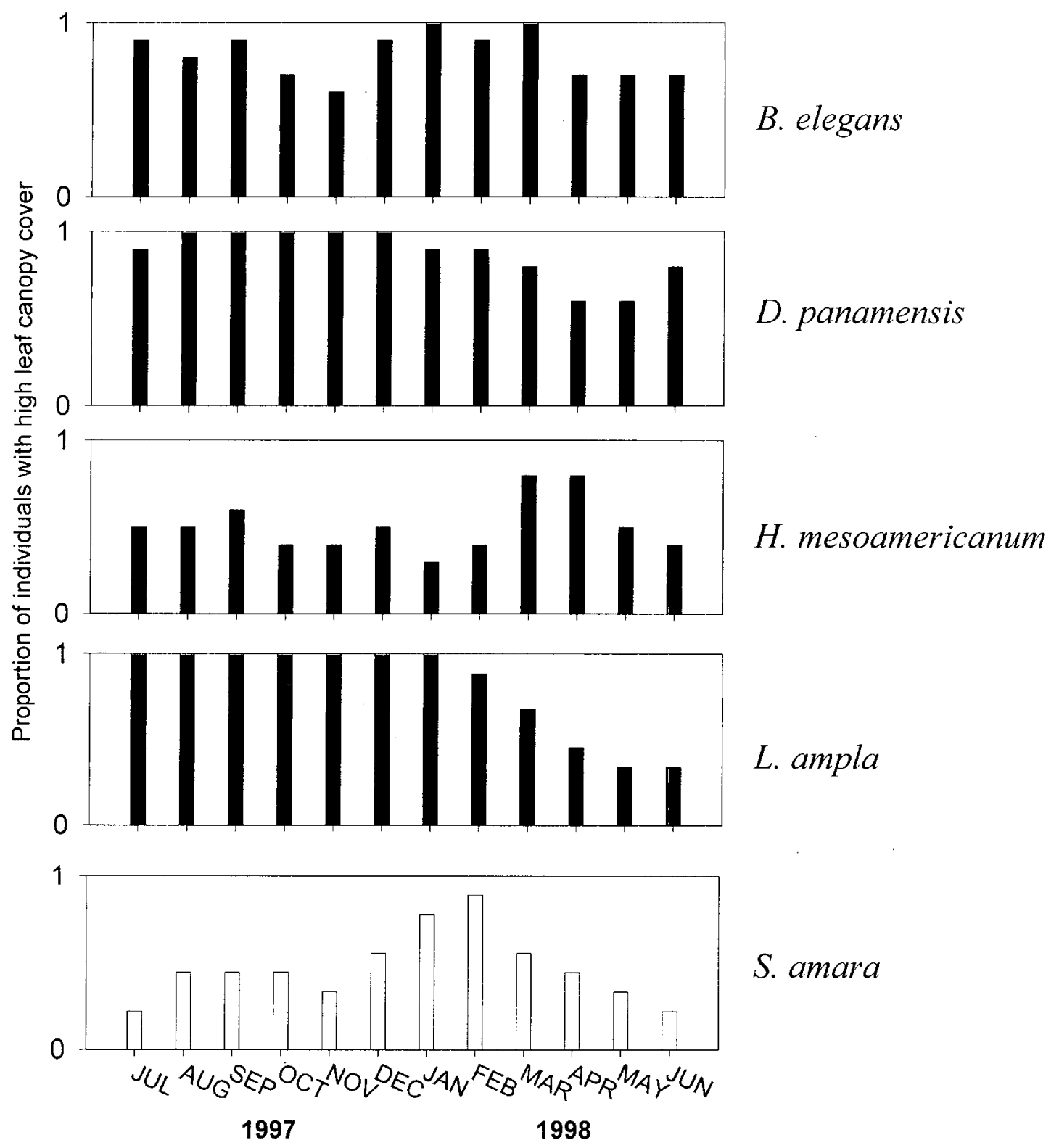


Figure 5. Synchronization of leaf phenology of the deciduous species. Each solid line represents the crown cover of mature leaves of an individual tree.
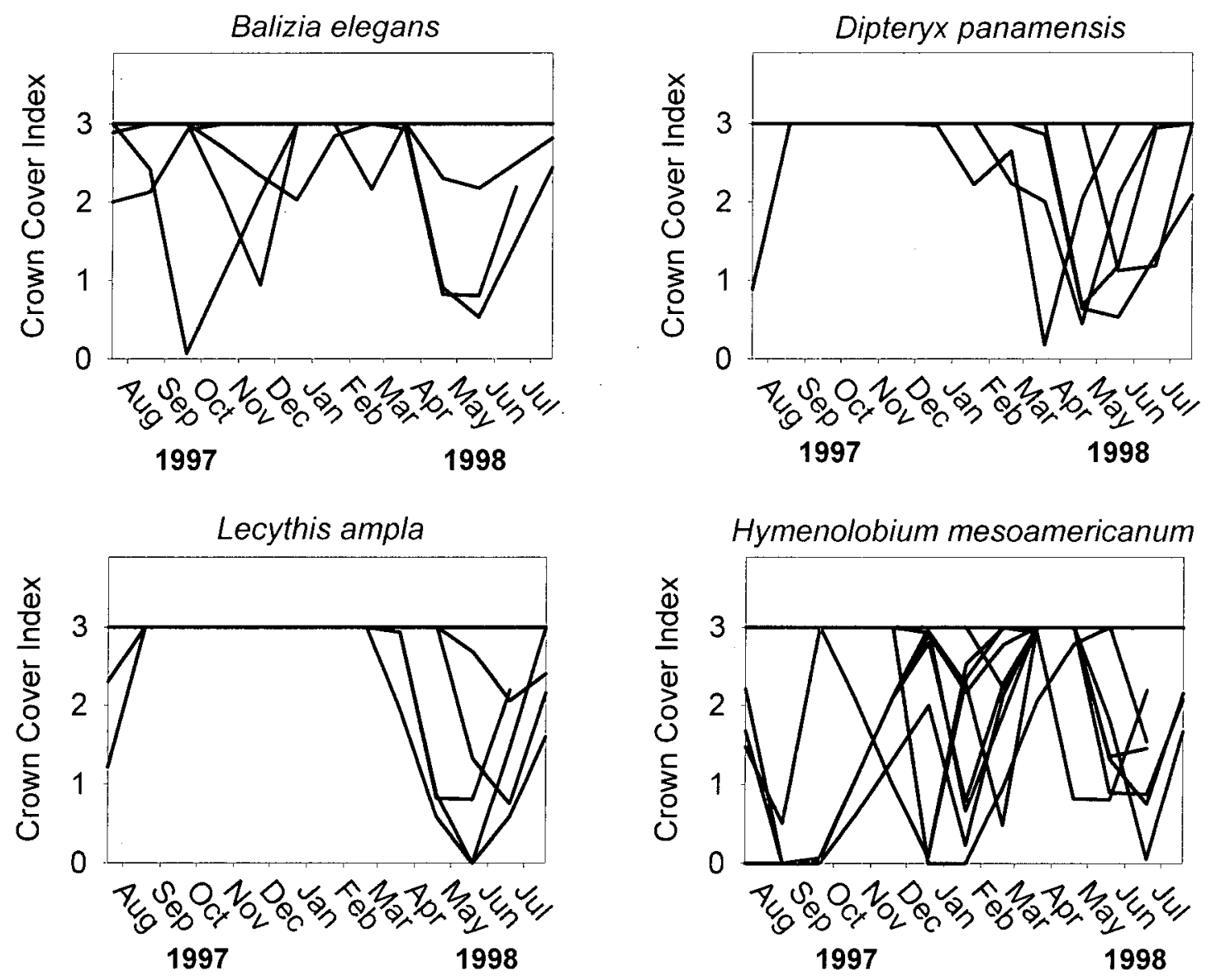
Figure 6. Flowering phenology of the study species. The bars represent the proportion of the trees flowering at least $25 \%$ capacity (inferred from crown size).

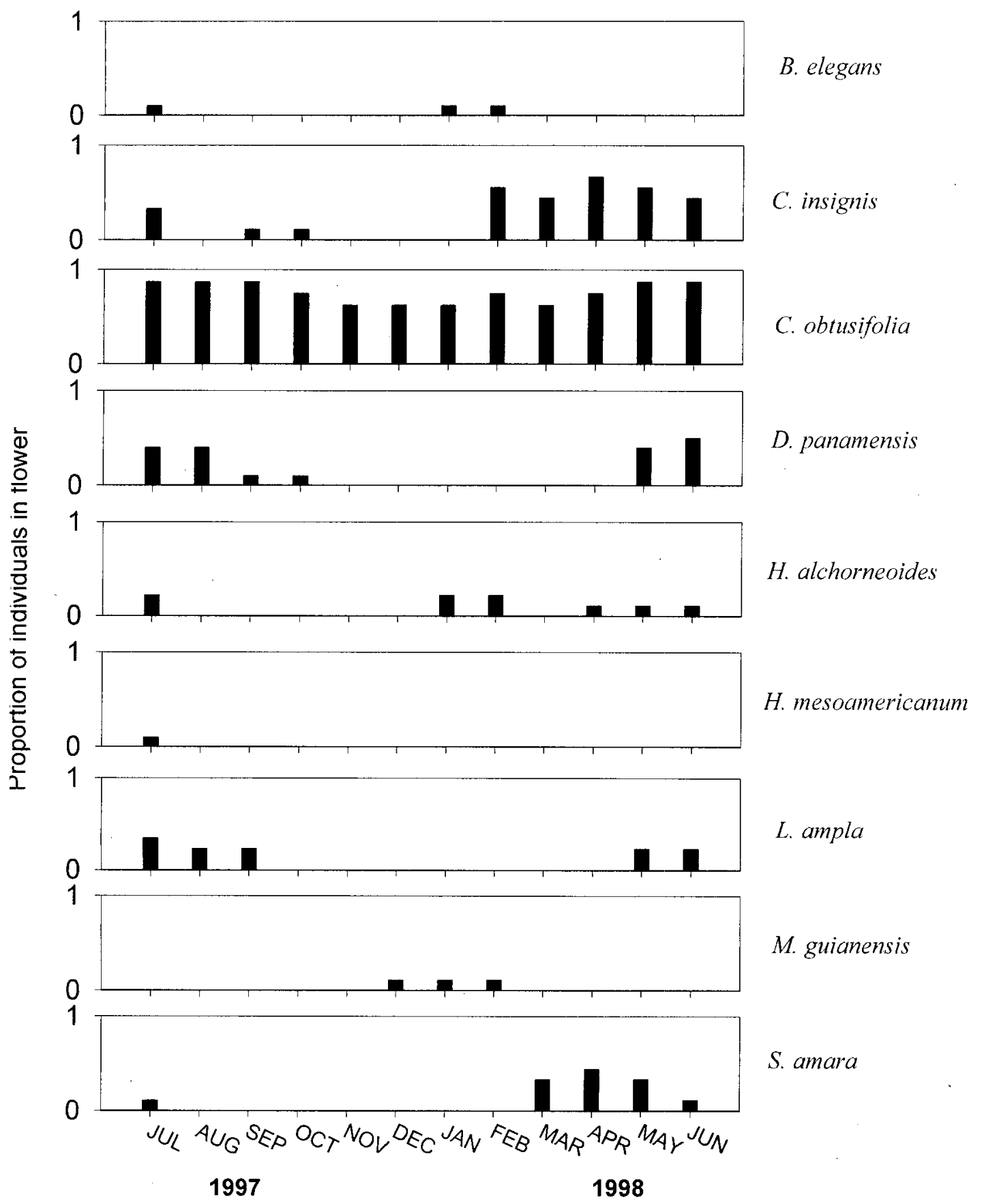


flower production differed. H. mesoamericanum had a mast flowering event just prior to the beginning of our measurements. Minquartia guianensis only flowered sporadically during the observation period and never produced flowers in abundance. Only C. obtusifolia produced reproductive structures continuously. Few $B$. elegans and $H$. alchorneoides individuals we followed flowered, therefore we did not find any seasonal phenological patterns in these species.

There was no general correlation between the timing of leaf exchange and timing of flowering: e.g. H. mesoamericanum had annual leaf exchange but flowered supra-annually and $S$. amara had no annual leaf exchange but flowered annually. The timing of leaf and reproductive phenology was linked in two species; Lecythis ampla and D. panamensis both flowered shortly after leaf exchange.

\section{Growth}

Stem growth rhythms appeared either seasonal or continuous (Figures 7 and 8). Plots of the monthly growth increments show this pattern clearly; the deciduous species generally had variable stem growth rates, with $D$. panamensis and $L$. ampla having the most noticeable pattern (Figure 7). The slowing of growth seemed to coincide with the periods when these species were leafless. The growth trajectories of the evergreen species did not appear to fluctuate regularly or have seasonal rhythms (Figure 9).

The repeated measures ANOVA showed a significant 3-way interaction among species, month, and year (Pillai's Trace $=1.705, p<0.001$ ). Mean monthly diameter growth rates ranged from $0.213 \mathrm{~mm}$ to $0.879 \mathrm{~mm}$. Although yearly mean diameter growth varied among species, it did not vary within species (Figure 8 ).

The complicated 3-way interaction between the effects of species, month and year, masked the effect of interest: did species growth rates vary seasonally? To test for seasonal growth rhythms, we looked for differences in the species mean diameter growth rates within each year separately, and then compared the results of the two separate analyses. This technique, known as a test for simple main effects, reduces the number of pair-wise comparisons necessary if the higher order interactions are not of interest (Winer et al. 1991). Within each year, there was a species by month interaction indicating that different species had different growth rhythms (Table 4). Since there was an interaction between species and months, we compared months within each species case-by-case. Even though we applied the simple means technique, there were still a large number of pair-wise comparisons, therefore we used a conservative Bonferroni correction on our post-hoc tests to minimize Type I error rates.

Tests of simple main effects were significant for eight out of ten species for at least one year (Table 5). The other two species, C. obtusifolia and M. guianensis, did not have any differences in monthly growth over the entire study period: Table 6 contains the results of the pairwise comparisons among months for the eight taxa that varied significantly. Seven of the eight species with significant ANOVA tests had significant differences in monthly growth rates. The single exception, $C$. insignis, had differences that occurred in some other linear combination of means, but not in any pair-wise contrasts of monthly means. Three evergreen species had variable monthly grow rates. Pentaclethra macroloba grew less in February 1999 than June 1999. In 1997, H. alchorneoides grew faster in June than in February and March, and growth in May was greater than growth in March. A possible growth spurt occurred in S. amara during the months of October and November, though the pattern only occurred in 1997-98.

Of the deciduous species, two showed more consistent growth rhythms than the others. Dipteryx panamensis and L. ampla had significantly higher growth in the months following leaf exchange compared to the months just before and during leaf fall. Balizia elegans grew more 
Figure 7. Growth curves of the four deciduous species. The curves represent cumulative growth increment from the initiation of band reading, not trunk diameters.
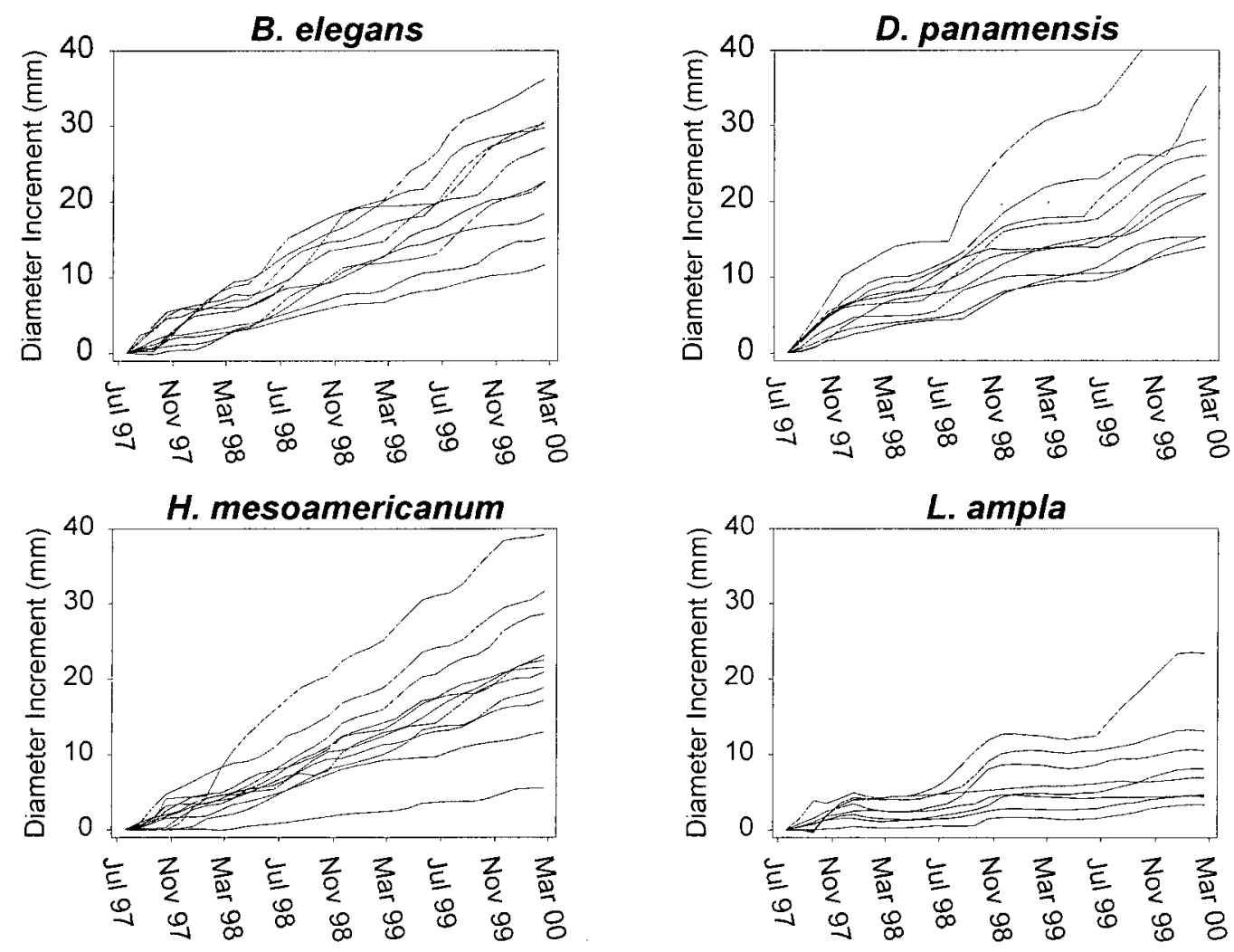
Figure 8. Growth curves of the six evergreen species. The curves also represent cumulative growth increment from the initiation of band reading, not trunk diameters.
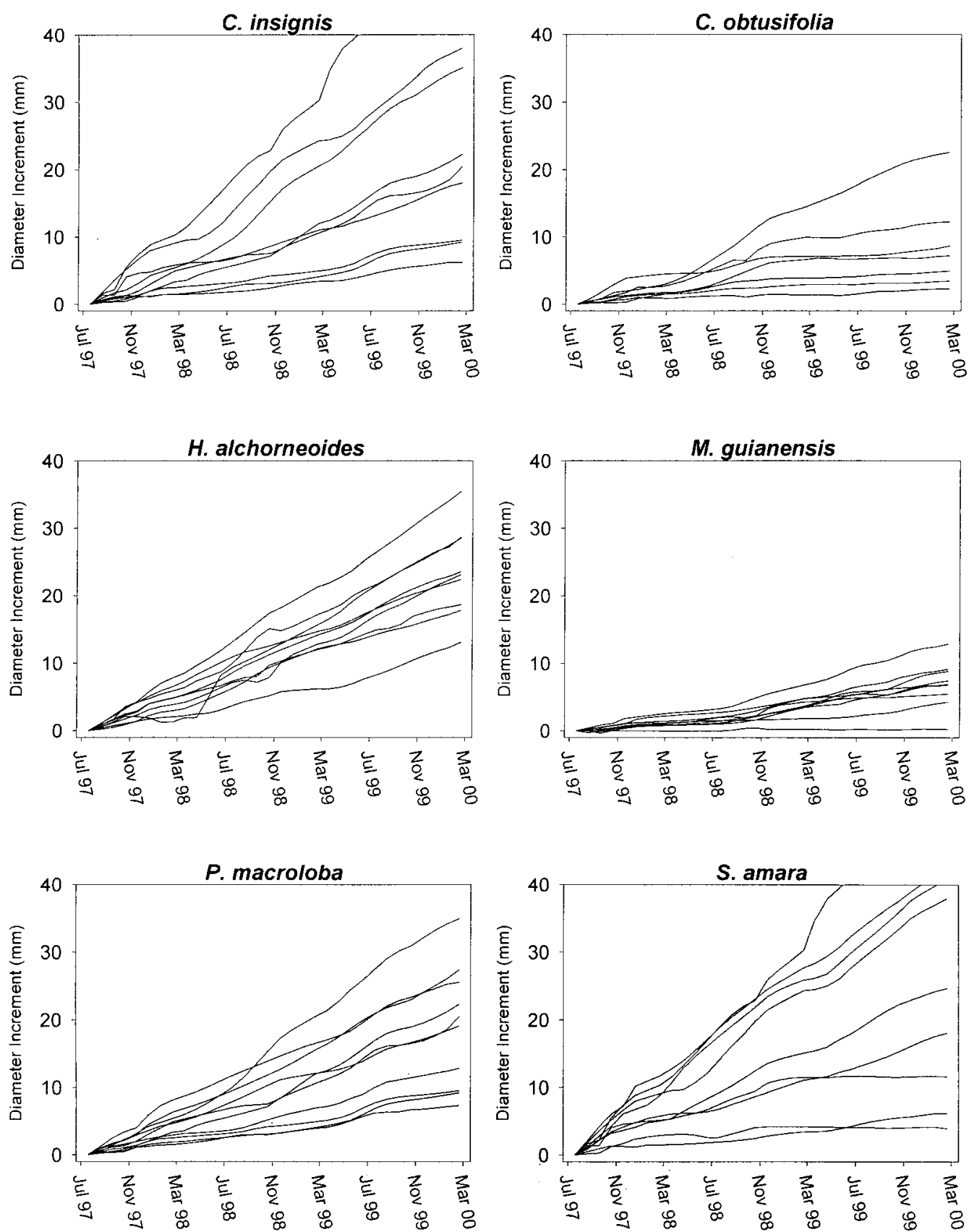
Figure 9. Mean growth of the ten species. The solid bars represent growth from August 1997 to July 1998, and the open bars represent growth from August 1998 to July 1999. The vertical lines are one standard deviation. There was no difference in growth rates between the two years ( $p>0.05$ ). Species that did not differ at $\alpha=0.05$ are marked by the four lines under the $x$-axis.

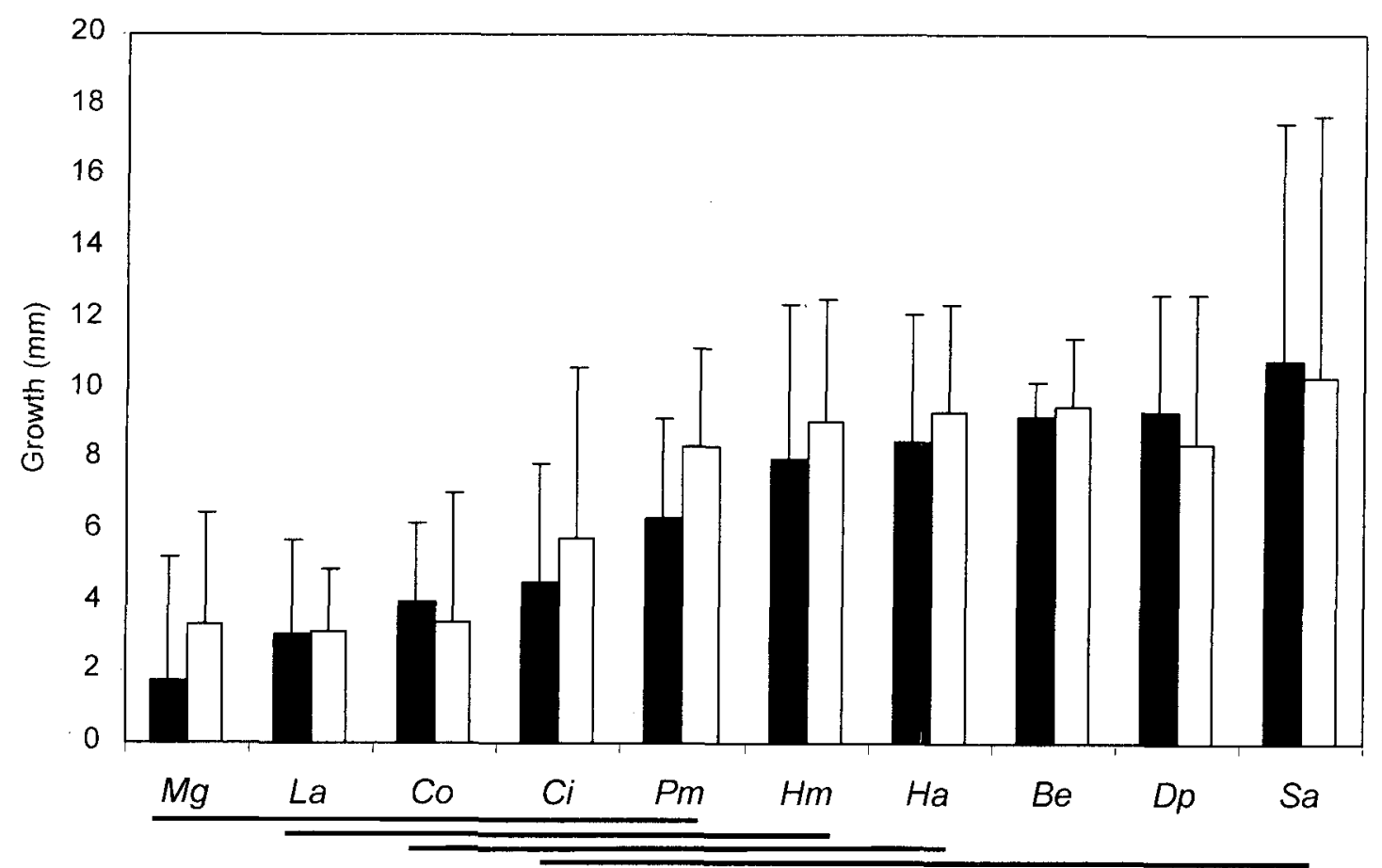


Table 4. Results of multivariate simple means interaction tests.

Year Effect Pillai's Trace F Hypothesis df Error df Sig.

\begin{tabular}{llllll}
\hline 1997-98 Month by Species & 1.63 & 1.61 & 99 & 720 & 0.0004 \\
1998-99 Month by Species & 2.07 & 2.17 & 99 & 720 & 0.0000
\end{tabular}

Table 5. Results of simple means tests for between month growth variation within species and within years.

Species Year Pillai's trace F Hypothesis df Error df Sig.

\begin{tabular}{ccccccc}
\hline $\mathrm{Be}$ & $1998-99$ & 0.483 & 6.11 & 11 & 72 & 0.000 \\
$\mathrm{Ci}$ & $1997-98$ & 0.234 & 2.00 & 11 & 72 & 0.041 \\
& $1998-99$ & 0.289 & 2.66 & 11 & 72 & 0.006 \\
$\mathrm{Co}$ & $1997-98$ & 0.077 & 0.55 & 11 & 72 & 0.865 \\
& $1998-99$ & 0.198 & 1.61 & 11 & 72 & 0.113 \\
$\mathrm{Dp}$ & $1997-98$ & 0.487 & 6.23 & 11 & 72 & 0.000 \\
& $1998-99$ & 0.465 & 5.68 & 11 & 72 & 0.000 \\
$\mathrm{Ha}$ & $1997-98$ & 0.281 & 2.56 & 11 & 72 & 0.009 \\
& $1998-99$ & 0.176 & 1.39 & 11 & 72 & 0.195 \\
$\mathrm{Hm}$ & $1997-98$ & 0.339 & 3.36 & 11 & 72 & 0.001 \\
& $1998-99$ & 0.483 & 6.11 & 11 & 72 & 0.000 \\
$\mathrm{La}$ & $1997-98$ & 0.373 & 3.89 & 11 & 72 & 0.000 \\
& $1998-99$ & 0.301 & 2.81 & 11 & 72 & 0.004 \\
$\mathrm{Mg}$ & $1997-98$ & 0.035 & 0.24 & 11 & 72 & 0.994 \\
& $1998-99$ & 0.047 & 0.33 & 11 & 72 & 0.978 \\
$\mathrm{Pm}$ & $1997-98$ & 0.182 & 1.46 & 11 & 72 & 0.167 \\
& $1998-99$ & 0.302 & 2.83 & 11 & 72 & 0.004 \\
$\mathrm{Sa}$ & $1997-98$ & 0.388 & 4.14 & 11 & 72 & 0.000 \\
& $1998-99$ & 0.354 & 3.59 & 11 & 72 & 0.000
\end{tabular}


slowly in the months of June and July, though not in both years. Hymenolobiun mesoamericanum had a similar response; growth was greater in December to February compared to April and May, but only in 1998-99. The growth patterns in B. elegans and H. mesoamericanum were not strongly seasonal, which might be explained by the lack of synchrony in the shedding of leaves (Figure 5).

Only two species showed strong seasonal differences in growth, where monthly growth rates differed in a clear pattern (Table 6). Lecythis ampla and D. panamensis showed significantly slower growth rates in or immediately following the spring dry season respectively.

\section{Effects of phenology on growth}

Logistic regression analysis of the effect of leaflessness on growth showed that growth in months following leaf shedding was significantly slower than in other months in all the deciduous species except $B$. elegans (Table 7). Other lags did not show as strong an effect. Trees without a full canopy of leaves the month before measurement were $2.6(\mathrm{H}$. mesoamericanum), 4.4 (L. ampla), and 9.3 (D. panamensis) times more likely to grow less than average than trees with a full crown. B. elegans trees without leaves were less likely to grow as well as fully leaved trees, but the effect was not significant at $\alpha=0.05$, which was due to the small number of leafless trees during the study period. In contrast, we found no significant effect of reproduction on growth for any species (Table 8 ).

\section{Discussion}

Distinctly seasonal growth rhythms occurred in two of the ten species, both of which were deciduous with synchronous leaf drop. None of the evergreen species or asynchronously deciduous species had clearly seasonal patterns of growth. Not surprisingly, leaflessness slowed growth, and there was little lag in the growth response to leaflessness; the slowest growth occurred in the months immediately after leaf drop. These species might be dependent on recently fixed carbon unavailable during leafless periods. Alternatively, stored resources might have been insufficient to maintain growth or were directed elsewhere. Latt et al. (2001) found that in several species of tropical dry forest trees, growth depended on both recently fixed and stored carbohydrates. Hormonal growth regulation mediated by leaves could also have been disrupted during the leafless periods. Which of these or other factors was driving the decline in growth we cannot determine.

Growth in the evergreen taxa was nearly continuous, with brief periods of slower growth but no obvious periods of dormancy. In contrast to this study, Hazlett (1987) and Breistsprecher and Bethel (1990) found long periods of dormancy in several taxa growing in the same forest, including $D$. panamensis, $H$. mesoamericanum, and $P$. macroloba. The study period they reported on was not unusually dry or wet compared to our study period, ruling out meteorological explanations for the discrepancy. The dormant periods observed by those authors were sufficiently long that we should have been able to detect them in monthly censuses, so different sampling techniques were also not an adequate explanation. Rather, the lack of dormancy we observed was likely due to our selection of healthy, unshaded trees in the fastest growing size class. Older trees, trees overtopped by other trees, or diseased trees might be expected to show periods of undetectable growth or be more sensitive to unfavorable weather conditions.

We did not detect any effect of reproductive activity on growth. The amount of resources directed to reproductive activities may be masked by the size of the pool consumed by stem growth or leaf flushing. In some species, flowering occurred coincident with the peak of new leaf 
Table 6. Tabulations of the pair-wise comparisons of growth increments among months over the two years analyzed. The tables include data from the seven species with at least one significantly different pair-wise comparison among monthly means. If a cell is blank, the mean growth between those months did not differ. A plus sign indicates the row mean was significantly higher than the column mean, a minus sign indicates that the row mean was significantly lower than the column mean. A sign to the left of the vertical bar indicates the means differed in the 1997-98 season, a sign to the right indicates a difference in the 1998-99 season. Signs on both sides indicate the means differed in both years.

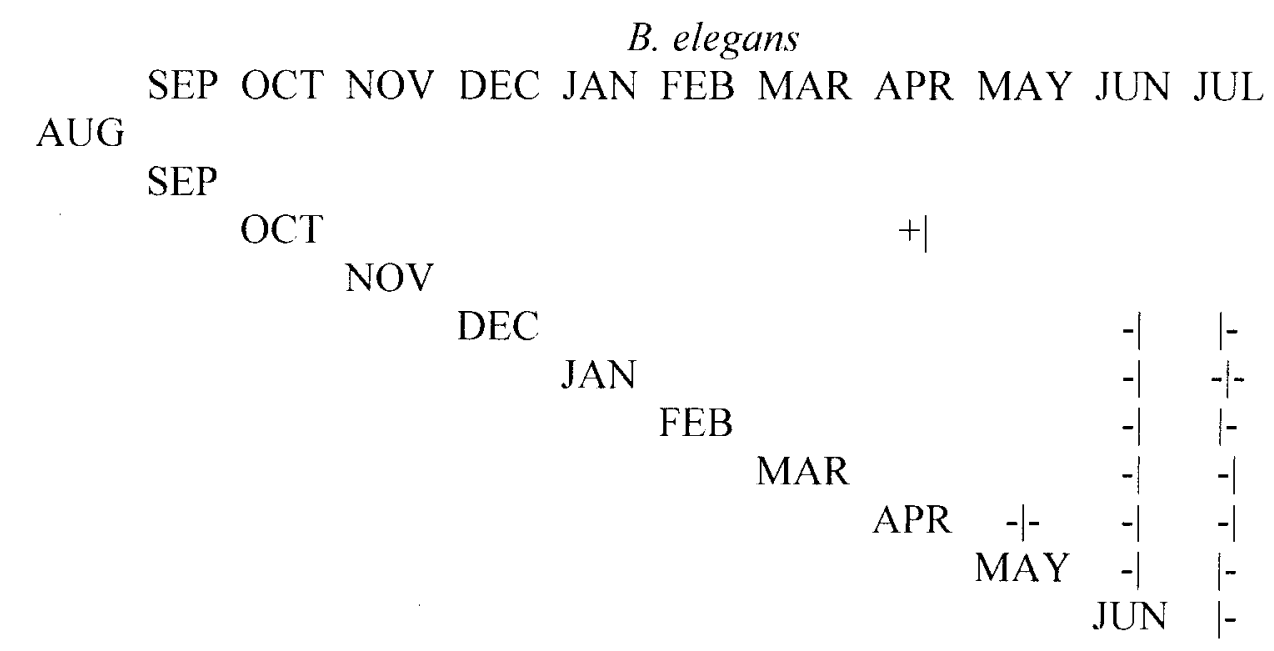


Table 6 cont.

\section{D. panamensis}

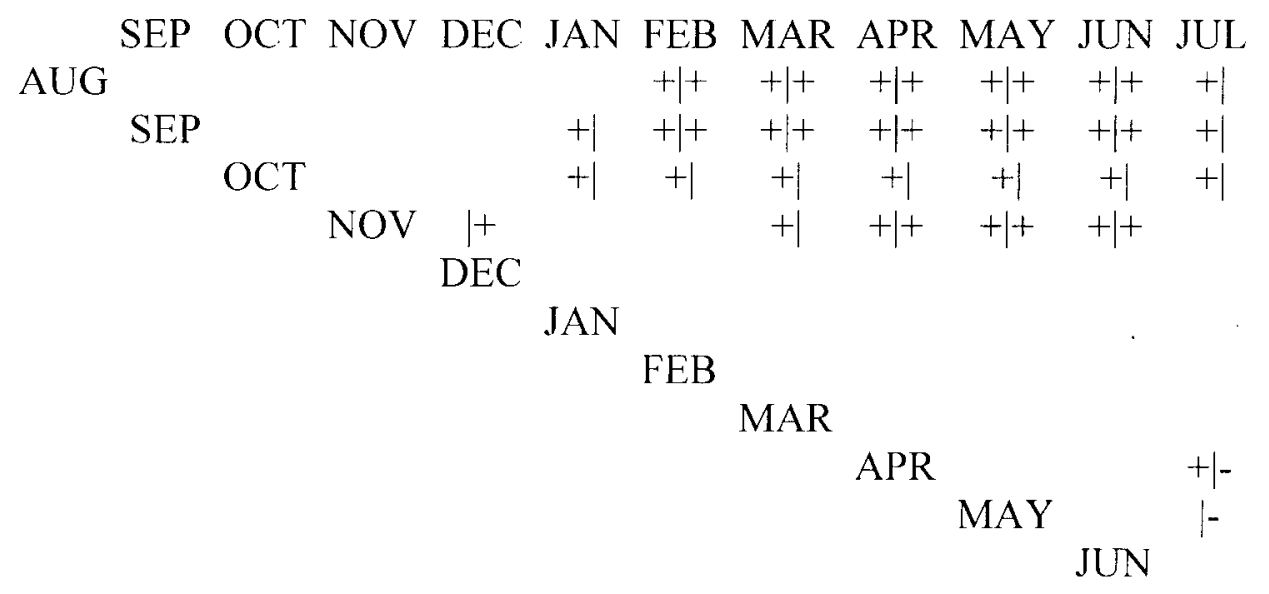

H. alchorneoides

SEP OCT NOV DEC JAN FEB MAR APR MAY JUN JUL AUG

SEP

OCT

NOV

DEC

JAN

FEB

$\begin{array}{cccc}\text { MAR APR } & -1 & -1 \\ & \text { MAY } & \\ & & \text { JUN }\end{array}$ 
Table 6 cont.

\section{H. mesoamericanum}

SEP OCT NOV DEC JAN FEB MAR APR MAY JUN JUL AUG SEP OCT

NOV

DEC JAN

FEB

L. ampla

SEP OCT NOV DEC JAN FEB MAR APR MAY JUN JUL AUG

$$
\begin{aligned}
& \text { SEP } \\
& \begin{array}{lccccc} 
& & \mid+ & \mid+ & & \mid+ \\
\text { OCT NOV } & & +\mid+ & +\mid+ & +1+ & +\mid+ \\
& +1 & +1 & & +1
\end{array} \\
& \text { JAN } \\
& \text { FEB } \\
& \text { MAR } \\
& \text { MAY } \\
& \text { JUN }
\end{aligned}
$$


Table 6 cont.

\section{P. macroloba}

SEP OCT NOV DEC JAN FEB MAR APR MAY JUN JUL AUG

SEP OCT NOV

DEC JAN

FEB MAR

APR

MAY

JUN

S. amara

SEP OCT NOV DEC JAN FEB MAR APR MAY JUN JUL AUG

SEP

$$
\begin{aligned}
& \begin{array}{lllllll}
\text { OCT } & & +\mid & +\mid & + & + & +1 \\
\operatorname{DEC} & & & & &
\end{array} \\
& \text { JAN } \\
& \text { FEB } \\
& \text { MAR } \\
& \text { MAY }
\end{aligned}
$$


Table 7. Results of logistic regression on crown status and growth for each species. The crown status represented whether or not the crown was fully occupied by leaves ( $>75 \%$ cover) the month prior or the month of stem measurement. The positive coefficients indicated that there was a greater chance that a tree with a full crown grew better than average. The exponentiation of the B coefficient represents the log-likelihood ratio.

\section{Balizia elegans}

\begin{tabular}{rrrrrr} 
B & S.E. & Wald & df & Sig. & $\operatorname{Exp}(\mathrm{B})$ \\
\hline 0.854 & 0.478 & 3.195 & 1 & 0.074 & 2.349
\end{tabular}

Lecythis ampla

\begin{tabular}{rrrrrr} 
B & S.E. & Wald & df & Sig. & $\operatorname{Exp}(\mathrm{B})$ \\
\hline 0.965 & 0.387 & 6.203 & 1 & 0.013 & 2.624
\end{tabular}

\section{Hymenolobium mesoamericanum}

\begin{tabular}{rrrrrr} 
B & S.E. & Wald & df & Sig. & Exp(B) \\
\hline 2.228 & 0.348 & 40.943 & 1 & 0.000 & 9.286
\end{tabular}

\section{Dipteryx panamensis}

\begin{tabular}{rrrrrr} 
B & S.E. & Wald & df & Sig. & Exp(B) \\
\hline 1.470 & 0.403 & 13.326 & 1 & 0.000 & 4.351
\end{tabular}

Table 8. Results of the logistic regression on reproduction and growth. Any reproductive activity the month prior to measurement was the independent variable.

B Coeff. S.E. Wald Statistic df Sig. Exp(B)

\section{Reproductive Activity}

$\begin{array}{llllll}0.07 & 0.54 & 0.261 & 1 & 0.609 & 1.082\end{array}$


production, so the drain on resources dedicated to the production of non-photosynthetic organs might be offset by the higher photosynthetic capacity of new leaves. Nevertheless, flowering and fruiting did not affect growth in the evergreen and deciduous species where leaf flushing or leaf exchange did not directly coincide with reproduction, indicating that the amount of energy trees diverted to these activities might not have been sufficient to slow growth. Alternatively, the effect of reproductive activity on growth may have been too small to detect by our methods, or in species such as D. panamensis, in which flowers and fruit are produced over a long period of time, any effect of reproduction on growth would have been spread over several months making detection of the magnitude of the effect difficult.

Maximizing the capture of light could be one of the most important factors driving the phenology of rainforest trees (Wright and van Shaik 1994). Oberbauer and Strain (1986) showed that light levels were the limiting factor in $P$. macroloba canopies. Light limitation might be ubiquitous in wet tropical forest trees: Raich et al. (1991) and Oberbauer et al. (2000) reported that irradiance drove whole forest net primary productivity in Central American and Amazonian forests. Using cost-benefit analysis, Kikuzawa (1991) predicted that evergreen plants are favored under weakly seasonal conditions such as those found at our study site, and deciduousness becomes more common as seasonality becomes more pronounced. Indeed, in the weakly seasonal environment of La Selva, the majority of canopy trees are evergreen, but deciduous species are not uncommon, especially in emergent taxa. These species had growth rates equivalent to or greater than evergreen taxa (Figure 9). Why then would deciduous species persist in this weakly seasonal environment?

Old leaves are shed immediately or shortly following the period of highest irradiance in the deciduous taxa D. panamensis and L. ampla. Leaflessness occurring during the annual period of lower light would minimize the impact of reduced photosynthesis by a leafless or partially leafless canopy. This would also maximize the amount of time for leaf expansion and chloroplast development prior to high light conditions, but also would expose the leaves to herbivores, physical damage, or pathogens for a longer period prior to months with higher light. Maximizing light capture might also be driving phenological patterns in some evergreen species such as $S$. amara that flush more new leaves coincidentally with the period of highest light. These young leaves might have higher assimilation rates than older, senescent leaves (Wilson et al. 2000).

Leaflessness could also be a mechanism for drought avoidance (Fetcher et al. 1994). Though drought is rare at La Selva, D. panamensis and L. ampla species occur over much wider ranges and in areas where rainfall is much more seasonal, and leaflessness can be a drought avoidance mechanism. If drought were severe enough to initiate leaf shedding, the leaves would be near the end of their lifespan and cost to the tree would be mitigated. Although light limitation seems to be driving phenology in the tropics, leaf construction costs, photosynthetic capacity and the relationship between photosynthetic efficiency and leaf age also affect phenological patterns (Kikuzawa 1995). Asynchronous leaf exchange, such as seen in B. elegans and $H$. mesoamericanum, might be a mechanism to avoid herbivory by minimizing the amount of palatable leaves of a species present in the forest at any one time (Janzen 1974).

Seasonal leaf drop could also be a result of phylogenetic inertia in some of the deciduous species, such as species in the genera Dipteryx and Lecylhis, whose center of diversity occurs in the central and northern Amazon, where the climate is more seasonal. This is unlikely in the case of Lecythis, since there are some evergreen species that co-occur with deciduous species in the Amazon, suggesting the evolution of different strategies. Information on the phenology of all the Dipteryx species is incomplete, therefore the plasticity of leaf exchange in this genus cannot be assessed. 
One of the predictions of general circulation models is a change in the degree and patterns of seasonality in the tropics; the climate of Central America and elsewhere is predicted to have greater seasonal variability in soil moisture, driven by changes in rainfall patterns (Hulme and Viner 1998). The degree of plasticity in tropical tree phenological response to changing climatic cues is unknown, but is high in temperate species (Chuine et al. 2000). While phenological plasticity could also be high in the tropics, large climatic changes could still affect the competitive ability of species with different phenological strategies. Alteration in the pattern of seasonal irradiance could cause a shift in forest composition as the relative competitive ability of deciduous and evergreen species shifted. If plasticity of tropical tree phenology were low, the effects of any changes in climatic seasonality on tropical forests would be magnified. If rainfall and irradiance become more seasonal, deciduous species might become more abundant. A cascade of changes in forest species composition could then occur as seedlings and understory trees respond to higher light conditions due to a leafless overstory. Carbon fixation would also diminish and respiration of stored carbohydrates would increase in deciduous taxa during leafless periods which would alter forest carbon dynamics. While the likelihood of this scenario is unknown, our results indicate the potential impact of phenology on forest carbon dynamics and species composition.

Investigations of tree growth, carbon cycling, and climate change in wet tropical forests must consider the interaction of climate and phenology on tree and forest carbon dynamics. In this study, both seasonally and non-seasonally deciduous species grew less following leaflessness. An examination of the correlation between climate and growth would be masked by slowed growth driven by leafless canopies in these species, not by a direct effect of climate during these periods of leaflessness. Depending on the proportion of deciduous taxa in a forest, the relationship between whole forest carbon uptake and climate could become partially decoupled as trees lost their leaves and individual tree growth slowed, especially if species were responding to only one or few environmental cues. This effect might be magnified should the predicted increased seasonality occur, and deciduous taxa became more dominant in areas currently occupied by evergreen tropical forests. 


\section{ASSESSMENT OF NET PRIMARY}

\section{VI.1. Course Woody Debris Stocks and Fluxes}

\section{Introduction}

Large fallen dead wood, termed coarse woody debris (CWD), plays a variety of ecological roles in forest systems. Depending on the forest type, stage of succession, land use history and management practices, the pool of CWD may contain significant portions of a given forest's carbon and nutrient stocks. McGee at al. (1999) and Spetich et al. (1999) reviewed several dozen studies showing the importance of CWD in temperate forests for a range of plant and animal groups, including amphibians, reptiles, birds, mammals, arthropods, vascular plants, bryophytes, lichens and fungi. In addition, CWD has strong physical and biological effects on freshwater ecosystems (Harmon et al. 1985). The biomass, rates of production, and ecological roles of large pieces of dead wood have been extensively studied in temperate forests. More than a decade ago Harmon et al. (1985) reviewed $>500$ papers on CWD ecology in temperate forests, and hundreds of articles have been published subsequently. In contrast, data on CWD stocks and inputs in lowland tropical rain forests (TRF) are limited (Yoneda et al. 1977;1990; Raich 1983; Foster Brown et al. 1995; Delaney et al. 1998), and studies on the ecology of tropical CWD are few.

Tropical landscapes play a key role in the global carbon cycle due to the large amounts of carbon currently stored there (Dixon et al. 1994) and to high rates of land use change. CWD is potentially a significant component of the stocks and fluxes of tropical forest carbon cycles. However, there are currently insufficient data from tropical forests to adequately evaluate CWD total stocks, annual inputs, and the factors that control these variables. One aspect in particular that has not been addressed is the issue of how to scale up estimates from small plots to larger landscapes.

In this research our goal was to assess the magnitude of CWD stocks and inputs across an upland old-growth TRF landscape. We asked if within-landscape variation in soil nutrients, topography and various metrics of stand structure and function influenced the magnitude of CWD stocks and inputs. This study was conducted within a larger project analyzing the factors that control carbon stocks and fluxes in old-growth lowland TRF (the Carbono Project). The experimental design was conceived specifically to enable comparisons between areas of similar topography but widely differing soil nutrients, and between areas with similar soil nutrients but contrasting topography. We thus had a priori planned comparisons for soil nutrient effects controlling for topography, and for topographic effects controlling for soil nutrients.

Our questions were:

1) What are the stocks of CWD under different soil nutrient and topographic conditions in this old growth tropical wet forest?

2) What are the rates of CWD input, and what factors control these rates?

3) Are CWD stocks and inputs related to stand structure and dynamics?

4) How accurate were the estimates we obtained for stocks and rates of input of CWD, and what does this tell us about sampling strategies and scaling up?

5) What is the current role of CWD in TRF carbon and nutrient cycling, and how might this change with on-going global climate change? 


\section{Methods}

Study site

The study site was the La Selva Biological Station in Costa Rica. La Selva is classified as tropical wet forest in the Holdridge system (Hartshorn and Peralta 1988), and averages ca. 4000 mm annual rainfall and $26^{\circ} \mathrm{C}$ (Sanford et al. 1994).

Our study area is all upland (non-swamp) old growth. We used a network of 180.5 ha plots that were sited to sample three edaphic conditions in an unbiased fashion: flat inceptisol (old alluvial) terraces, flat ultisol ridgetops, and steep ultisol slopes. Details of plot siting, stand structure and a map are given in Clark and Clark (2000). We annually measured stem diameter $( \pm 1 \mathrm{~mm})$ at breast height or above buttresses and assessed mortality for all trees, palms, and lianas $\geq 10 \mathrm{~cm}$ diameter in all 18 plots. We also measured annually the diameter of all standing dead stems, and in 1999 their height, using a 15 telescoping rod or a laser rangefinder. Data from the September 1997, 1998, and 1999 censuses were used here (the study is on-going).

\section{Documentation of treatment soil and slope conditions}

To document nutrient conditions among treatments we sampled soil to $1 \mathrm{~m}$ depth in all plots. Soil samples came from six composited samples per plot for the inceptisol and ultisol plateaus, and from 18 composited samples from the ultisol slope plots (6 each from upslope, midslope, and downslope positions). Sample depths were 0-10, 10-30, 30-50, and 50-100 cm.

To document slope conditions we measured slope angle $\left( \pm 0.5^{\circ}\right)$ at 55 standard locations in each plot using a clinometer sighting between two vertical $1.5 \mathrm{~m}$ tall staffs.

\section{Estimation of CWD standing stocks}

As a pilot study to determine the CWD sampling possible given available resources, we mapped every piece of C.WD with a minimum diameter of $10 \mathrm{~cm}$ in one plot (A2). We measured the length plus three diameters of each piece of CWD, then sketched it in pencil on waterproof paper maps. A large tree calipers was used for diameter measurements $(+/-1 \mathrm{~cm})$. For pieces that crossed the plot boundaries only the section within the plot was measured. For sections that decreased in diameter to $<10 \mathrm{~cm}$, only the section $\geq 10 \mathrm{~cm}$ diameter was measured. The volume of each piece was calculated using Newton's formula (Harmon and Sexton 1996), minus the volume of externally visible hollow sections, calculated as cones using $V=\pi r^{2} *(h / 3)$ where $\mathrm{V}=$ cone volume, $\mathrm{h}=$ height of cone and $\mathrm{r}$ the radius of the base. There were 174 pieces of $\mathrm{CWD}$ in the half hectare. Pieces with a maximum diameter of $\geq 30 \mathrm{~cm}(\mathrm{~N}=32)$ accounted for $78.2 \%$ of the total volume. Based on that figure and available resources we decided to map all pieces of CWD of this size in all 18 plots.

To determine how many of the pieces of CWD between 10 and $30 \mathrm{~cm}$ diameter could be measured, we calculated the total volume of CWD of this size for each of the 100.05 ha subplots in the pilot 0.5 ha plot. We calculated (Zar 1996, 3rd edition, pg. 108) the number of 0.05 ha subplots necessary to measure the average mass of the $10-30 \mathrm{~cm}$ diameter component of CWD to within differing accuracies with $95 \%$ confidence. For estimates within $\pm 50 \%, 11$ subplots would have been required (note that there are only 10 such subplots per 0.5 ha plot). Given that the 10 $30 \mathrm{~cm}$ diameter CWD was found to be only ca. $20 \%$ of the volume, we decided to map this size class in three 0.05 ha subplots in each CARBONO plot. The 30.05 ha plots were selected to span the 0.5 ha plot (the same 0.05 ha plots were used in all 0.5 ha plots).

All pieces were classified in one of three decay categories: 
Sound: More than $75 \%$ of the volume intact and/or hard. This could be a recently fallen bole or branch, or could be a piece that had weathered until only the hard heartwood was left (a common situation with the dominant tree species Pentaclethra macroloba (Mimosaceae)).

Fully decayed: More than $75 \%$ of the wood soft and rotten, a machete blade entered easily, collapsed when stepped on.

Partially decayed: Intermediate between Sound and Fully Decayed.

To sample for density, a further subsampling of the mapped pieces was necessary for strictly logistic reasons. We assumed that within-log density variance would increase with log length. Given the available resources, we decided to sample logs at the rate of 1 sample per 4 meters length. Thus, for $\operatorname{logs} \leq 4 \mathrm{~m}$ long we extracted 1 sample, $>4-8 \mathrm{~m} 2$ samples, $>8-12 \mathrm{~m} 3$ samples etc. The location of each sample was determined by eye to divide the log into equal length sections. We sampled for density in this way all CWD pieces $>50 \mathrm{~cm}$ diameter, $50 \%$ of all pieces $30-50 \mathrm{~cm}$ diameter, and $33.3 \%$ of pieces $10-30 \mathrm{~cm}$ diameter. For the $30-50 \mathrm{~cm}$ pieces we selected every other piece as they appeared in order on the datasheet; for the $10-30 \mathrm{~cm}$ pieces, we took every third piece. Samples were cut in wedge-shaped sections from the exterior to the center of each piece with a chain saw. In the field, some logs were measured as two or more sections. These are written down as consecutive lines in the datasheets; each of these sections was considered a separate piece of CWD. The decay category of each piece was not considered in this selection.

Density of each piece was determined from volume displacement of water and oven dry weight. Volumetric displacement of water was measured in a $8 \mathrm{~L}$ pail with a right-angle $3.75 \mathrm{~cm}$ PVC tube as the water exit. A bucket was considered "stable" when it dripped 1 drop every $\geq 5 \mathrm{~s}$. The time elapsed between cutting the piece in the field and determining its volume averaged around 2-3 mo (with a maximum of ca. $5 \mathrm{mo}$ ). During the period between cutting and volume measurement, each wood piece was kept under shade-cloth and sprinkled with a hose daily to minimize shrinkage.

After volume determination the pieces were oven dried at $80^{\circ} \mathrm{C}$. Because of oven space constraints, pieces were frequently air-dried under a clear plastic roof for several weeks before oven space was available. Oven-dried pieces were weighed $( \pm 0.1 \mathrm{~g})$ until they varied $\pm \leq 0.2 \%$ between weighings. This typically took 7 to $20 \mathrm{~d}$ total oven time.

Seven samples from each of the three decay classes were haphazardly selected for analysis of $\mathrm{C}$ and $\mathrm{N}$.

To determine annual input of CWD, in 1998 and 1999 we mapped and measured all pieces of $C W D \geq 30 \mathrm{~cm}$ that appeared on the ground in that year, using the techniques described above. We measured all new CWD $10-30 \mathrm{~cm}$ diameter in one 0.05 ha subplot in each 0.5 ha plot, thus sampling $10 \%$ of the area for this size class.

\section{Results}

Inter-treatment soil nutrient stocks and slope conditions

Soil analyses confirmed the existence of a strong soil nutrient difference among treatments. Compared to the flat ultisol plots, the inceptisol plots had significantly larger stores of $\mathrm{P}$ and $\mathrm{K}$ in the first meter of soil, as well as lower $\mathrm{C} / \mathrm{N}$ ratios (Table 1). Between plots on ultisol slopes and ultisol flats, the flat plots had significantly higher stocks of $\mathrm{C}$ and $\mathrm{N}$, but the $\mathrm{C} / \mathrm{N}$ ratio did not differ, nor did stocks of $\mathrm{P}, \mathrm{K}, \mathrm{Ca}$, and $\mathrm{Mg}$.

Mean slope angles ( 55 measurements per plot) for the treatments were: $0.8^{\circ}$, flat inceptisol plots (range $\left.0.0-2.3^{\circ}\right) ; 2.2^{\circ}$, ultisol ridgetops $\left(0.2-5.7^{\circ}\right)$; and $20.9^{\circ}$, ultisol slopes $\left(17.8-26.2^{\circ}\right.$ ) 
Table 1. Mean carbon and nutrient stocks to $1 \mathrm{~m}$ depth in different edaphic conditions at the La Selva Biological Station, Costa Rica. Values are reported \pm 1 standard error of the mean. Stocks were compared between soils on the same topography (flat inceptisol versus flat ultisol) and within soil type between topographic classes (ultisol flats versus ultisol slopes). Means with different superscripts differ at $\mathrm{p}<.05$; $\mathrm{a}$ and $\mathrm{b}$ superscripts represent comparisons between soil types, $\mathrm{x}$ and $\mathrm{y}$ superscripts comparisons between topographic classes.

\begin{tabular}{|c|c|c|c|c|c|c|c|c|c|c|}
\hline $\mathbf{s} \underline{\mathbf{s}}$ & & $\underline{N}$ & $\underline{\mathrm{C} / \mathrm{N}}$ & $\underline{P}$ & & & & & & \\
\hline & 1011 & & $10.7 \pm 0.3^{\mathrm{a}}$ & & $375.3 \pm 49.1^{\mathrm{a}}$ & & & & & 3600.7 \\
\hline tis & & $18.8 \pm 0.4^{\mathrm{x}}$ & $12.0 \pm 0.1^{\mathrm{b}}$ & $5.0 \pm 0.4^{\mathrm{b}}$ & & & & & & $3405.8 \pm 101.1$ \\
\hline tisol slope & $84.6 \pm 13.6^{y}$ & $15.8 \pm 1.0^{y}$ & $11.6 \pm 0.2$ & $.7 \pm 0.8$ & $22.9 \pm 12.8$ & 250.13 .5 & $158.7 \pm 14.1$ & $59.5 \pm 13.1$ & $144.1 \pm 44.8$ & $2904.6 \pm 98.9^{y}$ \\
\hline
\end{tabular}


These results validate the basic experimental design. Comparisons of flat ultisols to flat inceptisols compare areas with soils of differing fertility but similar topography, while comparisons of flat ultisols to ultisol slopes contrast areas with similar nutrient stocks but very different topography.

\section{CWD Density and Decay Classes}

Density of CWD pieces varied significantly among decay classes (Table 2). Pieces classified as sound averaged $85 \%$ denser than fully decayed pieces; partially decayed pieces were intermediate. Between soil types, CWD density was slightly higher on the more fertile sites; between the ultisol flats and slopes, densities were higher on the slopes ( $\mathrm{P}<.001$ in both cases). The distribution of decay classes also varied significantly between slopes and flats in the ultisols $(\mathrm{P}<.04)$, due to more partially and fully decayed samples on the flats. There was no difference in frequency of decay classes between the flat sites on the two soil types.

Mean carbon concentrations decreased and nitrogen concentrations increased along the decay sequence (Table 3 ). As a consequence, mean $\mathrm{C} / \mathrm{N}$ ratios declined from 170.5 in sound samples to 119.3 in fully decayed pieces. However, sample sizes were small and the variation considerable, and only the decrease in carbon concentration was statistically significant (KruskalWallis ANOVA $\mathrm{P}<.004$ ).

\section{C.WD Stocks}

CWD averaged 46 tons per ha, distributed in 469 pieces with a total volume of $109 \mathrm{~m}^{3}$ (Table 4). The area covered on the ground, estimated as the square of the cube root of CWD volume, was $22.7 \mathrm{~m}^{2} \mathrm{ha}^{-1}$, comparable to the basal area of living trees $\left(23.6 \mathrm{~m}^{2} \mathrm{ha}^{-1}\right.$, Clark and Clark 2000). CWD biomass, volume and number of pieces did not differ significantly between flat ultisols and inceptisols, or between ultisol flats and slopes. However, all three variables were considerably higher on the ultisol slope plots than on the flat ultisols and inceptisols, suggesting that differences might be detectable with larger sample size.

$\mathrm{C}$ and $\mathrm{N}$ content for each section of CWD were calculated using the mean concentrations of these elements for each decay class (Table 3). The decay-class weighted mass percentages of CWD stocks for $\mathrm{C}$ and $\mathrm{N}$ were $48.17 \%$ and $0.304 \%$, leading to stock estimates of $22.30 \mathrm{MgC} \mathrm{ha}^{-1}$ and $1.41 \times 10^{-1} \mathrm{MgN} \mathrm{ha}^{-1}$.

\section{CWD inputs and turnover}

Annual C.WD inputs were highly variable among plots as well as between soil types and years (Table 5). There was significantly higher input in 1998 than in 1999. Comparing 1998 to 1999 , the mean number of pieces was 110 vs. 38 , mean volume $17.6 \mathrm{vs} .7 .5 \mathrm{~m}^{3}$, and mean mass $8.0 \mathrm{vs}$. $3.3 \mathrm{Mt} /$ ha (Wilcoxson signed rank tests two-tailed $\mathrm{P}=.02, .03$, and .03 respectively). There was no significant difference in average annual input of CWD between soil types or between topographic classes within ultisols in terms of number of pieces, total volume or biomass. However, of the six contrasts three were $\mathrm{P}<.07$, suggesting that significant differences may emerge with longer-term data. The $\mathrm{C}$ and $\mathrm{N}$ percentages by decay classes (Table 3 ) were used to calculate the decay-class adjusted $\mathrm{C}$ and $\mathrm{N}$ annual inputs in CWD. CWD inputs averaged 48.3\% carbon and $0.299 \% \mathrm{~N}$, leading to annual inputs of $2.7 \mathrm{MgC} \mathrm{ha}^{-1} \mathrm{yr}^{-1}$ and $1.67 \times 10^{-2} \mathrm{MgN} \mathrm{ha}^{-1} \mathrm{yr}^{-1}$. Inputs had less than half the percentage of mass in partially and fully decayed wood than did the CWD stocks (4.1\% vs. 10.9\%).

We also calculated the estimated biomass of trees dying and falling to the ground during this interval as an independent estimate of the lower bound of CWD input. This is a conservative 
Table 2. Mean densities ( \pm 1 standard error of the mean) of CWD pieces in three decay categories (see Methods). Different superscripts indicate groups with significantly different medians in a post-factoriori test (overall Kruskal-Wallis ANOVA $\mathrm{P}<.001$ ).

Decay Category

SOUND

PARTIALLY DECAYED

FULLY DECAYED

Total sample

\section{Density $\left(\mathrm{g} / \mathrm{cm}^{3}\right)$}

Mean

$0.453+0.003^{\mathrm{a}}$

0.454

$0.080-1.374$

1366

$0.349 \pm 0.007^{\mathrm{b}}$

$0.353 \quad 0.096-0.655$

291

$0.245 \pm 0.011^{\mathrm{c}} \quad 0.222 \quad 0.044-0.646 \quad 116$

$0.422+0.003$

0.439

$0.044-1.374$

1773

Table 3. Chemical composition of coarse woody debris in different decay classes from oldgrowth tropical wet forest, La Selva Biological Station, Costa Rica. $N=7$ per decay class. Data are reported indicating \pm 1 standard error of the mean.

\begin{tabular}{|l|c|c|c|c|}
\hline $\begin{array}{l}\text { Decay } \\
\text { class }\end{array}$ & $\begin{array}{c}\text { Density } \\
\left(\mathbf{g ~ c m}^{-3}\right)\end{array}$ & \% C & \% N & C/N ratio \\
\hline Sound & $0.501 \pm 0.026$ & $48.3 \pm 0.3$ & $0.299 \pm 0.029$ & $170.5 \pm 15.6$ \\
\hline $\begin{array}{l}\text { Partially } \\
\text { decayed }\end{array}$ & $0.238 \pm 0.050$ & $47.2 \pm 0.3$ & $0.318 \pm 0.033$ & $155.7 \pm 12.6$ \\
\hline $\begin{array}{l}\text { Fully } \\
\text { decayed }\end{array}$ & $0.198 \pm 0.035$ & $46.4 \pm 0.4$ & $0.462 \pm 0.071$ & $119.3 \pm 21.6$ \\
\hline
\end{tabular}


Table 4. Coarse Woody Debris (CWD) stocks in old-growth tropical rain forest at the La Selva Biological Station, Costa Rica. Data for each edaphic condition are from six 0.5 ha plots (see Methods), and are extrapolated to a per-hectare basis. Values are reported \pm one standard error of the mean.

\begin{tabular}{|c|c|c|c|}
\hline Treatment & $\begin{array}{c}\text { Biomass } \\
\text { (Mt/ha) }\end{array}$ & $\begin{array}{c}\text { Volume } \\
\left(\mathbf{m}^{\mathbf{3}} / \mathbf{h a}\right)\end{array}$ & $\begin{array}{c}\text { N Pieces } \\
\text { CWD/ha }\end{array}$ \\
\hline Flat inceptisol & $38.5 \pm 3.4$ & $91.1 \pm 8.6$ & $438 \pm 15$ \\
\hline Flat ultisol & $42.2 \pm 4.9$ & $99.3 \pm 11.3$ & $459 \pm 25$ \\
\hline Steep ultisol & $58.2 \pm 5.6$ & $135.6 \pm 12.6$ & $508 \pm 65$ \\
\hline All plots & $46.3 \pm 3.3$ & $108.6 \pm 7.6$ & $469 \pm 23$ \\
\hline
\end{tabular}

Table 5. Annual input of CWD in old growth tropical rain forest at the La Selva Biological Station, Costa Rica. Areas sampled per plot were 0.05 ha for $\mathrm{CWD}<30 \mathrm{~cm}$ maximum diameter and 0.5 ha for $\mathrm{CWD} \geq 30 \mathrm{~cm}$ diameter. $\mathrm{N}=6$ for each edaphic class. Data are expressed as the mean of measurements in 1998 and 1999, extrapolated to a per-ha basis. Data are reported \pm 1 standard error of the mean.

\begin{tabular}{|l|c|c|c|}
\hline Edaphic type & $\begin{array}{c}\text { N CWD } \\
\text { pieces/ha/yr }\end{array}$ & $\begin{array}{c}\text { Mean volume } \\
\left(\mathbf{m}^{\mathbf{3}} / \mathbf{h a} / \mathbf{y r}\right)\end{array}$ & $\begin{array}{c}\text { Mean dry mass } \\
(\mathbf{m t} / \mathbf{h a} / \mathbf{y r})\end{array}$ \\
\hline Flat inceptisols & $76 \pm 27$ & $7.8 \pm 3.1$ & $3.6 \pm 1.5$ \\
\hline Flat ultisols & $78 \pm 11$ & $16.8 \pm 2.2$ & $7.5 \pm 1.0$ \\
\hline Steep ultisols & $67 \pm 14$ & $13.1 \pm 5.6$ & $5.8 \pm 2.5$ \\
\hline Mean & $74 \pm 10$ & $12.6 \pm 2.3$ & $5.6 \pm 1.0$ \\
\hline
\end{tabular}


estimate of CWD input, because it does not account for fallen branches or the biomass of trees that were standing dead at the beginning of the interval and that fell to the ground during the measurement period. Biomass of trees that died and fell was estimated from their last live diameter using Brown's (1997) tropical wet forest allometric equation. Average estimated annual CWD input from trees that died and fell to the ground over the 2-yr period was $3.6 \mathrm{Mt} \mathrm{ha}^{-1} \mathrm{yr}^{-1} \pm$ 4.7 (1 s.e.m). Although the confidence intervals are broad for both estimates, the CWD input estimated from tree deaths is in fact somewhat less than the annual measured CWD input, as expected.

The ratio of mean CWD stocks to mean annual inputs over this 2 -yr period (46.3 Mt / 5.6 Mt $\mathrm{ha}^{-1} \mathrm{yr}^{-1}$ ) implies a turnover time of approximately $8 \mathrm{yr}$ for the CWD pool, assuming long-term equilibrium of stocks and inputs.

\section{Relation of CWD stocks and inputs to forest structure and stand dynamics}

CWD inputs over the 97-99 period were highly correlated with stand dynamics, expressed as the summed basal area or number of trees falling during that period $\left(\mathrm{r}_{\mathrm{s}}=0.81\right.$ and $0.58, \mathrm{P}<.001$ and .01 respectively). In contrast, there was no relation between stocks or inputs of CWD in plots and measures of their stand structure. Among all 18 plots, neither CWD volume, mass, number of pieces, or rates of annual CWD input were significantly correlated with number of trees per stand, their basal area, or their estimated above-ground biomass (Spearman's $\mathrm{r}_{\mathrm{s}}, \mathrm{P}<.05$ in all cases).

\section{Discussion}

\section{Landscape-scale factors affecting CWD stocks and inputs}

CWD stocks and inputs were largely independent of the large differences in soil nutrients and topographic conditions sampled across this upland landscape. This was surprising for at least two reasons. Stand structure varied considerably across the same gradient, with significantly more and smaller stems on the ultisols compared to the inceptisols (Clark and Clark 2000). Also, a wide range of variation in stand structure was encompassed in the 180.5 ha plots. Stem number, basal area, and estimated aboveground biomass varied by factors of $1.73,1.68$, and 1.85 (respectively) among plots in 1997.

There are at least three potential explanations for the general lack of relation of CWD stocks and input to edaphic conditions and to stand structure. It is possible that no landscape-scale differences in CWD stocks and inputs actually exist. Although stem number and mean tree size varied significantly among treatments, mean estimated above ground biomass did not (Clark and Clark 2000). However, even given the very substantial sampling effort in this study, variation in estimates of CWD stocks and inputs was still high. Our sample was sufficient to reliably detect differences of $\pm 20 \%$ in stocks among treatments (see below). For CWD inputs, however, the variability was much higher, and we could easily have failed to detect real intertreatment differences of $\pm 20 \%$.

Another reason for the general lack of explanatory power of the edaphic and stand structure variables is that the highly variable nature of tree mortality had much greater and immediate effects on CWD distribution. Mean mortality rates themselves did not vary among treatments over this 2 -yr period. However, tree mortality varied 15 -fold among plots during this period, and CWD inputs varied considerably more. This level of variation could swamp even substantial treatment differences over the spatial and temporal scales of this study. 
Evaluating CWD at landscape scales and prospects for scaling up

Table 6 shows the sample sizes necessary to estimate CWD characteristics based on the landscape-scale degree of variation encountered at La Selva. The standard error of the mean of the estimated stocks was relatively low (Table 4), and the Carbono design had sufficient replicates to have a probability of $>95 \%$ of measuring the landscape mean CWD biomass within $\pm 20 \%$. Annual CWD input was considerably more variable, however, and even 180.5 ha annual samples averaged over a 2 -yr period were not sufficient for a very precise estimate. This is undoubtedly due to the spatially patchy nature of tree mortality over this 2-yr interval; mortality of stems $\geq 10 \mathrm{~cm}$ diameter ranged 0.7 to $10.8 \% \mathrm{yr}^{-1}$ among the 18 plots. Our data suggest that for studies lasting one to several years, a very large sampling effort would be needed to accurately estimate CWD inputs over upland landscapes of old growth tropical forest.

An alternative approach to measuring CWD inputs is to calculate them based on estimated above ground biomass (EAGB) of trees dying during a given interval (cf. Chambers et al. 2000). This is an indirect approach. It uses an allometric equation to estimate biomass, and there is no direct validation of the EAGB. If the allometric equations were developed from "perfect" (undamaged) trees, these equations will in general overestimate, to an unknown extent, the biomass of average trees (Clark et al. 2000). Stand estimates of C.WD input must also account for trees that were standing dead at plot initiation and then fell, and for trees that died during the intercensus interval but did not fall.

Here we found that the annual input estimate derived from EAGB of trees that died and fell (3.6 $\pm 4.7 \mathrm{Mt} \mathrm{ha}^{-1} \mathrm{yr}^{-1}$, not accounting for initially standing dead stems), was similar to the estimate derived by ground measurements of CWD inputs $\left(5.6 \pm 1.0 \mathrm{Mt} \mathrm{ha}^{-1} \mathrm{yr}^{-1}\right)$ (Note, this difference is about $50 \%$ ). The CWD input data here were developed using a total of 9 ha sampled annually for $2 \mathrm{yr}$, requiring approximately 80 total person-days of field work. This level of effort was not sufficient to produce very accurate estimates, but it was sufficient to show the general magnitude of CWD input, and to show that it was similar to the dead tree-based estimate. For long-term studies, and to be able to compare many sites, it will usually be necessary to calculate CWD inputs from tree death, and these estimates will be sufficient for many purposes. If precise estimates of annual CWD input are required, our results give an idea of the level of sampling effort that will be necessary.

In contrast to CWD stocks and inputs, CWD densities could be estimated with relatively few samples. With as few as 35 samples taken randomly from all C.WD pieces over the landscape, there was a $95 \%$ probability of estimating the true mean density within $10 \%$ (Table 6). If however estimates within each decomposition class are required, more samples are necessary, because the more advanced decay classes have more variable densities.

Our results suggest that, for upland TRF landscapes, scaling up CWD estimates to larger spatial scales is more likely to be limited by within-site measurement variation than by major effects of nutrients and topography on CWD stocks. We emphasize that we did not study azonal soils such as white sands, and that our slopes were both relatively mild and short (ca. $21^{\circ}$ over ca. $50 \mathrm{~m}$ ). However, this degree of variation in soil nutrients and slope is typical of large areas of the tropics (cf. Duivenvoorden 1995; Laurance et al. 1999).

\section{The role of CWD in tropical rain forest carbon cycles}

Our results from La Selva are in broad agreement with those from similar studies in other tropical rain forests (cf. Yoneda et al 1977, 1990; Vogt et al. 1986; Delaney et al. 1998; Chambers et al. 2000; Clark and Clark 2000; D.A. Clark unpublished data). The relation of 
Table 6. Sample sizes needed to estimate stocks and fluxes of CWD within $10 \%$ and $20 \%$ with a $95 \%$ probability in old-growth tropical wet forest at the La Selva Biological Station, Costa Rica. Calculations follow Zar (1996, pg. 108). The 180.5 ha plots are blocked in a stratified random design to provide an unbiased estimate of the upland landscape at La Selva (see Methods).

\section{Variable}

CWD standing stocks, Mt/ha

CWD input, Mt/ha/year

CWD density, sound samples, $\mathrm{g} / \mathrm{cm}^{3}$

CWD density, partially decayed samples, $\mathrm{g} / \mathrm{cm}^{3}$

CWD density, fully decayed samples, $\mathrm{g} / \mathrm{cm}^{3}$

All CWD density samples, $\mathrm{g} / \mathrm{cm}^{3}$
Sample description

180.5 ha plots, complete sampling for $\mathrm{CWD}>30 \mathrm{~cm}$ max. diameter subsampling for $\mathrm{CWD}<30 \mathrm{~cm}$ diam. per Methods

180.5 ha plots, complete sampling for $\mathrm{CWD}>30 \mathrm{~cm}$ max. diameter, subsampling for $C W D<30 \mathrm{~cm}$ diam. per Methods. Annual measure- ments averaged over 2 years.

Randomly sampled for all CWD over 180.5 ha plots, $\mathrm{N}=1366$

Randomly sampled for all CWD over 180.5 ha plots, $N=291$

Randomly sampled for all CWD over 180.5 ha plots, $\mathrm{N}=226$

Randomly sampled for all CWD over 180.5 ha plots, $\mathrm{N}=1773$

\section{Mean}

$46.3 \quad 1.96 \mathrm{E}+02$ for $+10 \%$

38

12

$5.6 \quad 1.97 \mathrm{E}+01$

240

62

$\begin{array}{cccc}0.453 & 1.04 \mathrm{E}-02 & 23 & 8 \\ 0.349 & 1.43 \mathrm{E}-02 & 48 & 14 \\ 0.245 & 1.48 \mathrm{E}-02 & 98 & 26 \\ & & & \\ 0.422 & 1.50 \mathrm{E}-02 & 35 & 11\end{array}$


CWD to aboveground carbon fluxes and pool sizes in old-growth TRF can be described as follows:

Carbon stocks: live tree biomass $>\mathrm{CWD}>$ fine litter

Annual inputs to forest floor: $\mathrm{CWD}=$ (live trees dying and falling + standing dead falling) $<$ fine litter

Turnover time: fine litter $<\mathrm{CWD}<$ live tree biomass

The magnitude of the CWD pool will vary as a function of the relation of inputs and outputs. CWD input rates at landscape scales may be increasing in tropical forests, due to the effects of forest fragmentation (Ferreira and Laurance 1997, Laurance et al. 1997), rising global temperatures and increasing fire frequency (Cochrane et al. 1999; Nepstad et al. 1999). Output rates (C.WD decomposition) are controlled by temperature, humidity and substrate quality (Harmon et al. 1985). Global climate change is already affecting temperature and possibly precipitation patterns in many areas. In addition, understory temperature and humidity in TRF have changed over large areas due to forest fragmentation and increased fire frequency (Kapos 1989). The net result of these changes in CWD input and outputs is not possible to predict. However, it seems likely that CWD pools are likely to change in magnitude and vagility under many plausible climate and land-use change scenarios. 


\section{VI.2. Biomass production}

\section{Methods}

For the ground-based measurements of carbon stocks, above- and belowground production, and soil respiration, we installed 180.5 ha plots (Fig. 1) to provide 6 samples of forest that were unbiased in terms of forest structure, in each of the three major edaphic conditions of this landscape (inceptisol terraces, flat terrain on ultisols, and steep slopes on ultisols). The 0.5 ha plot size was chosen based on analysis of tree biomass across a range of plot sizes. At plot sizes between 0.25 and 0.50 ha the variance in aboveground biomass stabilizes in this landscape. The plots were sited in a stratified, non-biased design by selecting coordinates within the topographic and soil coverages in the La Selva Geographical Information System (GIS). These plots provide a set of replicated unbiased samples of forest structure and biomass across the La Selva landscape. To our knowledge, this research design is unique for the tropical rain forest biome. This approach, which enables us to study carbon processes at the landscape scale and with statistical power, was made possible by an exceptional set of research tools available at La Selva: topographic mapping based on $6000^{+}$surveyed points, a 1:10000 soils map, a site-wide grid installed at $50 \mathrm{~m} \times 100 \mathrm{~m}$ spacing (accuracy $\pm 20 \mathrm{~cm}$ ), a GIS (Arc/INFO, ArcView), and a well-documented flora. For no other tropical rain forest site does this level of support exist for studies at the landscape-scale. An additional important advantage of the site is the Republic of Costa Rica's traditional welcoming stance towards facilitating research by nonresident scientists (Clark 1985).

Plots were surveyed with a transit and internally gridded with permanent markers (10 $\times 10 \mathrm{~m}$ spacing, slope-corrected). Within each plot all trees and lianas $\geq$ $10 \mathrm{~cm}$ diameter were identified and mapped, and replicated soil samples (stratified by depth to $1 \mathrm{~m}$ ) were taken for analyses of cations, $\mathrm{Fe}, \mathrm{Al}, \mathrm{P}, \mathrm{N}$, total carbon, and $\mathrm{pH}$. Standing stocks of coarse woody debris (CWD; all pieces $>30 \mathrm{~cm}$ dia.; subsamples of those $10-\leq 30 \mathrm{~cm}$ dia.) were mapped, measured, and subsampled for specific density in all plots in late 1997-early 1998. A preliminary inventory was made of coarse roots by depth, in both the ultisols and the inceptisols, by sieving all roots $\geq 2 \mathrm{~mm}$ in diameter out of soil at successive depths in $0.8 \times 0.8 \times 3.0 \mathrm{~m}$ monoliths ( 3 in each soil type). Methods appropriate to the conditions of tropical rain forest were worked out for sampling fine litterfall and fine roots. For litterfall, large items such as 6-m long palm fronds and large flowering structures are collected in slope-corrected ground traps that are paired with the more standard standing basket traps. Because of the potential for within-year changes in the depth distribution of fine roots, these are sampled with cores that integrate from the ground surface to $50 \mathrm{~cm}$ depth. We designed a simple automated agitation system to separate roots from soil; this gave more consistent results than a conventional root elutriator. 
Figure -1. Locations of the CARBONO eddy flux tower (left, center) the 180.5 ha plots (rectangles), stratified by soil type and slope, and the six deep soil shafts $\left({ }^{*}\right)$. The map was developed using the La Selva GIS (the soil coverage is described in Clark et al.1998).

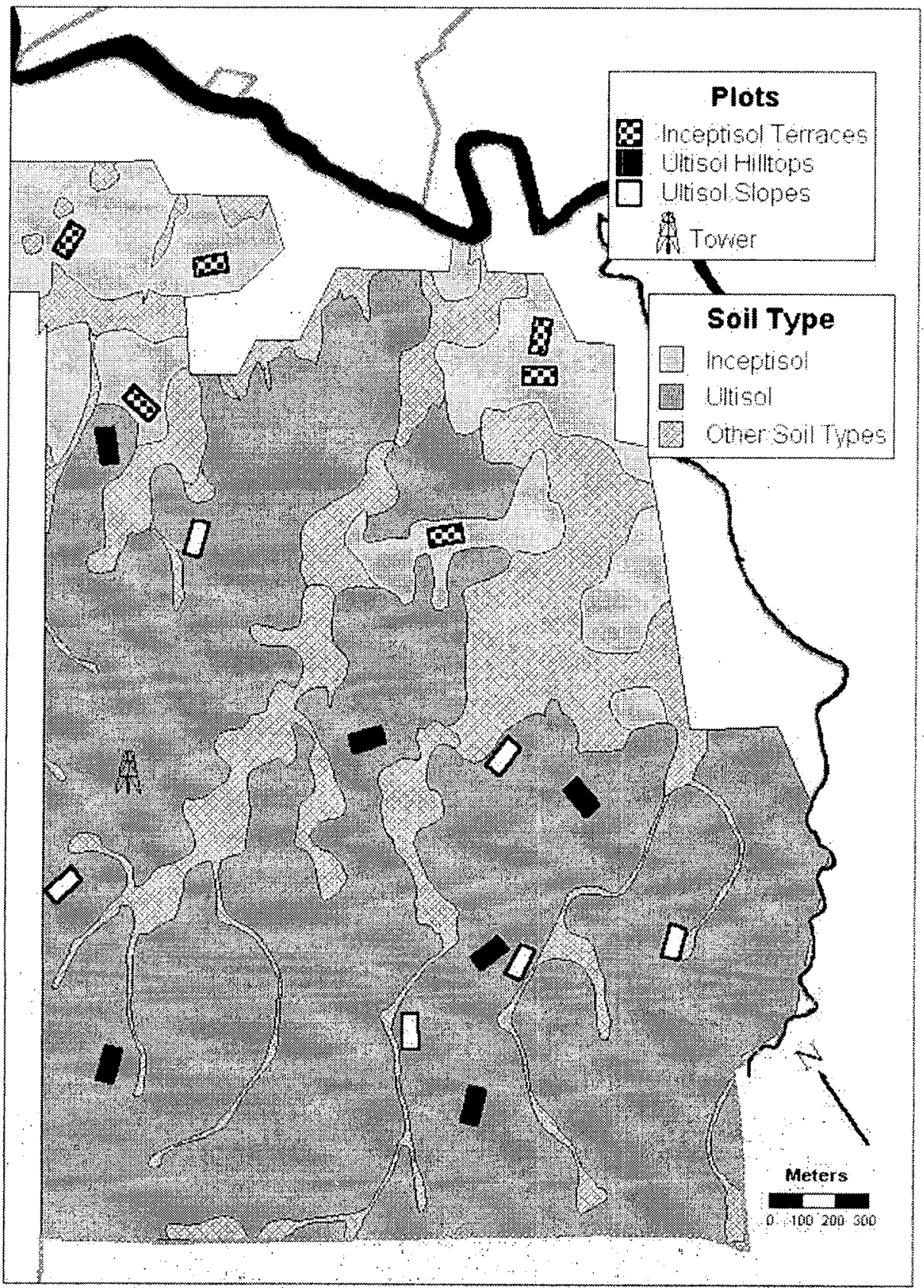


Since September 1997, on-going measurements in all plots include: aboveground biomass increment (annual re-measurement of all trees $\geq 10 \mathrm{~cm}$ diameter); fine litterfall (biweekly); fine woody litterfall $(1-<10 \mathrm{~cm}$ diameter; monthly); standing stocks of live and dead fine roots $(<2 \mathrm{~mm}$ and $2-<5 \mathrm{~mm}$ diameter; approximately bimonthly); and annual input of CWD. Twice annually (wet season and dry season), hemispherical canopy photographs are taken at the same set of 6 randomly chosen grid points in each plot for an estimation of percent canopy coverage and leaf area index. Data from the first year are summarized in Table 1.

\section{Results}

Aboveground biomass of the La Selva forest, as measured in these plots (Table 1), is substantially lower than values reported in the literature for many tropical moist and wet forests (Clark et al., in review, $a$ ). Multiple lines of evidence indicate that these data from La Selva are in fact much more representative of lowland neotropical rain forest than is generally appreciated. As shown by Brown and Lugo (1992), when tropical forest biomass is estimated based on very small, subjectively-located plots, which was the case in $>80 \%$ of the studies reviewed by Clark et al. (2000), there is a strong bias towards unrepresentative sites dominated by very large trees, and the result is a large overestimation of forest-level biomass. For example, in one 0.8 ha plot selected by Holdridge et al. (1971) to represent the forest at La Selva, the basal area $\left(51.4 \mathrm{~m}^{2} \mathrm{ha}^{-1}\right)$ was double the mean basal area found in larger plots $\left(24.7 \mathrm{~m}^{2} \mathrm{ha}^{-1}\right.$; Lieberman \& Lieberman 1994) or by landscape-scale sampling $\left(23.6 \mathrm{~m}^{2} \mathrm{ha}^{-1}\right.$; Clark \& Clark, 2000) at this site. Our aboveground biomass values, which are based on replicated, non-biased plots stratified over the La Selva landscape, are corroborated by values produced by extensive systematic sampling (1170 0.01 ha plots) over the same 600 ha of old-growth forest (Clark \& Clark, 2000).

In Year 1, NPP components varied significantly with edaphic patch type; furthermore, different patterns were shown by the different components (Table 1). Within the ultisols, aboveground biomass increment was significantly higher on the slopes than on the flat plateaus; we suspect this topographic effect reflects the higher incidence of gaps on the slopes (Clark et al. 1996), and the vigorous re-growth associated with this greater dynamism. The inceptisol plots showed a much broader range of values for aboveground increment than the plots on ultisol slopes or ultisol plateaus; the inceptisol values overlapped with those from both of the ultisol site types. Total fine litterfall did not differ among the three edaphic site types. This is interesting, given the significant differences that did exist among site types in terms of aboveground increment and fine root stocks (and soil respiration - see below). Clearly, relative patterns of total NPP among edaphic site types within a landscape cannot be simply predicted from measurement of only one or a few of the components. Although total fine litterfall did not differ among edaphic treatments, the flower and fruit component was significantly higher on the (more fertile) inceptisols than on the ultisols. Taken together, these findings illustrate the complex effects on NPP that come from within-landscape edaphic variation, and they show the power of our stratified, replicated plots for revealing such effects.

An important consideration for interpreting these findings from Year 1, however, is that 1998 was an extreme year in terms of temperature, both globally and at La Selva (the 1998 mean for daily minimum temperatures was the highest in the 17 year record; OTS unpublished data). For example, it is likely that the low aboveground biomass increments seen in this first measurement year were particularly low due to the high nighttime respiratory burden on the trees. In the following two 
years growth increments were similar to those of $98 / 98$ (Fig. 2). Mortality declined from the highs seen in $1997 / 1998$

Table1. La Selva C stocks and fluxes measured in Year $1(10 / 97-9 / 98)$. Data are means per edaphic type (6 0.5 ha plots in each). Biomass is estimated to be $50 \% \mathrm{C}$. Aboveground biomass is calculated from inventory of all stems $\geq 10 \mathrm{~cm} \mathrm{dia.,} \mathrm{using}$ Brown's (1997) tropical wet forest allometric equation. Fine root data are means of 5 samplings through Year 1 (6 soil cores per plot per sampling). Soil organic carbon (SOC) was determined in 3 soil shafts per soil type (see below). Letters show differences at $\mathrm{P}<.05$ (K-W Anova or Repeated Measures GLM).

\begin{tabular}{|c|c|c|c|}
\hline \multicolumn{4}{|l|}{ STOCKS (Mg C / ha / yr): } \\
\hline -- Above-ground biomass & $83.5 \mathbf{a}$ & $74.5 \mathrm{a}$ & $83.0 \mathrm{a}$ \\
\hline -- Coarse woody debris & $19.0 \mathrm{a}$ & $21.0 \mathbf{a b}$ & $28.0 \mathrm{~b}$ \\
\hline $\begin{array}{l}\text {-- Live fine roots } 0-<5 \mathrm{~mm} \\
{[0-<2,2-<5 \mathrm{~mm} \mathrm{dia} .]}\end{array}$ & $\begin{array}{l}1.1 \mathbf{a} \\
{[0.7,0.5]}\end{array}$ & $\begin{array}{l}1.7 \mathbf{b} \\
{[1.0,0.7]}\end{array}$ & $\begin{array}{l}1.7 \mathbf{b} \\
{[0.9,0.7]}\end{array}$ \\
\hline $\begin{array}{l}-- \text { SOC to } 4 \mathrm{~m} \text { depth } \\
{[0-1 \mathrm{~m}, 1-4 \mathrm{~m} \text { depth }]}\end{array}$ & $266 \underset{[118,148]}{\mathbf{a}}$ & $\begin{array}{l}416 \mathbf{b} \\
{[150,266]}\end{array}$ & --- \\
\hline \multicolumn{4}{|l|}{ FLUXES (Mg C / ha / yr): } \\
\hline -- Abovegr. biomass increment & $1.7 \mathbf{a b}$ & $1.5 \mathrm{a}$ & $1.8 \mathbf{b}$ \\
\hline -- Total fine litterfall & $4.8 \mathrm{a}$ & $4.8 \mathrm{a}$ & $4.5 \mathbf{a}$ \\
\hline $\begin{array}{l}\text {-- Flower/fruit component } \\
\text { of fine litterfall }\end{array}$ & $0.8 \mathrm{a}$ & $0.4 \mathrm{~b}$ & $0.5 \mathbf{a b}$ \\
\hline $\begin{array}{l}\text {-- Soil respiration } \\
\text { (April-December '98) }\end{array}$ & $10.6 \mathrm{a}$ & $15.0 \mathbf{b}$ & --- \\
\hline
\end{tabular}


Figure 2. Summary of plot biometric measurements and tree mortality from the 18 study plots

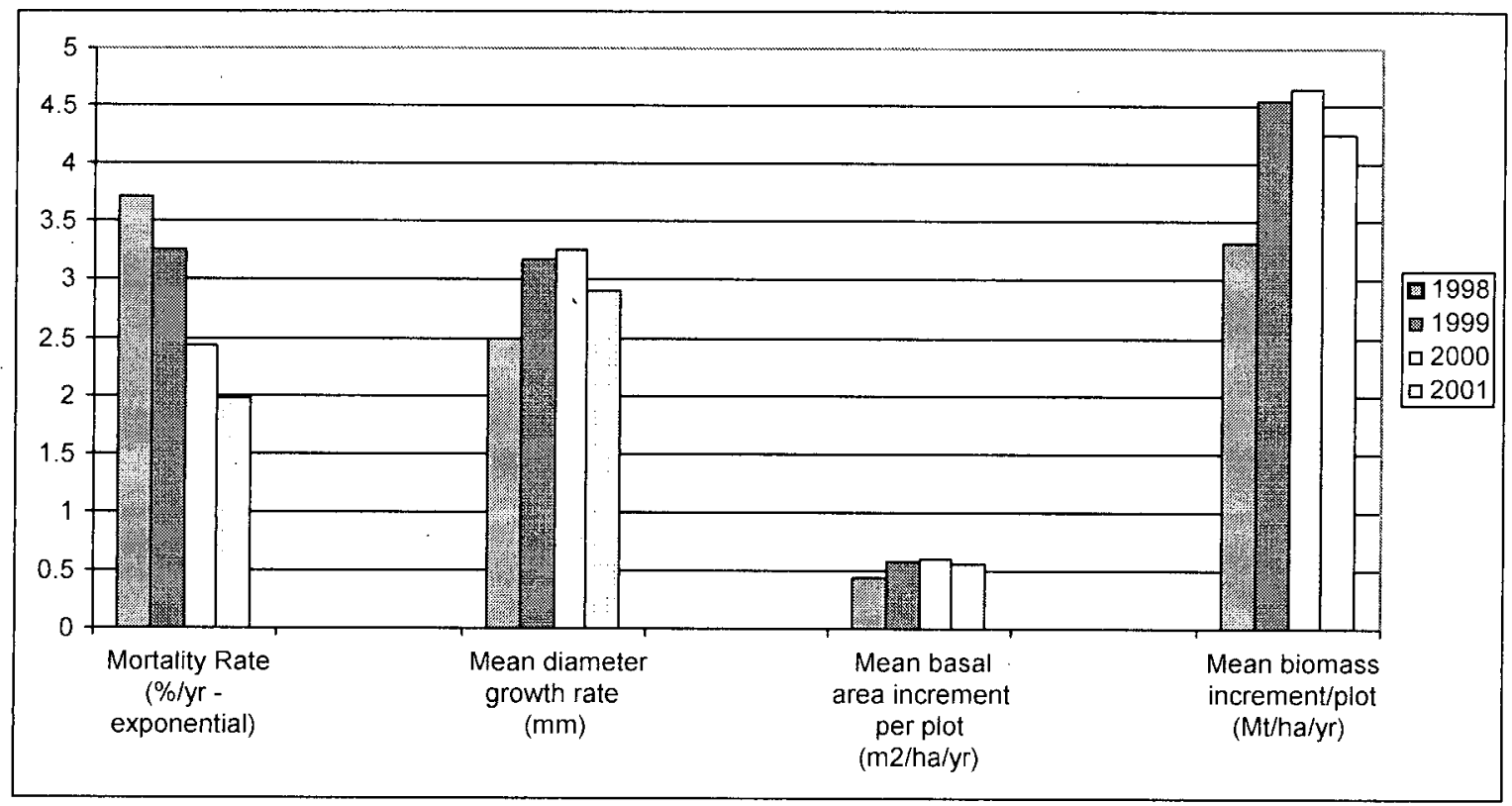




\section{SOIL CARBON STOCKS AND FLUXES}

\section{Introduction}

\section{VII.1. Soil Carbon Stocks}

Recent estimates show that the amount of carbon stored in tropical soils (616 $640 \mathrm{Gt} \mathrm{C}$ ) is about one quarter of the global soil carbon stock (Batjes, 1999). This amount is higher than the total estimated amount of carbon stored in global terrestrial vegetation $(\sim 600 \mathrm{Gt} \mathrm{C}$, Post et al, 1990). It also illustrates the potentially important role that tropical soils play in the global carbon cycle. However, the role that tropical soils will play in the global carbon cycle at present and in the future strongly depends on decomposability of this soil carbon and it's accessibility for the microbial biomass.

Traditionally, studies on the effects of land use change on soil organic carbon have been limited to the topsoil or the top meter of the soil. This is understandable as the strongest effects of land use change, the highest carbon levels and the highest microbial activities can be found in the topsoil (normally the A horizon). Furthermore soil organic carbon in the subsoil was considered to be inert. Since the mid 1990's however, there is an increasing awareness that especially in deeply weathered tropical soils there is a large carbon stock below the A horizon. Although concentrations of soil organic carbon (SOC) are low in the subsoil of these soils, the volume of this part of the soil is very large. As a result, the total carbon stock below the first meter, may actually be higher than the carbon stock in the top meter of the soil profile (Nepstad et al, 1994; Trumbore et al, 1995). This increasing awareness of the importance of deep soil carbon is also illustrated by the increasing global estimates of soil carbon stocks in tropical soils. In the 1980's the total amount of carbon stored in tropical soils was estimated at $316 \mathrm{Gt} \mathrm{C}$ (down to 1 meter, Post et al, 1982), whereas the most recent review estimated the carbon stock in the first two meter of tropical soils at 616-640 Gt C (Batjes, 1999).

In their study in Pará, Brazil, Nepstad and colleagues (1994) were the first to point out the importance of deep soil carbon in Amazonian forest soils. They demonstrated that the forest soil below $1 \mathrm{~m}$ depth contains more carbon than the aboveground biomass and they were able to demonstrate that $15 \%$ of this carbon turns over on annual to decadal timescales. They explained the occurrence of the deep carbon by the presence of deep roots, which are needed by the evergreen forest of Pará to maintain a green canopy during dry periods that may last up to five months. Our present study was conducted in the old-growth forest and adjacent pastures of La Selva Biological Station in the Atlantic Zone of Costa Rica. In contrast to the forest in Pará, this costarican forest has a perudic moisture regime with on average no month receiving less than $100 \mathrm{~mm}$ of rain (Sanford et al., 1994). In our present study we wanted to answer the following questions:

- How important is deep soil carbon in deeply weathered tropical rainforest soils with a perhumid climate?

- What is the effect of forest clearing for pasture on this deep soil carbon?

- Is there measurable microbial activity in the subsoil of deeply weathered tropical soils and what is the relative importance of microbial activity in the subsoil compared to the topsoil? To answer these questions we measured total soil carbon, ${ }^{13} \mathrm{C}$ carbon isotopes, soil microbial biomass and microbial activity in two different soil types on replicated forest and pasture sites. 
We found that large carbon stocks can be found in the subsoil of deeply weathered Oxisols even though we sampled no deep roots below $2 \mathrm{~m}$ depth. In addition we found that a considerable amount of this deep carbon can decompose after forest clearing for pasture establishment. Finally, our results show that large stocks of relatively labile carbon are not limited to areas with deeply weathered soils and a prolonged dry season, but can be found also in deeply weathered soils below wet tropical forests.

\section{Materials and Methods}

Soils

The landscape of La Selva is dominated by old lava flows and river terraces. La Selva is situated at the footslopes of the Barva volcano, from which the lava flows have originated. The lava flows have a basaltic composition and their age has been estimated at about I million years. Soils on these lava flows are deeply weathered clays (augering showed that on stable geomorphological units, saprolite occurs at 5 to $>6$ meter depth) with a very low base saturation. Previously, these soils have been classified as Ultisols (Sollins, et al.1994), a classification that was recently shown to be incorrect when Kleber et al (submitted), reclassified this soils as Typic

Haploperox. By La Selva convention these soils are normally termed 'Residual'. The Rio Puerto Viejo and the Rio Sarapiqui, at which confluence la Selva is situated, have deposited the river terraces of La Selva. The old alluvial terraces on which part of our study was conducted have not been dated but are regarded as Pleistocene (Sollins et al., 1994). These soils are deeply weathered clay soils (typically strongly weathered coarse material is found at $3 \mathrm{~m}$ depth) with a low base saturation, which is however higher than the soils on the Lava flows. Previously these soils have been classified as Inceptisols, but also this classification was corrected to Typic Haploperox (Kleber at al, submitted). By La Selva convention these soils are termed 'Old alluvium'.

Throughout this paper we use the terms 'old alluvial soils' and 'residual soils' because the new classification shows no distinction between the two soil types and to improve coherency with other papers that use this terminology (e.g. Clark \& Clark, 2000).

For this study we selected twelve sites: below old growth forest we selected three sites on old alluvium and three on residual soils. Below pastures, which were established in the 1970's, we also selected three sites on old alluvium and three on residual soils. Presently, pastures are dominated by Ischaeum indicum, a C4 grass which is considered to have a relatively low biomass production (Van Dam et al, 1997). All sites were situated between elevations of $40-100 \mathrm{~m}$ above sea level.

\section{Sampling and sample processing}

In 1997 soil shafts of $3 \mathrm{~m}$ depth (old alluvium) and $4 \mathrm{~m}$ depth (residual soils) were established on the sites in the old growth forest. Undisturbed soil samples ( 300 $\mathrm{cm}^{3}$ ) were taken for bulk density measurements at $0.05,0.20,0.40,0.75,1.5,2.5$ and (on the residual soils) $3.5 \mathrm{~m}$ depth. On the pasture soils, undișturbed samples for bulk density were only taken at $0.05,0.20$ and $0.40 \mathrm{~m}$ depth. Earlier work in this area had shown that at greater depth there was no difference in bulk density between forest and pasture below $0.3 \mathrm{~m}$ depth (Veldkamp, 1994).

Disturbed soil samples for chemical and microbiological analyses were taken in August and September 1999 by auger for the following depth intervals: $0.0-0.10 \mathrm{~m}$, $0.10-0.30 \mathrm{~m}, 0.30-0.50 \mathrm{~m}, 0.50-1.0 \mathrm{~m}, 1.0-2.0 \mathrm{~m}, 2.0-3.0 \mathrm{~m}$ on all sties and $3.0-4.0 \mathrm{~m}$ on the residual soil only. Care was taken, not to contaminate the sampled soil with soil material from above lying layers. The soil samples were handled and homogenized 
using latex gloves. Each $0.0-0.1 \mathrm{~m}$ sample consisted of a composite sample of 6 different samples. Part of the samples was air-dried for $\mathrm{C}$ and ${ }^{13} \mathrm{C}$ analyses, the other part was passed through a $2 \mathrm{~mm}$ sieve and stored field-moist in polyethylene bags up to 2 days at $4^{\circ} \mathrm{C}$ before microbial measurements were done. Microbial measurements were done at maximum water capacity (Forster, 1995). Sampling for microbiological analyses were done only once during the rainy season, so we were not able to analyze seasonal changes. However, annual fluctuations in temperature are minimal and unlikely to cause seasonal changes. The only seasonal effect that can be expected is because of lower water contents in the topsoil during the drier season. Monitoring of soil water content below the forest showed that at $0.4 \mathrm{~m}$ depth volumetric water content rarely fell below field capacity and the maximum difference in volumetric water content over one year was 0.15 and even lower at greater depth (unpublished data). No seasonal changes in soil water content could be detected below $0.75 \mathrm{~m}$ depth.

\section{$\underline{\text { Soil Carbon and }{ }^{13} \mathrm{C} \text { analysis. }}$}

The air-dried soil samples were passed through a $2 \mathrm{~mm}$ sieve and ground to powder using a ball mill. Subsoil samples were treated with $\mathrm{HCl}$ to prevent any contamination by carbonates. We determined the total organic $\mathrm{C}$ using an automated $\mathrm{C} \& \mathrm{~N}$ analyzer (Heraeus vario $\mathrm{EL}$ ). The ${ }^{13} \mathrm{C}$ values were measured with an elemental $\mathrm{C} \& \mathrm{~N}$ analyzer (Fisons EA11081) coupled with an isotope ratio mass spectrometer (Delta plus, Finnigan MAT). Plant material was prepared an analyzed in the same way. The isotope ratios were expressed as $\delta^{13} \mathrm{C}$ values: $\delta^{13} \mathrm{C}(\% \mathrm{o})=\left[\left(\mathrm{R}_{\mathrm{san}} / \mathrm{R}_{\text {std }}\right)-1\right] \mathrm{x}$ $10^{3}$ where $\mathrm{R}_{\text {sam }}={ }^{13} \mathrm{C} /{ }^{12} \mathrm{C}$ ratio for the sample and $\mathrm{R}_{\text {std }}={ }^{13} \mathrm{C} /{ }^{12} \mathrm{C}$ ratio of the reference (PDB). The amounts of soil carbon derived from forest and pasture were calculated using a simple mixing equation (Balesdent $\&$ Mariotti, 1996) : $\mathrm{F}=\left(\delta^{13} \mathrm{Cp}-\delta^{13} \mathrm{Cf}\right) /$ $\left(\delta^{13} \mathrm{C}_{\mathrm{C} 4}-\delta^{13} \mathrm{C}_{\mathrm{C} 3}\right)$ where $\mathrm{F}=$ the fraction of new carbon in the pasture sample; $\delta^{13} \mathrm{Cp}=$ $\delta^{13} \mathrm{C}$ value of sample from pasture soil; $\delta^{13} \mathrm{C} \mathrm{f}=\delta^{13} \mathrm{C}$ value of sample from forest reference; $\delta^{13} \mathrm{C}_{\mathrm{C} 4}=\delta^{13} \mathrm{C}$ value of pasture residues; $\delta^{13} \mathrm{C}_{\mathrm{C} 3}=\delta^{13} \mathrm{C}$ value of forest residues. The average value measured for vegetation residues $(n=4)$ were: pasture leaves: $-12.08 \%$; pasture roots: $-15.25 \%$; forest leaf litter: $-30.00 \%$ and forest roots: $28.84 \%$. In our calculations we used the average of leaves and roots for forest C3 ($29.42 \%$ ) and pasture C4 (-13.67\%o).

\section{Microbial biomass and activity}

Basal respiration (BR) was measured as an indicator of microbial activity using the 'syringe incubation method' (Heilmann \& Beese, 1992). The $\mathrm{CO}_{2}$ production of a soil sample is calculated by incubating the sample in a gas-tight glass syringe and measuring the $\mathrm{CO}_{2}$ increase. Preliminary tests showed that in 24 hours the syringes lost less than $1 \%$ of a $\mathrm{CO}_{2}$ standard with a concentration of $4.93 \% . \mathrm{CO}_{2}$ was measured using a Shimadzu Gaschromatograph with a TCD detector. For more details on the $\mathrm{CO}_{2}$ analyses see Schwendenmann et al. (in press).

Microbial biomass $C$ was measured with substrate-induced respiration (SIR) using the syringe incubation method (Heilmann \& Beese, 1992). SIR is measured by adding an easily decomposable substrate (glucose) to the soil sample to induce a maximum respiration rate (Anderson \& Domsch, 1978). This maximum respiration rate is correlated with the living microbial biomass. To facilitate mixing of the soil sample with the glucose, the soil sample was mixed with a pulverized mixture of $50 \%$ quartz sand and $50 \%$ glucose. Preliminary test were done to establish the amount of Glucose (between $0.4 \%$ and $1.4 \%$ of the moist weight of the soil sample), needed 
induce a maximum respiration rate. No increase in $\mathrm{CO}_{2}$ production was measured above $1.0 \%$ glucose addition, which was used during the experiments. To convert the $\mathrm{CO}_{2}$ production rate into microbial biomass, we used the relation published by Anderson \& Domsch (1978). This relation has been developed for temperate top soils, so the validity of this conversion for tropical soils and for sub soils is questionable.

\section{Calculations and statistical analyses}

Carbon contents ( $\mathrm{kg} \mathrm{C} \mathrm{kg}^{-1}$ soil) were converted to total organic carbon stock (TOC in $\mathrm{Mg} \mathrm{ha}^{-1}$ ) using measured bulk density values and the volume of the sampled horizon. Because of the higher bulk density in the pasture in the topsoil, comparison of TOC was done on a common mass basis to avoid artifacts from soil compaction. Earlier work in the same area had shown that compaction was restricted to the top $0.3 \mathrm{~m}$ of the soil profile (Veldkamp, 1994). Microbial biomass and basal respiration are commonly expressed on a mass basis. However, we also calculated our results on a soil volume basis using bulk density and volume of the sampled soil horizon. We calculated the metabolic quotient $\mathrm{qCO}_{2}$ from the $\mathrm{BR}$ and $\mathrm{SIR}$. We compared the two soil types using the data down to $3 \mathrm{~m}$ depth, because that was the maximum depth that the alluvial soil reached.

Normal distribution of the data was determined by a goodness of fit test using the Kolomogorov-Smirnov D statistic. Carbon data and microbial parameters were both normally distributed. We used analysis of variance to test for significant effects of the factors landuse and soil type.

\section{Results}

Soil chemical and physical characteristics

In the forest soils, $\mathrm{pH}$ increased significantly from the topsoil to the subsoil $(\mathrm{p}<0.001)$. The pasture soils had no clear trend with soil depth in $\mathrm{pH}$. Compared to the residual soil, the old alluvium had slightly higher $\mathrm{pH}$ values at $0.1-0.3 \mathrm{~m}, 0.5-1.0 \mathrm{~m}$ and 1.0-2.0m depth, but the strongest effect on $\mathrm{pH}$ was landuse (Table 1). The $\mathrm{pH}$ of pasture soils was higher than forest soils in all depths, with the strongest effect in the topsoil. The highest $\mathrm{pH}$ measured in the pastures was 5.0, which is too low for carbonates to exist. Bulk density under forest was low in both soil types (Table 1). Values increased with depth from $0.63-0.71 \mathrm{Mg} \mathrm{m}^{-3}$ to about $1.0 \mathrm{Mg} \mathrm{m}^{-3}$ below $2 \mathrm{~m}$ depth. The topsoil of the pastures was compacted in comparison to the forest soils $(p<0.001)$. At $0.1-0.3 \mathrm{~m}$ depth, only the old alluvial soil showed a higher bulkdensity in the pasture $(p=0.05)$. The 0.3-0.5 showed no difference in bulkdensity, so that we assumed no differences in bulk density a greater depth. Both soils were clay soils. Clay content in the top two meters of the residual soil was between 73 and $80 \%$ (data not shown). Below $2.0 \mathrm{~m}$ depth clay content was about $67 \%$. In the alluvial soil clay content in the top $2 \mathrm{~m}$ varied between 67 and $73 \%$. Between 2.0 and $3.0 \mathrm{~m}$ depth clay content decrease to $37 \%$.

\section{Soil organic carbon stocks and dynamics}

Total organic carbon in the forest soil down to $3 \mathrm{~m}$ depth was higher for the residual soils ( $330 \mathrm{Mg} \mathrm{ha}^{-1}$ ) than for the old alluvium $\left(214 \mathrm{Mg} \mathrm{ha}^{-1}\right.$, Fig. 1). Also in the pasture soil down to $3 \mathrm{~m}$ depth, residual soil contained more TOC (291 $\mathrm{Mg} \mathrm{ha}^{-1}$ ) 
Table 1. Soil pH and bulk density in two soil types below forest and pasture. Mean values from 3 sites. (Standard deviation in parentheses; $\mathrm{nm}=$ not measured).

\begin{tabular}{l|cccccccc}
\hline & \multicolumn{4}{|c}{ Residual soil } & \multicolumn{5}{c}{ Alluvial soil } \\
\hline depth & \multicolumn{2}{|c}{ Forest } & \multicolumn{2}{c}{ Pasture } & \multicolumn{3}{c}{ Forest } & \multicolumn{2}{c}{ Pasture } \\
\hline $\mathrm{pH}\left(\mathrm{H}_{2} \mathrm{O}\right)$ & & & & & & & & \\
$0.00-0.10$ & 4.0 & $(0.2)$ & 5.0 & $(0.5)$ & 4.1 & $(0.0)$ & 4.9 & $(0.4)$ \\
$0.10-0.30$ & 3.9 & $(0.2)$ & 4.8 & $(0.4)$ & 4.2 & $(0.1)$ & 4.6 & $(0.1)$ \\
$0.30-0.50$ & 4.3 & $(0.1)$ & 4.7 & $(0.2)$ & 4.4 & $(0.1)$ & 4.7 & $(0.1)$ \\
$0.50-1.00$ & 4.4 & $(0.1)$ & 4.6 & $(0.1)$ & 4.5 & $(0.1)$ & 4.7 & $(0.0)$ \\
$1.00-2.00$ & 4.4 & $(0.1)$ & 4.6 & $(0.1)$ & 4.5 & $(0.1)$ & 4.7 & $(0.0)$ \\
$2.00-3.00$ & 4.5 & $(0.1)$ & 4.6 & $(0.2)$ & 4.6 & $(0.0)$ & 4.7 & $(0.1)$ \\
$3.00-4.00$ & 4.5 & $(0.1)$ & 4.8 & $(0.1)$ & & & & \\
\multicolumn{1}{l}{} & & & & & & & & \\
$\mathrm{Bulk}$ density $\left(\mathrm{Mg} \mathrm{m}^{-3}\right)$ & & & & & & & \\
$0.00-0.10$ & 0.63 & $(0.05)$ & 0.81 & $(295)$ & 0.71 & $(0.02)$ & 0.84 & $(0.07)$ \\
$0.10-0.30$ & 0.76 & $(0.07)$ & 0.76 & $(129)$ & 0.82 & $(0.01)$ & 0.89 & $(0.02)$ \\
$0.30-0.50$ & 0.84 & $(0.05)$ & 0.77 & $(62)$ & 0.85 & $(0.03)$ & 0.84 & $(0.02)$ \\
$0.50-1.00$ & 0.92 & $(0.03)$ & $\mathrm{nm}$ & $\mathrm{nm}$ & 0.85 & $(0.03)$ & $\mathrm{nm}$ & $\mathrm{nm}$ \\
$1.00-2.00$ & 0.98 & $(0.03)$ & $\mathrm{nm}$ & $\mathrm{nm}$ & 0.95 & $(0.03)$ & $\mathrm{nm}$ & $\mathrm{nm}$ \\
$2.00-3.00$ & 1.04 & $(0.12)$ & $\mathrm{nm}$ & $\mathrm{nm}$ & 1.07 & $(0.06)$ & $\mathrm{nm}$ & $\mathrm{nm}$ \\
$3.00-4.00$ & 0.98 & $(0.16)$ & $\mathrm{nm}$ & $\mathrm{nm}$ & & & & \\
\hline
\end{tabular}


Figure 1. Total organic carbon stocks at different depths for two soil types under forest and pasture in the wet tropics of Costa Rica

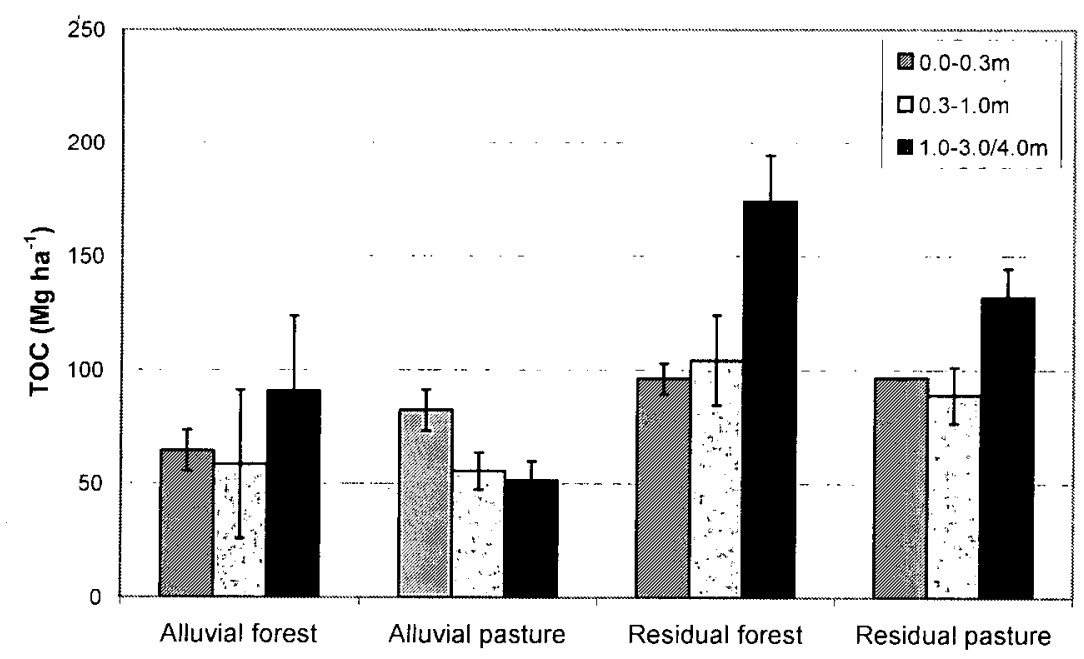


$(0.0-0.3 \mathrm{~m}$ depth) there was a significant effect of soil type $(p=0.001)$, with more TOC in the residual compared to the old alluvium but no significant effect of landuse $(p=0.062)$. No interaction could be demonstrated between landuse and soil type. In the subsoil $(0.3-3.00 \mathrm{~m}$ depth) results were different. Analyses of variance showed that the pasture subsoil contained less TOC than the forest subsoil $(p=0.014)$. Also the residual soils contained more TOC than the old alluvium $(p<0.001)$. Again no interaction was found between landuse and soil type.

Using the difference in $\delta^{13} \mathrm{C}$ isotope signature between $\mathrm{C} 3$ trees (in forest) and $\mathrm{C} 4$ grasses (dominant in tropical pastures) we distinguished between TOC derived from forest and TOC derived from tropical grasses (Fig. 2). This revealed that in the topsoil of the old alluvium, TOC derived from $\mathrm{C} 3$ vegetation decreased from $64 \mathrm{Mg}$ $\mathrm{ha}^{-1}$ to $41 \mathrm{Mg} \mathrm{ha}^{-1}$. At the same time the $\mathrm{C}$ derived from tropical grasses increased to $41 \mathrm{Mg} \mathrm{ha}^{-1}$. This resulted in a net increase of $18 \mathrm{Mg} \mathrm{hal}^{-1}$ in the topsoil of the old alluvium. For the residual soil the decrease in forest $\mathrm{C}$ was from $96 \mathrm{Mg} \mathrm{ha}^{-1}$ in the forest to $67 \mathrm{Mg} \mathrm{ha}^{-1}$ in the pasture. This was accomparied with an increase in pasture $\mathrm{C}$ of $30 \mathrm{Mg} \mathrm{ha}^{-1}$, resulting in no net change in TOC in the topsoil. In the subsoil (1.0$3.0 \mathrm{~m}$ ) of the alluvial soil, TOC derived from $\mathrm{C} 3$ vegetation decreased from $91 \mathrm{Mg}$ ha

' to $48 \mathrm{Mg} \mathrm{ha}^{-1}$. At the same time TOC derived from $\mathrm{C} 4$ vegetation increase from 0 in the forest to $3 \mathrm{Mg} \mathrm{ha}^{-1}$ in the pasture soil. The net decrease was $40 \mathrm{Mg} \mathrm{ha}^{-1}$. The subsoil of the residual soil $(1.0-4.0 \mathrm{~m})$ showed a decrease from $174 \mathrm{Mg} \mathrm{ha}^{-1}$ to $117 \mathrm{Mg}$ $\mathrm{ha}^{-1}$ of forest TOC while the pasture TOC increase to $15 \mathrm{Mg} \mathrm{ha}^{-1}$ resulting in a net decrease of $42 \mathrm{Mg} \mathrm{ha}^{-1}$.

\section{Microbial biomass}

Microbial biomass could be detected throughout all soil profiles, independent of landuse or soil type. As was expected, microbial biomass calculated on mass base was highest in the topsoil of all soil types and landuse combinations and rapidly decreased with depth (Table 2). Analysis of variance revealed that microbial biomass was higher in the pastures than in the forest for the top $0.0-0.1 \mathrm{~m}$ layer $(p=0.000)$, and for the layers at $0.5-1.0 \mathrm{~m}(\mathrm{p}=0.001)$ and $1.0-2.0 \mathrm{~m}(\mathrm{p}=0.014)$ depth. At other depths we detected no landuse effect. At none of the soil depths, we determined a significant soil type effect nor did we find an interaction between soil and landuse. Microbial biomass expressed on mass bases gives information about the concentration of microbial biomass only. It does not give insight in the total amount of microbial biomass per area. This is why we converted the results also in microbial biomass per hectare, using the bulk density data (Fig. 3). In all soil and landuse combinations, soil layers below 0.3 contributed more microbial biomass than the top $0.3 \mathrm{~m}$ that is normally sampled in studies of microbial biomass. Comparison showed that the total amount of microbial biomass in the 3 meter deep old alluvium soil profile increase from $202 \mathrm{~g} \mathrm{~m}^{-2}$ under forest to $333 \mathrm{~g} \mathrm{~m}^{-2}$ under pasture. The total amount of microbial biomass in the 4 meter deep residual soil increased from $297 \mathrm{~g} \mathrm{~m}^{-2}$ to $401 \mathrm{~g} \mathrm{~m}^{-2}$. The increase of total microbial biomass in the pasture was measured in all soil layers, with the strongest increase in the topsoil.

\section{Basal respiration}

Basal respiration could also be determined throughout all investigated soil profiles. Also basal respiration was highest in the topsoil and rapidly decreased with soil depth (Table 2). Analysis of variance showed that BR in the top $0.0-0.1 \mathrm{~m}$ layer was higher in the residual than in the old alluvial soil $(p=0.011)$. In the $0.1-0.3 \mathrm{~m}$ layer 
Figure 2. Changes in stocks of forest derived and pasture derived carbon at different depths for two soil types following forest clearing and pasture establishment

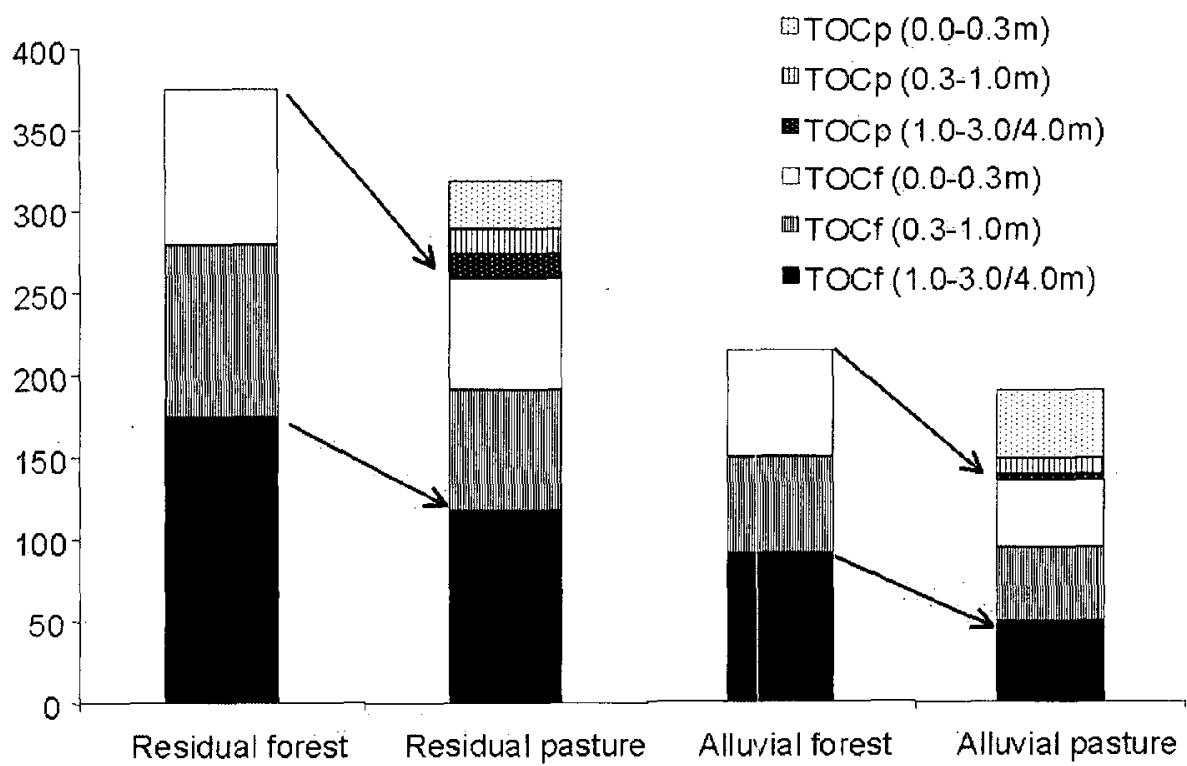

FIGURE 2 
Table 2. Microbial biomass and basal respiration in two soil types below forest and pasture. Mean values from 6 sites (Standard deviation in parentheses).

\begin{tabular}{|c|c|c|c|c|c|c|c|c|}
\hline & \multicolumn{4}{|c|}{ Residual soil } & \multicolumn{4}{|c|}{ Alluvial soil } \\
\hline depth & \multicolumn{2}{|c|}{ Forest } & \multicolumn{2}{|c|}{ Pasture } & \multicolumn{2}{|c|}{ Forest } & \multicolumn{2}{|c|}{ Pasture } \\
\hline \multicolumn{9}{|c|}{ Basal respiration $\left(\mu \mathrm{g} \mathrm{CO}_{2}-\mathrm{C} \mathrm{g}^{-1} \mathrm{dw} \mathrm{h}^{-1}\right)$} \\
\hline $0.00-0.10$ & 1.58 & $(0.35)$ & 1.49 & $(0.31)$ & 1.25 & $(0.46)$ & 1.13 & $(0.13)$ \\
\hline $0.10-0.30$ & 0.50 & $(0.27)$ & 0.29 & $(0.07)$ & 0.28 & $(0.13)$ & 0.17 & $(0.03)$ \\
\hline $0.30-0.50$ & 0.16 & $(0.09)$ & 0.11 & $(0.04)$ & 0.14 & $(0.05)$ & 0.08 & $(0.05)$ \\
\hline $0.50-1.00$ & 0.07 & $(0.03)$ & 0.06 & $(0.04)$ & 0.06 & $(0.05)$ & 0.05 & $(0.03)$ \\
\hline $1.00-2.00$ & 0.06 & $(0.04)$ & 0.04 & $(0.04)$ & 0.06 & $(0.03)$ & 0.06 & $(0.04)$ \\
\hline $2.00-3.00$ & 0.09 & $(0.05)$ & 0.04 & $(0.05)$ & 0.05 & $(0.02)$ & 0.04 & $(0.03)$ \\
\hline $3.00-4.00$ & 0.11 & $(0.06)$ & 0.07 & $(0.06)$ & & & & \\
\hline \multicolumn{9}{|c|}{ Microbial biomass $\mathrm{C}\left(\mu \mathrm{g} \mathrm{g}^{-1} \mathrm{dw}\right)$} \\
\hline $0.00-0.10$ & 999 & $(404)$ & 1483 & $(295)$ & 812 & $(289)$ & 1550 & $(419)$ \\
\hline $0.10-0.30$ & 346 & $(282)$ & 389 & $(129)$ & 253 & $(110)$ & 276 & $(116)$ \\
\hline $0.30-0.50$ & 205 & (174) & 177 & $(62)$ & 111 & $(55)$ & 173 & $(37)$ \\
\hline $0.50-1.00$ & 52 & $(23)$ & 108 & (43) & 56 & (26) & 91 & (20) \\
\hline $1.00-2.00$ & 40 & (21) & 62 & (19) & 32 & (16) & 48 & (13) \\
\hline $2.00-3.00$ & 37 & (16) & 39 & (21) & 28 & (12) & 38 & (14) \\
\hline $3.00-4.00$ & 47 & (25) & 45 & (21) & & & & \\
\hline
\end{tabular}


Figure 3. Total microbial biomas stocks at different depths for two soil types under forest and pasture in the wet tropics of Costa Rica.

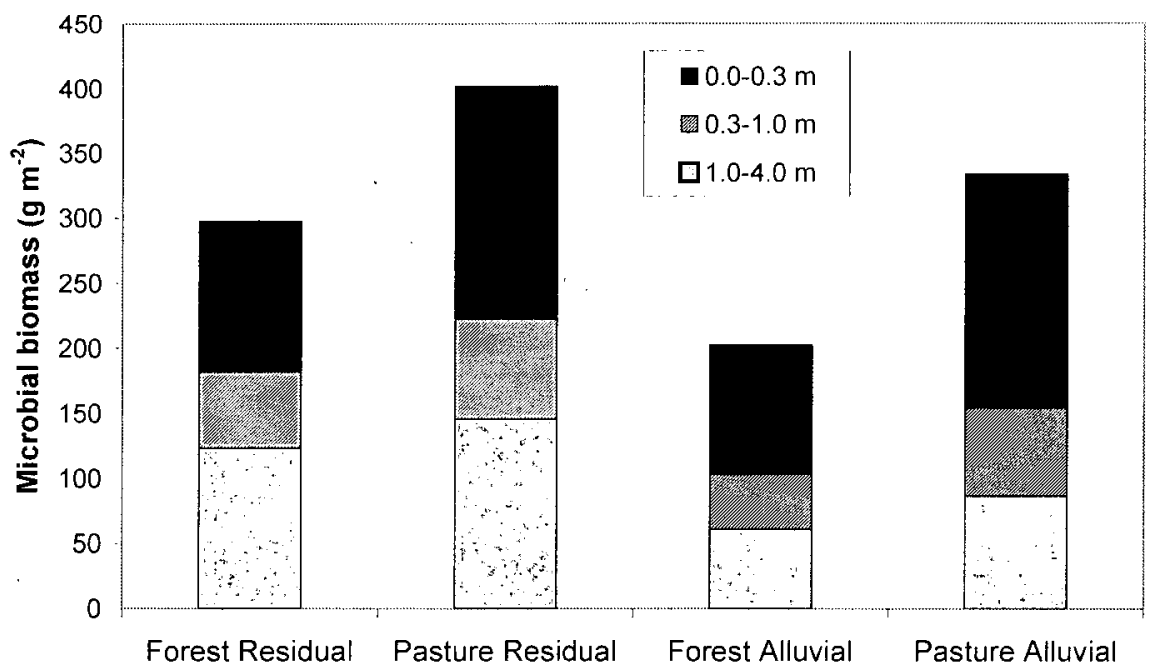


Table 3. Metabolic quotient ( $\mathrm{q} \mathrm{CO}_{2}$ ) below forest and pasture. Mean values from both soil types ( $\mathrm{n}=12$ and standard deviation in parentheses).

\begin{tabular}{|c|c|c|}
\hline & \multicolumn{2}{|c|}{$\mathrm{q} \mathrm{CO}_{2}\left(\mathrm{mg} \mathrm{CO}_{2}-\mathrm{C} \mathrm{mg}^{-1} \mathrm{Cmic}^{*} \mathrm{~h}^{-1}\right) * 10^{-4}$} \\
\hline Soil depth (m) & Forest & Pasture \\
\hline $0,00-0,1$ & $17.3(6.2)$ & $8.9(2.3)$ \\
\hline $0,1-0,3$ & $16.1(9.5)$ & $7.3(2.5)$ \\
\hline $0,3-0,5$ & $12.8(7.3)$ & $5.5(3.2)$ \\
\hline $0,5-1,0$ & $13.9(8.8)$ & $5.5(2.9)$ \\
\hline $1,0-2,0$ & $19.7(13.8)$ & $8.8(6.0)$ \\
\hline $2,0-3,0$ & $23.1(10.2)$ & $9.7(6.0)$ \\
\hline
\end{tabular}


$(p=0.024)$. In the $0.3-0.5 \mathrm{~m}$ layer only forest was higher than pasture $(p=0.049)$. In the lower part of the profile we could not detect a significant effect of either soil type or land use. Basal respiration expressed on mass base does not take into account the large soil volume that these soils have in the subsoil. For that reason we also expressed the BR on area basis using the bulk density data. The reason of this exercise is not to convert our laboratory data on BR to a field situation, but to demonstrate that a relatively low basal respiration multiplied over a large volume of soil can result in relatively large numbers. The volume based basal respiration was for all soil and landuse combinations higher in the soil layers below $0.3 \mathrm{~m}$ than the top $0.3 \mathrm{~m}$. Comparison showed that the volume based basal respiration in the 3 meter deep old alluvial soil profile decreased from $7.1 \mathrm{~g} \mathrm{~m}^{-2} \mathrm{~d}^{-1}$ under forest to $6.1 \mathrm{~g} \mathrm{~m}^{-2} \mathrm{~d}^{-1}$ under pasture. The volume based basal respiration in the $4 \mathrm{~m}$ deep residual soil decreased from $11.7 \mathrm{~g} \mathrm{~m}^{-2} \mathrm{~d}^{-1}$ to $8.3 \mathrm{~g} \mathrm{~m}^{-2} \mathrm{~d}^{-1}$. The decrease of volume based basal respiration in the pasture was only measured in the subsoil.

\section{Discussion}

$\underline{\text { Soil carbon stocks in forest soils and long-term C sequestration }}$

The soil carbon stocks we measured under forest are very high both compared to carbon stocks in the above ground vegetation and compared to other humid tropical forest sites. The standing carbon stock of the La Selva forest was $74.5 \mathrm{MgC} \mathrm{ha}^{-1}$ for the residual soils and 83.5 $\mathrm{Mg} \mathrm{C} \mathrm{ha}^{-1}$ for the old alluvial terraces (Clark \& Clark, 2000). This means that on the alluvial soil more than $70 \%$ and on the residual soil more than $80 \%$ of the ecosystem carbon was stored in the soil organic matter. This ratio of above and below ground carbon stocks is a lot higher than previously published numbers for tropical forests. There are two reasons for this. First, the measured carbon stocks of this tropical wet forest are low compared to numbers for tropical moist forests published for the Amazon basin. This is mainly a result of the different allometric equations between tropical wet and moist forests (Clark \& Clark, 2000). The second reason is that the total amount of carbon in the soil of this tropical wet forest is about twice as high as the carbon stocks typically found under the tropical moist forests in the Amazon basin. To illustrate this: Trumbore et al. (1995) measured $168 \mathrm{Mg} \mathrm{C}^{-1}$ down to 3 meter depth and Sommer et al (2000) reported $143 \mathrm{Mg} \mathrm{C} \mathrm{ha}^{-1}$ down to 3 meter, in both cases for Oxisols under forest in the state of Pará, Brazil. This is 46-71 $\mathrm{Mg} \mathrm{ha}^{-1}$ less than the old alluvial soils and less than $50 \%$ of the C stock in our residual soil. The reason for the higher $\mathrm{C}$ stocks in our costarican sites compared to Amazonian sites my lay in the different life zone. In his review, Post (1982) found that the mean soil carbon density in tropical wet forest was almost double the amount found in tropical moist forest. This corroborates well with the difference between our residual soil $\mathrm{C}$ stocks down to $3 \mathrm{~m}$ depth and the C stocks reported by Trumbore et al. (1995) and Sommer et al. (2000).

A comparison of forest SOC stocks with depth shows that both in the old alluvium and the residual soils, substantial carbon stocks were found below $1 \mathrm{~m}$ depth. Nepstad and colleagues (1994) reported similar results for the Brazilian Amazon. They conclude that the forest soil below $1 \mathrm{~m}$ depth contained more carbon than the top meter and explained these large subsoil carbon stocks by the deep root systems that are found in large areas of the amazon basin. Deep roots play an important role in these areas in maintaining dry season canopy greenness and evapotranspiration. In contrast to the study by Nepstad et al (1.994) our costarican site does not suffer from seasonal drought, nor did we sample any roots $>2 \mathrm{~mm}$ below $2 \mathrm{~m}$ depth. In addition, we only rarely observed roots below $2 \mathrm{~m}$ depth. Deep roots are therefore not the likely 
Figure 4. Soil volume based basal respiration at different depths for two soil types under forest and pasture in the wet tropics of Costa Rica.

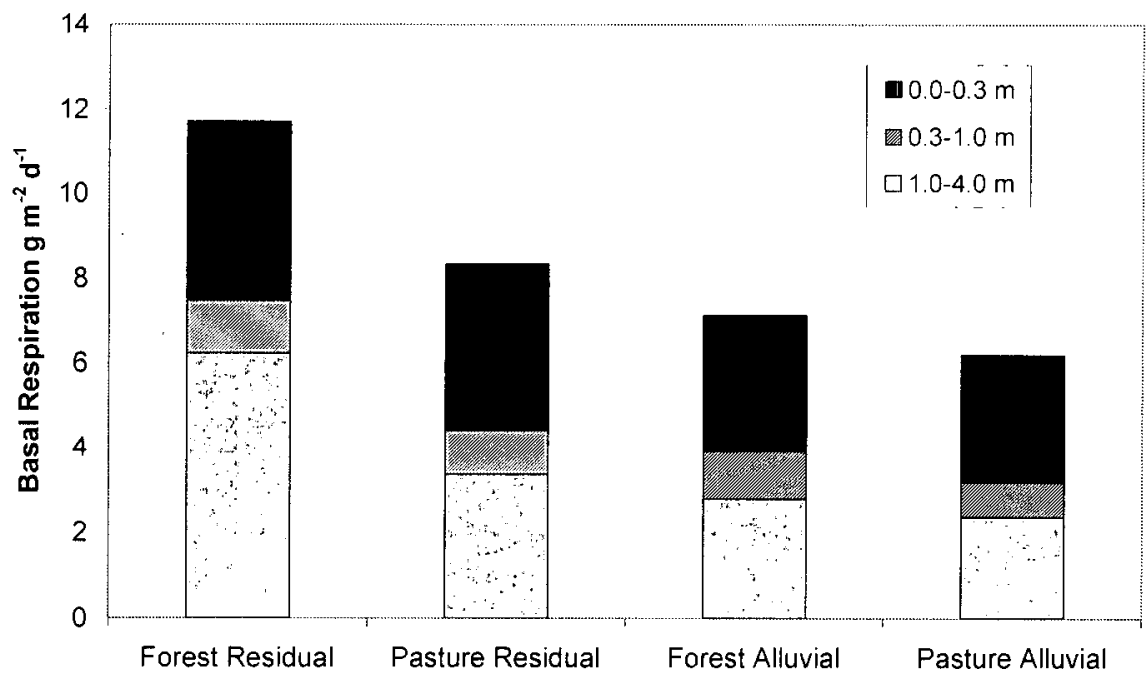


cause of the large $C$ stock that we measured below $1 \mathrm{~m}$ depth in our soils. The main difference between our site and large parts of the amazonian basin is that the average annual rainfall is about twice as high as the average annual evapotranspiration (Sanford et al, 1994). This means that on a yearly basis about $2000 \mathrm{~mm}$ of rain is draining through the soil profile each year, whereas in large parts of the Amazon basin yearly drainage is much lower. At the high drainage rates encountered at our sites, even relatively low concentrations of dissolved organic carbon can result in substantial amounts of carbon transported to lower soil horizons where they can be adsorbed. We hypothesize that this is the dominant process that has caused the large carbon stocks below $1 \mathrm{~m}$ depth.

Soil type explained $68 \%$ of the variance of the carbon stocks and was more important than land use. The parent materials of both the old alluvial and residual soils have a very similar mineralogy, their main difference is caused by the difference in age (Sollins, 1994). If we consider the old alluvial and residual soils being part of the same weathering chronosequence, then a comparison of C-stocks at different depths may reveal the long-term potential for Csequestration (Schlesinger, 1990; Fig. 1). This comparison clearly shows that the largest potential for $\mathrm{C}$-sequestration is found in the subsoil, although the residual soil has also a higher $\mathrm{C}$ stock in the top meter. However, on a yearly basis the $\mathrm{C}$ sequestration would be quite low. If we assume an age difference between the two soil types of about $10^{6}$ years, the long-term $\mathrm{C}$ sequestration potential would be only in the order of magnitude of about $160 \mathrm{~g} \mathrm{C} \mathrm{ha}^{-1} \mathrm{yr}^{-1}$. This could be considered the $\mathrm{C}$ sequestration due to proceeding weathering. This is several orders of magnitude lower than the $\mathrm{C}$-sequestration rates that have been reported for some Amazonian forests (Grace et al, 1995).

\section{Effects of land use change on C stocks}

Pasture establishment led to contrasting changes in carbon stock between soil types and between top- and subsoil. The increase in soil C-stock in the topsoil (0-0.3m depth) of the pastures of the old alluvium and no change in soil C-stock of the topsoil of the pastures of the residual soils can be explained by the relative productivity of the pastures established on these soils. In a period of about 25 years, the decrease in C3-derived carbon between the two different soil types was not significantly different (24 Mg for the alluvial soil and $30 \mathrm{Mg}$ for the residual soil). At the same time, the increase in pasture derived carbon was $41 \mathrm{Mg} \mathrm{ha}^{-1}$ on the alluvial soil, while the residual soil showed an increase in $\mathrm{C} 4$ carbon of only $30 \mathrm{Mg} \mathrm{ha}^{-1}$. The higher fertility of the alluvial soil may have caused the difference in pasture productivity. A similar control of pasture productivity on C-stocks was reported by Trumbore et al. (1995) who measured an increase in C-stocks under managed pastures, but a decrease in C-stocks under degraded pastures. No difference was found in carbon stocks for the soil horizons between 0.3 and $1.0 \mathrm{~m}$ depth. Surprisingly, we did find changes in soil C stocks below $1 \mathrm{~m}$ depth in the studied soils. Total Cstocks below 1 meter decreased substantially in the pastures compared to the forest sites (Fig. 2). This shows that a considerable part of the subsoil carbon can be mobilized within 25 years since forest conversion for pasture. For the residual soil this carbon, which should be considered as the sum of 'active' and 'slow' carbon pools, was about 33\% of the total subsoil C stock. For the old alluvial soil this was even as high as 46\%. In their study Trumbore et al. (1995) used a simple simulation model to calculate the contribution for 'active', 'slow' and 'passive' carbon in the forest soil. Their best fit revealed that $1 \%$ of the SOC in the depth between 1 and 3 meter should be considered 'active' and between 14 and 19\% should be considered 'slow' carbon. Our results indicate a larger contribution of the active and slow pools, especially in the residual soil. The reason for this discrepancy may lay in the different mechanisms that have transported the carbon to this depth. While in Brazil decomposing roots in the study of Trumbore et al (1995) were the 
main source of sub soil carbon, dissolve organic carbon (DOC) is the most likely source in our study. Decomposing roots may contain a considerable amount of more recalcitrant $\mathrm{C}$, while recent results have indicated that DOC may be less recalcitrant than previously thought (Kalbitz et al., 2000). In the residual pasture soils we could also demonstrate substantial amounts of C4 derived carbon below 1 meter depth. For the old alluvial soil this was only about $3 \mathrm{Mg} \mathrm{ha}^{-1}$, but for the residual soil it was $15 \mathrm{Mg} \mathrm{ha}^{-1}$ (down to 4 meter). As we can exclude that grass roots of this low productive grass species will reach this deep, this is another indication that the carbon was not transported to this depth by root growth but rather in dissolved organic form.

Care should be taken when using the change in ${ }^{13} \mathrm{C}$ to follow the loss of forest-derived (C3) and the accumulation of pasture-derived (C4) carbon because pastures can also contain considerable amounts of $\mathrm{C} 3$ herbs and bushes (Trumbore et al, 1995). Although $\mathrm{C} 4$ grasses dominate the vegetation at our sites, this is no guarantee that this has always been the case since forest clearing. Addition of recent C 3 carbon would mean that our calculated losses of forest derived carbon and the calculated addition of pasture derived carbon are both lower limits. This would mean that the size of the active and slow carbon pools could be even higher than we have estimated here.

Microbial biomass stocks and activity in forest soils

Traditionally it is assumed that the soil microbial biomass and activity below the topsoil is not important or even absent. However, in recent publications several authors have suspected that the microbial biomass below the topsoil is often underestimated (e.g. Bauhus \& Khanna, 1999). Our results confirm this. Although we consistently measured the highest concentration of microbial biomass in the topsoil, we were able to detect microbial biomass throughout all soil profiles. The microbial biomass concentrations in the subsoil were a factor 20 to 30 lower than the concentrations in the topsoil, yet the importance of the microbial biomass becomes apparent when we calculated the microbial biomass on an area basis. The amount of microbial biomass in the topsoil ( $0-0.3 \mathrm{~m}$ depth) of the forest old alluvium was only about $50 \%$ of the total amount of microbial biomass in the whole soil profile. For the residual soil this number was even lower (about 40\%). This demonstrates the importance of the subsoil in the contribution to microbial activity. Richter \& Markewitz (1995) reported comparable results. They reported that microbes were prolific throughout an $8 \mathrm{~m}$ deep Ultisol profile in the southeastern United States. In our study, the average concentration of microbial biomass $\mathrm{C}$ in the $0-0.1 \mathrm{~m}$ layer of the forest soils $\left(906 \mu \mathrm{g} \mathrm{g}^{-1}\right.$ soil) is well comparable with fertile temperate forest soils (Jörgensen, 1995) and are comparable with the values reported by Luizão et al. (1992) for a Brazilian Oxisol. The measured basal respiration for the subsoil of the forest profiles was about $6 \mathrm{~g} \mathrm{~m}^{-2} \mathrm{~d}^{-1}$ for the residual soil and almost $3 \mathrm{~g} \mathrm{~m}^{-2} \mathrm{~d}^{-1}$ for the old alluvium. If we assume a steady state situation in the forest soils, enough substrate has to reach below $1 \mathrm{~m}$ depth for the maintenance respiration which is normally assumed to be equal to the basal respiration (Anderson \& Domsch, 1978).

The presence of microbial activity was also confirmed by the $\mathrm{CO}_{2}$ concentration profiles that we measured in the forest soils. During a two-year period, the highest $\mathrm{CO}_{2}$ concentrations were consistently measured at the lowest sampling depth, which was $3.5 \mathrm{~m}$ in the residual soils and $2.5 \mathrm{~m}$ in the old alluvium (Schwendenmann et al, in press). These high soil $\mathrm{CO}_{2}$

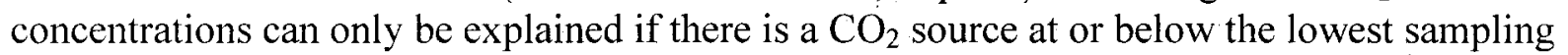
depth. The depleted stable isotope signature of the $\mathrm{CO}_{2}$ (unpublished data) pointed at a biological $\mathrm{CO}_{2}$ source, confirming that microbial activity is the most likely source of this deep $\mathrm{CO}_{2}$. 


\section{Effects of landuse change on microbial biomass and activity}

Microbial biomass, as part of the 'active' soil organic matter, reacts more rapidly to changes in land use and management than the total soil $\mathrm{C}$ stock. This is the reason why microbial biomass has been used as a sensitive indicator for changes in soil organic matter (Powlson et al., 1987). The pasture sites had a microbial biomass which was between $30 \%$ (old alluvium) and $50 \%$ (residual soil) higher than the forest sites. This difference was exclusively caused by differences in the topsoil. The increase in microbial biomass in the topsoil of the old alluvium is no surprise as the total amount of $\mathrm{C}$ has also increased in this soil. The increase of microbial biomass in the topsoil of the residual soil (without an increase in TOC) and the lack of decrease in the subsoil of both soils (with a decrease in TOC) is more puzzling. The explanation may lay in a change in the microbial population going from forest to pasture. In a study in tropical Hawaii, Nüsslein \& Tiedje (1999) found a significant shift in the soil bacterial community which correlated with a change from forest to pasture vegetation. Also the higher $\mathrm{pH}$ in the pasture soils may have provoked a shift from a fungi-dominated microbial population in the forest to a more bacterial dominated population in the pasture sites. This may have resulted in the observed changes in microbial biomass.

Differences in basal respiration between forest and pasture were minor, with a tendency of lower values in the pasture sites (Table 1). The apparent discrepancy in the topsoil between the increase in microbial biomass and the lack of change in basal respiration can be explained by a lower metabolic quotient $\left(\mathrm{qCO}_{2}\right)$ of the microbial biomass in the pastures (Table 3). Anderson \& Domsch (1993) have used the $\mathrm{qCO}_{2}$ as an indicator for environmental stress. If a microbial population experiences more stress, they need more energy for their maintenance metabolism. Translated to our study, the higher $\mathrm{qCO}_{2}$ in the forest could be the result of more environmental stress caused e.g. by lower nutrient availability, lower $\mathrm{pH}$ values and corresponding higher $\mathrm{Al}$ toxicity. This could lead to a rapid turnover of microbial biomass. To use $\mathrm{qCO}_{2}$ as an indicator for environmental stress is however controversial: several studies have shown that e.g. also succession influences $\mathrm{qCO}_{2}$ and with a drastic change in vegetation it may be difficult to separate the influence of environment and changes in microbial population.

\section{Consequences for the role of tropical wet forest soils in the global carbon cycle.}

When Nepstad and colleagues (1994) reported that soil carbon stocks in deeply weathered tropical soils are large and may be affected by changes in landuse that affect depth distributions of carbon inputs, they limited their conclusions to tropical evergreen forests that need deep soil water during the dry season. The input mechanism that they proposed for soil carbon below $1 \mathrm{~m}$ depth was the growth of deep roots that extract water during the dry season. Our results show that also in deeply weathered soils below tropical wet forests, lacking a clear dry season (at the 'wet' side of the rainfall spectrum), large stocks of soil carbon can occur. The absence of roots below $2 \mathrm{~m}$ depth makes deep roots a very unlikely source of this deep carbon. The C-input mechanism that we propose for the subsoil of this forest, where precipitation exceeds evapotranspiration, is transport of DOC followed by adsorption Our results furthermore show that more than $30 \%$ of this deep carbon can be mobilized in about 25 years if this forest is cleared for pasture. A possible mechanism for this mobilization may be the diminished DOM adsorption capacity at higher $\mathrm{pH}$ (Kalbitz et al., 2000). In our study this C-loss from the subsoil affected the overall $\mathrm{C}$ balance in such a way that the neutral balance or increase in C-stock in the topsoil was completely compensated by the C-loss in the subsoil. How large is the area where similar processes could take place? In Figure 5 we show areas in Central and South America where deeply weathered soils (Oxisols and Ultisols) occur and where precipitation exceeds $2500 \mathrm{~mm}$. The total area where these conditions occur is about 1.9 million $\mathrm{km}^{2}$. Most of this area $(\approx 80 \%)$ is still under tropical 
wet forest, and about $20 \%$ has been cleared for crops and pastures. Forest clearing in this area may lead to unexpected high $\mathrm{C}$ losses from the subsoil similar to the losses that we documented in this study.

From our results we cannot deduct whether the subsoil of the studied soil types presently act as a carbon source or sink. It is clear that on both soil types on average carbon has disappeared since forest clearing, but the contribution of $\mathrm{C} 4$ derived carbon below 1 meter depth in both soil types also indicates that since forest clearing carbon has been sequestered. However we cannot deduct whether this $\mathrm{C}$-sequestration is presently continuing or whether the $\mathrm{C}$ sequestration capacity has been reached with the present C-stocks.

Our results and earlier results by Nepstad et al (1994) stress that we have to rethink sampling strategies when studying soil processes and the effects of land use changes in deeply weathered soils. This is not only true for areas with a pronounced dry season, but also for areas with a wet tropical forest. When studies to the effects of land use changes on the global C cycle are limited to the topsoil we may draw the wrong conclusions as processes in the subsoil may have a completely opposite direction. We also show that more than $50 \%$ of microbial biomass and activity may be found in the subsoil, confirming that a study of the topsoil gives an incomplete picture at best. We conclude that the results of global change models should be questioned as long as carbon cycling in the subsoil of deeply weathered tropical soils is not included. 


\section{VII.2. Soil $\mathrm{CO}_{2}$ Fluxes}

\section{Introduction}

Tropical forests play an important role in the global carbon budget. Tropical evergreen forests account for $\sim 35 \%$ of the world's potential net primary production on land (Melillo et al. 1993, Field et al. 1998). In the past, old growth tropical rain forests were often considered as steady-state systems, but some evidence suggests that tropical rain forests may act as carbon sinks (Grace et al. 1995, Mahli et al. 1998). Other studies predict large carbon losses from tropical forests if temperature increases due to climate change (Cox et al. 2000, White et al. 2000). It is therefore critical to understand how the carbon budget of tropical forests will react to changes in environmental conditions. For this reason "CARBONO", a long-term, landscape-scale project was set up at La Selva Biological Station in Costa Rica. Its major goal is to assess the major carbon stocks and fluxes and to investigate the effects of climatic factors on ecosystem carbon dynamics.

To characterize the carbon exchange in forest ecosystems, an assessment of the dynamics of soil $\mathrm{CO}_{2}$ efflux is important as soil respiration is a major $\mathrm{CO}_{2}$ flux in the carbon cycle, second in magnitude to gross canopy photosynthesis (Raich \& Schlesinger 1992).

$\mathrm{CO}_{2}$ in the soil is produced by root respiration and by decomposition of litter and soil organic matter. Efflux of $\mathrm{CO}_{2}$ from the soil to the atmosphere is controlled by diffusion and therefore related to the concentration of $\mathrm{CO}_{2}$ in the soil atmosphere and soil textural and soil structural properties that control the diffusivity of $\mathrm{CO}_{2}$ in the soil (De Jong \& Schappert 1972). Although multiple factors influence the biological and physical processes controlling soil $\mathrm{CO}_{2}$ release, many studies have shown that soil temperature and soil moisture are the most important factors regulating soil $\mathrm{CO}_{2}$ efflux (Singh \& Gupta 1977, Howard \& Howard 1993, Kicklighter et al. 1994). A complication is that soil temperature and soil water content often covary, which makes it difficult to separate their effects (Reiners 1968, Dörr \& Münnich 1987, Davidson et al. 1998).

In this study our first objective was to quantify and compare the soil $\mathrm{CO}_{2}$ efflux rates of two different soil types in an old-growth neotropical rain forest in Costa Rica. Our second objective was to evaluate how environmental factors control the efflux of $\mathrm{CO}_{2}$ from the soil surface

\section{Materials and Methods}

For this study we selected three 0.5 hà plots on each of the two dominant soil types of La Selva: 'old alluvium' (plot A2, A3, A4) and 'residual' (plot L4, L5, L6) soils. For more details on site selection see Clark et al. (1998) and Clark \& Clark (2000). The 'old alluvium' soil is formed on old river terraces and has previously been classified as an Inceptisol. The strongly weathered 'residual' soils originate from andesitic lava flows and were classified as Ultisols (Sollins et al. 1994). Only 'residual' sites which were located on relatively flat ridges were studied. Kleber et al. (submitted) recently reclassified these soils. Both soil types meet the rationale for the classification as Oxisols: low silica:sesquioxide ratio, low base exchange capacity, low acitivity of clays, and low content of weatherable minerals. Considering the perudic moisture regime both soils were classified as Typic Haploperox (Kleber et al., submitted).

In August 1997 we took soil samples at $0.05,0.20,0.40,0.75,1.50$ and $2.50 \mathrm{~m}$ depth from one soil pit of each 0.5 ha plot. Bulk density was determined by taking undisturbed soil samples $\left(300 \mathrm{~cm}^{3}\right)$, which were subsequently dried at $105^{\circ} \mathrm{C}$ for $48 \mathrm{~h}$. Total pore space $\left(\mathrm{cm}^{3} \mathrm{~cm}^{-3}\right)$ was calculated from measurements of bulk density and an assumed particle density of $2.65 \mathrm{~g} \mathrm{~cm}^{-3}$. Soil air space $\left(\mathrm{cm}^{3} \mathrm{~cm}^{-3}\right)$ was estimated by subtracting volumetric soil water content $\left(\theta_{v}\right)$ from 
total pore space. To measure the particle size distribution, air-dried and sieved $(2 \mathrm{~mm})$ soil samples were treated with $\mathrm{H}_{2} \mathrm{O}_{2}$ to remove organic matter and then dispersed with pyrophosphate. The particle fractions were determined using the pipette method. Soil $\mathrm{pH}$ was measured with a combined electrode in potassium chloride $(1 \mathrm{M})$ at a soil:solution ratio of $1: 2.5$. To determine total carbon, nitrogen and phosphorus subsamples were dried $\left(40^{\circ} \mathrm{C}\right)$ and pulverized. An elemental analyzer (Elementar analysator CNS, Vario EL, elementar, Hanau, Germany) was used to estimate total carbon and nitrogen. To determine total $\mathrm{P}$, the ground samples were digested with $\mathrm{HNO}_{3}{ }^{-}$. The $\mathrm{P}$ content was measured with an ICP (Spectro Analytical Instruments, Kleve, Germany). Main physical and chemical characteristics of the upper $(0-1 \mathrm{~m})$ and lower soil profile (1-3 m) of the investigated soils are given in Table 1 .

\section{$\underline{\text { Soil } \mathrm{CO}_{2} \text { efflux }}$}

We used dynamic, closed chambers for measurement of soil $\mathrm{CO}_{2}$ efflux (Parkinson 1981, Norman et al. 1992). Eight chambers were deployed randomly along four parallel transects at each site. Transects were $15 \mathrm{~m}$ long and spaced $5 \mathrm{~m}$ apart. In August 1997, aluminum rings $(0.20$ $\mathrm{m}$ in diameter, $0.15^{\circ} \mathrm{m}$ tall) were inserted to a depth of about $0.02 \mathrm{~m}$ into the soil. Once inserted, the rings were left in place throughout the time investigated, except for two chambers which had to be replaced due to tree fall. The chambers were kept free of seedlings throughout the whole study period. Each of the six sites was sampled bi-weekly from April 1998 to April 2000. It took 2 days to measure the six sites; three sites per day were measured in a randomly chosen order. All measurements were conducted between 8 AM to 2 PM local time. Preliminary studies did not reveal a detectable diurnal pattern of $\mathrm{CO}_{2}$ efflux.

Flux chambers were closed with an aluminum cover $(0.15 \mathrm{~m}$ tall $)$ for about 5 minutes. Air was circulated at a flow rate of $0.61 \mathrm{~min}^{-1}$ between an infrared $\mathrm{CO}_{2}$ gas analyzer (April 1998 to January 2000: LI-6251, since February 2000: LI-800; LI-COR, Inc., Lincoln, Nebraska, USA) and the flux chambers. To prevent pressure differences between the chamber and atmosphere, the chamber was vented to the atmosphere through a $0.25 \mathrm{~m}$ long stainless steel tube $(3.2 \mathrm{~mm}$ outer diameter). $\mathrm{CO}_{2}$ concentrations were recorded at 5 second intervals with a datalogger (April 1998 to January 2000: Campbell CR 10X, since February 2000: Campbell CR 510X; Campbell Scientific, Inc., Logan, Utah, USA). $\mathrm{CO}_{2}$ flux was calculated from linear regression of increasing $\mathrm{CO}_{2}$ concentration within the chamber versus time, usually between 2 and 4 min after placing the cover over the ring. The coefficient of determination $\left(\mathrm{r}^{2}\right)$ of the simple linear regression was typically better than 0.99 . The infrared gas analyzer was calibrated in the lab using nitrogen as zero standard and a secondary $\mathrm{CO}_{2}$ standard $(450 \mathrm{ppm})$. Secondary standards were calibrated against primary standards supplied by Scott-Marin, Inc. (Riverside, CA, USA).

For each of the six sites the average $\mathrm{CO}_{2}$ efflux rate was calculated from the eight chamber flux measurements on a sampling day. Daily mean soil efflux for each site was calculated by linear interpolation between sampling dates. Daily $\mathrm{CO}_{2}$ flux rates were then cumulated to estimate annual flux rates. Due to equipment failure or heavy rainfall we lost approximately $1 \%$ of the data. Where there were missing data the average of the previous and following sampling date was used.

\section{$\underline{\text { Soil } \mathrm{CO}_{2}}$ profile concentration and $\mathrm{CO}_{2}$ storage}

At each of the six selected sites a soil shaft (about 0.75 by $2 \mathrm{~m}$ with 3 to $4 \mathrm{~m}$ depth) was installed. In August 1997, stainless steel tubing (3.2 mm outer diameter) was inserted horizontally at 0.05 , $0.20,0.40,0.75,1.50$ and $2.50 \mathrm{~m}$ depth. These tubes had holes at one end and a septum holder with septum at the other end to allow sampling of soil gases. The tubes at depths of $0.05-0.75 \mathrm{~m}$ 
Table 1. Characteristics of the investigated soil types. Data are means per soil type $(n=3)$ for the topsoil $(0-0.30 \mathrm{~m}$ depth $)$

\begin{tabular}{ccccccc}
\hline Soil type & $\begin{array}{c}\text { Clay content } \\
(\%)\end{array}$ & $\begin{array}{c}\text { Bulk density } \\
\left(\mathbf{c m}^{\mathbf{3}} \mathbf{c m}^{-\mathbf{3}}\right)\end{array}$ & $\begin{array}{c}\text { Total C } \\
(\%)\end{array}$ & $\begin{array}{c}\text { Total N } \\
(\%)\end{array}$ & $\begin{array}{c}\text { Total P } \\
(\mathbf{m g} / \mathbf{g})\end{array}$ & $\begin{array}{c}\mathbf{p H} \\
(\mathbf{K C l})\end{array}$ \\
\hline Inceptisol & $70.0 \mathrm{a}$ & $0.79 \mathrm{a}$ & $2.94 \mathrm{a}$ & $0.27 \mathrm{a}$ & $1.07 \mathrm{a}$ & $3.87 \mathrm{a}$ \\
Ultisol & $77.5 \mathrm{~b}$ & $0.70 \mathrm{a}$ & $4.23 \mathrm{a}$ & $0.36 \mathrm{a}$ & $0.67 \mathrm{~b}$ & $4.13 \mathrm{a}$ \\
\hline
\end{tabular}

${ }^{1}$ Different letters indicate differences between soil types, at $\mathrm{P}<0.05$ (ANOVA) 
sensors (Campbell CS 615) were installed at the same depths as the gas sampling tubes. The "pit wall effect' on $\mathrm{CO}_{2}$ concentration was tested. At $1.50 \mathrm{~m}$ depth tubes of $0.45,0.90,1.35,1.80$ and $2.70 \mathrm{~m}$ length were inserted horizontally. The horizontal $\mathrm{CO}_{2}$ concentration gradient was measured several times and a fit of the data revealed that the $\mathrm{CO}_{2}$ concentration, measured at 1.80 $m$ from the pit wall, was around $95 \%$ of the $\mathrm{CO}_{2}$ concentration at the estimated asymptode.

Soil gas samples were collected with a needle and polypropylene syringes with a threeway stopcock mounted to the tip. When sampling, first the 'dead' volume in the tubes was discarded. Then $30 \mathrm{ml}$ gas was withdrawn from each gas sampling tube. Within 6 hours the gas samples were analyzed in the lab for $\mathrm{CO}_{2}$ concentration using a Shimadzu GC-8 gas chromatograph with a thermal conductivity detector. Gas samples passed through an anhydrous $\mathrm{CaSO}_{4}$ (Drierite) trap to remove water vapor followed by a sample loop of about $1 \mathrm{ml}$. Samples were injected on a Porapak Q $(80 / 100$ mesh) packed stainless steel column $(2.0 \mathrm{~m} \times 3.2 \mathrm{~mm})$ using a 6-port manually actuated valve (Valco Instruments). Oven temperature was maintained at $40{ }^{\circ} \mathrm{C}$. Helium carrier gas flowed at approximately $30 \mathrm{ml} \mathrm{min}{ }^{-1}$. The retention time for $\mathrm{CO}_{2}$ was about 1.1 minutes. Soil air $\mathrm{CO}_{2}$ concentration was calculated by comparison of integrated peak areas of samples with standard gases $\left(0.045 \%\right.$ and $\left.4.93 \% \mathrm{CO}_{2}\right)$, which were used to make a two point calibration. Storage tests indicated that on average 1 to $2 \%$ (maximal $5 \%$ ) $\mathrm{CO}_{2}$ were lost between time of sampling and analyses.

The soil profile was divided into six layers $(0-0.10 \mathrm{~m}, 0.10-0.30 \mathrm{~m}, 0.30-0.50 \mathrm{~m}, 0.50$ $-1.00 \mathrm{~m}, 1.00-2.00 \mathrm{~m}$ and $2.00-3.00 \mathrm{~m}$ ). Soil $\mathrm{CO}_{2}$ storage of the different soil layers was calculated as follows (Equation 1):

Soil $\mathrm{CO}_{2}$ storage per soil layer $=$ Soil air $\mathrm{CO}_{2}$ concentration $\mathrm{x}$ soil air space $\mathrm{x}$ soil volume per soil layer $\mathrm{x}$ factor $\mathrm{x} 1000$

With:

Soil $\mathrm{CO}_{2}-\mathrm{C}$ storage of the different soil layers $\left(\mathrm{mg} \mathrm{C} \mathrm{m}^{-2}\right)$

Soil $\mathrm{CO}_{2}$ concentration measured in the soil air space per soil layer (volume \%)

Soil air space $\left(\mathrm{m}^{3} \mathrm{~m}^{-3}\right)=$ Total pore space $\left(\mathrm{m}^{3} \mathrm{~m}^{-3}\right)$ - Soil water content $\left(\mathrm{m}^{3} \mathrm{~m}^{-3}\right)$

Soil volume per soil layer $\left(\mathrm{m}^{3}\right)=1 \mathrm{~m}^{2} \mathrm{x}$ vertical extension of the respective soil layer $(\mathrm{m})$

Factor $=\underset{t}{\text { Molecular weight of carbon }\left(12 \mathrm{~g} \mathrm{~mol}^{-}\right.}$

Volume of a mole of gas $(0.0224 \mathrm{~mol}$

$\mathrm{m}^{-3}$ )

Soil $\mathrm{CO}_{2}$ storage calculated for each of the six soil layers was then added up for the upper part of the soil profile $(0-1 \mathrm{~m})$, the lower part of the soil profile $(1-3 \mathrm{~m})$ and for the whole profile $(0-3 \mathrm{~m})$.

\section{Environmental parameters}

Soil temperature was measured adjacent to each flux chamber at approx. $0.05 \mathrm{~m}$ depth and within the soil shaft with a thermocouple T-probe and a thermometer reader (OMEGA HH 64).

Soil water content was determined using frequency domain reflectometry (FDR). The probe (Campbell CS 615) consisted of $0.30 \mathrm{~m}$ long stainless steel rods that were placed horizontally into the soil (O'Brien \& Oberbauer 2001). The sensor output was converted to estimates of volumetric soil water content $\left(\theta_{\mathrm{v}}\right)$ using the calibration curve developed by Veldkamp \& O'Brien (2000).

For two study sites ('old alluvium' site A4 and 'residual' site L6) the volumetric water content (from $0.05 \mathrm{~m}$ depth) was converted to matric potential using water retention curves 
generated from pressure plate analyses of intact cores. Volumetric water contents $\left(\theta_{\mathrm{v}}\right)$ were measured at $0,0.25,5.6,10,33,100,300$ and $1500 \mathrm{kPa}$ tension. Based on these data the following exponential functions were calculated (Papendick \& Campbell 1981):

'old alluvium': matric potential $(\mathrm{MPa})=843.4 \mathrm{e}^{-0.224 \times 0 \mathrm{v}}$

'residual': matric potential $(\mathrm{MPa})=320.5 \mathrm{e}^{-0.209 \times}$. $\mathrm{v}$

$\underline{\text { Statistical analyses }}$

Prior to statistical analyses the parameters were tested for normality. One-way analysis of variance was used to determine spatial and temporal differences. Linear and nonlinear regression analyses were used to examine relationships between soil $\mathrm{CO}_{2}$ efflux, soil water content, soil temperature and other factors. Significant effects were determined at $\mathrm{P}<0.05$. All our statistical analyses were carried out using the STATISTICA 5.5 software package (StatSoft Inc., Tulsa, Oklahoma, USA).

\section{Results}

Spatial and temporal variation in soil $\mathrm{CO}_{2}$ efflux

Within-site spatial variation among soil chambers was large. The coefficient of variation (CV) within a site at each date was on average about $35 \%$ of the mean for 'old alluvium' sites and 45 $\%$ for 'residual' sites and ranged typically from 15 to $70 \%$.

Soil $\mathrm{CO}_{2}$ efflux rates also varied between sites. The two-year average $\mathrm{CO}_{2}$ flux rates between 'old alluvium' sites ranged from 117.3 to $128.9 \mathrm{mg} \mathrm{C} \mathrm{m}^{-2} \mathrm{~h}^{-1}$. Efflux of $\mathrm{CO}_{2}$ was higher on the 'residual' sites $(\mathrm{P}<0.05)$, ranging from 141.1 to $184.2 \mathrm{mg} \mathrm{C} \mathrm{m}^{-2} \mathrm{~h}^{-1}$ (Table $2 \mathrm{a}$ ).

Besides the spatial variability, soil atmosphere $\mathrm{CO}_{2}$ efflux also varied in time. There was a progressive decrease in soil $\mathrm{CO}_{2}$ efflux during the wet season. Minimum $\mathrm{CO}_{2}$ flux values were always measured at the end of the wet season when the soil volumetric water content was highest. Soil $\mathrm{CO}_{2}$ release started to increase again at the onset of the drier season. Although there were seasonal changes in soil $\mathrm{CO}_{2}$ efflux, the magnitude of soil $\mathrm{CO}_{2}$ efflux between the wet and drier season was not different $(\mathrm{P}>0.05)$. Seasonal trends were similar for both soil types; however, the variation in $\mathrm{CO}_{2}$ efflux seemed to be more pronounced at the 'old alluvium' sites (Figure 1).

We estimated cumulative (annual) $\mathrm{CO}_{2}$ emissions by integrating soil $\mathrm{CO}_{2}$ efflux over time. Annual soil $\mathrm{CO}_{2}$ efflux of each soil-type group did not differ between Year 1 and Year 2; however, annual $\mathrm{CO}_{2}$ efflux was higher at 'residual' than at 'old alluvium' sites $(\mathrm{P}<0.05)($ Table 2).

Spatial and temporal variation in soil $\mathrm{CO}_{2}$ storage

Soil air $\mathrm{CO}_{2}$ concentrations varied between soil depth and soil types. In the uppermost layer $(0$ $0.10 \mathrm{~m}$ depth) an average $\mathrm{CO}_{2}$ concentration of $0.7 \%$ was measured in 'old alluvium' soils. At the same depth a significantly lower $\mathrm{CO}_{2}$ concentration $(0.2 \%)$ was found in 'residual' soils. In both soil types soil air $\mathrm{CO}_{2}$ concentration increased throughout the depth profile. Between 2 and 3 $\mathrm{m}$ depth the average $\mathrm{CO}_{2}$ concentration was $2.8 \%$ in 'old alluvium' and 'residual' sites.

Large spatial variations and differences in $\mathrm{CO}_{2}$ storage between the upper and lower profile were identified for both soil types (Figure 2, Table 2). For example, the two-year average $\mathrm{CO}_{2}$ storage ( $0-3 \mathrm{~m}$ depth) between 'old alluvium' sites ranged from 719 to $1881 \mathrm{mg} \mathrm{C} \mathrm{m}^{-2}$. Between 1184 and $1248 \mathrm{mg} \mathrm{C} \mathrm{m}^{-2}$ were stored in the 'residual' soil profiles ( $0-3 \mathrm{~m}$ depth). Although the average amount of $\mathrm{CO}_{2}$ stored in the whole profile did not differ between 'old alluvium' (1190 $\mathrm{mg} \mathrm{C} \mathrm{m}^{-2}$ ) and 'residual' sites (1198 $\mathrm{mg} \mathrm{C} \mathrm{m}^{-2}$ ), a closer examination shows that the $\mathrm{CO}_{2}$ storage in the upper and lower part of the profiles are significantly different between 'old 
Table 2. Soil respiration $\left(\mathrm{mg} \mathrm{C} \mathrm{m}^{-2} \mathrm{~h}^{-1}\right)$ measured in Year 1 (April 14, 1998 to April 9, 1999) and Year 2 (April 23, 1999 to April 20, 2000)

\begin{tabular}{|c|c|c|c|c|c|c|}
\hline \multirow{2}{*}{$\begin{array}{c}\text { Soil type } \\
\text { Site } \\
\end{array}$} & \multicolumn{3}{|c|}{ Inceptisol } & \multicolumn{3}{|c|}{ Ultisol } \\
\hline & A2 & A3 & A4 & L4 & $\mathbf{L 5}$ & L6 \\
\hline \multirow{3}{*}{$\begin{array}{c}\text { Year } 1 \\
\text { Average Year } 1\end{array}$} & 137.3 & 113.6 & 114.1 & 182.7 & 179.4 & 146.1 \\
\hline & \multicolumn{3}{|c|}{121.7} & \multicolumn{3}{|c|}{169.4} \\
\hline & \multicolumn{3}{|c|}{$10.7^{1} a^{2}$} & \multicolumn{3}{|c|}{$14.8 \mathrm{~b}$} \\
\hline \multirow{3}{*}{$\begin{array}{c}\text { Year } 2 \\
\text { Average Year } 2\end{array}$} & 120.4 & 121.1 & 121.7 & 171.6 & 189.0 & 136.1 \\
\hline & \multicolumn{3}{|c|}{121.1} & \multicolumn{3}{|c|}{165.6} \\
\hline & \multicolumn{3}{|c|}{$10.6 \mathrm{a}$} & \multicolumn{3}{|c|}{$14.5 \mathrm{~b}$} \\
\hline \multirow{3}{*}{ Overall average } & 128.9 & 117.3 & 117.9 & 177.2 & 184.2 & 141.1 \\
\hline & \multicolumn{3}{|c|}{121.4} & \multicolumn{3}{|c|}{167.5} \\
\hline & \multicolumn{3}{|c|}{$10.6 \mathrm{a}$} & \multicolumn{3}{|c|}{$14.7 b$} \\
\hline
\end{tabular}

${ }^{1}$ Average annual soil respiration $\left(\mathrm{Mg} \mathrm{C} \mathrm{ha-1} \mathrm{yr}^{-1}\right)$

${ }^{2}$ Different letters indicate within-year differences between soil types, at $\mathrm{P}<0.05$ (ANOVA) 
Figure 1. Bi-weekly measurements of soil respiration, soil water content and soil temperature at $0.05 \mathrm{~m}$ depth. Each point is the mean of three sites (for soil respiration with 8 chamber measurements at each site). Error bars represent \pm standard error of the mean. Gray background is the drier season; white background is the wet season.

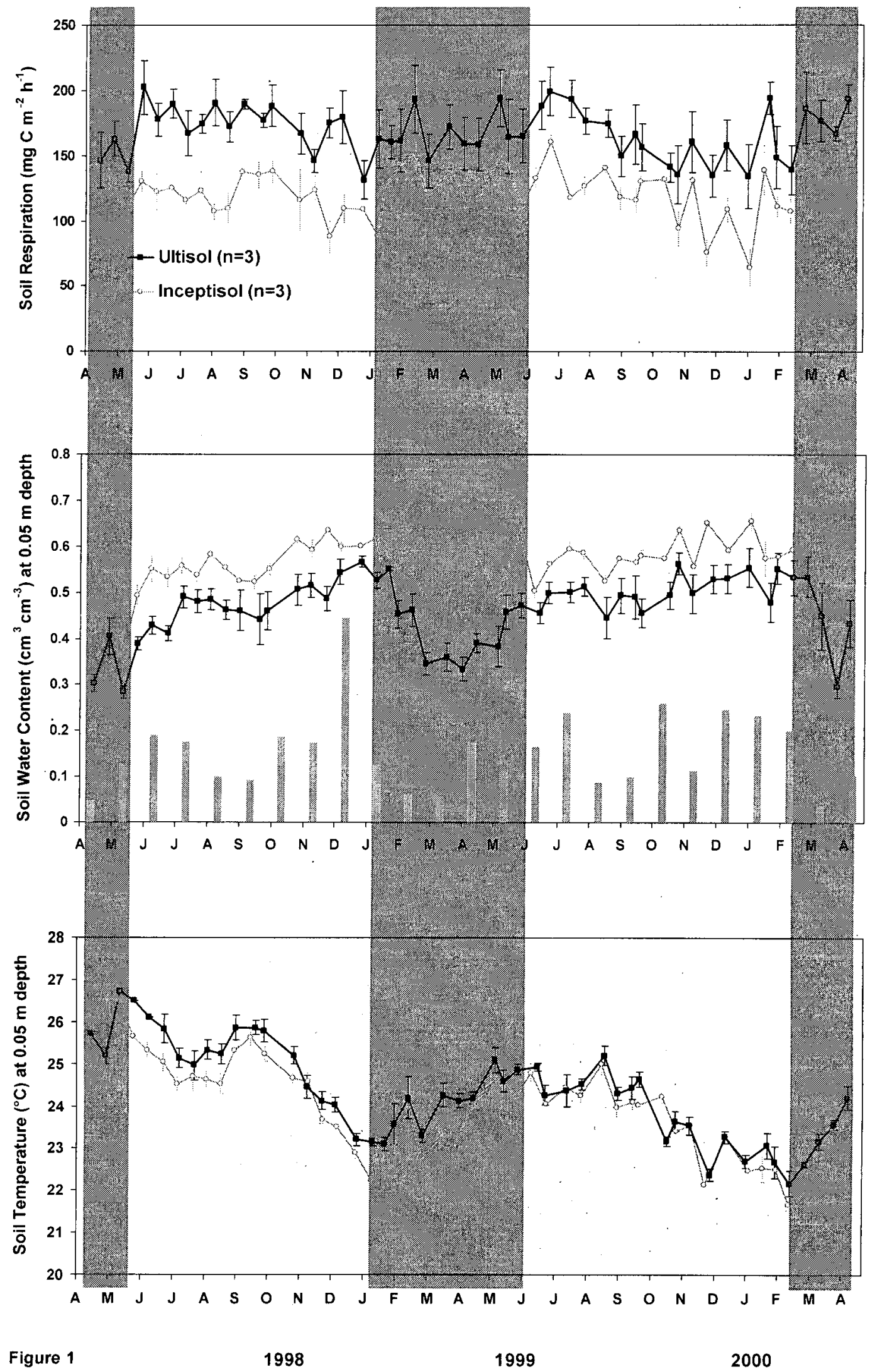


profile of the 'old alluvium' soils than for 'residual' soils $\left(576 \mathrm{mg} \mathrm{C} \mathrm{m}^{-2}\right)$. In contrast, in the lower part of the profile ( $1-3 \mathrm{~m}$ depth) more $\mathrm{CO}_{2}$ was stored in the 'residual' $\left(627 \mathrm{mg} \mathrm{C} \mathrm{m}^{-2}\right)$ soils as compared to the 'old alluvium' soils $\left(538 \mathrm{mg} \mathrm{C} \mathrm{m}^{-2}\right)$ (Table 2).

Generally, no pronounced seasonal changes in soil $\mathrm{CO}_{2}$ storage could be observed. However, during the wet season 1998 the amount of $\mathrm{CO}_{2}$ stored in the upper soil profile $(0-1 \mathrm{~m}$ depth) of the 'old alluvium' sites tended to increase steadily. Due to extraordinary high soil air $\mathrm{CO}_{2}$ concentrations (up to $3 \%$ in $0-0.10$ and $0.10-0.30 \mathrm{~m}$ depth) a $\mathrm{CO}_{2}$ storage of approx. 1000 $\mathrm{mg} \mathrm{C} \mathrm{m}{ }^{-2}$ was calculated. At the onset and during the drier season 1999 the $\mathrm{CO}_{2}$ storage decreased in the upper soil profile of the 'old alluvium' sites. During April and May 1998 when comparatively low soil moisture contents were measured (Figure 1), the $\mathrm{CO}_{2}$ storage in the lower profile in all sites was unusually high (Figure 2).

Although individual sites showed differences in $\mathrm{CO}_{2}$ storage between Year 1 and Year 2 (A4, L4, and L6), the average amount of $\mathrm{CO}_{2}$ accumulated in the upper and lower profile did not differ between years (Table $2 \mathrm{~b}$ ). However, during Year 2 soil $\mathrm{CO}_{2}$ storage in the 'old alluvium' and 'residual' sites varied within a greater range between sampling dates and no distinct accumulation peak was found at the end of the wet season as compared to Year 1 (Figure 2).

Effects of soil water content and soil temperature on soil $\mathrm{CO}_{2}$ efflux and soil $\mathrm{CO}_{2}$ storage Combining the $\mathrm{CO}_{2}$ efflux measurements from all dates per site showed that the relationship between soil $\mathrm{CO}_{2}$ efflux and the volumetric water content (at $0.05 \mathrm{~m}$ depth) can best be described as a parabolic function. This function could be applied to both 'old alluvium' and 'residual' sites (Figure 3). However, the shape of the curves and the soil water content at which maximum $\mathrm{CO}_{2}$ evolution occurred differed between sites and soil types. At the 'old alluvium' sites the highest soil $\mathrm{CO}_{2}$ efflux occurred when the soil water content (at $0.05 \mathrm{~m}$ depth) ranged between 0.45 and $0.50 \mathrm{~cm}^{3} \mathrm{~cm}^{-3}$. At the 'residual' sites the highest $\mathrm{CO}_{2}$ release from the soil was measured when the water content was between 0.35 and $0.50 \mathrm{~cm}^{3} \mathrm{~cm}^{-3}$ (Figure 3). At the peak $\mathrm{CO}_{2}$ emission, the soil matric potential for the 'old alluvium' site A4 was equivalent to - 0.01 MPa. For the 'residual' site $\mathrm{L} 6$ the highest $\mathrm{CO}_{2}$ efflux occurred at a matric potential of - $0.03 \mathrm{MPa}$.

We correlated the residuals from the parabolic soil water - soil $\mathrm{CO}_{2}$ efflux relationship with soil temperature (at $0.05 \mathrm{~m}$ depth) to test if we could explain any further part of $\mathrm{CO}_{2}$ efflux with soil temperature. For one of the six sites ('residual' site L6), we found a significant positive correlation between the residuals and soil temperature. Selecting only wet season data, we found a negative linear relationship between $\mathrm{CO}_{2}$ flux and soil water content. The median $\mathrm{r}^{2}$ for 'old alluvium' and 'residual' sites was 0.51 and 0.21 , respectively. For the wet season data a significant positive correlation between the residuals and soil temperature was found for one of the six sites ('old alluvium' site A2). Hence, for two sites soil temperature was useful as a variable explaining variance in soil $\mathrm{CO}_{2}$.efflux.

Variations in $\mathrm{CO}_{2}$ storage, spatial as well as temporal, were due to changes in soil air $\mathrm{CO}_{2}$ concentration and soil water content (see equation 1). However, the relationship between soil air $\mathrm{CO}_{2}$ concentration, soil water content and $\mathrm{CO}_{2}$ storage was different for the upper and lower soil profile. In the upper profile changes in $\mathrm{CO}_{2}$ storage were mainly due to changes in $\mathrm{CO}_{2}$ concentration. No correlation was found between soil moisture content and $\mathrm{CO}_{2}$ storage. In contrast, below one meter changes in $\mathrm{CO}_{2}$ storage cannot be explained by variations in $\mathrm{CO}_{2}$ concentration but by changes in soil air space.

The apparent effect of temperature on soil $\mathrm{CO}_{2}$ efflux (parabolic function with an optimum at around $24^{\circ} \mathrm{C}$ ) is probably the result of the covariance between soil temperature and soil water content. At 'old alluvium' sites (at $0.05 \mathrm{~m}$ depth) soil temperature and soil water content were negatively correlated across seasons (Figure 4). The same pattern was observed for 


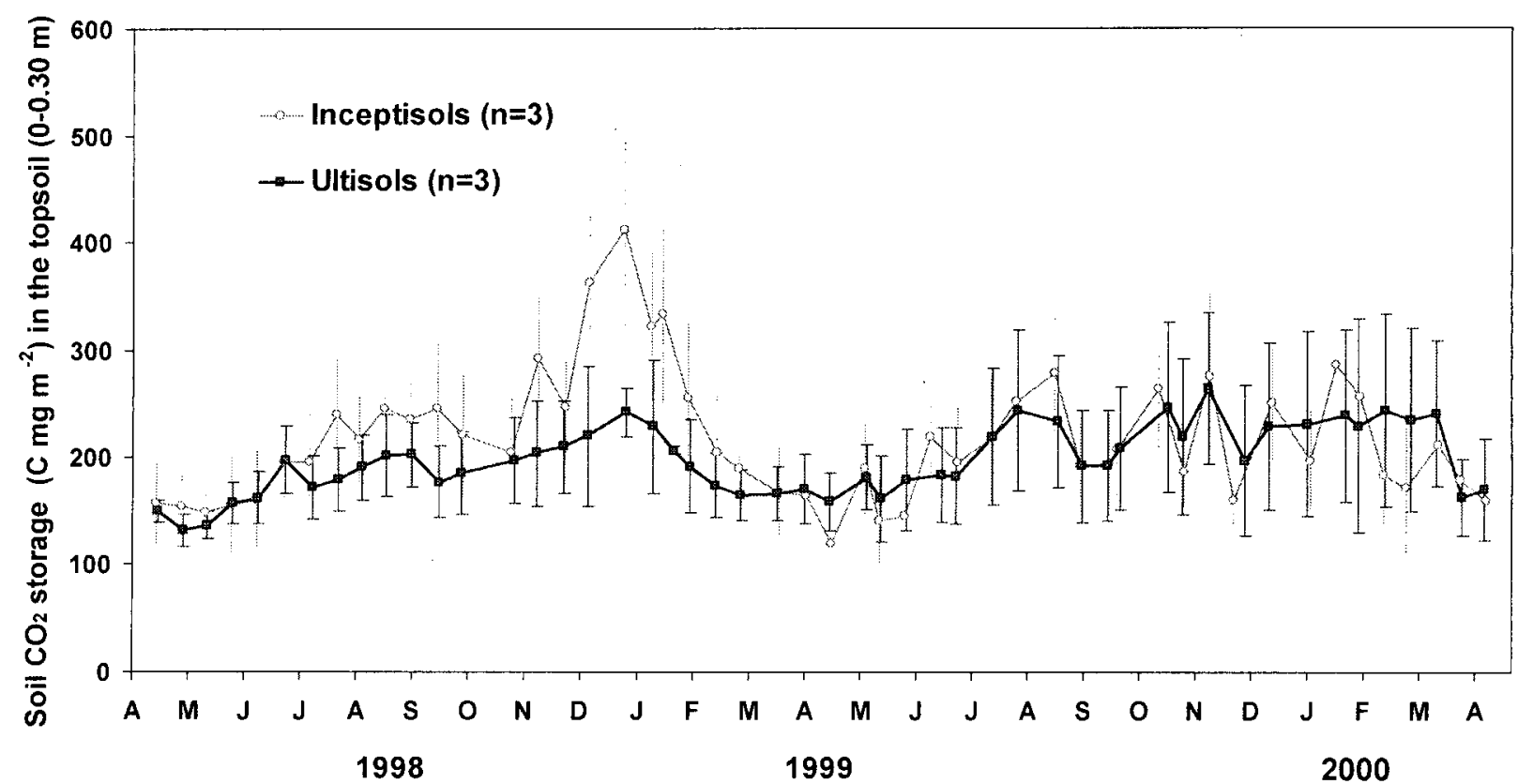

Figure 2. Bi-weekly measurements of soil $\mathrm{CO}_{2}$ storage in the topsoil $(0-0.30 \mathrm{~m}$ depth). Means ( \pm standard error) are given $(\mathrm{n}=3)$. 

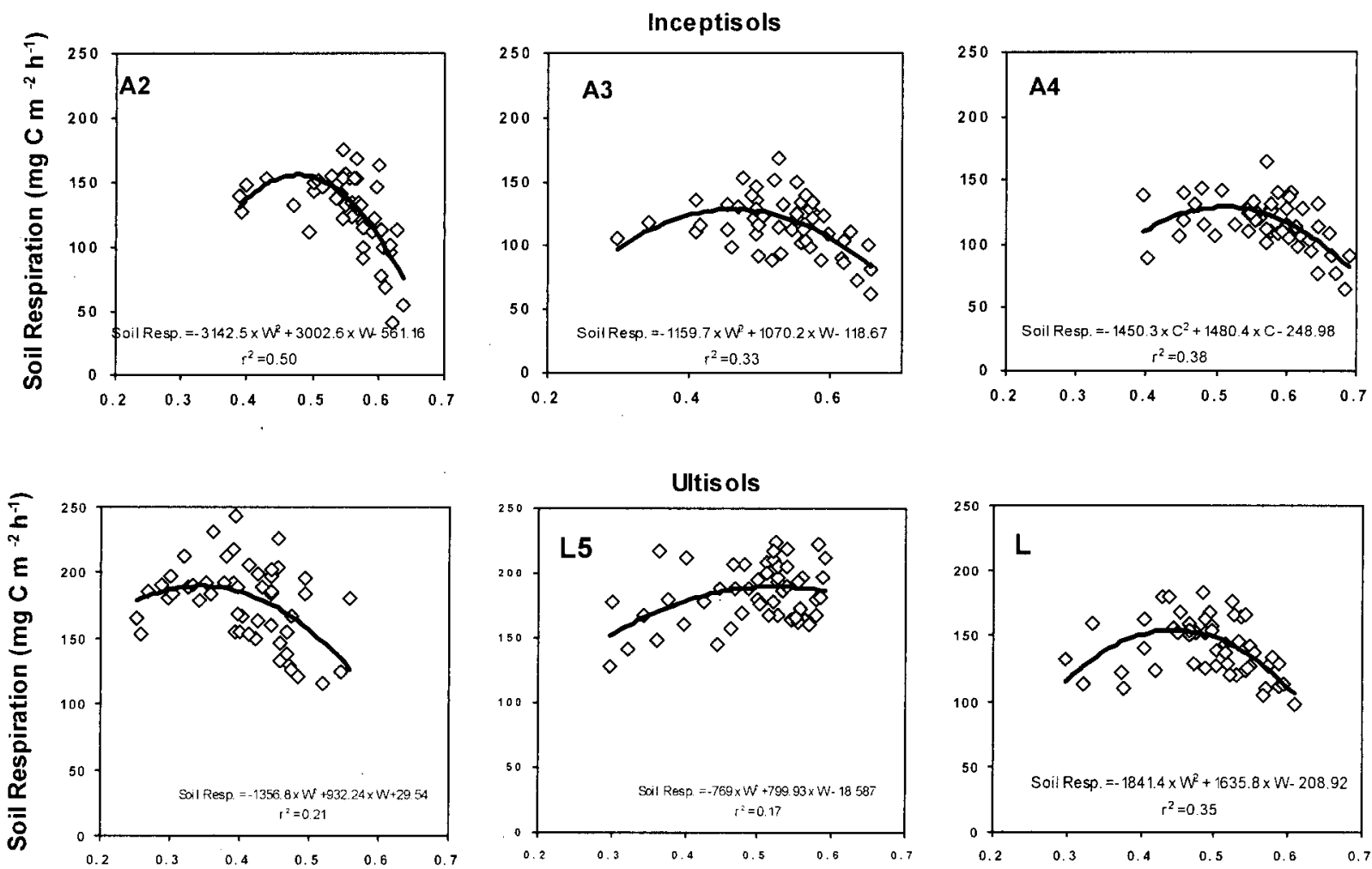

Figure $3 \mathrm{a}_{\text {. }}$ Relationship between soil water content and soil respiration. Each estimate of soil respiration is a mean of 8 chamber measurements and one soil water measurement at $0.05 \mathrm{~m}$ depth made on a given date. 

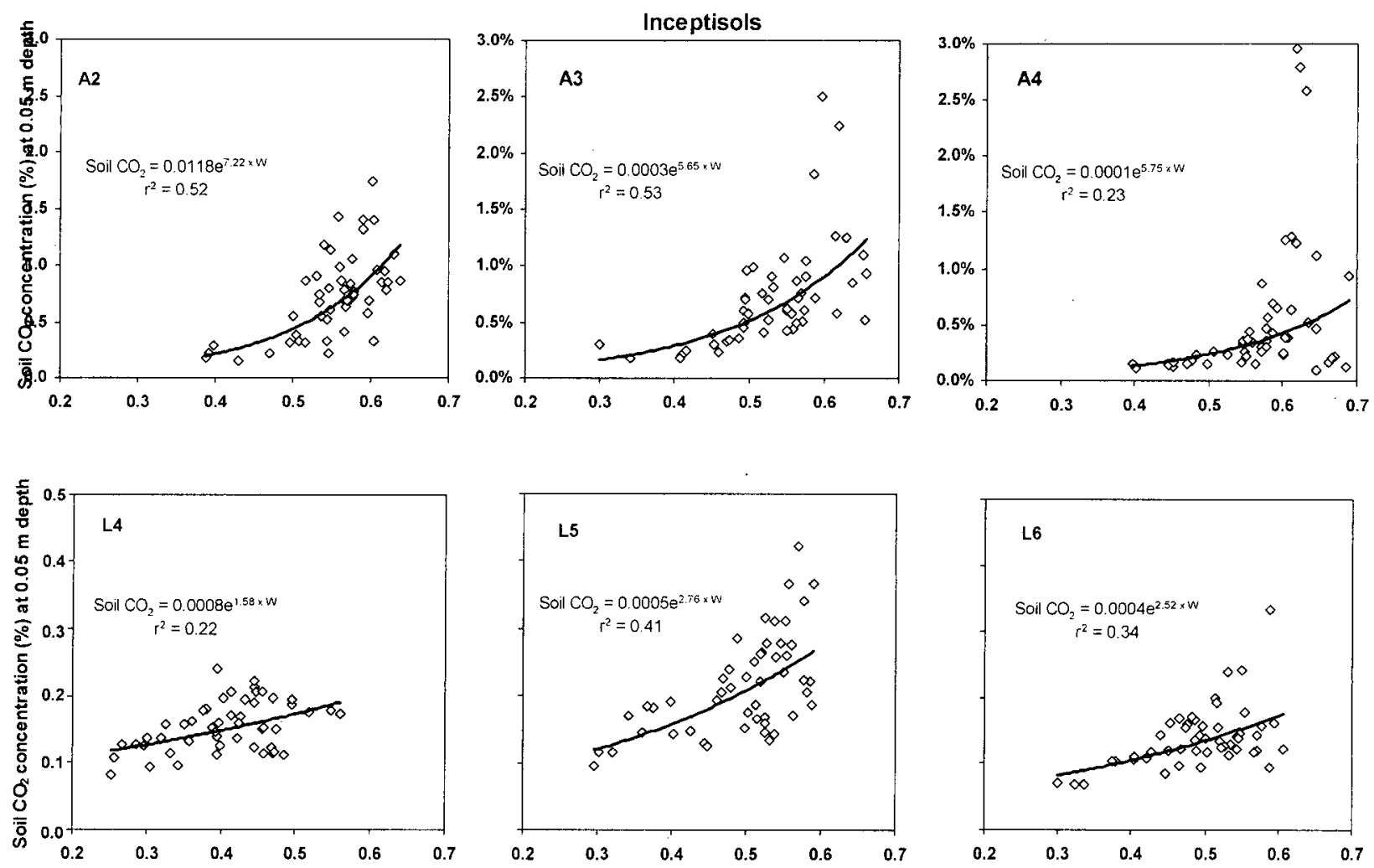

Figure 3b. Correlation between soil $\mathrm{CO}_{2}$ profile concentration and soil water content. Each point represents soil $\mathrm{CO}_{2}$ concentration and soil water measurements at $0.05 \mathrm{~m}$ depth made on a given date. 


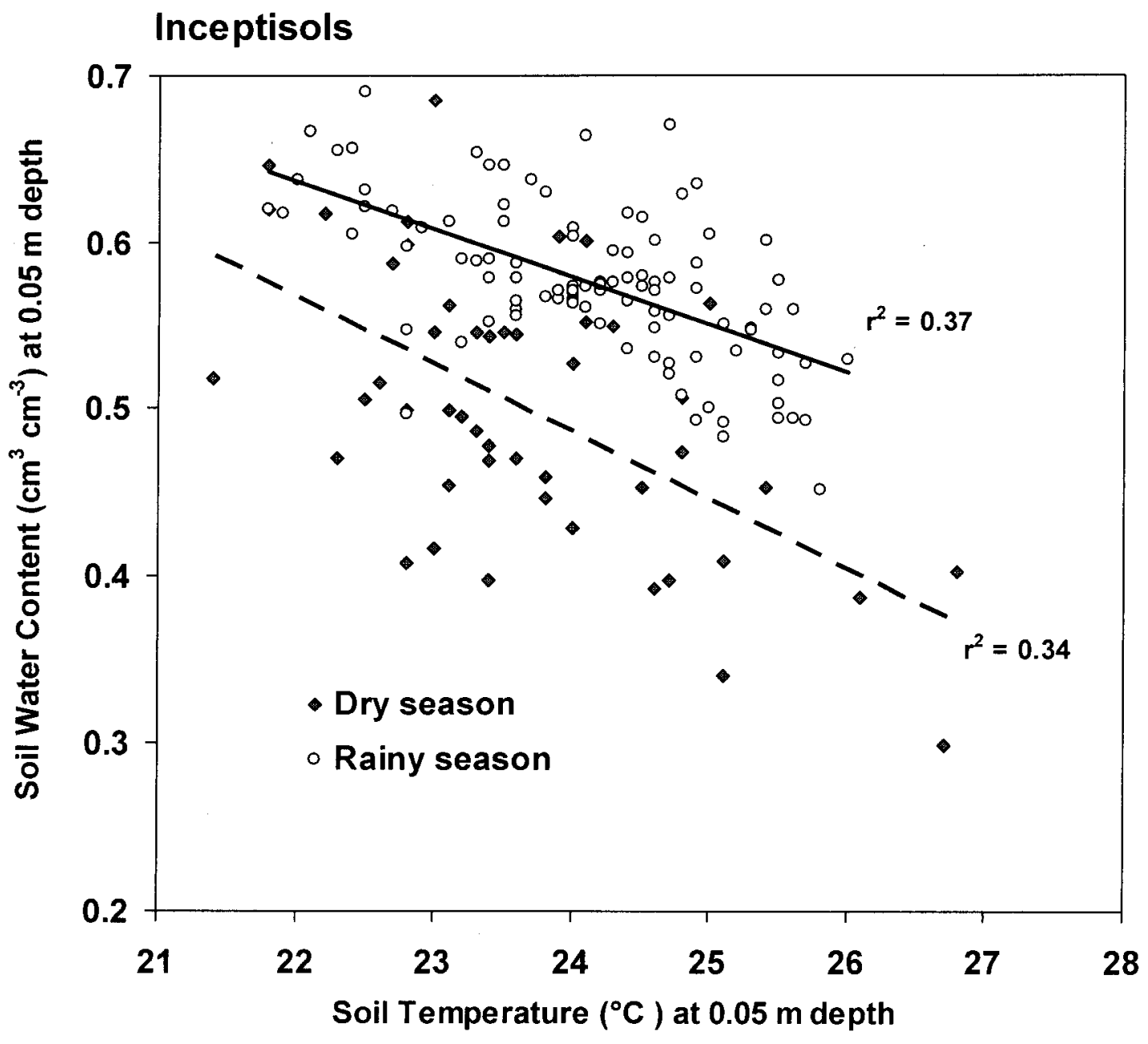

Figure 4. Covariation of soil temperature with soil water content at $0.05 \mathrm{~m}$ depth for Inceptisols. Each point represents individual soil temperature and soil water measurements made at all Inceptisol sites on a given date. 
'residual' sites (wet season and drier season $\mathrm{r}^{2}=0.33$ ) although the soil (at $0.05 \mathrm{~m}$ depth) at these sites was significantly warmer and drier than at the 'old alluvium' sites. In general, both soil types were wetter but warmer $(\mathrm{P}<0.05)$ during wet season (Figure 1, Figure 4). Exceptionally high temperatures $\left(>26^{\circ} \mathrm{C}\right)$ and comparatively low soil water contents were observed in May 1998 (Figure 1). This was probably caused by the occurrence of an El Niño Southern Oscillaton (ENSO) drought cycle in 1997/1998.

\section{Discussion}

$\underline{\text { Spatial variation and magnitude of } \mathrm{CO}_{2} \text { efflux }}$

The two-year average $\mathrm{CO}_{2}$ flux from 'residual' plots was about $40 \%$ higher than that from 'old alluvium' plots (Figure 1, Table 2). These weathered 'residual' sites have a significantly higher amount of fine roots (DA Clark, unpublished data) and greater numbers of arbuscular mycorrhizal fungal spores (C Lovelock, unpublished data). This finding indicates that root respiration may explain part of the differences of soil $\mathrm{CO}_{2}$ efflux and that root biomass gave a good reflection of root respiration. Previous research has suggested that roots/rhizosphere contribute 30 to $70 \%$ to total soil $\mathrm{CO}_{2}$ efflux and that the release of $\mathrm{CO}_{2}$ from the soil generally increases with increase in root/rhizosphere biomass (Epron \& Badot 1997, Janssens et al. 1998, Hanson et al. 2000). Furthermore, soil $\mathrm{CO}_{2}$ efflux and fine root biomass were negatively correlated with the soil phosphorus level (DA Clark, DB Clark, E Veldkamp, unpublished data). We suggest that more fine roots were accumulated in the 'residual' sites in order to provide enough phosphorus for tree physiological processes and that mycorrhizal associations might have the potential to increase the uptake of phosphorus at sites with low soil P levels. A positive correlation was found between $\mathrm{CO}_{2}$ efflux and soil carbon and nitrogen concentrations. In addition to these nutrient-related parameters, part of the site-specific differences in soil $\mathrm{CO}_{2}$ efflux may also be explained by the spatial variance in soil water content. However, none of these trends was significant at $\mathrm{P}<0.05$, most likely because of the high variability within the relatively small data set $(n=6)$ (Table 3$)$.

$\mathrm{CO}_{2}$ efflux measured in this study $\left(10.0\right.$ to $\left.16.6 \mathrm{Mg} \mathrm{C}_{\mathrm{ha}}^{-1} \mathrm{yr}^{-1}\right)$ were consistent with the range reported by Raich \& Schlesinger (1992) for tropical moist/humid forests ( 8.9 to $15.2 \mathrm{Mg} \mathrm{C}$ $\left.\mathrm{ha}^{-1} \mathrm{yr}^{-1}\right)$. Higher $\mathrm{CO}_{2}$ flux rates than ours were reported for an old-growth forest in eastern Amazonia where the $\mathrm{CO}_{2}$ efflux was $20 \mathrm{Mg} \mathrm{ha}^{-1} \mathrm{yr}^{-1}$ (Trumbore et al. 1995, Davidson et al. 2000). We didn't find a difference in the magnitude of soil $\mathrm{CO}_{2}$ efflux between the wet and drier season. Other studies from tropical wet forest show a clear seasonal trend with lower $\mathrm{CO}_{2}$ emission during dry hot periods (Feigl et al. 1995, Rajvanshi \& Gupta 1986). The difference may be because our sites received during the time investigated more than $100 \mathrm{~mm}$ of precipitation each month even during the drier season. Our estimate of soil $\mathrm{CO}_{2}$ emission was approx. $45 \%$ lower than the estimate reported by Raich (1980) for La Selva. He measured an average of $19 \mathrm{Mg}$ $\mathrm{C} \mathrm{ha}^{-1} \mathrm{yr}^{-1}$ for May/July based on the soda-lime absorption technique $(\mathrm{n}=6)$ in a mature forest site on old alluvial material. The use of a different methodology for soil $\mathrm{CO}_{2}$ efflux, as well as the high spatial heterogeneity were most likely the reasons for this difference.

\section{Temporal variation in soil $\mathrm{CO}_{2}$ efflux and soil $\mathrm{CO}_{2}$ storage}

Fluctuations in $\mathrm{CO}_{2}$ emission and $\mathrm{CO}_{2}$ storage between sampling days, most likely due to shortterm weather conditions, were overlaid by some distinctive seasonal trends. Soil $\mathrm{CO}_{2}$ efflux rates increased at the onset of the wet season. Flushes of $\mathrm{CO}_{2}$ following the re-wetting of soil have frequently been observed and are caused by pulses of microbial activity (Birch 1958, Orchard \& Cook 1983, Kieft et al. 1987) or due to the $\mathrm{CO}_{2}$ displacement in the soil by rain water (Singh \& Gupta 1977). However, with the wet season well underway the efflux of $\mathrm{CO}_{2}$ from the soil 
Table 3. Investigated biotic and abiotic factors and their correlation coefficient $(r)$ with soil respiration and level of significance (P). Analysis (Pearson product-moment correlation) is based on the data from the six study sites.

\begin{tabular}{|c|c|c|}
\hline Factors & $\mathbf{r}$ & $\mathbf{P}$ \\
\hline Total C (\%) & 0.70 & $n s^{\prime}$ \\
\hline Total N $(\%)$ & 0.72 & ns \\
\hline Total $P\left(m g g^{-1}\right)$ & -0.60 & ns \\
\hline Soil water content at $0.05 \mathrm{~m}$ depth $\left(\mathrm{cm}^{3} \mathrm{~cm}^{-3}\right)$ & -0.81 & $*^{2}$ \\
\hline Soil air space $\left(\mathrm{cm}^{3} \mathrm{~cm}^{-3}\right)$ & 0.67 & ns \\
\hline Soil temperature at $0.05 \mathrm{~m}$ depth $\left({ }^{\circ} \mathrm{C}\right)$ & 0.41 & ns \\
\hline Soil $\mathrm{CO}_{2}$ storage in the topsoil $\left(\mathrm{g} \mathrm{m}^{-2}\right)$ & -0.32 & ns \\
\hline
\end{tabular}

${ }^{1}$ Not significant, $\mathrm{P}>0.05$

${ }^{2}$ Significant, $\mathrm{P}<0.05$ 
surface steadily decreased at all sites, reaching minimum $\mathrm{CO}_{2}$ emission rates at the end of the wet season. Increases in soil moisture content may decrease $\mathrm{CO}_{2}$ production in the soil and also cause a decrease in $\mathrm{CO}_{2}$ flux from the soil surface. Although the $\mathrm{CO}_{2}$ concentration in the upper profile increased, the $\mathrm{CO}_{2}$ efflux decreased. This indicates that the $\mathrm{CO}_{2}$ exchange between soil and atmosphere was reduced due to lower diffusion rates caused by high soil water content. However, the contribution of $\mathrm{CO}_{2}$ storage to the efflux is comparatively small. The amount of $\mathrm{CO}_{2}$ stored in the whole soil profile (approx. $1200 \mathrm{mg} \mathrm{m}^{-2}$ ) is only 7 to 10 times higher than the $\mathrm{CO}_{2}$ efflux per hour. We also calculated the rate of $\mathrm{CO}_{2}$ accumulation/loss (in $\mathrm{mg} \mathrm{m}^{-2} \mathrm{~h}^{-1}$ ) by interpolating the increase/decrease of storage which took place over a two-week period, assuming a uniform linear change between sampling dates. This rate was then compared to the observed surface flux rate on a given date. For the upper soil profile the $\mathrm{CO}_{2}$ storage term would only account for 0.1 to $2 \%$ of the flux rate. Thus, diffusion and storage cannot solely explain the observed decline of $\mathrm{CO}_{2}$ efflux. We suggest that $\mathrm{CO}_{2}$ production was also reduced during the course of the wet season. The production of $\mathrm{CO}_{2}$ from decay of organic matter could be inhibited either by oxygen limitation and/or temperature. In addition, several other factors have to be considered. Temporal changes in litterfall and root biomass may play an important role explaining seasonal variation in soil $\mathrm{CO}_{2}$ efflux. Wofsy et al. (1988) attributed lower soil $\mathrm{CO}_{2}$ efflux from an Amazonian forest during wet season to lower solar flux rates, which could affect photosysnthetic rates. Reduction of overall photysynthesis may also lead to lower root respiration rates. At La Selva lower solar flux rates are measured during months with higher average precipitation rates and, hence, higher persistent cloud cover (Sanford et al. 1994).

The increase in $\mathrm{CO}_{2}$ flux and the decline of soil air $\mathrm{CO}_{2}$ concentration and $\mathrm{CO}_{2}$ storage in the upper profile at the onset of the drier season were probably due to soil drying which opens soil macropores and thus enhanced release of $\mathrm{CO}_{2}$ that was accumulated in the soil during wet season. Increases in $\mathrm{CO}_{2}$ efflux at the onset of the dry season could not be attributed to the emission of $\mathrm{CO}_{2}$ stored in deeper layers as the amount of $\mathrm{CO}_{2}$ stored below one meter was low during the wet season and at the onset of the drier season.

\section{Effects of soil temperature and soil water content on soil $\mathrm{CO}_{2}$ efflux}

The relationship between soil $\mathrm{CO}_{2}$ efflux, soil temperature and soil water content involves complex interactions depending on the relative limitation of temperature and moisture to both microbial and root activity as well gas diffusion. However, the importance of each factor varies among ecosystems and different environments. Temperature has been found to explain much of the variance in soil $\mathrm{CO}_{2}$ efflux in temperate or boreal environments. The strong relationship between fluxes of $\mathrm{CO}_{2}$ and temperature is not unexpected in these ecosystems since soil $\mathrm{CO}_{2}$ efflux reflects heterotrophic and autotrophic activities and variations in temperature are high. In contrast, soil moisture is the major controlling variable during periods of very wet/dry conditions or in regions where soil temperatures are high and relatively invariable (Schlesinger 1977, Rout \& Gupta 1989, Holt et al. 1990, Davidson et al. 2000). Soil temperature of the La Selva sites are isothermic (Sanchez 1976); thus, its average monthly changes may be too small to be detected in the soil $\mathrm{CO}_{2}$ efflux signal. Furthermore, the influence of temperature on temporal variation in $\mathrm{CO}_{2}$ efflux was masked by the effect of soil water, which may have led to a weaker relationship between soil $\mathrm{CO}_{2}$ release and soil temperature. Hence, it is not surprising that on both investigated soil types temporal variation in soil $\mathrm{CO}_{2}$ efflux was primarily controlled by soil water content. A parabolic function has also been used by others to describe the relationship between soil $\mathrm{CO}_{2}$ efflux and soil moisture (Ino \& Monsi 1969, Edwards 1975, Londo et al. 1999). This reflects the general observation that $\mathrm{CO}_{2}$ flux declines in both saturated and in very dry soils. Matric potential can be used as an indicator of water availability to plant roots and soil 
microorganisms (Skopp et al. 1990). We found a decrease in $\mathrm{CO}_{2}$ efflux when the matric potential fell below -0.01 MPa ('old alluvium' site A4) and -0.03 MPa ('residual' site L6), respectively. In April and May 1998, at the end of the El Niño Southern Oscillaton (ENSO) drought cycle 1997/1998, matric potential exceeded -0.25 ('old alluvium' site A4) and $-0.93 \mathrm{MPa}$ ('residual' site L6). The constraints on soil $\mathrm{CO}_{2}$ efflux may have resulted from reduced microbial activity owing to low soil moisture. According to Wong \& Griffin (1976) bacterial activity declines sharply as water potential falls $(-0.05$ to $-0.3 \mathrm{MPa})$ and is negligible at $-1.5 \mathrm{MPa}$ as bacterial movement is largely restricted to water films in soil and bacteria can only remain active while nutrients are able to diffuse toward and waste products away from them. But not only microbial activity is controlling $\mathrm{CO}_{2}$ production rates and soil $\mathrm{CO}_{2}$ efflux. Root respiration has been estimated to account for $10-90 \%$ of total $\mathrm{CO}_{2}$ emission (Medina et al. 1980, Behera et al. 1990, Hansen et al. 2000). Water limitation can inhibit root growth and affects root metabolism (Sanford \& Cuevas 1996, Mulkey \& Wright 1996). At all study sites a peak in dead fine root biomass was found during the El Niño Southern Oscillation (ENSO) drought cycle (DA Clark, unpublished data). Fine root mortality may also contribute to a decrease in root respiration during extraordinary dry periods. However, without direct studies on root and microbial moisture responses and estimates on the contribution of soil microbial and root respiration to total soil $\mathrm{CO}_{2}$ efflux, it is impossible to make solid conclusions about the differing soil moisture responses across sites from our data alone. Although $\mathrm{CO}_{2}$ efflux showed an optimum soil water content on all sites (except one site, L5), the water content and matric potential at which maximum $\mathrm{CO}_{2}$ evolution occurred differed between 'old alluvium' and 'residual' sites. This could probably be due to site-specific soil characteristics which caused differences in porosity and tortuosity, influencing gas diffusion. For example, the upper profile $(0-1 \mathrm{~m}$ depth) of the 'residual' sites had a significantly higher soil air space volume as compared to the 'old alluvium' sites (Table 1). Our sites at La Selva receive a considerably amount of rain and as a result the volumetric water content can reach levels where diffusion is inhibited due to water-filled pores, even though the soil is well aggregated and has a high porosity and infiltration rates (Sollins \& Radulovich 1988). Whereas at other study sites very high or low soil water contents are restricted to a short period of time, at La Selva soil water resided at $>-0.008 \mathrm{MPa}$ for many weeks due to the perudic moisture regime.

Our $\mathrm{CO}_{2}$ flux data represent an integrated measure of root and heterotrophic respiration as well as gas diffusion. All these processes may respond differently to biotic and abiotic factors. Thus, it is difficult to obtain a strong correlation between soil $\mathrm{CO}_{2}$ efflux and a single factor. As expected, our study showed that in this wet tropical environment, soil water content explained a considerable amount of the seasonal variation in soil $\mathrm{CO}_{2}$ efflux rates despite the fact that our sampling occurred across a large area with substantial spatial variation. During periods of high soil water content $\mathrm{CO}_{2}$ efflux rates decreased, probably due to a lower diffusion rate. But diffusion and $\mathrm{CO}_{2}$ storage cannot fully explain the observed pattern in $\mathrm{CO}_{2}$ efflux. $\mathrm{CO}_{2}$ production seemed also to be reduced during the course of the wet season. 


\section{Introduction}

\section{VII.3. Dissolved Organic Carbon Fluxes}

Dissolved organic carbon (DOC) interacts with biogeochemical cycles of nitrogen and phosphorus (Qualls et al. 1991, Campbell et al. 2000), plays an important role in pollutant transport (Kalbitz et al. 2000) and may be a main source of energy for microorganisms (Tranvik 1992). Dynamics of DOC have been studied in several temperate forest ecosystems (Qualls et al. 1991, Michalzik et al. 2001). However, little is known of the origin, composition and fate of DOC in wet tropical forest ecosystems (McDowell 1998).

'CARBONO', a long-term, landscape-scale project was set up at La Selva Biological Station in Costa Rica to assess the major carbon stocks and fluxes in a wet tropical forest, and to investigate the effects of climatic factors on ecosystem carbon dynamics. Soils at La Selva contain large carbon stocks (between $200-300 \mathrm{Mg} \mathrm{C} / \mathrm{ha}$ to 3 $\mathrm{m}$ depth). DOC fluxes through the soil followed by the sorption on mineral surfaces may be one of the dominant processes leading to accumulation of these large carbon stocks (Veldkamp et al., in press). At the same time, substantial microbial activity in La Selva's subsoil require a $\mathrm{C}$ and $\mathrm{N}$ source which may be provided by dissolved organic matter (Veldkamp et al., in press).

Studies have shown that in undisturbed temperate and tropical montane forest ecosystems, dissolved organic nitrogen (DON) often represents the main form of dissolved N (Campbell et al. 2000, McDowell 2001, Perakis \& Hedin 2002). In contrast, the contribution of DON to total dissolved nitrogen (TDN) is commonly low $(<10 \%)$ on sites affected by high anthropogenic $\mathrm{N}$ deposition $(>10 \mathrm{~kg} / \mathrm{ha} / \mathrm{yr} \mathrm{N}$; Gunderson et al. 1998, Michalzik \& Matzner 1999, Solinger et al. 2001).

Our objectives in this study were: (i) to quantify the contribution of dissolved organic carbon and nitrogen to the total aboveground litter carbon and nitrogen input, (ii) to track changes in DOM biodegradability and DOC composition, (iii) to determine the importance of sorption in regulating DOC concentrations. To achieve these objectives, dissolved organic matter (DOM) and dissolved inorganic nitrogen (DIN) in throughfall, litter leachate and soil solution were measured over one year. Laboratory experiments were made to quantify the portion of rapidly biodegradable DOM and estimate the sorption capacity of the soil. Finally, chemical and isotopic composition of DOC was measured using fractionation and mass spectrometry.

\section{Materials and Methods}

$\underline{\text { Site Description, Materials and Methods, Experimental Protocols }}$

Measurements were conducted at La Selva Biological Station, Costa Rica, Central America. La Selva is located in northeastern Costa Rica between the Atlantic coastal plain and the foothills of the Central Cordillera $\left(10^{\circ} 26^{\prime} \mathrm{N}, 83^{\circ} 59^{\prime} \mathrm{W}\right)$. Elevation ranges from approximately 35 to $150 \mathrm{~m}$ above sea level. Long-term average annual precipitation at La Selva is $4,200 \mathrm{~mm}$. Monthly distribution of the precipitation is bimodal, with peaks of more than $400 \mathrm{~mm}$ per month occurring in June-July and November-December. February-April is the period with least precipitation (averaging about $180 \mathrm{~mm}$ per month), while March is usually the driest month (Sanford et al. 1994). Long-term average monthly air temperature is $24.6^{\circ} \mathrm{C}$, which differs little among months (Sanford et al. 1994). 
La Selva is classified as Tropical Wet Forest in the Holdridge Life Zone System (Hartshorn \& Hammel 1994). The forest is dominated by the legume canopy species, Pentaclethra macroloba (Willd.) Kuntze (Clark \& Clark 2000). The forest floor is covered with a thin layer of litter (leaves, fine and coarse woody debris) in different stages of decomposition. We selected four plots for this study: two plots on 'old alluvium' (plot A2 and A4) and two plots on 'residual' (plot L5 and L6) soils. All 'residual' sites were located on relatively flat ridges. The 'old alluvium' soils formed on old river terraces have previously been classified as Inceptisols. The strongly weathered 'residual' soils originating from lava flows were classified as Ultisols (Sollins et al. 1994). Kleber (pers. comm.) recently reclassified these soils as Typic Haploperox (Oxisols) because of low silica:sesquioxide ratio, low base exchange capacity and the low content of weatherable minerals. Throughout this paper the terms 'old alluvium' and 'residual' soils will be used in consistency with former publications. Basic soil properties are summarized in Table 1.

Four throughfall collectors were placed randomly in each of the four investigated 0.5 ha plots. Collectors consisted of funnels with a surface area of $95 \mathrm{~cm}^{2}$; which were attached to 3.79 l jugs. A $30 \mathrm{~mm}$ high PVC ring was fixed to the perimeter of each funnel to prevent splash-out. Each collector was positioned $0.37 \mathrm{~m}$ above the ground under differing canopy heights and plant structures. A plug of glass wool was placed in the funnel neck to exclude particulate matter from the collectors.

At each of the four selected sites, a soil pit (about 0.75 by $2 \mathrm{~m}$ and 3 to $4 \mathrm{~m}$ depth) was dug. Two different devices were employed to collect soil solution. Water percolating through the litter layer was collected with suction plates. Close to each soil pit two suction plates (approx. $350 \mathrm{~cm}^{2}, \mathrm{P} 25 \mathrm{~b}$, max pore size $5 \mu \mathrm{M}, \mathrm{KPM} \mathrm{GmbH}$, Berlin, Germany) were installed. Soil was gently removed with a spade to approximately $0.03 \mathrm{~m}$ depth, the plate was inserted and covered with the removed soil. Ceramic suction cups (P80, max pore size $1 \mu \mathrm{M}, \mathrm{KPM} \mathrm{GmbH}$, Berlin, Germany) were positioned horizontally ( $~ 0.5 \mathrm{~m}$ deep) into the pit wall at $0.20,0.40,0.75,1.50,2.50$ and $3.50 \mathrm{~m}$ ('residual' only) depth to obtain soil solution from the mineral soil. The self made porous suction plates/cups were acid washed and rinsed before installation. Suction plates/cups were installed 3 to 5 month prior to the first sampling to reduce disturbance effects and to reach equilibrium with the soil. A vacuum of 0.4 bar $(40 \mathrm{kPa})$ was applied once every 2 weeks following sample collection.

Throughfall and soil solution were collected bi-weekly from May 2000 to May 2001. During drier periods (March - May 2001) some suction plates dried out and could not be sampled. Precipitation was collected at the top of a $42 \mathrm{~m}$ walk-up tower (above the canopy) eight times during the study period. All samples were collected in acid-washed, dark glass bottles and stored at $4{ }^{\circ} \mathrm{C}$ until analysis. $\mathrm{pH}$ was measured in a sub-sample with a glass electrode ( $\mathrm{pH}$ meter 245, Corning Inc., New York, USA) immediately following collection. Rainfall and throughfall samples were filtered prior to further analyses (Glass microfibre filters GF/C, Whatman International Ltd, Springfield Mill, England).

Analytical Method-Dissolved organic carbon was determined using Pt-catalyzed, hightemperature combustion followed by infrared detection of $\mathrm{CO}_{2}$ (TOC-5050, Shimadzu Corp., Tokyo, Japan). Before determination of organic $\mathrm{C}$ in rainfall and TABLE 1. Basic 
soil characteristics of 'old alluvium' ( $\mathrm{OAl}$ ) and 'residual' (Re) soils at La Selva Biological Station, Costa Rica.

\begin{tabular}{|c|c|c|c|c|c|c|c|c|c|c|c|c|c|c|}
\hline \multirow[t]{2}{*}{$\begin{array}{c}\text { Soil } \\
\text { depth }\end{array}$} & \multicolumn{2}{|c|}{ pH (KCl) } & \multicolumn{2}{|c|}{$\begin{array}{c}\text { Base } \\
\text { saturation }\end{array}$} & \multicolumn{2}{|c|}{ Total C } & \multicolumn{2}{|c|}{ Total N } & \multicolumn{2}{|c|}{ Clay } & \multicolumn{2}{|c|}{$\mathrm{Fe}_{0}$} & \multicolumn{2}{|c|}{$\mathrm{Al}_{0}$} \\
\hline & oAl & $\mathrm{Re}$ & oAl & $\mathrm{Re}$ & $\mathrm{oAl}$ & $\mathrm{Re}$ & $\mathrm{oAl}$ & $\operatorname{Re}$ & oAl & $\mathrm{Re}$ & oAl & $\mathrm{Re}$ & oAl & $\mathrm{Re}$ \\
\hline $\mathrm{m}$ & & & & - & & 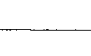 & $--\mathrm{g}$ & . & - & 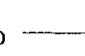 & & $\mathrm{g}$ & s & \\
\hline 0.05 & $\begin{array}{l}3.7^{\mathrm{a}} \\
(4)\end{array}$ & $\begin{array}{c}3.8 \\
(17)\end{array}$ & $\begin{array}{c}17 \\
(25)\end{array}$ & $\begin{array}{c}16 \\
(23)\end{array}$ & $\begin{array}{c}4.0 \\
(16)\end{array}$ & $\begin{array}{l}5.6 \\
(4)\end{array}$ & $\begin{array}{c}3.5 \\
(14)\end{array}$ & $\begin{array}{l}4.5 \\
(2)\end{array}$ & $\begin{array}{l}69 \\
(4)\end{array}$ & $\begin{array}{l}79 \\
\text { (1) }\end{array}$ & 6.1 & 5.1 & 5.6 & 4.5 \\
\hline 0.20 & $\begin{array}{l}4.0 \\
(1)\end{array}$ & $\begin{array}{c}4.1 \\
(11)\end{array}$ & $\begin{array}{c}10 \\
(30)\end{array}$ & $\begin{array}{c}7 \\
(24)\end{array}$ & $\begin{array}{c}2.2 \\
(16)\end{array}$ & $\begin{array}{c}4.0 \\
\text { (11) }\end{array}$ & $\begin{array}{c}2.0 \\
(15)\end{array}$ & $\begin{array}{l}3.2 \\
(9)\end{array}$ & $\begin{array}{l}74 \\
(9)\end{array}$ & $\begin{array}{l}82 \\
(2)\end{array}$ & 5.5 & 3.7 & 5.9 & 4.8 \\
\hline 0.40 & $\begin{array}{l}4.1 \\
(2)\end{array}$ & $\begin{array}{l}4.1 \\
\text { (1) }\end{array}$ & $\begin{array}{c}12 \\
(43)\end{array}$ & $\begin{array}{c}8 \\
(44)\end{array}$ & $\begin{array}{c}1.5 \\
(14)\end{array}$ & $\begin{array}{c}2.4 \\
(26)\end{array}$ & $\begin{array}{l}1.4 \\
(7)\end{array}$ & $\begin{array}{c}1.9 \\
(26)\end{array}$ & $\begin{array}{l}71 \\
(0)\end{array}$ & $\begin{array}{l}73 \\
(3)\end{array}$ & 3.2 & 3.2 & 4.3 & 6.9 \\
\hline 0.75 & $\begin{array}{l}4.0 \\
\text { (1) }\end{array}$ & $\begin{array}{l}4.1 \\
\text { (1) }\end{array}$ & $\begin{array}{c}10 \\
(38)\end{array}$ & $\begin{array}{c}8 \\
(14)\end{array}$ & $\begin{array}{l}0.8 \\
(5)\end{array}$ & $\begin{array}{c}1.4 \\
(15)\end{array}$ & $\begin{array}{l}0.9 \\
(0)\end{array}$ & $\begin{array}{l}1.2 \\
(8)\end{array}$ & $\begin{array}{l}75 \\
\text { (1) }\end{array}$ & $\begin{array}{l}77 \\
(3)\end{array}$ & 3.6 & 2.1 & 4.9 & 5.1 \\
\hline 1.50 & $\begin{array}{l}4.0 \\
(3)\end{array}$ & $\begin{array}{l}4.2 \\
(2)\end{array}$ & $\begin{array}{c}9 \\
(34)\end{array}$ & $\begin{array}{c}9 \\
(29)\end{array}$ & $\begin{array}{c}0.7 \\
(44)\end{array}$ & $\begin{array}{c}0.8 \\
(18)\end{array}$ & $\begin{array}{c}0.6 \\
(70)\end{array}$ & $\begin{array}{c}0.7 \\
(14)\end{array}$ & $\begin{array}{l}70 \\
(3)\end{array}$ & $\begin{array}{l}79 \\
(1)\end{array}$ & 5.4 & 1.7 & 4.6 & 4.3 \\
\hline 2.50 & $\begin{array}{l}4.0 \\
(3)\end{array}$ & $\begin{array}{l}4.4 \\
(5)\end{array}$ & $\begin{array}{c}10 \\
(48)\end{array}$ & $\begin{array}{c}14 \\
(75)\end{array}$ & $\begin{array}{c}0.2 \\
(21)\end{array}$ & $\begin{array}{c}0.5 \\
(18)\end{array}$ & $\begin{array}{l}0.3 \\
(0)\end{array}$ & $\begin{array}{c}0.4 \\
(70)\end{array}$ & $\begin{array}{c}38 \\
(17)\end{array}$ & $\begin{array}{c}79 \\
(13)\end{array}$ & 4.5 & 1.8 & 5.1 & 2.8 \\
\hline 3.50 & & $\begin{array}{c}4.4 \\
(13)\end{array}$ & & $\begin{array}{l}15 \\
(6)\end{array}$ & & $\begin{array}{c}0.5 \\
(24)\end{array}$ & & $\begin{array}{c}0.4 \\
(13)\end{array}$ & & $\begin{array}{c}62 \\
(35)\end{array}$ & & 3.5 & & 2.5 \\
\hline
\end{tabular}

${ }^{\text {a }}$ Mean of $N=2$ sites per soil type. Coefficient of variation $(\%)$ in parentheses.

Cations were quantified using an ICP-AES (Spectro Analytical Instruments, Kleve, Germany) after leaching the soil samples with $1 \mathrm{~N} \mathrm{NH}_{4} \mathrm{Cl}$ (Meiwes et al. 1984).

Total $\mathrm{C}$ and $\mathrm{N}$ were measured with a CHN analyzer (Vario EL, Elementar Analysensysteme GmbH, Hanau, Germany)

Particle size distribution was estimated using air-dried, sieved $(2 \mathrm{~mm})$ and with $\mathrm{H}_{2} \mathrm{O}_{2}$ treated soil samples. The clay fraction was determined using the pipette method.

Oxalate-extractable aluminum $\left(\mathrm{Al}_{0}\right)$ and iron $\left(\mathrm{Fe}_{0}\right)$ was determined according to Blakemore et al. (1987) by shaking $2 \mathrm{~g}$ of soil for four hours in the dark in $100 \mathrm{ml}$ of extracting solution (mixture of ammonium oxalate and oxalic acid, $0.2 \mathrm{M}$ with respect to oxalate, with proportions adjusted to give $\mathrm{pH} 3$ ). The aluminum and iron concentrations in the supernatant were determined by ICP-AES. The analysis were done at the Institute of soil Science and Plant Nutrition, University of Halle-Wittemberg, Germany. 
throughfall, inorganic $\mathrm{C}$ was removed by adjusting the $\mathrm{pH}$ of the solution to a value of 2 using concentrated $\mathrm{H}_{3} \mathrm{PO}_{4}$ and sparging with $\mathrm{CO}_{2}$ free synthetic air.

Total dissolved nitrogen (TDN) was determined in a continuous flow system using alkaline persulfate digestion to convert both $\mathrm{NH}_{4}{ }^{+}-\mathrm{N}$ and dissolved organic nitrogen to $\mathrm{NO}_{3}{ }^{-} \mathrm{N}$ (König \& Fortmann 1996). Complete oxidation was achieved by ultra violet digestion. $\mathrm{NH}_{4}{ }^{+}-\mathrm{N}$ and $\mathrm{NO}_{3}{ }^{-} \mathrm{N}$ were measured on a Skalar autoanalyzer (Skalar, Erkelenz, Germany). The automated procedure for the determination of ammonium was based on the Berthelot reaction. Nitrate was reduced to nitrite with a copperized cadmium column, followed by conversion to an azo dye using $\mathrm{N}$-naphtylethylendiamin. The sum of $\mathrm{NH}_{4}{ }^{+}-\mathrm{N}$ and $\mathrm{NO}_{3}{ }^{-}-\mathrm{N}$ is referred to dissolved inorganic nitrogen (DIN). Dissolved organic nitrogen (DON) was computed from the relationship DON $=$ TDN - DIN. TDN analysis was restricted to one site per soil type (A4 and L6).

The $\delta^{13} \mathrm{C}$ of DOC was measured on composite water samples. Frozen samples were freeze-dried (Freeze Dryer, Delta II, Martin Christ GmbH \& Co KG, Osterode, Germany) until a fine powder was left. The carbon isotopic composition of freeze-dried DOC was determined on $\mathrm{CO}_{2}$ samples after quantitative combustion using an elemental analyzer (Fisions EA11081), connected to an isotope ratio mass spectrometer (DELTA plus, Finnigan MAT, Bremen, Germany). The stable $\mathrm{C}$ isotope data are reported in the standard notation $\left(\delta^{13} \mathrm{C}\right)$ in parts per thousand $(\%$ ) relative to the international Pee Dee Belemnite (PDB) standard, where $\delta^{13} \mathrm{C}=[($ Rsample/Rstandard $)-1] \times 1000$ and $\mathrm{R}$ is the molar ratio ${ }^{13} \mathrm{C}^{12} \mathrm{C}$. The standard deviation of replicate samples was $\pm 0.45 \%$.

BIODEGRADABILITY OF DOM. -- The rapidly degradable fraction of dissolved organic matter was tested in a laboratory batch experiment. We collected throughfall, litter leachate and soil solution (two to four replicates each) from 'old alluvium' plots at the end of the rainy season in February 2001 . The filtered samples $(100 \mathrm{~mL})$ were transferred to $250 \mathrm{ml}$ glass flasks and inoculated. The inoculum was prepared by adding $500 \mathrm{~mL}$ of deinoized water to $50 \mathrm{~g}$ of dried and ground litter material. The extract was shaken periodically during 25 hours and was then filtered using $0.2 \mu \mathrm{m}$ cellulose acetate filters (Sartorius AG, Goettingen, Germany). To provide extra surface for microbial growth one shredded-glass-fiber filter was added (Qualls \& Haines 1992). During the 22 days of incubation, temperature was kept between 20 and $22{ }^{\circ} \mathrm{C}$. Flasks were stirred once a day to maintain aerobic conditions. Samples for DOC and TDN analyses were taken directly after inoculation and after 1, 4, 7 and 22 days of incubation. Biodegradable dissolved organic carbon or nitrogen (\%) is defined as the amount of DOC or DON lost during incubation divided by the initial amount of DOC or DON.

DOC FRACTIONATION BY MOLECULAR SIZE. -- Gel permeation chromatography coupled with organic carbon detection (LC-OCD) was used for DOC fractionation and detection (Huber et al. 1994, Huber \& Frimmel 1996). Polymer filled columns were used for the chromatographic separation process. Phosphate buffer ( $\mathrm{pH} 6.58 ; 28 \mathrm{mmol} / \mathrm{l})$ was used as an eluent at a flow rate of $1 \mathrm{ml} / \mathrm{min}$. Standards were used (e.g. humic and fulvic standards form the International Humic Substance Society) to identify the fractions. Calibration for molecular mass was made on the basis of standard humics for the Suwannee River, Georgia, USA. The quantitative organic carbon detection (OCD) is based on a Gräntzel 
gravity-flow thin-film reactor where the quantitative oxidation of the carbon bound to organic moieties takes place in an oxygen-free atmosphere via radiolytic dissociation of small amounts of water into highly reactive oxygen radicals. The reaction product carbon dioxide is measured by non-disperse infrared absorption. Four different groups of organic components (polysaccharides $=$ PS, Humic substances $=$ HS, low molecular weight acids = LMWA; low molecular weight neutrals and amphiphilics = LMWN) could be fractionated by the column according to their molecular weight associated with specific retention times. The specific UV adsorbance coefficient (SAC) of humic substances was measured at $254 \mathrm{~nm}$ as a parameter to estimate the aromaticity of DOM.

SORPTION EXPERIMENT. -- Soil samples from one site on each soil type (A4 and L6) were collected in February 2001. Using a soil auger, samples were taken for the depth intervals: $0.1-0.3 \mathrm{~m}, 0.3-0.5 \mathrm{~m}, 0.5-1.0 \mathrm{~m}, 1.0-2.0 \mathrm{~m}, 2.0-3.0 \mathrm{~m}$ and $3.0-4.0 \mathrm{~m}$ (L6 only). The field moist samples were stored at $4{ }^{\circ} \mathrm{C}$ until use. Sorption of DOC was estimated by the use of the initial mass (IM) relationship (Nodvin et al. 1986). The IM approach has been widely applied for the description of DOC sorption in soils (e.g. McDowell \& Wood 1984, Moore et al. 1992). For this batch sorption study, $5 \mathrm{~g}$ of field moist soil and $50 \mathrm{ml}$ of DOC solution (solid:solution ratio $=1: 10$ ) were placed in PE flasks. We used the DOC extract which was prepared for the biodegradability experiment and diluted it with deionized water to obtain DOC solutions with concentrations between 0 and $100 \mathrm{mg} \mathrm{C} / \mathrm{l}$. To allow sufficient time for DOC to reach equilibrium with the soil, the solution was shaken with $120 \mathrm{rpm}$ for 3 hours (VKS 75, Bühler GmbH, Tübingen, Germany). After equilibration, the soil solution was filtered through pre-washed ashless filters (Schleicher und Schuell, Dassel, Germany) and analyzed for DOC as described above. The amount of DOC released into or removed from solution (normalized to soil mass, in $\mathrm{mg} \mathrm{g}^{-1}$ soil, $R E$ ) was plotted as function of the initial concentration of DOC (normalized to soil mass in $\mathrm{mg} \mathrm{g}^{-1}$ soil, $X i$ ). The slope of the linear regression (m) gives a measure for the affinity of the added DOC for the soil material (sorption isotherm, regression or partition coefficient). The intercept of the equation (b) is the amount of indigenous soil organic carbon released per gram soil if $X i=0$. The null-point DOC concentration $\left(D O C_{N P}\right)$ at which no net removal or release of DOC from the solution takes place, was taken as the intercept of the sorption isotherm and the $\mathrm{y}$-axis (when $R E$ or net sorption is $0 ; \mathrm{mg} / 1$

CALCULATION OF WATER AND ELEMENT FLUAES. -- Annual DOC, DON and DIN fluxes for the different strata (precipitation, throughfall, litter leachate and soil solution) were obtained by multiplying the annual water fluxes by the respective mean annual element concentrations. Precipitation data were collected at the La Selva Meteorological Station, located in a clearing about 2 to $4 \mathrm{~km}$ from the study sites (La Selva (OTS) Meteorological Station, 2002). Throughfall volume was derived by subtracting interception from bulk precipitation (Parker 1983). Average interception was calculated from meteorological data applying a Ruttner-type model (Loescher et al. 2002). Interception losses were about $18 \%$ of bulk precipitation. Annual evapotranspiration for La Selva was calculated using the Priestly-Taylor equation (Loescher pers. comm.) and ranged from 54 to $66 \%$ of bulk precipitation. We assumed that the volume of water percolating through the litter layer was assumed to be equal to the throughfall volume as soil evaporation in such a wet 
environment is usually negligibly small. We assigned approximately $90 \%$ of the transpiration losses to the top $0.3 \mathrm{~m}$. Transpiration losses from deeper layers were presumably small as $90 \%$ of fine roots at these sites are concentrated in the upper $0.3 \mathrm{~m}$ of the soil (Veldkamp et al., in press).

DATA ANALYSES. -- All element concentrations are presented as arithmetic means. Significance of the differences between soil type, soil depth and season were estimated using the Kruskal-Wallis test, which does not require a normal distribution and allows the analysis of unbalanced groups. Correlation analysis was carried out using Spearman rank correlation. Significant effects were determined at $\mathrm{P}<0.05$. All statistical analyses were performed with STATISTICA (Version 6, Statsoft, Inc., Tulsa, OK).

\section{Results}

ELEMENT CONCENTRATIONS AND FLUXES. -- As we found no differences in element concentration between the two soil types, we treated the four sites as replicates. DOC, DON and DIN concentrations and fluxes increased as rainfall was percolating through the canopy (Table 2, Figure 1a). Throughfall DOC flux ( $232 \mathrm{~kg} \mathrm{C} / \mathrm{ha} / \mathrm{yr}$ ) was 6 to 10 times higher than rainfall DOC flux $(22-36 \mathrm{~kg} \mathrm{C} / \mathrm{ha} / \mathrm{yr})$. Concentration and flux of DOC was highest in the litter leachate. The highest fluxes of dissolved organic $N(13 \mathrm{~kg} \mathrm{~N} / \mathrm{ha} / \mathrm{yr})$ and dissolved inorganic $\mathrm{N}(200 \mathrm{~kg} \mathrm{~N} / \mathrm{ha} / \mathrm{yr})$ were also found in the litter leachate. During periods of high precipitation, DOC, DON and DIN concentrations in throughfall and litter leachate tended to decrease (data not shown). Yet, average element concentrations were not different between wet season and 'drier' season $(\mathrm{P}>0.05)$. 
TABLE 2. Mean DOC, DON and DIN concentrations, $\mathrm{pH}$, and $\delta^{13} \mathrm{C}$ values in throughfall, litter leachate and soil solution at La Selva Biological Station, Costa Rica.

\begin{tabular}{cccccc}
\hline Stratum & DOC & DON & DIN & $\mathbf{p H}$ & $\boldsymbol{\delta}^{13} \mathbf{C}$ \\
\cline { 2 - 5 } Rainfall & 3.9 & n.d. & 0.1 & 6.0 & -20.20 \\
Throughfall & $7.0(0.8)^{\mathrm{a}}$ & $0.26(0.05)$ & $0.5(0.1)$ & $5.0(0.1)$ & $-27.04(0.52)$ \\
Litter leachate & $8.4(2.0)$ & $0.38(0.08)$ & $6.1(1.8)$ & $3.9(0.2)$ & $-28.24(0.17)$ \\
Soil Solution (m) & & & & & \\
0.20 & $3.8(1.6)$ & $0.14(0.08)$ & $1.3(1.0)$ & $4.2(0.3)$ & $-27.54(0.24)$ \\
0.40 & $3.6(1.0)$ & $0.11(0.02)$ & $0.4(0.3)$ & $4.6(0.2)$ & $-27.57(0.40)$ \\
0.75 & $2.5(0.7)$ & $0.06(0.02)$ & $0.4(0.1)$ & $4.6(0.2)$ & $-27.29(0.33)$ \\
1.50 & $2.8(0.7)$ & $0.07(0.01)$ & $0.5(0.3)$ & $4.6(0.3)$ & $-27.05(0.18)$ \\
2.50 & $3.2(0.5)$ & $0.06(0.02)$ & $0.4(0.3)$ & $4.6(0.3)$ & $-26.82(0.18)$ \\
3.50 & $2.9(1.1)$ & 0.02 & $0.2(0.1)$ & $4.8(0.4)$ & $-26.59(1.22)$ \\
\hline
\end{tabular}

${ }^{\mathrm{a}}$ Mean $(N=4)$ and $\mathrm{SD}$ (in parentheses)

n.d. not determined 
mineral soil (Table 2; Table 3; Figure 1a). Below a soil depth of $0.75 \mathrm{~m}$ soil solution DOC fluxes were between $51-58 \mathrm{~kg} \mathrm{C} / \mathrm{ha} / \mathrm{yr}$ and DON fluxes ranged from 0.4 to $1 \mathrm{~kg} \mathrm{~N} / \mathrm{ha} / \mathrm{yr}$. The amount of dissolved inorganic nitrogen in deeper layers was between 4 and $9 \mathrm{~kg} \mathrm{~N} / \mathrm{ha} / \mathrm{yr}$. Soil solution concentrations and fluxes did not differ between wet and 'drier' season $(\mathrm{P}>0.05)$.

Dissolved inorganic nitrogen compounds dominated in all strata over DON (Table 2). Nitrate represented $\geq 95 \%$ of total dissolved inorganic $\mathrm{N}$ in all strata, except in bulk precipitation where $\mathrm{NH}_{4}-\mathrm{N}$ was the main inorganic $\mathrm{N}$ compound (data not shown). The proportion of DON to TDN decreased from $30 \%$ in throughfall to less than $10 \%$ in litter leachate. In soil solution from deeper layers DON contributed between 10 and $20 \%$ to TDN.

BIODEGRADABILITY OF DOM. -- The incubation experiment revealed two distinct phases of decomposition. During the first 7 days we observed a linear decrease of DOC. This was followed by a second phase during which the decrease was less rapidly or even a slight increase in DOC was observed. We therefore defined the biodegradable DOC as the fraction decomposed during the first 7 days. The biodegradable fraction of DOM differed between throughfall, litter leachate and soil solution. Biodegradable DOC in throughfall was $23 \%$ and in litter leachate $33 \%$. In the soil solution the fraction of biodegradable DOC ranged between 41 and $46 \%$. The proportion of biodegradable DON was $15 \%$ in throughfall, $33 \%$ in litter leachate, and around $55 \%$ in soil solution. The annual amount of biodegradable DOC was calculated by multiplying the annual DOC flux per strata with the proportion of biodegradable DOC. The highest flux of biodegradable DOC occurred in the litter leachate $(90 \mathrm{~kg} \mathrm{C} / \mathrm{ha} / \mathrm{yr})$. Below $0.75 \mathrm{~m}$ depth around $20 \mathrm{~kg} / \mathrm{ha} / \mathrm{yr}$ were biodegradable (Figure $1 \mathrm{~b}$ ).

DOC COMPOSITION AND ISOTOPIC SIGNATURE. -- The chemical composition of the DOC as determined by gel chromatography changed as water passed through the canopy and soil profile. The chromatographic DOC fraction of throughfall and litter leachate contained a high proportion (up to $80 \%$ ) of humic substances (HS) (Table 4). The remaining fractions were polysaccharides, low molecular weight neutrals and hydrophobic compounds. As water was percolating through the upper layer of the mineral soil, the fraction of humic substances decreased substantially. In $1.5 \mathrm{~m}$ depth only approximately $15 \%$ of the remaining DOC consisted of humic substances. Low molecular weight acids, indicating microbial activity and/or the release of root exudates were only detected in soil solution collected at $0.2 \mathrm{~m}$ depth. To account for the decline in DOC flux over depth we multiplied the proportion of each fraction by the amount of DOC measured in the corresponding strata. The highest flux of humic substances. was found in the litter leachate with $220 \mathrm{~kg} \mathrm{C} / \mathrm{ha} / \mathrm{yr}$. In contrast, in $1.5 \mathrm{~m}$ depth less than $10 \mathrm{~kg} \mathrm{C} / \mathrm{ha} / \mathrm{yr}$ of the DOC flux consisted of humic substances (Figure 1c). Not only the contribution of humic substances relative to total DOC changed as water was percolating through the profile, but also its characteristics. The SAC:DOC ratio, a measure for the aromaticity, and the molecular weight of HS declined with depth (Table 4).

DOC $-{ }^{13} \mathrm{C}$ mass spectrometry measurements showed that litter leachate was depleted in $\delta^{13} \mathrm{C}$ as compared to precipitation, throughfall and soil solution (Table 2). At both soil types, $\delta^{13} \mathrm{C}$ of DOC increased slightly with depth $(\mathrm{P}>0.05)$. 
SORPTION CAPACITY. -- The sorption experiment showed that soil samples could both desorb and adsorb DOC. At zero or low DOC additions, all soil samples released indigenous DOC (negative intercept b) (Table 5). The amount of DOC released at Xi $=0$ was similar to the concentrations measured in soil solution collected with suction cups at the corresponding depth (Table 2; Table 5). DOC additions higher than $\mathrm{DOC}_{\mathrm{NP}}$ not only suppressed a further release of indigenous DOC

TABLE 3. Fluxes of DOC, DON and DIN at La Selva Biological Station, Costa Rica

\begin{tabular}{ccccc}
\hline Stratum & Water flux & DOC & DON & DIN \\
\cline { 2 - 5 } & $\mathrm{mm}$ & & $\mathrm{kg} / \mathrm{ha} / \mathrm{yr}$ & \\
\cline { 3 - 5 } Rainfall & 4073 & $22-36^{*}$ & $1-6^{*}$ & $4-8^{*}$ \\
Throughfall & 3300 & $232(27)^{\mathrm{a}}$ & $9(2)$ & $17(0)$ \\
Litter leachate & 3300 & $277(67)$ & $13(3)$ & $200(4)$ \\
Soil solution (m) & & & & \\
0.20 & 2500 & $95(40)$ & $3(2)$ & $32(0.3)$ \\
0.40 & 1800 & $64(17)$ & $2(0.3)$ & $8(0.0)$ \\
0.75 & 1800 & $44(12)$ & $1(0.3)$ & $7(0.0)$ \\
1.50 & 1800 & $51(12)$ & $1(0.2)$ & $9(0.0)$ \\
2.50 & 1800 & $58(9)$ & $1(0.4)$ & $8(0.0)$ \\
3.50 & 1800 & $53(20)$ & 0.4 & $4(0.0)$ \\
\hline
\end{tabular}

* Element concentrations from Eklund et al. (1997)

${ }^{a}$ Mean $(N=4)$ and SD (in parentheses) 
FIGURE 1. Fluxes of DOC, biodegradable DOC and humic substances at La Selva Biological Station, Costa Rica.
(a) DOC
(b) Biodegradable DOC
(c) Humic substances
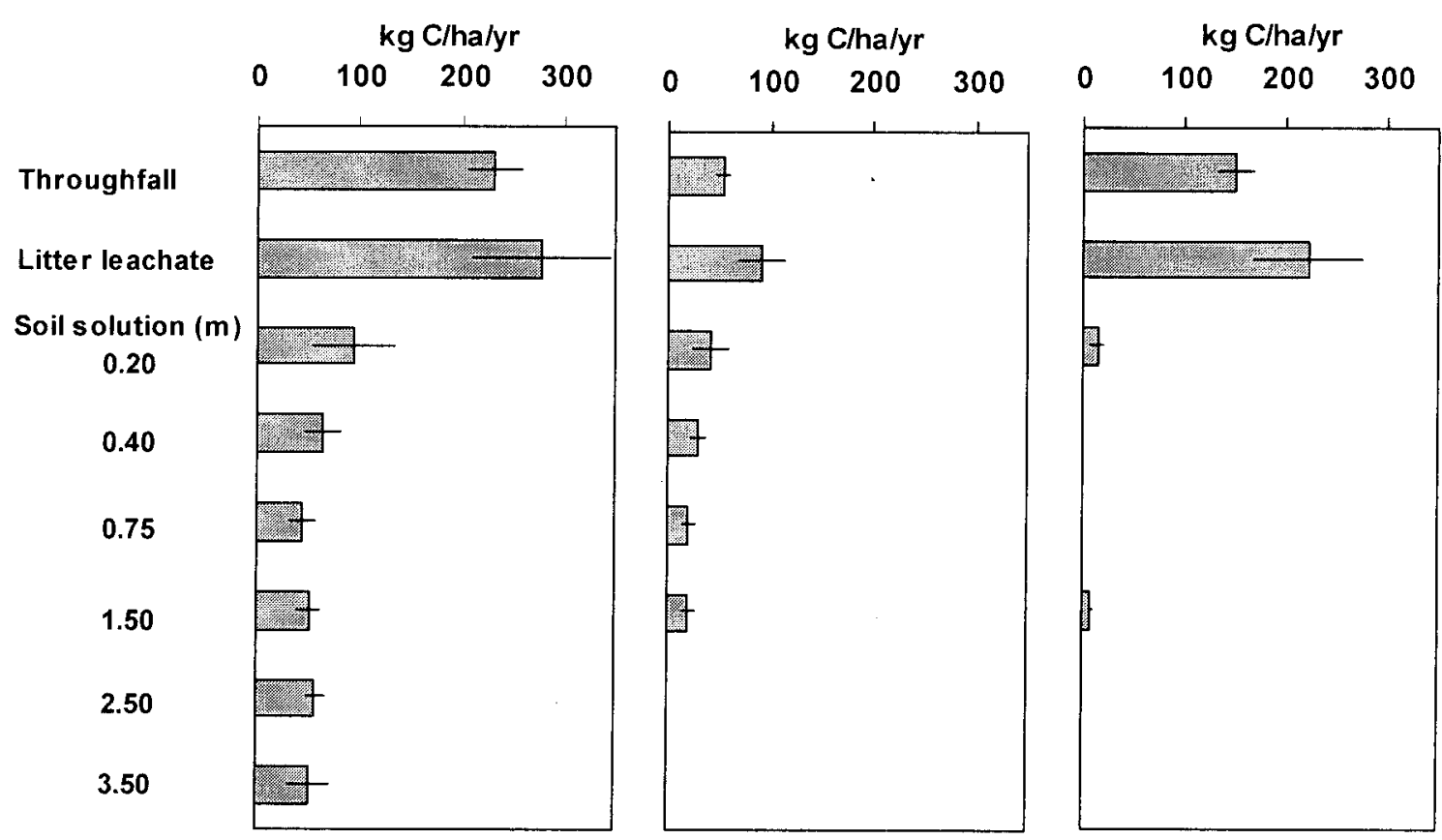
TABLE 4. Concentrations of total DOC and the PS, HS, LMWA and LMWN fractions in throughfall, litter leachate and soil solution (0.2 and $1.5 \mathrm{~m}$ depth).

\begin{tabular}{|c|c|c|c|c|c|c|c|c|c|}
\hline \multirow[t]{2}{*}{ Stratum } & \multirow{2}{*}{$\begin{array}{l}\text { Total } \\
\text { DOC }\end{array}$} & \multirow[t]{2}{*}{ HOC } & \multirow[t]{2}{*}{ CDOC } & \multirow[t]{2}{*}{ PS } & \multicolumn{3}{|c|}{ HS } & \multirow[t]{2}{*}{ LMWA } & \multirow[t]{2}{*}{ LMWN } \\
\hline & & & & & content & SAC:DOC & MW & & \\
\hline & \multicolumn{5}{|c|}{$\mathrm{mg} \mathrm{C} / \mathrm{l}$} & $1 / \mathrm{mg} / \mathrm{m}$ & $\mathrm{g} / \mathrm{mol}$ & \multicolumn{2}{|c|}{$\mathrm{mg} \mathrm{C} / \mathrm{l}$} \\
\hline Throughfall & 1.8 & 0.3 & 1.6 & 0.2 & 1.2 & 4.7 & 690 & 0.0 & 0.2 \\
\hline Litter leachate & 8.1 & 3.8 & 7.8 & 0.1 & 6.6 & 4.3 & 770 & $<0.1$ & 1.0 \\
\hline \multicolumn{10}{|l|}{ Soil solution } \\
\hline $0.20 \mathrm{~m}$ & 3.9 & 1.2 & 2.7 & 0.2 & 0.6 & 2.9 & 622 & 0.4 & 1.5 \\
\hline $1.50 \mathrm{~m}$ & 0.7 & 0.4 & 0.3 & 0.1 & 0.1 & 0.9 & 602 & 0.0 & 0.1 \\
\hline
\end{tabular}

Legend:

CDOC - Chromatographic fraction of total DOC $=\Sigma$ PS $+\mathrm{HS}+\mathrm{LMWA}+\mathrm{LMWN}$

HOC - Hydrophobic compounds

HS - Humic substances

LMWA - Low-molecular weight organic acids;

LMWN - Low-molecular weight neutrals and amphiphilics

MW - Molecular weight

PS - Polysaccharides

SAC - spectral adsorption coefficient at $254 \mathrm{~nm}$

Total DOC $=\Sigma$ HOC + CDOC 
TABLE 5. Dissolved organic carbon sorption characteristics (partition coefficient $m$, intercept $b$, null-point concentration $D O C_{N P}$ and coefficient of determination $\left.r^{2}\right)$

\begin{tabular}{ccccc}
\hline Depth interval & $\mathbf{b}$ & $\mathbf{m}$ & $\mathbf{r}^{2}$ & DOC $_{\mathbf{N P}}$ \\
\hline $\mathrm{m}$ & $\mathrm{mg} / \mathrm{g}$ & & & $\mathrm{mg} \mathrm{C} / \mathrm{l}$ \\
$0.0-0.3$ & $-0.10(0.01)^{\mathrm{a}}$ & $0.60(0.06)$ & $0.97(0.02)$ & $17.1(2.4)$ \\
$0.3-0.5$ & $-0.04(0.01)$ & $0.90(0.03)$ & $0.99(0.00)$ & $4.8(0.9)$ \\
$0.5-1.0$ & $-0.04(0.01)$ & $0.90(0.01)$ & $0.99(0.00)$ & $3.8(0.8)$ \\
$1.0-2.0$ & $-0.03(0.01)$ & $0.88(0.05)$ & $0.99(0.00)$ & $3.5(1.5)$ \\
$2.0-3.0$ & $-0.03(0.00)$ & $0.87(0.09)$ & $0.98(0.01)$ & $3.5(0.4)$ \\
$3.0-4.0$ & $-0.03(0.01)$ & $0.93(0.01)$ & $0.95(0.06)$ & $3.2(0.3)$ \\
\hline
\end{tabular}

${ }^{\text {a }}$ Mean $(N=2$ to 8 replicates per depth interval) and SD (in parentheses) 
but also promoted the removal of DOC from the solution. All isotherms showed a linear relationship between DOC released or sorbed by the soil and DOC added at the start of the batch equilibrium experiment. Coefficients of determination $\left(\mathrm{r}^{2}\right)$ for the partition coefficients $(\mathrm{m})$ were always higher than 0.95 . Slopes of the sorption isotherms ranged from 0.60 in upper mineral soil to 0.93 in the deeper mineral soil.

\section{Discussion}

DOC, DON AND DIN FLUXES AND THEIR ECOLOGICAL SIGNIFICANCE. -- DOC and DON fluxes in throughfall $(237 \mathrm{~kg} \mathrm{C} / \mathrm{ha} / \mathrm{yr}, 9 \mathrm{~kg} \mathrm{~N} / \mathrm{ha} / \mathrm{yr})$ were a factor ten higher than the DOC and DON input by rain. The above ground biomass thus represented a net source of dissolved organic matter. These throughfall fluxes of DOC and DON are large compared to fluxes for temperate forests $(40-160 \mathrm{~kg} \mathrm{C} / \mathrm{ha} / \mathrm{yr}, 2-12 \mathrm{~kg} \mathrm{~N} / \mathrm{ha} / \mathrm{yr}$; Michalzik et al. 2001). Although DOM concentrations below the litter layer were lower than those for temperate forests, our DOC and DON fluxes $(277 \mathrm{~kg} \mathrm{C} / \mathrm{ha} / \mathrm{yr}$ and $13 \mathrm{~kg} \mathrm{~N} / \mathrm{ha} / \mathrm{yr})$ were within the range reported for temperate forests $(100-400 \mathrm{~kg} \mathrm{C} / \mathrm{ha} / \mathrm{yr}, 1-18 \mathrm{~kg} \mathrm{~N} / \mathrm{ha} / \mathrm{yr}$; Michalzik et al. 2001, Neff \& Asner 2001). For tropical forests this has been observed before and can be explained by the higher rainfall in tropical forest ecosystems compare to temperate forests (Aitkenhead-Peterson et al. 2002). DOM concentrations and fluxes decreased with soil depth. This has also been observed in many temperate forests. In temperate ecosystems DOM fluxes at a soil depth of about $0.9-1.0 \mathrm{~m}$ are considered to represent the DOC export by leaching (Guggenberger \& Kaiser 2003). Based on this assumption we calculate a DOM export from soils at La Selva of $50 \mathrm{~kg} \mathrm{C} / \mathrm{ha} / \mathrm{yr}$ and of 1 $\mathrm{kg} \mathrm{N} / \mathrm{ha} / \mathrm{yr}$. Compared to litterfall (Davidson et al. 2002), DOC and DON fluxes in litter leachate were about $10 \%$ of the $\mathrm{C}$ and $\mathrm{N}$ fluxes in litterfall. Rates of dissolved organic carbon leaching from the mineral soil were less than $1 \%$ compared to the losses via soil $\mathrm{CO}_{2}$ efflux (11 - $14 \mathrm{Mg} \mathrm{C} / \mathrm{ha} / \mathrm{yr}$; Schwendenmann et al., in press).

At La Selva, dissolved $\mathrm{N}$ fluxes were dominated by mineral $\mathrm{N}$ (mainly $\mathrm{NO}_{3}^{-}{ }^{-} \mathrm{N}$ ) in all strata. Substantial leaching losses of $\mathrm{NO}_{3}{ }^{-}-\mathrm{N}$ combined with significant losses through trace gasses (Keller \& Reiners 1994) suggests that this old-growth forest is not N limited. This can be explained by the high proportion of legumes, which are able of symbiotic nitrogen fixation (Parker et al. 1994), and by the high decomposition rates of organic matter and corresponding rapid N-cycling. Our observations contrast with undisturbed Nlimited forests in North America and tropical montane forests, where DON was the dominant form of $\mathrm{N}$ leaching (Qualls et al. 2000, McDowell 2001, Perakis \& Hedin 2002).

BIODEGRADABILITY OF DOM. -- The biodegradable DOC fraction of throughfall $(23 \%)$ and litter leachate $(33 \%)$ we measured is within the range that has been reported for temperate forest ecosystems (throughfall: 18 - 50\% and litter leachate: 6 - 20\%; Qualls \& Haines 1992; Yano et al. 1998, 2000). However, rapid decomposition of DOM before collection in the field may underestimate the bioavailability of DOM, which may explain higher values (up to $75 \%$ ) reported in some studies (Hongve et al. 2000, Cleveland et al., in press). The biodegradability of DOM is influenced by the chemical structure of the material. Aromatic structures are considered stable, whereas carbohydrates can be easily mineralized by microorganisms (Marschner \& Kalbitz 2003). The yellowish color of our throughfall and litter samples combined with results of the DOC fractionation experiment 
(Table 4) show that those samples contained a considerable amount of humic substances. The high content of humic substances in throughfall samples is most likely related to the large amount of decomposing litter in the canopy. However, we cannot exclude that decomposing fine litter which was sometimes found in the collector funnel also contributed. The abundance of humic substances, a high SAC:DOC ratio (indicating higher aromaticity) and a high molecular weight explain why the proportion of rapidly biodegradable DOC in throughfall and litter leachate was lower than in the soil solution (41-46\%). Despite this comparatively low proportion of biodegradable DOC, the actual flux from the litter leachate was higher than in any other strata because of the higher total DOC flux. The proportion of biodegradable DOC in our soils was slightly higher than reported values from temperate forests where $10-44 \%$ of DOM in soil solution was biodegradable (Kalbitz et al. 2000; Yano et al. 1998, 2000). Our results for DON did not differ significantly from the DOC results.

SORPTION OF DOM. -- Our sorption experiment showed that our soil samples have a high affinity for DOC. This is indicated by the slope of the adsorption isotherm, also called the partition coefficient. Partition coefficients for all soil samples between 0.3 and $4.0 \mathrm{~m}$ depth were higher than 0.8 and some were as high as 0.93 . As far as we know, these are the highest partition coefficients ever reported for natural soil samples. Moore et al. (1992), investigating 48 soil samples from various soils types and different soil depths reported partition coefficient between 0.16 and 0.78 . On Ultisols in a tropical forest site in Puerto Rico the partition coefficients ranged from 0.39 to 0.59 (McDowell 1998). Mineralogical analysis of both La Selva soil types has shown that clay minerals were dominated by iron and aluminum oxides, kaolinite, halloysite and gibbsite (Kleber, pers. comm.). Several studies emphasize the importance of sesquioxides in controlling DOC

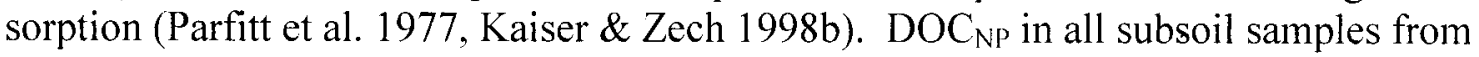
La Selva ranged between 3 and $4 \mathrm{mg} \mathrm{C} /$, indicating that DOC concentrations above this threshold value will be adsorbed by the soil. This explains the relatively constant DOC concentrations in deeper horizons over the year, indicating effective sorption even after heavy rain showers. This is also supported by the chemical analyses of DOC. The absolute amount of humic substances decreased with depth (Figure 1c) and the remaining humic substances at $1.5 \mathrm{~m}$ depth were characterized by a lower SAC:DOC ratio and lower molecular weight. These results imply that preferential sorption of aromatic high molecular organic substances occurs in the soil. Kaiser and Zech (1997) and Kaiser and Guggenberger (2000) also reported that hydrophobic DOC fractions are preferentially sorbed to mineral surfaces.

CONTROLS ON DOM IN THE SOIL AND CONSEQUENCES FOR C STORAGE. -- Two mechanisms can potentially explain the observed decrease in DOC concentrations with soil depth: biodegradation of DOC and sorption by the mineral phase. We hypothesize that in soils at La Selva, sorption is the dominant process. While the absolute amount of biodegradable DOC slowly decreased with depth, the proportion of biodegradable DOC did not decrease but increase with soil depth. This indicates that biodegradable DOC was removed less rapidly from the soil solution than the DOC that was removed by sorption. Rapid removal of DOC by adsorption has been observed before: Kaiser and Zech (1998a) showed that up to $90 \%$ of added DOC could be retained by the mineral soil within 15 
minutes after addition to the soil. Our hypothesis is also supported by the drastic decline of humic substances in the upper mineral soil (Figure 1c) and the high partition coefficients measured throughout the soil profile. The decline in DOC concentration in the upper mineral soil was accompanied by an increase in $\mathrm{DO}-\delta^{13} \mathrm{C}$ values. Although decomposition of DOC can preferentially release ${ }^{12} \mathrm{C}$ via the evolution of $\mathrm{CO}_{2}$ (Blair $e t$ al. 1985, Trumbore et al. 1992, Ludwig et al. 2000), Cleveland et al. (in press) showed that isotopic fractionation during biological decomposition DOC was not significant. The observed DO- $\delta{ }^{13} \mathrm{C}$ increase may also be explained by different mobility and sorption of the more ${ }^{13} \mathrm{C}$ depleted humic DOC fraction (e.g. lignin and aliphatic material; Deines 1980, Boutton 1996). This mechanism was also suggested by Kaiser et al. (2001) to explain isotopic enrichment with soil depth. At La Selva ${ }^{13} \mathrm{C}$ enrichment with depth is also observed for soil organic matter and the $\delta^{13} \mathrm{C}$ signature of DOC collected in deeper layers was close to the $\delta^{13} \mathrm{C}$ value of the soil organic carbon (Veldkamp et al., in press). Our results indicate that sorption is the dominant process controlling DOC concentrations the soils at La Selva. Sorption is probably also the dominant process that has caused the large carbon stocks in these soils, especially between 1.0 and $4.0 \mathrm{~m}$ depth (Veldkamp et $a l$. , in press). Assuming that sorption is the dominant process causing carbon storage in the subsoil, there are limited ways in which carbon sequestration in the subsoil could further increase: formation of more sesquioxides that have a high affinity for DOM sorption or higher concentrations of humic substances in DOM (increasing adsorption). Formation of new sesquioxides has probably been the main long-term carbon sequestration process in these soils, which was estimated at $160 \mathrm{~g} \mathrm{C}^{-1} \mathrm{ha}^{-1}$ (Veldkamp et al., in press). Higher concentrations of humic substances in DOM could potentially be the result of elevated $\mathrm{CO}_{2}$ or increased $\mathrm{N}$-deposition (both processes are likely to happen at La Selva in the near future). However, until now there is no evidence that such changes in DOM composition occur (Hagedorn et al. 2002) and there is no indication that this mechanism will lead to additional $\mathrm{C}$ storage in the coming decades. 


\section{LITERATURE CITED}

Aitkenhead-Peterson, J. A., W. H. McDowell, and J. C. Neff. 2002. Sources, production and regulation of allochthonous dissolved organic matter. In S. E. G. Findlay and R. L. Sinsabaugh (Eds.). Aquatic Ecosystems: Interactivity of dissolved organic matter, pp. 26-70. Academic Press, Amsterdam.

Anderson, D.E., Verma, S.B., Clement, R.J., Baldocchi, D.D., Matt, D.R. 1986 Turbulence spectra of $\mathrm{CO}_{2}$, water vapor, temperature and velocity over a deciduous forest. Agr. For. Met. 38, 81-99.

Anderson, J.P. and K.H. Domsch. 1978. A physiological method for the quantitative measurement of microbial biomass in soils. Soil Biology and biochemistry 10, 215-221.

Andrade J.L., Meinzer F.C., Goldstein G., Holbrook N.M., Cavelier J., Jackson P. \& Silvera K. (1998) Regulation of water flux through trunks, branches, and leaves in trees of a lowland tropical forest. Oecologia 115, 463-461.

Andreae, M.O., T.W. Andreae, R.J. Ferek, and H. Raemdonck, Long range transport of soot carbon in the marine atmosphere, Sci. Total Environ., 36, 73-80, 1984.

Arya, S.P., Introduction to micrometeorology, 307 pp., Academic Press, London, 1988.

Ashton, P., T.J. Givnish, and S. Appanah. 1988. Staggered flowering in the Dipterocarpaceae: new insights into floral induction and the evolution of mast fruiting in the aseasonal tropics. American Naturalist 132: 44-66.

Baldocchi, D., Meyers, T. 1988 On using eco-physiological, micrometeorological and biogeochemical theory to evaluate carbon dioxide, water vapor and trace gas fluxes over vegetation: a perspective. Agricultural and Forest Meteorology 90: 125.

Baldocchi, D.D., B.B. Hicks, T.P. Meyers, Measuring Biosphere-Atmosphere Exchanges of Biologically Related Gases With Micrometeorological Methods, Ecol. 69, 1331-1340, 1988

Baldocchi, DD 1996 Strategies for measuring and modeling carbon dioxide and water vapour fluxes over terrestrial ecosystems. Global Change Biology 2:159-168.

Balesdent, J. and A. Mariotti. 1996. Measurement of soil organic matter turnover using 13C Natural abundance. IN: Boutton, T.W and S. Yamasaki (eds.) Mass Spectrometry of Soils. Marcel Dekker, New York. pp: 83-112.

Baron, P.A., and K. Willeke, Gas and particle motion, in Aerosol measurement, principles, techniques and application, edited by. K. Willeke and $\mathrm{P}$. Baron, pp. 23-41, Van Nostrand Reinhold Pub. N.Y., 1993.

Barrie, L.A., Artic air pollution: an overview of current knowledge, Atmos. Environ., 20, 643-663, 1986.

Barry, R.G., and R.J Chorley, Atmopshere, weather and climate. New York Methuen, 1987.

Batjes, $\mathrm{NH}, 1999$. Management options for reducing $\mathrm{CO}_{2}$-concentrations in the atmosphere by increasing carbon sequestration in the soil. Technical paper 30 , International soil reference and information centre, Wageningen, the Netherlands. 
Bauhus J. and P.K. Khanna. 1999. The significance of microbial biomass and activity in forest soils. In: Rastin, N., and J. Bauhus (eds.) Going underground - ecological studies in forest soils. Signpost research, Trivandrum, India.

Behera N, Joshi SK \& Pati DP (1990) Root contribution to total soil metabolism in a tropical forest soil from Orissa, India. For. Ecol. Manag. 36: 125-134

Bier, C., Hansen, K., \& Gunderson, P. 1993. Spatial variability of throughfall fluxes in a spruce forest. Environmental Pollution 81:257-267.

Bigelow, S., Evapotranspiration modeled from stands of three broad-leaved tropical trees in Costa Rica, Hydrological Processes, 15, 2779-2796, 2001.

Birch HF (1958) The effect of soil drying on humus decomposition and nitrogen availability. Plant Soil 10: 9-31

Blair, N., A. Leu, E. Munos, J. Olsen, E. Kwon, and D. des Marais. 1985. Carbon isotope fractionation in heterotrophic microbial metabolism. Applied Environmental Microbiology 50: 996-1001.

Blakemore, L. C., P. L. Searle, and B. K. Daly. 1987. Methods for chemical analysis of soils. New Zealand Soil Bureau Scientific Report 80. Lower Hutt, New Zealand.

Borchert, R. 1983. Phenology and control of flowering in tropical trees. Biotropica 15: 81-89.

Borchert, R. 1992. Computer simulation of tree growth periodicity and climatic hydroperiodicity in tropical forests. Biotropica 24: 385-395.

Borchert, R. 1998. Responses of tropical trees to rainfall seasonality and its long-term changes. Climatic Change 39: 381-393.

Borchert, R., and G. Rivera. 2001. Photoperiodic control of seasonal development and dormancy in tropical stem-succulent trees. Tree Physiology 21:213-221.

Boutton, T. W. 1996. Stable carbon isotope ratios in soil organic matter and their use as indicators of vegetation and climate change. In T. W. Boutton \& S. Yamasaki (Eds.). Mass spectrometry of soils, pp. 47-82. Marcel Dekker, Inc., New York.

Breitsprecher, A., and J.S. Bethel. 1990. Stem-growth periodicity of trees in a tropical wet forest of Costa Rica. Ecology 71: 1156-1164.

Bruinzeel, L. A., \& Wiersum, K. F. 1987. Rainfall interception of a young Acacia auriculiformis (A. Cunn.) plantation forest in West Java, Indonesia: application of Gash's analytical model. Hydrological Processes 1:309-319.

Bullock, S.H. 1997. Effects of seasonal rainfall on radial growth in two tropical tree species. International Journal of Biometeorology 41: 13-16.

Calder, I.R., I.R. Wright and D. Murdiyaso, A study of evapotranspiration from tropical rain forest-west Java, Journal of Hydrology, 89, 13-31, 1986.

Calder, L. R. 1986. A stochastic model of rainfall interception. Journal of Hydrology 89:65-71.

Campbell, G.S. \& Norman J.M. (1998) An Introduction to Environmental Biophysics. Springer-Verlag, New York, 286 pages.

Campbell, J. L., J. W. Hornbeck, W. H. McDowell, D. C. Buso, J. B. Shanley, and G. E. Likens. 2000. Dissolved organic nitrogen budgets for upland, forested ecosystems in New England. Biogeochemistry 49: 123-142.

Charlson, R. J., S. E. Schwartz, J. M. Hales, R. D. Cess, J. A. Coakley, Jr., J. E. Hansen, and D. J. Hofmann, Science, 255, 423, 1992. 
Chuang, C. C., J. E. Penner, J. M. Prospero, K. E. Grant, G. H. Rau, and K. Kawamoto, Cloud susceptibility and the first aerosol indirect forcing: Sensitivity to black carbon and aerosol concentrations. Journal of Geophysical Research, 107, art. no. $-4564,2002$.

Chuine, I., J. Belmonte, and A. Mignot. 2000. A modelling analysis of the genetic variation of phenology between tree populations. Journal of Ecology 88: 561-570.

Clark D.A. \& Clark D.B. (1992) Life history diversity of canopy and emergent trees in a neotropical rain forest. Ecological Monographs 62, 315-344.

Clark D.A. \& Clark D.B. (1994) Climate-induced annual variation in canopy tree growth in a Costa Rican tropical rain forest. Journal of Ecology 82, 865-872.

Clark D.A. \& Clark D.B. (1999) Assessing the growth of tropical rain forest trees: Issues for forest modeling and management. Ecological Applications 9, 981-997

Clark D.A., and D.B. Clark. 1999. Assessing the growth of tropical rain forest trees: Issues for forest modeling and management. Ecological Applications 9: 981-997.

Clark D.A., S.C. Piper, C.D. Keeling, and D.B. Clark, Tropical forest growth and atmospheric carbon dynamics linked to annual temperature variation, Proc. Nat. Acad. Science, 100 (10): 5852-5857, 2003.

Clark D.B. \& Clark D.A. (1990) Distribution and effects on tree growth of lianas and hemiepiphytes in a Costa Rican tropical wet forest. Journal of Tropical Ecology 6, 321-331.

Clark DB \& Clark DA (2000) Landscape-scale variation in forest structure and biomass in a tropical rain forest. For. Ecol. Manage. 137: 185-198

Clark DB, Clark DA \& Read JM (1998) Edaphic variation and the mesoscale distribution of tree species in a neotropical rain forest. J. Ecol. 86: 101-112

Clark, D. A., and D. B. Clark, Climate-Induced Annual Variation in Canopy Tree Growth in a Costa-Rican Tropical Rain-Forest. J. Ecol., 82, 865-872, 1994.

Clark, D. A., and D. B. Clark, Life-History Diversity of Canopy and Emergent Trees in a Neotropical Rain-Forest, Ecol. Mono., 62, 315-344, 1992.

Clark, D. B., \& Clark, D. A. 2000. Landscape-scale variation in forest structure and biomass in a tropical rain forest. Forest Ecology and Management. 137:185-198.

CLark, D. B., Clark, D. A., Rich, P. M., Weiss, S., \& Oberbauer, S. F. 1996. Landscapescale evaluation of understory light and canopy structure: methods and application in a Neotropical lowland rain forest. Canadian Journal of Forest Research 26:747-757.

Clark, D.B., Clark, D.A., Rich, P.M., Weiss, S., Oberbauer, S.F. 1996 landscape-scale evaluation of understory light and canopy structure: methods and application in a Neotropical lowland rain forest. Can. J. For. Res. 26:747-757.

Clark, K. L., Nadkarni, N. M., Schaeffer, D., \& Gholz, H. L. 1998. Atmospheric deposition and net retention of ions by the canopy in a tropical montane forest, Monteverde, Costa Rica. Journal of Tropical Ecology 14:27-45.

Clark, K.L., H.L. Gholz, J.B. Moncreiff, F. Cropley, and H.W. Loescher, Environmental controls over net exchanges of carbon dioxide from contrasting Florida ecosystems, Ecol.l Apps., 9, 936-948, 1999

Clark, K.L., H.L. Gholz, J.B. Moncreiff, F. Cropley, and H.W. Loescher, Environmental controls over net exchanges of carbon dioxide from contrasting Florida ecosystems, Ecol.l Apps., 9, 936-948, 1999 
Clearwater M.J., Meinzer F.C., Andrade J.L., Goldstein G. \& Holbrook N.M. (1999) Potential errors in measurement of non-uniform sap flow using heat dissipation probes. Tree Physiology 19, 681-687.

Cleveland, C. C., J. C. Neff, A. R. Townsend, and E. Hood. Composition, dynamics, and fate of leached dissolved organic matter in terrestrial ecosystems: Results from a decomposition experiment. Ecosystems. In press.

Cooke, W.F., and J.J.N. Wilson, A global black carbon aerosol model, J. Geophys. Res., $101 \mathrm{D} 14,19,395-19,409,1996$.

Corlett, R.T., and J.V. Lafrankie, Jr. 1998. Potential impacts of climate change on tropical Asian forests through an influence on phenology. Climatic Change 39: 439-453.

Cox PM, Betts AR, Jones CD, Spall SA \& Totterdell IJ (2000) Acceleration of global warming due to carbon-cycles feedbacks in a coupled climate model. Nature 408: 184-187

Davidson EA, Belk E \& Boone RD (1998) Soil water content and temperature as independent or confounded factors controlling soil respiration in a temperate mixed hardwood forest. Global Change Biol. 4: 217-227

Davidson EA, Verchot LV, Cattânio JH, Ackerman IL \& Carvalho JEM (2000) Effects of soil water content on soil respiration in forests and cattle pastures of eastern Amazonia. Biogeochemistry 48: 53-69

Davidson, E. A., K. Savage, P. Bolstad, D. A. Clark, P. S. Curtis, D. S. Ellsworth, P. J. Hanson, B. E. Law, Y. Luo, K. S. Pregitzer, J. C. Randolph, and D. Zak. 2002. Belowground carbon allocation in forests estimated from litterfall and IRGAbased soil respiration measurements. Agricultural and Forest Meteorology 113(14): 39-51.

De Jong E \& Schappert HJV (1972) Calculation of soil respiration and activity from $\mathrm{CO}_{2}$ profiles in the soil. Soil Sci. 119:328-333

Deines, P. 1980. Handbook of environmental Isotope Geochemistry: The Terrestrial Environment Elsevier Amsterdam.

Denslow, J.S, Hartshorn, G.S. 1994. Tree-fall gap environments and forest dynamic processes. In: L.A. McDade, K.S. Bawa, H.A. Hespenheide, and G.S. Hartshorn, (eds.), La Selva: Ecology and Natural History of a Neotropical Rain Forest. University of Chicago Press, Chicago, IL. pp. 120-127.

Dixon R.K., S. Brown, R.A. Houghton, A.M. Solomon, M.C. Trexler, and J. Wisniewski, Carbon pools and flux of global forest ecosystems, Science, 263, 185-190, 1994.

Dörr H \& Münnich KO (1987) Annual variation in soil respiration in selected areas of the temperate zone. Tellus 39B: 114-121

Drake J.B., Dubayah R.O., Clark D.B., Knox R.G., Blair J.B., Hofton M.A., Chazdon R.L., Weishampel J.F. \& Prince S.D. (2002) Estimation of tropical forest structural characteristics using large-footprint lidar. Remote Sensing of Environment 79, 305-319.

Edwards NT (1975) Effects of temperature and moisture on carbon dioxide evolution in a mixed deciduous forest floor. Soil Sci. Soc. Am. Proc. 39: 361-365

Eklund, T. J., and W. H. McDowell. 1997. Seasonal variation of tropical precipitation chemistry: La Selva, Costa Rica. Atmospheric Environment 31(23): 3903-3910.

Englund, S. R., O’Brien, J. J., \& ClarkK, D. B. 2000. Evaluation of digital and film hemispherical photography and spherical densiometry for measuring forest light environments. Canadian Journal of Forest Research 30:1999-2005. 
Epron D \& Badot PM (1997) Fine root respiration in forest trees. In: Puech JC, Latché A, Bouzayen M (Eds) Plant Sciences (pp 199-200). SFPV, Paris

Ewers B.E. \& Oren R. (2000) Analysis of assumptions and errors in the calculation of stomatal conductance from sap flow measurements. Tree Physiology 20, 579-589.

Feigl BJ, Steudler PA \& Cerri CC (1995) Effects of pasture introduction on soil $\mathrm{CO}_{2}$ emissions during the dry season in the state of Rondonia, Brazil Biogeochemistry 31: 1-14

Fetcher N., Oberbauer S.F. \& Chazdon R.L. (1994) Physiological ecology of trees, shrubs, and herbs at La Selva. In La Selva: Ecology and Natural History of a Neotropical Rainforest (eds. L.A. McDade, K.S. Bawa, H.A. Hespenheide, \& G.S. Hartshorn), pp. 128-141. University of Chicago Press, Chicago, Illinois.

Field CB, Behrenfeld MJ, Randerson JT \& Falkowski P (1998) Primary production of the biosphere: integrating terrestrial and oceanic components. Science 281: 237-240

Forster J.C. 1995. Soil physical analysis. In: Methods in applied soil microbiology and biochemistry. pp 105-109.

Forsythe, W.C., E.J. Rykiel Jr., R.S. Stahl, H. Wu, and R.M. Schoolfield. 1995. A model comparison for daylength as a function of latitude and day of year. Ecological Modelling 80: 87-95.

Frankie, G. W., Baker, H. G., Opler, P. A. 1974 Comparative Phenological Studies of Trees in Tropical Wet and Dry Forests in Lowlands of Costa-Rica. Journal of Ecology. 62:881-919.

Freidlander, S.K., Smoke, dust, and haze. Wiley, N.Y., 1977.

Gallagher, W.M., K.M., Beswick, J. Duyzer, H. Westrate, T.W., Choularton, and J.P. Hummelsho, Measurements of aerosol fluxes to Speudler forest using micrometeorological technique, Atmospheric Environment, 31, 359-373, 1997.

Gash, J. H. C. 1979. An analytical model of rainfall interception by forests. Quarterly Journal of Royal Meteorological Society 105:43-45.

Gash, J.H., and W.J. Shuttleworth, Tropical deforestation: Albedo and the surface-energy balance, Climatic Change, 19, 123-133, 1991.

Goldstein G., Andrade J.L., Meinzer F.C., Holbrook N.M., Cavelier J., Jackson P. \& Celis A. (1998) Stem water storage and diurnal patterns of water use in tropical forest canopy trees. Plant, Cell and Environment 21, 397-406.

Goovaerts, P. 1998. Geostatistical tools for characterizing the spatial variability of microbiological and physico-chemical soil properties. Biology and Fertility of Soils 27:315-334.

Goulden, M.L., Munger, J.W, Fan, S-M.,.. Daube, B.C, Wofsy, S.F. 1996 Measurements of carbon sequestration by long-term eddy-covariance: methods and critical evaluation of accuracy. Global Change Biology 2:169-182.

Grace J, Lloyd J, Mcintyre J, Miranda A, Meir P, Miranda H, Nobre C, Moncrieff J, Massheder J, Malhi Y, Wright I \& Gash J (1995) Carbon dioxide uptake by an undisturbed tropical rain forest in southwest Amazonia, 1992 to 1993. Science 270: 778-780

Grace, J., J. Lloyd, J. McIntyre, A. Miranda, P. Meir, H. Miranda, J. Moncrieff, J.

Massheider, I. Wright and J. Gash, Fluxes of carbon dioxide and water vapor over an undisturbed tropical forest in south-west Amazonia, Global Change Biology, 1, $1-12,1995$.

Grace, J., J. Lloyd, J. McIntyre, A. Miranda, P. Meir, H. Miranda, J. Moncrieff, J. Massheider, I. Wright and J. Gash, Fluxes of carbon dioxide and water vapor over 
an undisturbed tropical forest in south-west Amazonia, Global Change Biology, 1, $1-12,1995$.

Granier A, Lousteau D. \& Bréda N. (2000). A generic model of forest canopy conductance dependent on climate, soil water availability and leaf area index. Annals of Forest Science 57, 755-765.

Granier A. \& Lousteau D. (1994) Measuring and modelling the transpiration of a maritime pine canopy from sap-flow data. Agricultural and Forest Meteorology $71,61-81$.

Granier A. (1987) Evaluation of transpiration in a Douglas fir stand by means of sap flow measurements. Tree Physiology 3, 309-320.

Granier A., Huc, R. \& Colin F. (1992) Transpiration and stomatal conductance of two rain forest species growing in plantations (Simarouba amara and Goupia glabra) in French Guyana. Annals of Forest Science 49, 17-24.

Grant, K. E., C.C. Chuang, A.S. Grossman, and J.E. Penner, Modeling the spectral optical properties of ammonium sulfate and biomass burning aerosols:

parameterization of relative humidity effects and model results. Atmospheric Environment, 33, 2603-2620, 1999.

Guggenberger, G., and K. Kaiser. 2003. Dissolved organic matter in soil: challenging the paradigm of sorptive preservation. Geoderma 113(3-4): 293-310.

Gunderson, P., B. A. Emmett, O. J. Kjonaas, C. J. Koopmans, and A. Tietema. 1998. Impact of nitrogen deposition on nitrogen cycling in forests: a synthesis of NITREX data. Forest Ecology and Management 101: 37-55.

Gutierrez M.V., Harrington R.A., Meinzer F.C.A., \& Fownes J.H. (1994) The effect of environmentally induced stem temperature gradients on transpiration estimates from the heat balance method in two tropical woody species. Tree Physiology 14 , 179-190.

Hagedorn, F., P. Blaser, and R. Siegwolf. 2002. Elevated atmospheric $\mathrm{CO}_{2}$ and increased $\mathrm{N}$-Deposition effects on dissolved organic carbon-clues from $\delta^{13} \mathrm{C}$ signature. Soil Biology and Biochemistry: 355-366.

Haggar, J.P., Ewel, J.J. 1994 Experiments on the ecological basis of sustainability: early findings on nitrogen, phosphorus, and root systems. Interciencia 19:347-352.

Haggar, J.P., Ewel, J.J. 1995 Establishment, resource acquisition, and early productivity as determined by biomass allocation patterns of three tropical tree species. Forest Science 41:689-708.

Hanson PJ, Edwards NT, Garten CT \& Andrews JA (2000) Separating root and soil microbial contributions to soil respiration: A review of methods and observations. Biogeochemistry 48: 115-146

Hartshom, G.S., and R. Peralta, Preliminary description of primary forests along the La Selva-Volcan Barva altitudinal transect, Costa Rica, in Tropical rainforests: Diversity and Conservation, edited by F. Alemda and C. Pringle, pp. 281-295, California Academy of Science, San Fransisco, 1994.

Hartshorn GS \& Hammel BE (1994) Vegetation types and floristic patterns. In: McDade LA, Bawa KS, Hespenheide HA \&, Hartshorn GS (Eds) La Selva: Ecology and natural history of a neotropical rain forest (pp 73-89). The University of Chicago Press, Chicago

Hartshorn, G. S., and B. E. Hammel. 1994. Vegetation types and floristic patterns. In L.

A. McDade, K. S. Bawa, H. A. Hespenheide, and G. S. Hartshorn (Eds.). La 
Selva: Ecology and natural history of a neotropical rain forest, pp. 73-89. The University of Chicago Press, Chicago.

Hassenrath, S.L. 1988 Climate and circulation in the tropics. (Riedel, Dordrecht). Hazlett, D.L. 1987. Seasonal cambial activity for Pentaclethra, Goethalsia, and Carapa trees in a Costa Rican lowland forest. Biotropica 19: 357-360.

Heilmann, B. and F. Beese. 1992. Miniaturized method to measure carbon dioxide production and biomass of soil microorganisms. Soil Science Society of America Journal 56, 596-598.

Hicks, B.B., D.R. Matt, R.T. McMIlen, J.D. Womack, M.L. Wesely, R.L. Hart, D.R. Cook, S.E. Lindberg, R.G. De Pena, and D.W. Thompson, A field investigation of sulphate fluxes to a deciduous forest, Journal of Geophysical Research, 94, 13003-13011, 1989.

Hicks, B.B., D.R. Matt, R.T. McMllen, J.D. Womack, M.L. Wesely, R.L. Hart, D.R. Hicks, B.B., M.L. Wesely, J.L. Durham, and M.A Brown, Some direct measurements of atmospheric sulphate fluxes over a pine plantation, Atmospheric Environment, 12 , 2899-2903, 1982.

Holdridge L.R. 1967. Life zone ecology. Tropical Science Center, San Jose, Costa Rica. Holdridge, L.R., Grenke, W.C., Hatheway, W.H., Liang, T., Tosi, J.A. jr. 1971 Forest environments in tropical life zones: a pilot study. Pergamon Press, Oxford. Pp. 747

Holt JA, Hodgen MJ \& Lamb D (1990) Soil respiration in the seasonally dry tropics near Townsvill, North Queensland. Austr. J. Soil Res. 28: 737-745

Hongve, D., P. A. W. van Hees, and U. S. Lundstrom. 2000. Dissolved components in precipitation water percolated through forest litter. Eur. J. Soil. Sci. 51: 667-677.

Hosker, R.P. and Lindberg, S.E., Review: atmospheric deposition and plant assimilation of gases and particles, Atmos. Environ., 16, 889-910, 1982.

Howard DM \& Howard PJA (1993) Relationships between $\mathrm{CO}_{2}$ evolution, moisture content and temperature for a range of soil types. Soil Biol. Biochem. 25: 1537-1546

Huber, S.A, and F. H. Frimmel .1996. Size-exclusion-chromatography with organic carbon detection (LC-OCD): A fast and reliable method for the characterization of hydrophilic organic matter in natural waters. Von Wasser 86: 277-290.

Huber, S.A., A. Balz, and F. H. Frimmel 1994. Identification of diffuse and point sources of dissolved organic carbon (DOC) in a small stream (Alb, Southwest Germany), using gel filtration chromatography with high-sensitive DOC-detection. Fresenius Journal of Analytical Chemistry 350: 496-503.

Hulme, M., and D. Viner. 1998. A climate change scenario for the tropics. Climatic Change 39: 145-176

Ino $\mathrm{Y} \&$ Monsi M (1969) An experimental approach to the calculation of $\mathrm{CO}_{2}$ amount evolved from several soils. Jap. J. Bot. 20: 153-188

IPCC, IPCC Second Assessment Report: Climate Change, pp 64. Geneva, Switzerland, 1995.

Jackson, I. J. 1971. Problems of throughfall and interception assessment under tropical forest. Journal of Hydrology 12:234-254.

Jacobson, M.Z., Strong radiative heating due to the mixing state of black carbon in atmospheric aerosols, Nature, 409, 675-695, 2001.

Janssens IA, Barigah $\mathrm{T} \&$ Ceulemans $\mathrm{R}$ (1998) Soil $\mathrm{CO}_{2}$ efflux rates in different tropical vegetation types in French Guiana. Ann. For. Sci. 545: 671-680 
Janzen, D.H. 1975. Ecology of Plants in the Tropics. The Institute of Biology's Studies in Biology, no.58. Edward Arnold, London. 66 pages.

Jarvis P.G. \& McNaughton K.G. (1986) Stomatal control of transpiration: scaling up from leaf to region. Advances in Ecological Research 15, 1-49.

Jennings, S.G., F.M. McGovern, and W.F. Cooke, Carbon mass concentration measurements at Mace Head, on the West coast of Ireland, Atmospheric Environment, 27A, 1229-1239, 1993.

Jimenéz M.S., Nadezhdina N., Čermák J. \& Morales D. (2000) Radial variation in sap flow in five laurel forest tree species in Tenerife, Canary Islands. Tree Physiology 20, 1149-1156.

Kaimal, J.C., Finnigan, J.S. 1994 Atmospheric boundary-layer flows; Their structure and measurement. Oxford University Press, UK. pp 453.

Kaiser, K, and G. Guggenberger and W. Zech. 2001. Isotopic fractionation of dissolved organic carbon in shallow forest soils as affected by sorption. Eur. J. Soil Sci. 52: 585-597.

Kaiser, K, and G. Guggenberger. 2000. The role of DOM sorption to mineral surfaces in the preservation of organic matter in soils. Org. Geochem. 31: 711-725.

Kaiser, K., and W. Zech. 1997. Competitive sorption of dissolved organic matter fractions to soils and related mineral phases. Soil Sci. Soc. Am. J. 62: 129-136.

Kaiser, K., and W. Zech. 1998a. Rates of dissolved organic matter release and sorption in forest soils. Soil Sci. 163(9): 714-725.

Kaiser, K., and W. Zech. 1998b. Soil dissolved organic matter sorption as influenced by organic and sesquioxide coatings and sorbed sulfate. Soil Sci. Soc. Am. J. 62: 129-136.

Kalbitz, K., S. Solinger, J.H. Park, B. Michalzik and E. Matzner. 2000. Controls on the dynamics of dissolved organic matter in soils: a review. Soil Science 165 (4) pp. 277-304.

Keeland, B.D., and R.R. Sharitz. 1993. Accuracy of tree growth measurements using dendrometers bands. Canadian Journal of Forest Research 23: 2454-2457.

Keller, M., and W. A. Reiners. 1994. Soil-atmosphere exchange of nitrous oxide, nitric oxide, and methane under secondary succession of pasture to forest in the Atlantic lowlands of Costa Rica. Global Biogeochemical Cycles 8(4): 399-409.

Kicklighter DW, Melillo JM, Peterjohn WT, Rastetter EB, McGuire AD, Steudler PA \& Aber JD (1994) Aspects of spatial and temporal aggregation in estimating regional carbon dioxide fluxes from temperate forest soils. J. Geophys. Res. 99: 1303-1315

Kieft TL, Soroker E \& Firestone MK (1987) Microbial biomass response to a rapid increase in water potential when dry soil is wetted. Soil Biol. Biochem. 19: 119-126

Kikuzawa, K. 1991. A cost-benefit analysis of leaf habit and leaf longevity of trees and their geographic pattern. American Naturalist 138: 1250-1263.

Kikuzawa, K. 1995. Leaf phenology as an optimal strategy for carbon gain in plants.

Canadian Journal of Botany 73: 158-163.

Kindermann, J., G. Wurth, G. H. Kohlmaier, and F. W., Badeck, Interannual variation of carbon exchange fluxes in terrestrial ecosystems, Glob. Biogeochem. Cycles, 10, 737-755, 1996.

King D.A. (1996) Allometry and life history of tropical trees. Journal of Tropical Ecology 12, 25-44. 
Kleber et al., submitted. Does mineralogy of highly weathered volcanic soils contribute to tree species distribution at La Selva Biological Station, Costa Rica? Geoderma.

Kleber M, Schwendenmann L, Veldkamp E, Rößner J \& Jahn R (submitted) The mineral inventory of highly weathered andesitic soils at La Selva Biological Station, Costa Rica. Geoderma

Ko, J.Y., C.A.S. Hall, and L.G.L. Lemus, Resource use rates and efficiency as indicators of regional sustainability: an examination of five countries, Environ. Monit. Ass., 51, 571-593, 1998.

König, N., and Fortmann, H. 1996. Probenvorbereitungs-, Untersuchungs- und Elementbestimmungs-Methoden des Umweltanalytik-Labors der Niedersächsischen Forstlichen Versuchsanstalt. For. Ecosyst. Res. Center Göttingen.

Koutrakis, P. and C. Sioutas, Physico-Chemical Properties and Measurements of Ambient Particles, in Particles in Our Air, edited by Richard Wilson and John D. Spengler, pp. 15-40, Harvard University Press, Cambridge, MA, 1996.

Kurpius, M.R. and A.H. Goldstein, Gas-phase chemistry dominates $\mathrm{O}_{3}$ loss to a forest, implying a source of aerosols and hydroxyl radicals to the atmosphere.

Geophysical Research Letters, 30, 24(1)-24(4), doi 10.1029, 2003.

Landsberg J.J., Blanchard T.W. \& Warrit B. (1976) Studies on the movement of water through apple trees. Journal of Experimental Botany 27, 579-596.

Latt, C.R., P.K.R. Nair, and B.T. Kang. 2001. Reserve carbohydrate levels in the boles and structural roots of five multipurpose tree species in a seasonally dry tropical climate. Forest Ecology and Management 146: 145-158.

Laurance, W. F., and G.B. Williamson, Positive feedbacks among forest fragmentation, drought, and climate change in the Amazon, Conservation Biology, 15, 1529$1535,2001$.

Lavanchy, V.M.H., H.W. Gaggeler, S. Nyeki, and U. Baltensperger, Elemental carbon and black carbon measurements with a thermal method and an aethalometer at the high-alpine research station Jungfraujoch, Atmos. Environ., 33, 2759-2769, 1999.

Law, B.E., M. Williams, P.M. Anthoni, D.D. Baldocchi, and M.H. Unsworth, Measuring and modelling seasonal variation of carbon dioxide and water vapour exchange of a Pinus ponderosa forest subject to soil water deficit, Glob. Change Biol., 6, 613630, 2000.

Law, B.E., Ryan, M.G., Anthoni, P.M. 1999 Seasonal and annual respiration of a pondersoa pine ecosystem. Global Change Biology. 5:169-182.

Lee, X., Barr, A.G. 1998, Climatology of gravity waves in a forest. Quarterly Journal of Royal Meteorological Society. 124: 1403-1419.

Leigh, E.G., Jr. 1999. Tropical Forest Ecology: A View from Barro Colorado Island. Oxford University Press, New York. 245 pages.

Lewellen, W.S., Modeling turbulent exchange in forest canopies, in The forestatmosphere interaction, edited by B.A. Hutchison and B.B. Hicks, pp.481-500, Dordrecht, Boston, 1985.

Liming, F.G. 1957. Homemade dendrometers. Journal of Forestry 55: 575-577.

Linn DM \& Doran JW (1984) Effect of water-filled pore space on carbon dioxide and nitrous oxide production in tilled and untilled soils. Soil Sci. Soc. Am. J. 48: 1267-1272 
Liousse, C., J.E. Penner, C.Chuang, J.J. Walton, and H. Eddleman, A global threedimensional model study of carbonaceous aerosols, Journal of Geophysical Research, 101 D14, 19,411-19,432, 1996.

Liu, S. 1992. Predictive models of forest canopy interception. Scientia Silvae Sinicae 28:445-449.

LiuU, S. 1998. Estimation of rainfall storage capacity in the canopies of cypress wetlands and slash pine uplands in North-Central Florida. Journal of Hydrology 207:32-41.

Lloyd, C. R., \& Marques, A. O. 1988. Spatial variability of throughfall measurements in Amazonian rainforest. Agricultural and Forest Meteorology 43:277-294.

Lloyd, C. R., Gash, J. H. C., \& Shuttleworth, W. J. 1988. The measurement and modelling of rainfall interception by Amazonian rain forest. Agricultural and Forest Meteorology 43:277-294.

Lloyd, C.R., Gash, J.H.C., Shuttleworth, W.J. 1988 The measurement and modelling of rainfall interception by Amazonian rain forest. Agricultural and Forest Meteorology 43:277-294.

Lodge, J. P. Jr., Methods of Air Sampling and Analysis, Michigan, 1989.

Loescher H.W., Oberbauer S.F., Gholz H.L. \& Clark D.B. (2003) Environmental controls on net ecosystem-level carbon exchange and productivity in a Central American tropical wet forest. Global Change Biology 9, 396-412.

Loescher, H. W., J. S. Powers, and S. F. Oberbauer. 2002. Spatial variation of throughfall volume in an old-growth tropical wet forest, Costa Rica. Journal of Tropical Ecology 18: 397-407.

Londo AJ, Messina MG \& Schoenholtz SH (1999) Forest harvesting effects on soil temperature, moisture, and respiration in a Bottomland Hardwood Forest. Soil Sci. Soc. Am. J. 63: $637-644$

Ludwig, B., B. Heil, H. Flessa, and F. Beese, F. 2000. Dissolved organic carbon in seepage water - production and transformation during soil passage. Acta Hydrochimica et Hydrobiologica 28(2): 77-82.

Luizão, R.C.C., T.A. Bonde and T.A. Rosswall (1992). Seasonal variation of soil microbial biomass - the effects of clearfelling a tropical rainforest and establishment of pasture in the central Amazon. Soil Biology \& Biochemistry 24, 805-813.

Mahli Y, Nobre AD, Grace J, Kruit B, Pereira MGP, Culf A \& Scott S (1998) Carbon dioxide transfer over a Central Amazonian rain forest. J. Geophys. Res. 103: 31593-31612

Malhi, Y., E. Pegorano, A.D., Nobre, M.G.P. Pereira, J. Grace, A.D. Culf, and R. Clement, Energy and water dynamics of a central Amazonian rain forest. $J$. Geophys. Res., 107, art no. 8061, 2002.

Marschner, B., and K. Kalbitz. 2003. Controls of bioavailability and biodegradability of dissolved organic matter in soils. Geoderma 113(3-4): 211-235.

Massman W. J. 1983. The derivation and validation of a new model for the interception of rainfall by forest. Agricultural Meteorology 28:261-286.

McDade, L.A., K.S. Bawa, H.A. Hespenheide, and G.S. Hartshorn. 1994. La Selva: Ecology and Natural History of a Neotropical Rain Forest. University of Chicago Press, Chicago. 486 pages.

McDowell, W. H, and T. Wood. 1984. Podzolization: processes control dissolved organic carbon concentrations in stream water. Soil Sci. 137(1): 23-32. 
McDowell, W. H. 1998. Internal nutrient fluxes in a Puerto Rican rain forest. Journal of Tropical Ecology 14: 521-536.

McDowell, W. H. 2001. Hurricanes, people, and riparian zones: controls on nutrient losses from forested Caribbean watersheds. Forest Ecology and Management 154: 443-451.

McMillen, R. T. 1988 An Eddy-Correlation Technique With Extended Applicability to Non-Simple Terrain Boundary-Layer Meteorology 43: 231-245.

Medina E, Klinge H, Jordan C \& Herrera (1980) Soil respiration in Amazonian rain forests in the Rio Negro Basin. Flora 170: 240-250

Medina, E. 1983. Adaptations of tropical trees to moisture stress. Pages 225-237, in Golley, F.B., (ed.). Tropical Rain Forest Ecosystems: Structure and Function. Elsevier, Amsterdam.

Meinzer F.C. \& Andrade J.L. (1997) Control of transpiration from the upper canopy of a tropical forest: the role of stomatal, boundary layer and hydraulic architecture components. Plant, Cell and Environment 20, 1242-1252.

Meinzer F.C. \& Grantz D.A. (1990) Stomatal and hydraulic conductance in growing sugarcane: stomatal adjustment to water transport capacity. Plant, Cell and Environment 13, 383-388.

Meinzer F.C., Goldstein G. \& Andrade J.L. (2001) Regulation of water flux through tropical forest canopy trees: Do universal rules apply? Tree Physiology 21, 19-26.

Meinzer F.C., Goldstein G., Jackson P., Holbrook N.M., Gutiérrez M.V. \& Cavelier J. (1995) Environmental and physiological regulation of transpiration in tropical forest gap species: the influence of boundary layer and hydraulic properties. Oecologia, 101, 514-522.

Meinzer F.C.A., Goldstein G., Holbrook N.M., Jackson P. \& Cavelier J. (1993) Stomatal and environmental control of transpiration in a lowland tropical forest tree. Plant, Cell and Environment 16, 429-436.

Meiwes, K. J., N. König, P. K. Khanna, and B. Ulrich. 1984. Chemische Untersuchungsverfahren für Mineralböden, Auflagehumus und Wurzeln zur Charakterisierung und Bewertung der Versauerung in Waldböden. For. Ecosyst. Res. Center Göttingen.

Melillo J.M., A.D. McGuire, D.W. Kicklighter, B. Moore III, C.J. Vorosmarty, and A.L. Schloss, Global climate change and terrestrial net primary productivity, Nature, 363, 234-240, 1993.

Melillo JM, McGuire AD, Kicklighter DW, Moore B, Vorosmarty CJ \& Schloss AL (1993) Global climate change and terrestrial net primary production. Nature 363: 234-240

Michalzik, B., and E. Matzner. 1999. Dynamics of dissolved organic nitrogen and carbon in a Central European Norway spruce ecosystem. European Journal of Soil Science 50: 579-590.

Michalzik, B., K. Kalbitz, J. H. Park, S. Solinger, and E. Matzner. 2001. Fluxes and concentrations of dissolved organic carbon and nitrogen - a synthesis for temperate forests. Biogeochemistry 52: 173-205.

Monteith J.L. (1995) A reinterpretation of stomatal responses to humidity. Plant Cell and Environment 18, 357-364

Monteith, J.L., and M.H., Unsworth, Principles of Environmental Physics, pp. 291, Edward Arnold Publishers, NY, 1990. 
Moore, T. R., W. de Souza, and J. F. Koprivnjak. 1992. Controls on the sorption of dissolved organic carbon by soils. Soil Sci. 154(2): 120-129.

Moraes, R. M., W.B.C.Delitti, and J. Moraes, Gas exchange, growth, and chemical parameters in a native Atlantic forest tree species in polluted areas of Cubatao, Brazil. Ecotoxicology and Environmental Safety, 54, 339-345,2003.

Mulkey SS \& Wright SJ (1996) Influence of seasonal drought on the carbon balance of tropical forest plants. In: Mulkey SS, Chazdon RL \& Smith AP (Eds) Tropical forest plant ecophysiology (pp 187-216). Chapman and Hall, New York

Neff, J. C., and G. P. Asner. 2001. Dissolved organic carbon in terrestrial ecosystems: synthesis and a model. Ecosystems 4: 29-48.

Nepstad, D.C:, C.R. de Carvalho, E.A. Dávidson, P.H. Jipp, P.A: Lefebre, G.H.

Negreiros, E.D. da Silva, T.A. Stone, S.E. Trumbore and S. Vieira. 1994. The role of deep roots in the hydrological and carbon cycles of Amazonian forests and pastures. Nature 372, 666-669.

Newstrom, L.E., G.W. Frankie, and H.G. Baker. 1994. A new classification for plant phenology based on flowering patterns in lowland tropical rain forest trees at $\mathrm{La}$ Selva, Costa Rica. Biotropica 26: 141-159.

Newstrom, L.E., G.W. Frankie, H.G. Baker, and R.K. Colwell, Diversity of long-term flowering patterns, in La Selva, Ecology and natural history of a neotropical rain forest, edited by L. McDade, K.S. Bawa, H.A. Hespenheide, G.S. Hartschorn, pp. 142-160, University of Chicago Press, 1994.

Nodvin, C. C., C. T. Discroll, and G. E. Likens. 1986. Simple partitioning of anions and dissolved organic carbon in a forest soil. Soil Sci. 142: 27-35.

Norman JM, Garcia R \& Verma SB (1992) Soil surface $\mathrm{CO}_{2}$ fluxes and the carbon budget of a grassland. J. Geophys. Res. 97: 18845-18853

O'Brien JJ \& Oberbauer SF (2001) An inexpensive portable meter to read soil moisture probes. Soil Sci. Soc. Am. J., in press

Oberbauer S.F., Strain B.R., \& Riechers G.H. (1987) Field water relations of a wet-tropical forest tree species, Pentaclethra macroloba (Mimosaceae). Oecologia 71, 369-374.

Oberbauer, S.F., and B. R. Strain. 1986. Effects of canopy position and irradiance on the leaf physiology and morphology of Pentaclethra macroloba (Mimosaceae). American Journal of Botany 73: 409-416.

Oberbauer, S.F., H.W. Loescher, and D.B. Clark. 2000. Effects of climate factors on daytime carbon exchange from an old growth forest in Costa Rica. Selbyana 21: 66-73.

Ogren, J. A., S. Anthony, J. Barnes, M. Bergin, W. Huang, L. McInnes, C. Myers, P. Sheridan, S. Thaxton, and J. Wendell, in Climate Monitoring and Diagnostics Laboratory No. 23: Summary Report 1994-95, edited by D.J. Hofmann, J.T. Peterson, and R. M. Rosson, U.S. Department of Commerce report; 1996.

Orchard VA \& Cook FJ (1983) Relationship between soil respiration and soil moisture. Soil Biol. Biochem. 15: 447-453

Ott, R.L. 1993 An introduction to statistical methods and data analysis. Duxbury Press. Belmont CA. pp. 1051.

Papendick RI \& Campbell GS (1981) Theory and measurement of water potential. In: Parr JF, Gardner WR \& Elliot LF (Eds) Water potential relations in soil microbiology (pp 1-27). Soil Science Society of America Special Publications Number 9, Madison, WI 
Parfitt, R. L., A. R. Fraser, and V. C. Farmer. 1977. Adsorption on hydrous oxides. III. Fulvic and humic acid on goethite, gibbsite, and imogolite. J. Soil Sci. 28: 289296.

Parker, G. G. 1983. Throughfall and stemflow in the forest nutrient cycle. Advances in Ecological Research 13: 58-120.

Parker, G. G. 1985. The effect of disturbance on water and solute budgets of hillslope tropical rainforest in northeastern Costa Rica. PhD Dissertation, University of Georgia. 161 pp.

Parker, G. G. 1994. Soil fertility, nutrient acquisition, and nutrient cycling. In L. A. McDade, K. S. Bawa, H. A. Hespenheide, and G. S. Hartshorn (Eds.). La Selva: Ecology and natural history of a neotropical rain forest, pp. 54-63. The University of Chicago Press, Chicago.

Parker, G.G. 1985 The effect of disturbance on water and solute budgets of hillslope tropical rainforest in northeastern Costa Rica. University of Georgia, PhD Disseration. $161 \mathrm{pp}$.

Parkinson KJ (1981) An improved method for measuring soil respiration in the field. J. Appl. Ecol. 18: 221-228

Penner, J. E., C.C. Chuang, and K. Grant, Climate forcing by carbonaceous and sulfate aerosols. Climate Dynamics, 14, 839-851, 1998.

Penner, J.E., R.J. Charlson, J.M. Hales, N. Laulainen, R. Leifer, T. Novakov, J. Ogren, L. F. Radke, S.E. Schwartz and L. Travis, Quantifying and Minimizing Uncertainty of Climate Forcing by Anthropogenic Aerosols, DOE/NBB-0092T, UC7405-Eng48, 1993.

Penner, J.E., S.Y. Zhang, M. Chin, C.C. Chuang, J. Feichter, Y. Feng, I.V. Geogdzhayev, P. Ginoux, M. Herzog, A. Higurashi, D. Koch, C. Land, U. Lohmann, M. Mishchenko, T. Nakajima, G. Pitari, B. Soden, I. Tegen, and L. Stowe, A comparison of model- and satellite-derived aerosol optical depth and reflectivity. J. Atmos. Sci., 59, 441-460, 2002.

Perakis, S. S., and L. O. Hedin. 2002. Nitrogen loss from unpolluted South American forests mainly via dissolved organic compounds. Nature 415: 416-419.

Phillips N., Oren R., Zimmermann R. \& Wright S.J. (1999) Temporal patterns of water flux in trees and lianas in a Panamanian moist forest. Trees: Structure and Function 14,116-123

Pontius, R.G., J.D. Cornell, and C.A.S. Hall, Modeling the spatial pattern of land-use change with GEOMOD2: application and validation for Costa Rica, Agric., Ecosys. Environ., 85, 191-203, 2001.

Powlson, D.S., P.C. Brookes and P.C. Christensen. 1987. Measurement of soil microbial biomass provides an early indication of changes in total soil organic matter due to straw incorporation. Soil Biology \& Biochemistry 19, 159-164.

Qualls, R. G., B. L. Haines 1992. Biodegradability of dissolved organic matter in forest throughfall, soil solution, and stream water. Soil Sci. Soc. Am. J. 56: 578-586.

Qualls, R. G., B. L. Haines, and W. T. Swank. 1991. Fluxes of dissolved organic nutrients and humic substances in a deciduous forest. Ecology 72(1): 254-266.

Qualls, R. G., B. L. Haines, W. T. Swank, and S. W. Tyler. 2000. Soluble organic and inorganic nutrient fluxes in clearcut and mature deciduous forests. Soil Sci. Soc. Am. J. 64: 1086-1077. 
Raich JW \& Schlesinger WH (1992) The global carbon dioxide flux in soil respiration and relationship to vegetation and climate. Tellus 44B: 81-99

Raich JW (1980) Carbon budget of a tropical soil under mature wet forest and young vegetation. Master Thesis. University of Florida, Miami, FL

Raich, J.W., E.B. Rastetter, J.M. Melillo, D.W. Kicklighter, P.A. Steudler, B.J. Peterson, A.L. Grace, B. Moore III, and C.J. Vorosmarty. 1991. Potential net primary productivity in South America: application of a global model. Ecological Applications, 1: 399-429.

Rajvanshi R \& Gupta SR (1986) Soil respiration and carbon balance in a tropical Dalbergia sissoo forest ecosystem. Flora 178: 251-260

Reich, P.B. 1995. Phenology of tropical forests: patterns, causes and consequences. Canadian Journal of Botany 73: 164-174.

Reiners WA (1968) Carbon dioxide evolution from the floor of three Minnesota forests. Ecology 49: $471-483$

Richards, P.W. 1996 The tropical rain forest; an ecological study. Cambridge University Press, Cambridge UK. Pp.575.

Richter, D.D. and D. Markewitz, 1995. How deep is soil? Bioscience 45 (9), 600-609

Roberts, J., O.M.R. Cabral, and L.F. de Aguiar, Stomatal and boundary-layer conductances in an Amazonian terra firme rain forest. .J. Appl. Ecol., 27, 336$353,1990$.

Rout SK \& Gupta SR (1989) Soil respiration in relation to abiotic factors, forest floor litter, root biomass and litter quality in forest ecosystems in Siwaliks in northern India. Acta Oecologia, Oecologia Plant 10: 229-244

Rutter, A. J., Morton, A. J, \& Robins, P. C. 1975. A predictive model of rainfall interception in forests II. Generalization of the model and comparison with observations in some coniferous and hardwood stands. Journal of Applied Ecology 12:367-380.

Ryan M.G., Hubbard R.M., Clark D.L. \& Sanford, Jr R.L. (1994) Woody tissue respiration for Simarouba amara and Minquartia guianensis, two tropical wet forest trees with different growth habits. Oecologia 100, 213-220.

Sanchez PA (1976) Properties and management of soils in the tropics. John Wiley and Sons, New York

Sandford RL \& Cuevas E (1996) Root growth and rhizosphere interactions in tropical forests. In: Mulkey SS, Chazdon RL \& Smith AP (Eds) Tropical forest plant ecophysiology (pp 268300). Chapman and Hall, New York

Sanford Jr., R.L., Paaby, P., Luvall, J.C., Phillips, E., 1993. The La Selva ecosystem: Climate, geomorphology, and aquatic systems. In: McDade, L.A., et al. (Eds.) La Selva: Ecology and natural history of a tropical rain forest. University of Chicago Press, Chicago, pp. 19-33.

Schlesinger WH (1977) Carbon balance in terrestrial detritus. Ann. Rev. Ecol. Syst. 8: 51-81

Schlesinger, W.H. 1990. Evidence from chronosequence studies for a low carbon-storage potential of soils. Nature 348, 232-234.

Schuepp, P.H., Leclerc, M.Y., Macpherson, J.I. and Desjardins, R.L. 1990 Footprint prediction of scalar fluxes from analytical solutions of the diffusion equation. Boundary-Layer Meteorology. 50:355-373.

Schultz, D. M., Bracken, W. E., Bosart, L. F. 1998 Planetary- and synoptic-scale signatures associated with central American cold surges. Monthly Weather Review 126: 5-27. 
Schwendenmann, L., E. Veldkamp, T. Brenes, J.J. O’Brien, J. Mackensen. 2002. Spatial and temporal variation in soil $\mathrm{CO} 2$ efflux in an old-growth neotropical forest, $\mathrm{La}$ Selva, Costa Rica. Biogeochemistry in press.

Seinfeld, J., Atmospheric chemistry and physics of air pollution. Wiley, N.Y., 1986. Shuttleworth, W.I., J.H.C. Gash, C.R. Lloyd, C.J. Moore, A.d.O.M. Filho, G. Fisch, V.d.P.S. Filho, M.d.N.G. Ribeiro, L.C. Molion, L.D.d.A. Sa, J.C.A. Nobre, O.M.R. Cabral, S.R. Patel, J.C.d. Moraes, Eddy correlation of energy partition for Amazonian forest, Q.J.Roy. Met. Soc., 110, 1143-1162, 1984.

Sievering, H. Profile measurement of particle dry deposition velocity at an air-land interface, Atmospheric Environment, 16, 301-306, 1982.

Sievering, H., Small particle dry deposition under high wind speed condition: eddy flux measurements at the Boulder Atmospheric Observatory, Atmospheric

Environment, 21, 2179-2185, 1987.

Singh JS \& Gupta SR (1977) Plant decomposition and soil respiration in terrestrial ecosystems. Bot. Rev. 43: 449-528

Skopp J, Jawson MD \& Doran JW (1990) Steady-state aerobic microbial activity as a function of soil water content. Soil Sci. Soc. Am. J. 54: 1619-1625

Smith W.K. \& McClean T.M. (1989) Adaptive relationship between leaf water repellency, stomatal distribution, and gas exchange. American Journal of Botany $76,465-469$.

Smith, K.E.C., and K.C. Jones, Particles and vegetation: implications for the transfer of particle-bound organic contaminants to vegetation, Sci. Total Environ., 246, $207-$ $236,2000$.

Solinger, S., K. Kalbitz, and E. Matzner. 2001. Controls on the dynamics of dissolved organic carbon and nitrogen in a Central European deciduous forest.

Biogeochemistry 55: 327-349.

Sollins P \& Radulovich R (1988) Effects of soil physical structure on solute transport in a weathered tropical soil. Soil Sci. Soc. Am. J. 52., 1168-1173

Sollins P, Sancho F, Mata R \& Sanford RL (1994) Soils and soil process research. In L. A. McDade, K. S. Bawa, H. A. Hespenheide, and G. S. Hartshorn (Eds.). La Selva: Ecology and natural history of a neotropical rain forest, pp. 34-53. The University of Chicago Press, Chicago.

Sommer, R., M. Denich and P.L.G. Vlek. 2000. Carbon storage and root penetration in deep soils under small-farmer land-use systems in the Eastern Amazon region, Brazil. Plant and Soil 219, 231-241.

Sternberg, L., da S.L., Moreira, M.Z., Martinelli, L.A., Victoria, R.L., Barbosa, E.M., Bonates, L.C.M., Nepstad, D.C. 1997 Carbon dioxide recycling in two Amazonian tropical Forests. Agricultural and Forest Meteorology. 88:259-268.

Sternberg, L., da S.L., Mulkey, S.S., Wright, S.J. 1989 Ecological interpretation of leaf carbon isotope ratios: influence of respired carbon dioxide. 'Ecology. 70:13171324.

Ter Steege, H. 1996 Winphot 5: a programme to analyze vegetation indices, light, and light quality from hemispherical photographs. Tropenbos Guyana Report 95-2, Tropenbos Guyana Programme, Georgetown, Guyana.

Trangmar, B.B., Yost, R.S., Wade, M.K., Uehara, G. \& udjadi M. 1987. Spatial variation of soil properties and rice yield on recently cleared land. Soil Science Society of America Journal 51:668-674. 
Tranvik, L.R. (1992): Allochtonous dissolved organic matter as an energy source for pelagic bacteria and the concept of the microbial loop. Hydrobiologia 229: 107114.

Trumbore SE, Davidson EA, de Carmago PB, Nepstad DC \& Martinelli LA (1995) Belowground cycling of carbon in forests and pastures of Eastern Amazonia. Global Biogeochemical Cycles 9: 515-538

Trumbore, S. E., S. L. Schiff, R. Aravena, and R. Elgood. 1992. Sources and transformation of dissolved organic carbon in the harp lake forested catchment: the role of soils. Radiocarbon 34(3): 626-635.

Ubarana, V. N. 1996. Observation and modelling of rainfall interception at two experimental sites in Amazonia. Pp.151-161 in Gash, J.H.C., Nobre, C.A. Roberts, J.M., \& Victoria, R.L. (eds.). Amazonian deforestation and climate. Institute of Hydrology. John Wiley, Chichester, UK.

USEPA, Monitoring and QA Group, Emissions, Monitoring and Analysis Division, Particulate Matter (PM2.5) Speciation Guidance Document, USEPA Research Triangle Park, NC, 1998.

Valentini R, G. Matteucci, A.J. Dolman, E-D. Schulze, C. Rebmann, E.J. Moors, E. A. Granier, P. Gross, N.O. Jensen, K. Pilegaard, A. Lindroth, A. Grelle, C.

Bernhofer, T. Grunwald, M. Aubinet, R. Ceulemans, A.S. Kowalski, T. Vesala, U. Rannik, P. Berbigier, D. Loustau, J. Guomundsson, H. Thorgeirsson, A. Ibrom, K. Morgenstern, R. Clement, J.B. Moncrieff, L. Montagnani, S. Minerbi, and P.G. Jarvis, Respiration as the main determinant of carbon balance in European forests, Nature, 404, 861-865, 2000.

Van Dam D., E. Veldkamp and N. van Breemen. 1997. Soil organic carbon dynamics: variability with depth in forested and deforested soils under pasture in Costa Rica. Biogeochemistry, 39: 343-375.

Veldkamp E \& O'Brien JJ (2000) Calibration of a frequency domain reflectometry sensor for humid tropical soils of volcanic origin. Soil Sci. Soc. Am. J. 64: 1549-1553

Veldkamp, E., A. Becker, L. Schwendenmann, D. A. Clark, and H. Schulte-Bisping. Substantial labile carbon stocks and microbial activity in deeply weathered soils below a tropical wet forest. Global Change Biology. In Press.

Walter H. (1985) Vegetation of the Earth and Ecological Systems of the Geo-biosphere. Third edition, Springer-Verlag, Berlin. 318p.

Walter, H. 1985. Vegetation of the Earth and Ecological Systems of the Geo-biosphere. Third edition. Springer-Verlag, New York. 318 pages.

Waring, R., H., Schlesinger, W.H. 1985 Forest Ecosystems, concepts and management. Academic Press Inc. San Diego, California. 340 pp.

Waylen, P.R., Caviedes, C.N., Quesada, M.E. (1996) Interannual variability of monthly precipitation in Costa Rica. Journal of Climate 9:2606-2612P

Webb, E.K., Perman, G.I., Luening, R. 1980 Correction of flux measurements for density effects due to heat and water vapor transfer. Quarterly Journal of the Royal Meteorological Society 106:85-100.

Webster, R. 1985. Quantitative spatial analysis of soil in the field. Advances in Soil Science 3:1-70.

Weishampel J.F., Blair J.B., Knox R.G., Dubayah R. \& Clark D.B. (2000) Volumetric lidar return patterns from an old-growth tropical rainforest canopy. International Journal of Remote Sensing 21, 409-415. 
White A, Cannell MGR \& Friend $\mathrm{AD}(2000) \mathrm{CO}_{2}$ stabilization, climate change and the terrestrial carbon sink. Global Change Biol. 6: 817-833

Whitehead D. (1998) Regulation of stomatal conductance and transpiration in forest canopies. Tree Physiology 18, 633-644.

Williams M., Bond B. \& Ryan M.G. (2001) Evaluating different soil and plant hydraulic constraints on tree function using a model and sap flow data from ponderosa pine. Plant, Cell and Environment 24, 679-690.

Williams M., Mahli Y., Nobre A., Rastetter E.B., Grace J. \& Pereira M.G.P. (1998) Seasonal variation in net carbon exchange and evapotranspiration in a Brazilian rain forest: A modeling analysis. Plant, Cell and Environment 21, 953-968.

Williams, M.M.R., and S.K. Loyalka, Aerosol science; theory and practive, with special applications to the nuclear industry. Elsevier, N.Y., 1991.

Wilson, K.B., D.D. Baldocchi, and P.J. Hanson. 2000. Quantifying stomatal and nonstomatal limitations to carbon assimilation resulting from leaf aging and drought in mature deciduous tree species. Tree Physiology 20: 787-797.

Winer, B.J., D.R. Brown, and K.M. Michels. 1991. Statistical Principles in Experimental Design. McGraw-Hill, New York, NY. 1057 pages.

Wofsy SC, Harris RC \& Kaplan WA (1988) Carbon dioxide in the atmosphere over the Amazon basin. J. Geophys. Res. 93: 1377-1387

Wolterbeek, B., Biomonitoring of trace element air pollution: principles, possibilities and perspectives, Environ. Poll., 120, 11-21, 2002.

Wong PTW \& Griffin DM (1976) Bacterial movement at high matric potentials - 1. In artificial and natural soils. Soil Biol. Biochem. 8: 215-218

Worbes, M. 1999. Annual growth rings, rainfall-dependent growth and long-term growth patterns of tropical trees from the Caparo forest reserve in Venezuela. Journal of Ecology 87: 391-403.

Wright, I.R., J.H.C., Gash, H.R. da Rocha, and J.M. Roberts, Modelling surface conductance for Amazonian pasture and forest, in Amazonina deforestation and climate, edited by J.H.C. Gash, C.A. Nobre, J.M. Roberts, and R.L. Victoria, pp. 437-467, Institute of Hydrology, 1996.

Wright, S.J., and C.P. van Shaik. 1994. Light and the phenology of tropical trees. American Naturalist 143: 192-199.

Wu, Y-L, C.I. Davidson, D.A. Dolske, and S.I. Sherwood, Dry deposition of atmospheric contaminants: the relative importance of aerodynamic, boundary layer and surface resistances, Aerosol Sci. Tech., 16, 65-81, 1992.

Yamasoe, M.A., P. Artaxo, A.H. Miguel, and A.G. Allen, Chemical composition of aerosol particles from direct emissions of vegetation fires in the Amazon Basin: water-soluble species and trace elements, Atmos. Environ., 34, 1641-1653, 2000.

Yano, Y., W. H. McDowell, and J. D. Aber. 2000. Biodegradable dissolved organic carbon in forest soil solution and effects of chronic nitrogen deposition. Soil Biology and Biochemistry 32: 1743-1751.

Yano, Y., W. H. McDowell, and N. E. Kinner. 1998. Quantification of biodegradable dissolved organic carbon in soil solution with flow-through bioreactors. Soil Sci. Soc. Am. J. 62: 1556-1564.

Yasuda, N., Turbulent diffusivity and diumal variations in the atmospheric boundary layer, Boundary-Layer Met. 43, 209-221, 1988. 
Yasuda, N., Turbulent diffusivity and diurnal variations in the atmospheric boundary layer, Boundary-Layer Met. 43, 209-221, 1988.

Zhang, L., Gong, S., Padro, J., Barrie, L. A size-segregated particle dry deposition scheme for an atmospheric aerosol module. Atmos. Environ. 35, 549-560, 2001. 